The Quill and the Scalpel 



\section{The Quill and the Scalpel}

NABOKOV'S ART

AND THE WORLDS OF SCIENCE

Stephen H. Blackwell 
Copyright (C 2009 by The Ohio State University.

All rights reserved.

Library of Congress Cataloging-in-Publication Data

Blackwell, Stephen H. (Stephen Hardwick), 1965-

The quill and the scalpel : Nabokov's art and the worlds of science / Stephen H. Blackwell.

p. cm.

Includes bibliographical references and index.

ISBN 978-0-8142-1099-4 (cloth : alk. paper)-ISBN 978-0-8142-9197-9 (cd-rom) 1. Nabokov, Vladimir Vladimirovich, 1899-1977-Criticism and interpretation. 2. Art and science. 3. Science-Philosophy. 4. Science and the humanities. I. Title.

PS3527.A15Z63 2009

813.'54-dc22

2009012103

This book is available in the following editions:

Cloth (ISBN 978-0-8142-1099-4)

CD-ROM (ISBN 978-0-8142-9197-9)

Cover design by Mia Risberg

Text design by Juliet Williams

Type set in Adobe Sabon

Printed by Thomson-Shore, Inc.

( The paper used in this publication meets the minimum requirements of the American National Standard for Information Sciences-Permanence of Paper for Printed Library Materials. ANSI Z39.48-1992.

$\begin{array}{lllllllll}9 & 8 & 7 & 6 & 5 & 4 & 3 & 2 & 1\end{array}$ 
For Aleka, Timothy, and Gabriel 
I've drawn my scalpel through spacetime, space being the tumor, which I assign to the slops.

-Interview with Nicholas Garnham on BBC-2, 1968 


\section{contents}

List of Illustrations

Preface

Acknowledgments

xiii

INTRODUCTION Nabokov's Science and Art

CHAPTER $1 \quad$ Nabokov as a Scientist

CHAPTER 2 Nabokovian Science and Goethean Science

CHAPTER 3

Utility and Futility: Nabokov's Biological Etudes

CHAPTER 4

Anti-Psychological

CHAPTER 5

Nabokov's Physics:

Particles, Waves, and Uncertainty

CHAPTER 6 Minding the Gap:

Discontinuities in Nature, Art, and Science

CONCLUSION

Art, Science, and Ethics

Notes

Bibliography

Index 

FIGURE $1 \quad$ Ciliated wing drawing.

[Butterflies. Scrapbook] containing diagrams and notes on the evolution of wing patterns. Berg Collection, New York Public Library.

FIGURE 2 Triangles drawing.

[Butterflies. Scrapbook] containing diagrams and notes on Lycaeides genitalia, dated Feb 20, 1946. Berg Collection, New York Public Library.

FIGURE 3 Spiral speciation.

[Butterflies. Scrapbook] containing diagrams and notes on the evolution of wing patterns. Undated. Berg Collection, New York Public Library.

FIGURE 4 Poetry diagram: "Iambic hexameter rhythms of E. A. Baratynsky."

"Ritmy shestistopnago iamba. E. A. Baratynsky. Holograph notebook, described as Album 1B, unsigned. [c.1918].” Berg Collection, New York Public Library. 
FIGURE 5 Wing spot progression chart.

[Butterflies. Scrapbook] containing diagrams and notes on the evolution of wing patterns. Berg

Collection, New York Public Library.

FIGURE 6 Polynesian butterfly-hunter.

Reproduced in Rul', 21 June 1925; originally

published in Berliner Illustrierte Zeitung,

1 April 1925, 445.

FIGURE $7 \quad$ Wing image with mention of species gaps.

[Butterflies. Scrapbook] containing diagrams and notes on the evolution of wing patterns. Berg

Collection, New York Public Library. 


\section{preface}

THIS BOOK SPANS two distinct intellectual domains-art and scienceand it seeks to be of use to readers on both sides of that sometimes contentious boundary. Nabokov's thought as an artist was heavily informed by his scientific passions: his lepidopteral research was guided by his aesthetic sense of the world around him. Everything Nabokov undertook had in it components of both discovery and expression, aesthetic evaluation and composition. Artistic creation becomes a kind of extension of scientific research, inasmuch as art is an explicit practice through which one can make known individual discoveries about life that would not find a place in the laboratory. If we treat artwork, no matter how strange or disturbing it might be, as something akin to a scientific experiment, then we cease to be troubled by art's occasional obscurity or ambivalence or by the tendency of artistic meaning to slip out from under efforts to define it. These same problems exist in the world of empirical research, too.

Like scientific advances, novels and other art forms can be thought of as tentative steps forward in a world full of the unknown. Some works may endure in their ability to lead humanity toward greater knowledge and vision; others are more quickly eclipsed and forgotten. In this sense, artistic progress undergoes a confirmation procedure not completely unlike the scientific method. This development is essentially non-Popperian: great 
artworks are not falsified (although lesser ones might be-there is such a thing as "flawed art"), but rather they may be outgrown when they cease to lead the mind toward new discoveries.

Nabokov's works in various genres offer the chance to consider art as part of the human quest for knowledge and understanding, to expand the traditional meaning of "science" to include art. It is not enough, however, for literary or artistic theorists to note the "scientific" importance of their subject, as if in confirmation of their own intellectual significance. Scientists and philosophers or historians of science, too, must be invited to consider the significance of such a reconceptualization. For this reason, I have chosen to craft a book not only for literary specialists or Nabokov scholars, but also for those who think more specifically about the role of science in human life and history. As a result, Nabokov specialists will find here many things that they already know among many other things that perhaps they only barely suspected. On the other hand, scientists and related scholars will view this study as the work of an outsider. Nevertheless, without their potential interest and engagement, a project such as this one means little. If, in fact, we believe that the arts have a role to play within the advance of knowledge, then what task could be more urgent than a consideration of a writer whose career blended the "passion of science" with the "precision of art"?

This book makes no claim to definitiveness or comprehensiveness. It provides at most an overview of some of the major concepts and their variations in Nabokov's works. There is much that has been left out-most prominently, whole branches of natural science such as mathematics and chemistry. The first of these is being treated by others far more competent for that task than I. There are, of course, more details to be discovered regarding each of the fields I have treated here, especially psychology, whose variegated reflections in Nabokov really warrant a book-length study in themselves. Nabokov's likely relation to early modern philosophy of science has been barely hinted at. And there is much more to be learned about aesthetic qualities in Nabokov's scientific work. Such explorations will require the efforts of many scholars, and I hope that some of my readers will join in mapping these uncharted domains. 


\section{acknowledgments}

MANY PARTS of this book could not have been written without access to restricted archival materials kindly granted by Dmitri Nabokov; likewise, I thank him for his permission to quote from unpublished sources and to reproduce here images from the archive. I am pleased to acknowledge support provided by a National Endowment for the Humanities Summer Stipend in 2005. In 2005 and 2006, the University of Tennessee granted me a research leave, without which the bulk of the work presented here could never have been completed, and in 2006 it provided Professional Development funding for trips to the Nabokov archives at the New York Public Library and the Library of Congress. The Department of Modern Foreign Languages and Literatures has been generous with travel funds, allowing me to present early versions of this work at various conferences during the last several years. Permission fees for the images in this book were paid by the University of Tennessee Exhibition, Performance, and Publication Expense fund. Stephen Crook of the Berg Collection at the New York Public Library was invaluable as a resource on the contents of the archive, and the staffs of the Berg and the Manuscript Room of the Library of Congress epitomized efficiency.

Many friends and colleagues have generously shared their acumen and wisdom as I have worked on the materials for this book during the last 
decade. I am especially grateful to Dana Dragunoiu, who read the entire first draft and large portions of later drafts, making countless suggestions for improvements in substance and providing encouragement that helped sustain me through more difficult stretches. Victor Fet read a version of chapters 1 and 3 and saved me from important taxonomic blunders. Kurt Johnson kindly sent me an extended version of his ALA paper on Nabokov's lepidoptery and offered feedback on early drafts of the biological sections. Eric Naiman read almost the complete manuscript in its penultimate form and challenged me, as always, to think about my subject from surprising angles. Dieter Zimmer provided guidance in absentia for navigating Berlin's libraries during my visit there in 2004, as well as serving the discipline with background research of the highest importance in his incomparable Guide to Nabokov's Butterflies and Moths. Victoria Alexander shared her own research with me and offered challenging suggestions on early phases of this project. Jerry Friedman, Stan Kelly-Bootle, Jenefer Coates, and Gerhard Devries each gave a thoughtful critique of a late version of chapter 5, resulting in significant changes. Peter Hoeyng read chapter 2 and brought me to Berlin and its libraries in 2004. Brian Boyd provided encouragement and ideas throughout the project. I would also like to thank Tatyana Ponomareva of the Nabokov Museum in St. Petersburg, who invited me to lead a seminar on the subject of this book in July 2005. Yevgeny Belodubrovsky helped situate me in the National Library in St. Petersburg during that visit. Joanna Trzeciak, Yuri Leving, Marina Grishakova, and Leland de la Durantaye generously shared their own research with me.

University of Tennessee colleagues provided a valuable early audience and interdisciplinary perspective on this work: Alan Rutenberg helped me frame the original proposal; Allen Dunn and Natalia Pervukhina read the full manuscript and offered valuable comments. The faculty colloquy on the History and Philosophy of Science and Technology (Ted Richards, Heather Douglas, Denise Phillips, Richard Pagni, Jeff Kovac, Millie Gimmel, Bruce MacClennan, and Susan North) provided scientific, philosophical, and historical feedback on several chapters. My colleague Daniel Magilow kindly translated the epigraph to chapter 3. I am indebted to Aleka Akoyunoglou Blackwell, who provided meticulous proofreading and stylistic help in the final preparations and forced me to be more accurate in my characterizations of scientific method.

Sarah Stanhope, an artist and former student who once performed in a reader's theater production of The Man from the USSR, has my admiration and gratitude for the marvelous work she did for this book's cover. Work- 
ing with Sandy Crooms, Maggie Diehl, Linda Patterson, Jennifer Forsythe, Laurie Avery, and Ben Shriver of The Ohio State University Press has been pure pleasure. A more professional and competent team could not be imagined, and I am especially grateful for their flexibility and responsiveness to my needs during the production process.

With so much help from so many extraordinary people, one might expect this book to be perfect. It is not, and the only one responsible for its blemishes is me. Had I been able to incorporate every suggestion made, it would have been a far better book than it is. Whatever errors and gaps remain are my own, and I hope, in some other place, to make amends for its flaws.

A note on the title: while checking for earlier uses of my chosen phrase, I found a student journal at Johns Hopkins University, published from 1990 to 1993, called “The Quill and Scalpel." It was devoted to the metamorphosis of medical students into physicians and was succeeded by an electronic version, called "Chrysalis." What more could one ask of a namesake for this book? 



\section{introduction}

You can get as close as possible to these living creatures and see reflected in them a higher law. Mimicry and evolution are for me more and more fascinating. . . I I cannot separate the aesthetic pleasure of seeing a butterfly and the scientific pleasure of knowing what it is.

—Interview with Robert H. Boyle, Sports Illustrated, 1959'

There is an unknown, lawlike something in the object that corresponds to an unknown, lawlike something in the subject.

-Goethe, Maxims and Reflections \#1344

IN THE MID-1920s and early 1930s, Vladimir Nabokov lived in a series of Berlin apartments within a short walk of Albert Einstein's residence, and they surely trod some of the same sidewalks on the same days. This coincidence makes a pleasing icon for the overlapping worlds of science and art, even though the two figures had no reason ever to meet. From a small patch of cityscape emerged some of the twentieth century's most potent rustlings. ${ }^{3}$

As The Gift's Fyodor Godunov-Cherdyntsev moves around Berlin in the 1920s, a time when "time is in fashion," 4 he appears somehow immune to the laws of physics: he wanders heedlessly but harmlessly across busy streets; he transforms straight tram-lines into circular ones; his watch occasionally goes backwards. Like other modernist writers, Nabokov had discovered the exciting philosophical and metaphorical potential of the new physics. Unlike most others, he was himself a scientist as well as an artist. Once we start to notice these references in The Gift and other works, they weave into a network of concepts deriving from Nabokov's scientific outlook, his constant effort to know the world. This passion to know is part scientific and part aesthetic; the resulting inseparability of art and science 
is the core of Nabokov's creative vision. The last of Nabokov's Russian novels, The Gift, covertly but extensively incorporates themes from the new physics that had been lurking in the background of his works since the mid-1920s.

Nabokov's first adult years coincided with the fall of the Russian Empire and the rise of the new physics. Einstein completed his general theory of relativity in 1915 , but it did not receive wide attention until it was confirmed by Arthur Eddington's eclipse-imaging expedition in May 1919. In November of that year, when Nabokov had just arrived at Cambridge University, newspapers everywhere loudly proclaimed the beginning of a new era in science. Subatomic and quantum theories were developing rapidly-Nabokov's new College Master was J. J. (“Atom”) Thomson, one of the electron's earliest investigators. The early post-war years also saw the first wave of Freudian psychoanalysis as a mass culture phenomenon. Indeed, by 1919 it had become such a fad that it was already attracting parodies and condemnations. At around the same time, Darwinian theory was undergoing significant challenge and refinement. Nabokov was busy too: in October of that year, he wrote his first published scientific article"A Few Notes on Crimean Lepidoptera"-as a newly enrolled student of zoology at Cambridge's Trinity College. Before long, he switched to French and Russian literature so he could spend more time writing poetry. ${ }^{5}$

Nabokov didn't need the excitement of these astonishing years to become interested in science: he began studying butterflies at the age of seven. At thirteen, he made his first submission to a scientific journal (The Entomologist)—and was rejected: the species he thought was new wasn't. His first scientific publication, in the same journal, came when he was twenty-one. While living in Berlin in the 1920s and 1930s as an émigré writer, Nabokov frequently sought out butterfly experts, and he spent hours working in museums' collections, examining known species against what he had found during his regular summer collecting trips. ${ }^{6}$ Later, having arrived in the United States in 1940, Nabokov quickly resumed his lepidoptery work, beginning at the American Museum of Natural History in New York and soon moving to a nominally part-time curatorship at the Museum of Comparative Zoology at Harvard, where for six years in the 1940s he conducted innovative research on North and South American butterflies. No wonder this was his least productive decade artistically-he wrote only one novel, Bend Sinister, and only after leaving his museum position in 1948 did he begin work on Lolita in earnest.

Nabokov's passion for lepidoptery drove him to work unpaid overtime even when it would have been expedient to do something else more 
remunerative (his family was constantly in financial need, then and even afterwards when he was well employed by Cornell University). ${ }^{7}$ Instead of working full time on his literary prospects, he risked damage to his eyesight by spending too much time at the dissecting microscope (he examined several thousand and dissected at least fifteen hundred specimens, attending particularly to their minuscule reproductive apparatuses and the counting of tiny wing scales). This obsessive drive to create order in a disheveled area of taxonomy emerged as if directly from The Gift, in which he had indulged his childhood fantasy of becoming a great explorer and naturalist. Emblematically, that novel had helped prepare him for his first real stint as a professional scientist. This sort of artistic prediction of life was itself a mirror-image of the prefiguration of art in a real butterfly's wing displaying "a dab of gilt redolent of turpentine," as Nabokov's surrogate told it behind the scenes of The Gift. ${ }^{8}$

The laws of nature: these are the goal of the scientist. For Nabokov, aesthetic pleasure and scientific pleasure are inseparable. They both reflect a higher law. The aesthetic pleasure of seeing connects to the scientific pleasure of knowing. Both acts—seeing and knowing-represent peaks of consciousness, itself the pinnacle of natural evolution (as known on Earth). Vision and knowledge are among the main themes of nearly all Nabokov's works, sometimes through their negations, blindness and ignorance (or solipsism). Nabokov's comment to Robert Boyle asserts the unity of the two sides of human consciousness, the aesthetic and the scientific, and in a subtle way it insists on the importance of art (aesthetics) in humanity's effort to know its world. Science alone is not enough, and neither for that matter is art ("there is no science without fancy, no art without facts"). Every poem, painting, and melody can, and perhaps should, be viewed as a particular part of the human effort to know the world. That the languages of literature, music, or the plastic arts are not the language of science means only that they see, and represent, the world differently than science does. Nabokov would insist that the difference is crucial, that aesthetic seeing is just as vital to human existence and "progress" as scientific exploration.

Art and science are commonly thought to occupy totally different spheres of thought and activity. When someone comes along who excels in both areas, (a rare enough occurrence), it forces a reconsideration of stereotypes. Do art and science have a common boundary? Do they perhaps overlap in important ways? Could it be that they are intimately related? This study begins with a desire to understand why Nabokov, at least, found that they were kindred fields of passion, patience, and precision. ${ }^{10}$ 


\section{Historical Context}

\section{Scientific Revolutions in Nabokov's Early Years}

Three areas of acute scientific interest stand out in Nabokov's literary works: zoology (especially lepidoptery and evolutionary theory); psychology (especially as the study of consciousness); and physics (especially in the post-Newtonian guise ushered in by Einstein, Planck, Bohr, and Heisenberg, among others). While Nabokov the naturalist is widely known, and the psychologist can be deduced fairly quickly after reading any of his novels, Nabokov the (armchair) physicist keeps a fairly low profile. This is surely because his level of study in physics was neither as deep nor as practical as his exposure to the fields of entomology or psychology. ${ }^{11}$ Of the latter he surely felt that his own everyday experience, extensive technical reading, and artistic acumen gave him a strong foundation. We have no evidence, however, that Nabokov ever performed a physical experiment, or succeeded (or even attempted!) in mastering the formulas of relativity or quantum mechanics. In one interview, he quipped, "while not having much physics, I reject Einstein's slick formulae." ${ }^{12}$ However, before taking him at his word, we should remember that his standards for what constitutes knowledge of a subject were extremely high (his much trumpeted ignorance of German was based on his mere six years of high-quality secondary school study, for which he received top grades). His interest in relativity and quantum theory probably grew as he became familiar with their outlandish consequences, and as their story was told and retold on the pages of newspapers around the world. These included the Berlin paper his father co-founded, Rul' (The Rudder), where his acquaintance Vladimir Tatarinov wrote articles summarizing the recent and ongoing scientific revolutions. Dozens of books were published on the new physics throughout the 1920s and 1930s, along with regular discussions in the émigré Russian press. Many of the expositions in Rul' and in Paris-based Poslednie novosti (The Latest News) are quite detailed. As we will see in chapter 5, Nabokov's familiarity with at least the popular versions of the new physics shines through in direct and indirect references in several of his novels and in his lectures on literature.

\section{Nabokov and the Materialists}

Nabokov's engagement with science was distinctive for other reasons besides his double-edged intellectual persona. It also needs to be viewed 
against the background of his personal history, his philosophical commitments, and the rise of the Soviet Union. This last event, especially, was the political culmination of a particular view of what the world is, what it can be, and humanity's role in its progress. That view is generally known as positivist materialism in its socialist interpretation, and it was directly opposed to Nabokov's core beliefs in every imaginable way. Soviet socialism brought its own brand of science with roots deep in the nineteenth century.

The reasons for Nabokov's antipathy to socialism were various, and not related to any kind of Tsarist sympathies. His father, Vladimir Dmitrievich Nabokov, was a leading member of the Constitutional Democrats ("Kadet") party, and he was imprisoned by the Tsar's police in 1908 for signing the Vyborg manifesto condemning the dissolution of the Duma. ${ }^{13}$ Despite his wealth, V. D. Nabokov worked to produce democratic and socially just political reform, including the transfer of more land from the nobility to the peasants. This liberal agenda was based upon principles of respect for the individual, and it was also at least obliquely related to the work of the neo-idealists in the Moscow Psychological Society, a philosophical organization. The neo-idealists included some prominent former Marxists like Nikolai Berdiaev and Sergei Bulgakov, and they produced an important volume in 1902 called Problems of Idealism and a more famous follow-up called Landmarks [Vekhi] in 1909, in which they worked to develop first principles for a liberal political philosophy as an alternative to revolutionary socialism. ${ }^{14}$ Several members of the circle were close to V. D. Nabokov, and there is reason to believe that he agreed with many of their positions and their neo-idealist foundations (he himself was an observing Orthodox Christian, though not strict in his son's religious formation). ${ }^{15}$

This liberal, "bourgeois" agenda was the main target of the Bolshevik revolution: the liberal revolution of February/March 1917 had installed a government led by the Constitutional Democrats, which was swept away by Bolsheviks that October. If the value of the individual person as an end in itself grounded the neo-idealists' philosophy and Nabokov's own, in the Bolshevik outlook the individual had no meaning except as a participant in building the communist future. The same was true of all human activities that might emphasize individual achievement-including art and science. As Nikolai Bukharin wrote in 1925, "Bourgeois scholars speak of any branch of learning with mysterious awe, as if it were a thing produced in heaven, not on earth. But as a matter of fact any science, whatever it be, grows out of the demands of society or its classes." ${ }^{16}$ Thus Nabokov's two great passions were nullified in the new regime. 
Nabokov emerged from his chrysalis at a time when his core identity was rejected and negated in his homeland, both practically and philosophically. His life and career, as artist and scientist, were set in a contest with the positivist materialist philosophy embodied by the Bolsheviks, and in many ways it was a life-or-death battle waged in ink. He waged the battle not because he was rejected, but because he believed unflinchingly in the absolute falsity, cruelty, and crudity — alongside the patently self-contradictory nature-of the new regime and its political/philosophical program; and also because, as he repeatedly discovered, more than a few western intellectuals were sympathetic to the Soviet project and ignorant about its real nature in practice. What he opposed to the Bolsheviks' ideology of positivist certainty, teleology, mass conformity and control was an artistic and scientific program based on individuality, curiosity, beauty, and the unknown, a program in which these central elements hover over any human intellectual endeavor. This stance gives his work and his life a particular anti-materialist, even idealist tinge, to which we now turn.

\section{Philosophical Context}

\section{Science, Materialism, and Idealism}

In response to a criticism of his 1949 article "Nearctic Members of the Genus Lycaeides," Nabokov retorted: "After all, science is responsible to philosophy, not to statistics." ${ }^{17}$ On some level this statement must be true, as one's philosophy determines how one thinks about the ultimate constituents, or ground, of the empirical world. ${ }^{18}$ In other words, all scientific investigations are set within tacit or explicit assumptions about the world's "ultimate essence." From this point of view, there is one critical difference between an idealist stance and a materialist one. A monistic materialist metaphysics, which posits matter as the ultimate and only reality-and consciousness as a side effect of material interactions in the brain-tends to carry with it the assumption that all aspects and laws of the material world can be known and understood by the human mind. This, at least, is the version of materialism that came to dominate among Marxists in the nineteenth century, not least in Russia, eventually guiding the Bolsheviks in their revolution. Within such a world, science sets as its goal certain knowledge and, paradoxically, the eventual scientific and technological victory of humanity over all of nature, including human nature.

The attractions of such an ideology are plain enough to see, but so of 
course are the contradictions. Although this interpretation of materialism is not logically inevitable, it does seem to have possessed an irresistible allure in the age of high industrialism, perhaps because it took the tangible physical object, which seems so solid, stable, and real, as its icon and exemplar. A post-Kant idealist outlook, such as was embraced by Russia's neo-idealists, presents a far more elusive field of study, and lends itself to much more tentative sorts of conclusions. For even if idealism may encourage belief in the reality of the phenomenal world, it recognizes explicitly the limits of knowledge caused by the "peculiar constitution of [human] cognitive faculties," to use Kant's own words. ${ }^{19}$ By the same token, because of this acceptance of an unknown, perhaps unknowable element at its very core, idealism allows more easily for a phenomenal reality that is not always a perfect fit with scientific conceptions of it. Notwithstanding the metaphysical implications of an idealist outlook, Kant suggested that human knowledge of the world can only proceed along the lines provided by empirical science. ${ }^{20}$ That is, no matter what the ultimate, metaphysical "truth" might be, we can only know our world by establishing facts in the scientific manner, according to the categories and a priori essence of consciousness. That still leaves the enormous, even infinite space of the unknown, unknowable (because inaccessible to human perception or reason) depths of reality. The invisible ubiquity of this unknown domain is what leads Nabokov to posit "leakings and drafts" in the world, ${ }^{21}$ indications that the empirical world does not exhaust all of reality. Its limits, he suggests, though not directly perceptible, can be inferred from irregularities or patterns in nature noticed by the extremely careful observer.

In at least the early and middle parts of his career, Nabokov even held to the belief that science itself might discover such indications, for example in the notion that mimicry could not be explained by utilitarian natural selection (or by any other causal method, we may presume). This is not to say that Nabokov, as a scientist, set out to prove supernatural causes in nature (like modern "creation science" or "intelligent design"). Far from it. As we will see, his professional classificatory work was based upon the same strict procedures that characterize science today, and the results of his observations and innovations have gained increasing recognition and respect in the six decades since his work was completed. But he did frequently draw attention to the limits of science's scope: "We shall never know the origin of life, or the meaning of life, or the nature of space and time, or the nature of nature, or the nature of thought." 22 Thus, while scientific research is capable of providing astonishingly detailed information about nature in the broadest sense, it is not and cannot be all- 
encompassing. The constant awareness that science itself possesses a "beyond" defines Nabokov intellectually. This predilection reaches its extravagant apogee in $A d a$, his longest and most ambitious novel.

\section{Science and Metaphysics}

Due to the widespread attention to metaphysical formulations in Nabokov's works, and to his wife Véra's comment that the "beyond" is the "main theme" permeating his entire oeuvre, scientists writing about him have taken pains to demonstrate that his metaphysical outlook did not color his scientific practice. ${ }^{23}$ This main theme, potustoronnost', means literally "on-that-[other]-side-ness," best translated as "the beyond," and while it has primarily metaphysical associations in Russian, it can also have scientific or epistemological ones: that which is beyond human knowledge, or beyond the purview of human senses and consciousness. As practically all commentators have confessed, Nabokov revealed essentially nothing about his personal beliefs, although a majority accept that he certainly held some views that qualified as metaphysical or mystical. But did he actually believe in a benign creator, a "person unknown," a benevolent, aesthetically-minded designer of the world? ${ }^{24}$ There is no unequivocal answer. Thus, whatever Nabokov's credo was, we know with precision only one key commandment: thou shalt not reveal thy credo.

What is certain is that Nabokov liked to construct his fictional worlds in ways that drew upon mystical and metaphysical conceptions of reality. Images of the author or his world regularly appear in what he called a demiurgic capacity in relation to the created fiction. ${ }^{25}$ But he also exploited the figure of the dreamer and the dream, a significantly more ambiguous trope, foregrounding the inconsistencies and limitations of consciousness more than metaphysical agency. If his works tell us anything at all about metaphysical realities, it is that whatever the ultimate truth may be, it is quite beyond our human capacities to perceive, know, or understand it.

Science, in its modern guise as shaped by Francis Bacon, Newton, and Kant, is by logical necessity not concerned with metaphysical truths. On the other hand, science is also sometimes more interested in trumpeting its explanatory power than in probing its limits. The modern debate about parapsychological phenomena is an interesting case in point: a small number of researchers attempted during the twentieth century to apply the scientific method to such phenomena as ESP, precognition, and telekinesis, 
among other mysteries. Although endorsed by some major scientists and philosophers by means of the Society for Psychical Research, ${ }^{26}$ this work was viewed with derision and hostility by "mainstream" science, and it received little funding-in part, because it was apparently unable to produce replicable results in any domain. Yet unbiased observers, including Einstein, admitted that such researches were not in themselves unjustified and could be praiseworthy if done in a truly scientific manner. ${ }^{27}$ Uncanny psychological phenomena, in which Nabokov took a distinct interest, appear to have been beyond the testing capacities of science, at least for the time being. ${ }^{28}$ And yet pursuing such questions is not in itself unscientific, as long as one is willing to accept negative results. It is like testing to see whether one department of "metaphysics" can be moved into the domain of science. If no hypothesis about a particular subject can be proved or disproved, then it can be said to be beyond the limits of scientific inquiry. It remains metaphysics, and hence unknown.

Nabokov's scientific work mostly concerned testable hypotheses, although there is one ambiguity to be admitted here: it is notoriously impossible to prove a negative, and one of Nabokov's ambitions was to demonstrate the existence of non-utilitarian forms in nature. His wellknown early choice in this quest was mimicry (including object resemblance, or "crypsis"), which he felt exhibited precision beyond any imaginable predator's visual acuity. Although this last belief has turned out to be false, we do have some idea of how Nabokov might have made a scientific effort to show that non-utilitarian mimicry exists. ${ }^{29} \mathrm{Had}$ he been given the opportunity to complete his envisioned compendium of "all examples of mimicry in the animal kingdom," he must have hypothesized that such a mass of data would have provided a few striking or at least highly suggestive examples. ${ }^{30}$ His metaphysics appears to have included belief in the existence of mechanisms other than causal ones, and causes other than utilitarian ones. It was not unscientific of him to wonder whether these beliefs might be testable. However, knowing that his ideas were near the outer limits of the scientific method, he was circumspect in his approach, to the point of leaving the project undone. ${ }^{31}$ Nabokov knew where science ended and metaphysics began, and although he may have wanted to shift the boundary slightly, he was not able to do so. In this way, Nabokov's metaphysics left a distinct imprint on him as a scientist, and his desire that science might provide hints about metaphysical truths led to his interest in exceptions to established natural mechanisms. But he was never able to pursue these exceptions scientifically, and his published research remained within the traditional boundaries. 


\section{Science, Art, and the Limits of Cognition}

One of Nabokov's primary strategies for assaulting positivist materialism was his well-known tendency to question or qualify the existence of "reality," which he insisted should always appear within quotation marks. ${ }^{32}$ Most of these statements appear in interviews following upon his postLolita fame, but they also appear earlier, in essays and lectures on literary figures. The questioning of reality was, in the middle of the twentieth century, a surprising position for a scientist to take. However, upon careful review it becomes clear that Nabokov does not ever deny the existence of reality (that is, of existence itself); he disputes the independent existence of "average reality" - the concept that is at the core of naïve realism: "Average reality begins to rot and stink as soon as the act of individual creation ceases to animate a subjectively perceived texture." ${ }^{33}$ Nabokov's refutations of naïve realism and his assertions of the importance of consciousness and its creative activity are so insistent that they constitute a fundamental principle of his art and thought. In a virtual litany of such passages, quite early in his period of fame, Nabokov refers his audience to the "creative force of human consciousness," to the "depths of reality," to the "unquenchable," "infinite" nature of the quest for knowledge on even the most confined subject. ${ }^{34}$ Nabokov thus emphasizes the fact that nature is extraordinarily complex, and that many, even most elements of this complexity are inaccessible to immediate perception; some are hidden from the senses altogether, and hence also from direct knowledge. Nature, even without reference to a Kantian "thing in itself," in many ways escapes our awareness, because our senses have evolved to respond to a particular set of environmental stimuli that are relevant to human existence, and for the most part that means material existence.

\section{Knowledge and Falsehood in Art and Science}

The link between Nabokov's conceptions of art and science derives from his outlook on knowledge as a feature of human consciousness. Knowledge of nature and of other beings is elusive and hard-won. Few writers pay as much attention as Nabokov to the widespread existence of false beliefs about the world. In the Russian tradition, both Gogol (for example in The Government Inspector) and Tolstoy (especially in War and Peace) stand out as his major precursors. What is perhaps surprising is that in Nabokov's case this attention includes a sensitivity to false knowledge in 
the hard sciences. ${ }^{35}$ Like Goethe, another artist-scientist about whom we say more further on, Nabokov nurtured a suspicion of the dominant quantitative, Newtonian mode of scientific investigation and progress, with its atomistic mechanical base and its effort to explain all natural phenomena by means of quantifiable forms or formulae, which he called the "artificial logical world." ${ }^{36}$ But he found in popular Darwinism and Freudianism special opponents whose over-application of nonempirical (un- or undersubstantiated) theory contributed to a myth of the perfectibility of scientific knowledge in various spheres, such as the mechanisms or source of life, or the human mind. ${ }^{37}$ To understand why Nabokov took on these giants, we need to achieve a sense of how he viewed the entire project of coming to know something about "reality." A crucial part of Nabokov's view of knowledge was his understanding of how the mind can deceive itself.

\section{Epistemological Gaps and the Mind's Fictions}

Nabokov's characters are typically portrayed as possessing knowledge of only a limited portion of the world around them, although the better natures among them attempt to peer past the limits of individual existence. The ongoing, largely successful efforts of science to discover hidden aspects of reality imply two things: first, that the world is in fact more complex than we perceive it to be; and second, that our senses are attuned to only a fraction of the world's totality. Both of these facts are forgotten with amazing ease, along with an important corollary: that the mind tends to fill in gaps in knowledge with plausible theories- to "invent a cause or modify an effect rather than have none at all." ${ }^{38}$ It creates soothing fictions for itself and generally misinterprets the world around it. This tendency, in Fyodor's parodic literary portrait in The Gift, repeatedly describes the socialist agitator Nikolai Chernyshevsky. ${ }^{39}$ Such gap-filling is no less characteristic of the practice of philosophy itself than it is of individuals in their daily lives. More surprisingly, it is just as common within the natural sciences-which is why, of course, science "advances" as it overcomes its misconceptions. ${ }^{40}$ In fact, as we shall see in chapter 2, one of Goethe's main criticisms of Newton's optical experiments was that in them, Newton approached his experiments with a preconceived idea of what the outcome would be, and then conducted a few reductive tests - the experimentum crucis-in confirmation of the theory. ${ }^{41}$ (Nabokov was not very likely to have been aware of this critique of Newton, as the anti-Newtonian "Polemical Part" of Goethe's The Theory of Color was omitted from many 
German editions, and all translations. Indeed, the eminent Russian/Soviet geologist Vladimir Vernadsky, in his article on Goethe's science researched in the 1930s and published in 1944, appears not to have been aware of it. $)^{42}$ Consequently, it is just as important to be wary of misinterpreting the empirical data of phenomena as it is to be suspicious of the reports of others. "Bare facts," Nabokov asserts, do not exist because of the necessarily subjective nature of all observation, and all stories about "facts" are prone to involve many distortions introduced by the teller (this was also a major theme of Tolstoy's War and Peace). For Nabokov, "bare facts do not exist in a state of nature, for they are never really quite bare: the white trace of a wrist watch, a curled piece of sticking plaster on a bruised heel, these cannot be discarded by the most ardent nudist. A mere string of figures will disclose the identity of the stringer as neatly as tame ciphers yielded their treasure to Poe.... I doubt whether you can even give your telephone number without giving something of yourself." 43 And so for Nabokov, nature can be studied, and it can be known scientifically in part, but it cannot be known absolutely. This is due to the inherent limits of knowledge recognized by Kant (developing upon Hume's skepticism), who also recognized the possibility of more advanced or sensitive types of consciousness that would have a commensurately greater knowledge of the world. ${ }^{44}$ The problem of discerning where the inventions of one's own consciousness begin to diverge from empirical phenomena stands at the heart of some of Nabokov's most moving works.

\section{Nabokov's Solipsists}

Nabokov's interest in the failings of human perceptive abilities reaches full expression in his portraits-usually fictitious self-portraits, logically enough-of characters whose relationship to the world approaches pure solipsism. This side of human psychology drew Nabokov precisely because it allowed him to demonstrate vividly just how "realistic" an absolute fantasy world might seem to the afflicted individual. Most significantly, we see this type embodied in Lolita's Humbert Humbert, Despair's Hermann, Pale Fire's Kinbote, and to a somewhat lesser degree in The Eye and in Laughter in the Dark. This is the limit case of epistemological blindness: a character's deepest flaws, passions, and insecurities cause the creation of an alternate reality in conflict with the one perceived by others. Fragments of "real life" might contradict necessary features of that imaginary world, but they are modified or elided by those same cognitive mechanisms that 
fill in the gaps of a healthy outlook. The result, in Nabokov's worlds, is usually harm or even death to someone within reach of the afflicted character.

Nabokov's works represent an attempt to explore the far reaches of human consciousness, which, in all its incredible mysteriousness, includes these cases of individuals almost totally cut off from "reality" (with a literary heritage that goes back at least to Nabokov's favorite Dostoevsky novel, The Double). The study of such aberrations is part of the knowledge-seeker's quest to understand the details of nature in all its forms; consciousness too is a "gift of nature," as Fyodor's father tells us. ${ }^{45}$ These cases do raise troubling questions of culpability and of the individual's autonomy: for example, why do such aberrations occur? Do they arise from a cause? We are left to wonder where the intersection between freedom and causality lies in human consciousness. Mental activity at the other extreme-say, of artists like Fyodor, or of Van and Ada, or of John Shade-gives an alternative that emphasizes in varying degrees the ability to focus on and discover details of the outside world and other consciousnesses.

\section{Artistic and Scientific Modes of Discourse}

Once one accepts the limitations of consciousness and the inevitable distortions of "objective" narrative even in the domain of science, the door is opened to explore the murky territory where artistic and scientific modes of perception overlap. Nabokov chose to make such an experiment in an area where, he felt, art and nature themselves intertwine: in the patterns on a butterfly's wings, especially in mimicry. But first some background is in order.

As his memoir demonstrates, Nabokov cherished a desire to use animal mimicry (in its broadest sense, including “object resemblance”) as the main evidence in his argument against the omnipotence (August Weismann's “Allmacht”) of natural selection. ${ }^{46}$ The claim, as Nabokov put it, was that moth or butterfly mimicry of various natural objects in their environments is so precise that it must far surpass the visual acuity of the predators it is meant to deceive. However, although Nabokov did publish, in scientific papers, his doubts about the universal applicability of natural selection, and he submitted an article on mimicry to the Yale Review, he did not complete or even preserve materials for an envisioned comprehensive study of mimicry in nature. ${ }^{47}$ In other words, it seems that he became 
persuaded that his work would not receive a sympathetic hearing among the scientists he so respected, or else he himself came to doubt the validity of his claims in the face of mounting counterevidence. ${ }^{48}$ However, even before attempting to make these arguments within essentially scientific discourse, ${ }^{49}$ he had attempted to work them up within an artistic contextthrough his created lepidopterist Konstantin Godunov-Cherdyntsev and his son Fyodor in The Gift and its abandoned supplements.

\section{"Father's Butterflies"}

Almost all of The Gift's second chapter is devoted to the career and thoughts of the narrator's father, Konstantin Kirillovich Godunov-Cherdyntsev, who is presented as one of the top entomologists of his generation-and, philosophically, an idealist. In the abandoned expansion of The Gift recently published as "Father's Butterflies," 50 Nabokov adopted a special strategy in his effort to explore alternative theories of speciation, based on doubts raised by mimicry. Godunov-Cherdyntsev senior is said to have written a thirty-page summary of his proposed new theory of speciation. Rather than represent the professional voice of a scientist directly, by means of his lepidopterist character, Nabokov instead has the scientist's son Fyodor, a poet and budding novelist, re-create a vision of the Russian scientific text indirectly, by means of fragments that have been translated into English and retranslated back into Russian, with the assistance of memory. Why all these added layers of complexity? They might, most simply, reflect an artistic choice not to quote several pages of "scientific" prose within a fragment of fiction. But I think there was another, more important aim: to have the technical prose grasped almost from the void, distilled, and refracted by an artistic mind. The choice had two key benefits: it saved Nabokov from the need to set his scientific fancies in a form that might someday be mistaken as one of his actual scientific texts. That is, it preserved an adequate buffer to ensure that Godunov-Cherdyntsev's theories would never be attributed to Nabokov as a scientist: he was already a published amateur at the time. Still more significantly, it suggests an artistic component, and the intellectual validity of that component, in the scientist's perception of nature and even in nature's inner workings. In other words, we find in the story not an inserted, unassimilated piece of scientific discourse, but rather a scientific approach to nature that has been absorbed and interwoven with the very fabric of the artistic text itself, by means of the artist-son's consciousness and memory. Fyodor may not 
have fully grasped every aspect of the theory in his father's "supplement," but his intense urge to do so, and to integrate that experience into his art, tells us a great deal about Nabokov's ambitions for the nexus between his own scientific and artistic passions. This unusual intimacy between words' role in aesthetic form and their ability to describe nature precisely helped Nabokov to produce works that defied typical classification and sought out the boundary across which consciousness and "reality" confront one another.

\section{The Scientization of Literary Studies}

As background to The Gift's aestheticization of science, it is worth bearing in mind that Nabokov's career also began at a time when literary work itself-especially the study of literature-was striving to become more scientific and objective. The quantitative approach was spreading into traditional humanist fields, with the result that scholars like Boris Eikhenbaum, Viktor Shklovsky, Yuri Tynianov, and other Formalists (and, first of all and most intriguingly, Andrey Bely) were analyzing literary art into its component structures and motivating forces. Such methods grew up alongside biographical and historiographical practices that attempted to document the past by means of contemporary accounts and reminiscences, a method that was highly fashionable in the first two decades of the Soviet regime. In other words, study of the arts was undergoing a transformation that tended to emphasize their structured, constructed nature, and they were being integrated into anthropological, sociological, as well as psychological study, whose goal was to overcome notions of subjective content and authorial intent and replace them with formal and developmental laws. ${ }^{51}$ Aesthetics ceded to structural analysis, and authorial intent made way for psychological or psychoanalytical documentary. These approaches, with their tendency to valorize the knower (or the system of knowledge) at the expense of the "known," brought forth Nabokov's critical acumen and evoked in his work a constant attention to the pitfalls and limitations of knowledge, to the need to be wary of the tyrannical impulses of both science and narrative. This concern helped produce an increased aestheticepistemological tension in two important works from 1937-38, The Real Life of Sebastian Knight and "Pouchkine, ou le vrai et le vraisemblable" (Pushkin, or the True and the Verisimilar), which compounds the tension already so vividly foregrounded in the "Life of Chernyshevsky" chapter of The Gift. ${ }^{52}$ These works explore the relation between human life, aesthetic 
form, and the possibility of biographical knowledge. ${ }^{53}$ In each of them, just as in his science-saturated work on The Gift and its supplements, Nabokov points again and again to the contingency of knowledge and especially of narrative upon the activity of the perceiving consciousness, with its ability to reach out beyond itself to the phenomena around it. This is precisely what Chernyshevsky (as portrayed in The Gift) could not do, and his "objective" aesthetic study, The Aesthetic Relations of Art to Reality, is shown to be an altogether unreliable foundation upon which to construct any science or science-based worldview. For Nabokov, Chernyshevsky was the first and most important example of dangerous overconfidence in human cognitive abilities, in the power of language and logic to create a perfect understanding of reality. Chernyshevsky's glib prose stands as a foil to all of Nabokov's elusive, ambiguous, multivalent writings.

\section{Nabokov, Goethe, and the Science-Art Nexus}

I devote considerable attention in this book to another literary artist who was also a scientist, Johann Wolfgang von Goethe. This is a tempting step to take because, alongside many other affinities with Nabokov, Goethe invented the scientific term that names Nabokov's special research area, morphology. Organic form, as subjectively viewed and as a source for holistic insight, was crucial to both authors. Goethe stands as the most scientifically active and productive of major literary figures prior to Nabokov, and thus as a kind of prototype for the literary artist with a passion for scientific investigation. Awareness of their similarities should foster some insight into the possible advantages of alternative scientific methodologies. On the other hand, they were driven by divergent goals: Goethe worked to discover the universal and governing realia behind natural manifestations; Nabokov's passion appears to have been most drawn by the discovery of exceptional forms. Whereas Nabokov found joy and ultimate meaning in the unfathomable variety and complexity of nature, Goethe sought the common archetypes that unite and link nature's proliferation of forms: the "Urtypus," such as the Urpflanze, for example, or his discovery that contrary to prior belief, homo sapiens shares the intermaxillary bone of the face with all other mammals. Notwithstanding this difference in temperament, both were devoted to the idea of nature as dynamic and ever-changing.

Although he considered himself a realist, Goethe was famously told by Schiller that his notion of the Urpflantze was an "idea" in the Romantic, 
idealist sense. Nabokov, while appearing sympathetic toward the idealist outlook, does not reveal his ultimate metaphysical commitments, and only his fictional scientist Godunov-Cherdyntsev asserts anything like ideal forms. Nabokov projects in all of his work an intense connection to the actual experienced phenomenon. Moreover, Nabokov is more explicit than Goethe in his combination of principles of art and those of nature. Repeatedly within his own nonscientific writings-and occasionally in the scientific ones-he refers to the artistic qualities of nature. The artist deceives, and nature is the "arch-cheat." ${ }^{54}$ Nature seems "created precisely for the intelligent eyes of man"; it appears designed and patterned; it includes "family jokes" and "rhymes." 55 These types of comments occur across the spectrum of Nabokov's writings.

For those thinkers of the Romantic era who desired to broaden the scope of scientific (and not just artistic) approaches to truth, one available path was to challenge the ability of Newtonian science to provide a full account of nature's variety, intricacy, and beauty. More than elsewhere this took place within the context of the German proponents of Naturphilosophie, most especially Schelling and Schiller. Also among this group one often finds the name of Goethe; however, as we shall see, his approach to science was in many ways distinct from mainstream "nature philosophy." Nevertheless, there can be no doubt that Goethe too sought to develop an alternative to the Newtonian approach to empirical study. Obliquely associated with the idealist Naturphilosophen, yet strictly inductive in its methods and principles, Goethe's scientific work was long viewed as little more than a curiosity item in the history of literary art, and not at all as serious or important science in its own right. Reappraisals by leading figures of science like Helmholtz in the late nineteenth century and Heisenberg in the twentieth have sought to assign a much greater value to Goethe's work. Reflecting upon Goethe's scientific legacy, the student of Nabokov is immediately struck by the two authors' willingness to challenge major authorities and introduce radically new explanations and systems within their chosen fields of study. A closer look at their scientific achievements will also reveal even deeper affinities between the two, based in part on a firm commitment to the careful, detailed observation of phenomena, combined with a passionate embrace of nature as something of fundamental value within their outlooks. What distinguishes Goethe's scientific approach is his belief in the value of deep insight, intuition into the very nature of the object of study. Such a methodology reserves a special place for the subjective element in observation, a position starkly at odds with the putative absence of subjectivity within Newtonian practice 
as commonly understood. Goethe's method rests in part on a belief that human consciousness has more than passing, more than coincidental affinities with the empirical world (the "real" world, with or without Kantian "things in themselves")- a perspective that anticipates Nabokov's own comment about "bare facts." ${ }^{56}$ In the chapter exploring the contours of Nabokov's own scientific work and thought, I will consider to what extent his empirical approach to the natural world shares a view of this special relationship between the subject and the object, between the knowing, observing consciousness and the thing observed.

Over the centuries, science and art have moved together and apart in an irregular cycle. For the most part, the Newtonian brand of study with its Spartan, numerical emphasis has governed and driven nearly all mainstream science as science for the past three centuries. There is a variety of reasons why this should be so, not least among them the fact that numbers produce results that can lead to direct, practical application, and application leads both to technical innovation and to economic advancement. However, there is another side to science that is unashamed of its subjective elements, and which approaches art in spirit and helps us recognize the epistemological relationship between the two. It was Goethe who first advanced a highly developed version of this alternative methodology, based upon an experimental picture that observes phenomena in their natural situation and in their entirety, including an awareness of the perceiver's role in giving shape to phenomena. ${ }^{57}$ Nabokov too sought to develop a new kind of discourse about the natural world, not restricted by the Newtonian-Kantian emphasis upon causality and phenomenal experience. Godunov-Cherdyntsev's spherical species theory bears some resemblance to Goethe's archetype theory, in its "emergence" from his enormous empirical experience.

\section{The Questions of Science}

The key questions raised by Nabokov's conjunction of art and science are: how well do we know (or perceive) our habitat, "visible nature"; and how well do we know ourselves. Typical modern science tends to ask slightly different questions: How does the world (nature) work? How do we humans and our minds work? The difference is crucial, for the latter questions presume (or at least encourage the presumption) that our knowledge progresses in a thorough and accurate way, while the former investigate also the reliability of that knowledge itself. Nabokov refuses to suspend 
awareness that the world is given to us by our senses, and in many ways is created by our conscious activity which "animates" subjective reality, or may "invent a cause or modify an effect." 58 Hence the scientific study of the world is in part the study of human creativity, the hidden art of consciousness in presenting the phenomenal world to us. As we explore the scientific dimensions of Nabokov's art, we will discover a presentation that finds the maximum of human conscious potential fulfilled only in such observation as takes account of aesthetically perceived relations as well as quantitatively perceived ones. Accuracy, detail, aesthetic sense, and selfconsciousness are all key components of this activity that leads to what Nabokov considered the highest states of being available to humanity. It is a goal rarely achieved in the worlds he created, but one clearly indicated for the attentive character and reader.

This book's structure represents a series of concepts that, in my judgment, best illustrate several important aspects of Nabokov's commingling of scientific and aesthetic ideas. Rather than work on a novel-by-novel basis, I have chosen to offer six different science-related perspectives upon Nabokov and his work. Chapter 1 examines his actual work as a scientist in some detail, discovering particular features in his articles and research notes that shed significant light on his entire outlook. It also proceeds to give a closer examination of the fusion of scientific and artistic perspectives in The Gift and "Father's Butterflies." Chapter 2 offers a preliminary account of the suggestive commonalities shared between Nabokov and Goethe, the most distinguished artist-scientist of the modern era. Goethe's kinship with and differences from Nabokov provide a vital perspective from which to assess the later author's originality within this unusual interdisciplinary framework. I then offer three chapters on discrete scientific disciplines as they are reflected in Nabokov's writings: biology, psychology, and physics. Nabokov was an expert amateur and later a professional biologist with a special interest in evolutionary theory, and in the chapter devoted to biology I explore how his works embody some of his efforts to think about nature, which includes both human consciousness and art. In psychology, Nabokov's knowledge came primarily from his wide readings in the subject, and his attitude toward mind and consciousness is best elucidated by the writings of William James. Recognizing that everything known and experienced derives from the interaction of individual consciousness with phenomenal reality, Nabokov's psychological approach to human subjectivity focused on the shaping and self-deceiving potential within consciousness. Simultaneously, he waged a life-long battle against Freudian and other psychological approaches that attempt to explain 
mental life through clearly discernable causal mechanisms. Physics, Nabokov's worst subject in high school, attracted him later as the quantum and relativity theories raised questions about the essence of time and the role of causality at the deepest levels of "reality." Motifs from these new fields appear in his works throughout his career, and are a major shaping force in several. The penultimate chapter investigates in greater detail how Nabokov's scientific and epistemological concerns interrelate to produce the distinctive quality of his art by means of a poetics of absence and discontinuity. In the conclusion, I attempt to allay possible concerns about the uncomfortable proximity of Nabokov's thought to modern "anti-science," and I close with a reconsideration of previous Nabokov scholarship in the light of the present work.

Every Nabokov novel is enriched by a familiarity with its scientific undercurrents. These may not always be as strong as they are in The Gift, but still they are there in all but perhaps the very earliest works. By attending to the way Nabokov incorporates his understanding of biology, psychology, and physics into his philosophical outlook and creative practice, we can appreciate the strangeness of his novels as a reflection of his fundamental vision of the world's essence. His fiction suggests that the world is not exactly what quantitative science describes; that the creations of the mind are error-prone; and that life at its core is-or can be-driven by laws other than the utilitarian struggle to survive. The quantitative sciences provide only a single, limited perspective on "reality"; this must be supplemented by qualitative perception and study. ${ }^{59}$ Even so, consciousness cannot know more than its capacities allow, but it will, Nabokov optimistically asserts, be "looking in the right direction." 60 


\section{Nabokov as a Scientist}

Artists, first of all study science!

—Leonardo da Vinci

WHAT DOES ONE SAY about a scientist who claims to have stepped into the base of a rainbow? Nabokov did not make this claim, but his favorite fictional scientist did: Fyodor, the narrator of The Gift, tells us that "once in Ordos my father, climbing a hill after a storm, inadvertently entered the base of a rainbow-the rarest occurrence! and found himself in colored air, in a play of light as if in paradise. He took one more step-and left paradise." ${ }^{1}$ It is a puzzling vision, easily dismissed as the son's poetic interpolation, a mirage like the ones his father Konstantin GodunovCherdyntsev witnessed and heard of during his Asian travels. But Fyodor aspires to uncompromising truthfulness concerning his father's life, and although he recognizes the elusiveness of this ideal, he is unlikely to invent for his father such a fantasy. ${ }^{2}$ We have every reason to believe that the story comes from Godunov-Cherdyntsev himself. Meanwhile, Fyodor's father is "the leading entomologist of his time." ${ }^{3}$ In creating this image of a scientist who, like Marco Polo, experiences the impossible, Nabokov challenges his readers and the intellectual community at large to rethink the very nature of the scientist's work and the possibility of the marvelous even within a scientific life. And although Nabokov's published work as an amateur and professional scientist generally conforms to the standards of scientific 
discourse, there are some occasional wrinkles of style and image that remind his readers that he might be looking for secret loopholes in the norms of scientific practice.

There have now been several evaluations of Nabokov's work as a lepidopterist, including some from his scientific colleagues (such as Charles Remington), his successors (Kurt Johnson and Steve Coates, Robert M. Pyle), his translators, and, one might even say, general curators (Dieter E. Zimmer). Brian Boyd's pioneering biography is distinguished by careful and detailed treatment of Nabokov the scientist. Thus it is no longer necessary to rehabilitate Nabokov's entomological accomplishments, or to spend much time describing his major articles' scientific significance. My purpose here is not to create a detailed picture of what science Nabokov actually did, but rather, drawing on the texts and others' assessments of them, to explore what special qualities his scientific practice and discourse embodied. It will emerge that these qualities are ones that take us right to the common border of the aesthetic and the empirical.

What kind of scientist was Nabokov? When historians of science categorize or describe their human subjects, they draw attention to the inductive or deductive methodology behind a scientist's work, with its accompanying reliance on empirical or theoretical origins. No doubt every scientist is a blend of these types, with one tendency or the other dominant. Nabokov may be harder to categorize in this regard, because, as at least one scientist writing about him has observed, he incorporates significant components from both sides. According to Kurt Johnson and Steve Coates, "he was a lepidopterist of an analytic rather than a synthetic bent," suggesting an empirically grounded practice, but he "did, however, think about the broader aspects of systematics, and his notions [ ... ] were more sophisticated than he is sometimes given credit for." ${ }^{4}$ Within his chosen field of taxonomy, he struck a similar balance: here, the tension falls between "lumpers," who prefer a system leading to fewer, larger genera and a smaller total number of distinct species, and "splitters," who tend to award genus or species status based on a lower threshold of distinction. Nabokov was known to establish new genera where none had been before-thus splitting existing ones; but he also collapsed, or lumped, existing taxa into single groups. He was rigorous and consistent in applying rules that made sense to him. Likewise, he has not over-eager to promote a subspecies to a distinct species without the application of very strict criteria.

He was also an extraordinarily productive worker. In his six years at the Museum of Comparative Zoology, he dissected at least 1,570 butterfly 
genitalia under the microscope: an average of 261 per year, or one per weekday not accounting for summers spent away from Cambridge. ${ }^{5}$ Many, even most of these preparations he drew and annotated with extreme detail and precision. Add to this his wing-pattern analyses of over 3,500 butterflies, also with extensive figuration and the mapping and even counting of individual scales. When one takes into account his scientific correspondence, the time to compose the articles themselves, and the need to read existing research and reports on the relevant species and genera, it seems almost unimaginable that Nabokov was simultaneously researching and writing a novel and a memoir in English, teaching Russian language and literature, going on lecture tours, publishing translations of Russian poetry and a study of Nikolai Gogol as well as his own short stories. If the list sounds exhausting, the impression is deepened when one looks through the voluminous folders bursting with hundreds of meticulous, lovingly drawn and colored images of butterfly wings and genitalia at various magnifications, for his own personal research use and for publication with the articles themselves. Each minute cilium on a butterfly's wing is represented with the same care as the most radiant wingspot (see figure 1).

Characteristically, Nabokov was highly critical of sloppy work by some of his predecessors in the description and classification of certain lepidoptera. He found a scientific career for himself in the practice of perceiving with greater care and precision than those who came before him. He detected errors of consequence, saw patterns where others had not, and could distinguish both important differences and trivial similarities.

After several decades of neglect, Nabokov's scientific reputation was enhanced by a resurgence of interest in his research areas in the 1980s. Kurt Johnson, Zsolt Bálint, and Dubi Benyamini happened to be independently initiating studies of the genera that Nabokov had worked on in the 1940s, and in the process they found Nabokov's articles (which were prominently published in Psyche and elsewhere). They wound up continuing the work he had begun, updating that area of taxonomy and also giving greater publicity to his discoveries and innovations. The upshot of their work was a series of articles building upon Nabokov's foundations, and also the book Nabokov's Blues, written by Johnson together with Steve Coates. In their book, Johnson and Coates suggest that Nabokov's research amounted to more than simple classification work: he was "ahead of his time" and did "big science." In other words, Nabokov was a researcher who made significant contributions not only to taxonomic knowledge, but also to theoretical notions of how different species were likely to be related or to evolve. He offered important insights into the fundamental processes 


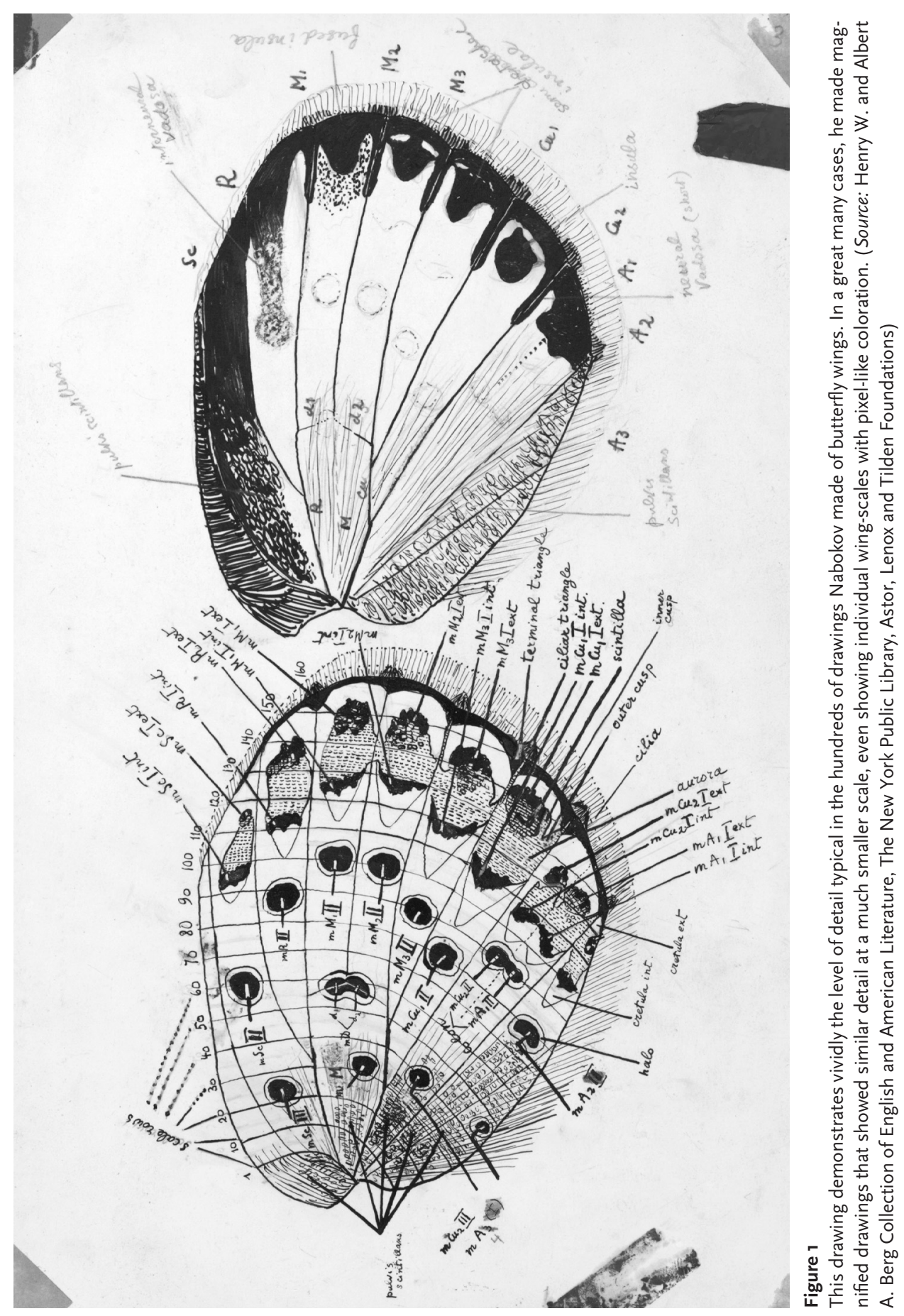


of nature; some of those insights, in their neglect, were duplicated much later by other scientists with far more sophisticated tools at their disposal. As Johnson and Coates observe, Nabokov's "good eye had brought him to a level of taxonomic sophistication beyond that of many of his contemporaries, but in a sense it also made it easier for his work to be overlooked or misunderstood by those who weren't disposed to look as deeply."7

The very concept of species was one of Nabokov's areas of particular interest. There was, at the time, a lingering controversy concerning the definition of species, and Nabokov had his own uncompromising views. He denied the primacy of "biological" definition advocated at the time by Ernst Mayr and especially Theodosius Dobzhansky, which relied upon real or theoretically interbreeding individuals, as too restrictive and dismissive of what to him was the true test of an organism's identity: morphology. ${ }^{8}$ Like other lepidopterists, Nabokov came to the conclusion that in general it is the morphology of the male (and to a lesser extent female) genital apparatus that provides the most useful clues for determining the closeness of related butterfly or moth species, and his criteria for establishing distinct taxa include both the specific proportions of the male armature and some details of wing structure. ${ }^{9}$ As a result, his main work consisted of the dissection, microscopic examination, and figuring of these forms (over fifteen hundred preparations for the four major papers), comparing the morphological and proportional variations of the different structural parts. Some of these he was the first to name-for example, Plebejus idas sublivens Nabokov ${ }^{10}$ - which is also like saying that he was the first human, ever, to see these butterflies distinctly. He proposed (inductively) the existence of a "magic triangle" formed by three apexes of the armature, creating a heuristic tool for his comparison of the many similar but subtly distinct apparatuses he studied (see figure 2). ${ }^{11}$

Nabokov's other key component for identifying specific distinctness, the hindwing, also called forth a new way of seeing: wing-patterns are made up of hundreds or thousands of individual scales, and these are laid out in a matrix that can be mapped and labeled. As a result, Nabokov was able to give a coordinate-level description of the variations between wingpattern features (such as macules_-spots-and lines), a level of detail that had not been imagined before. Thus, by applying these two simple principles with an unprecedented degree of accuracy, Nabokov within his area of study (subfamily Plebejinae) produced major advances in butterfly classification. As Kurt Johnson suggests, his methods and his interpretations of the data were ahead of their time and even audacious, uncovering deep realities that have withstood advances in science and technology through 


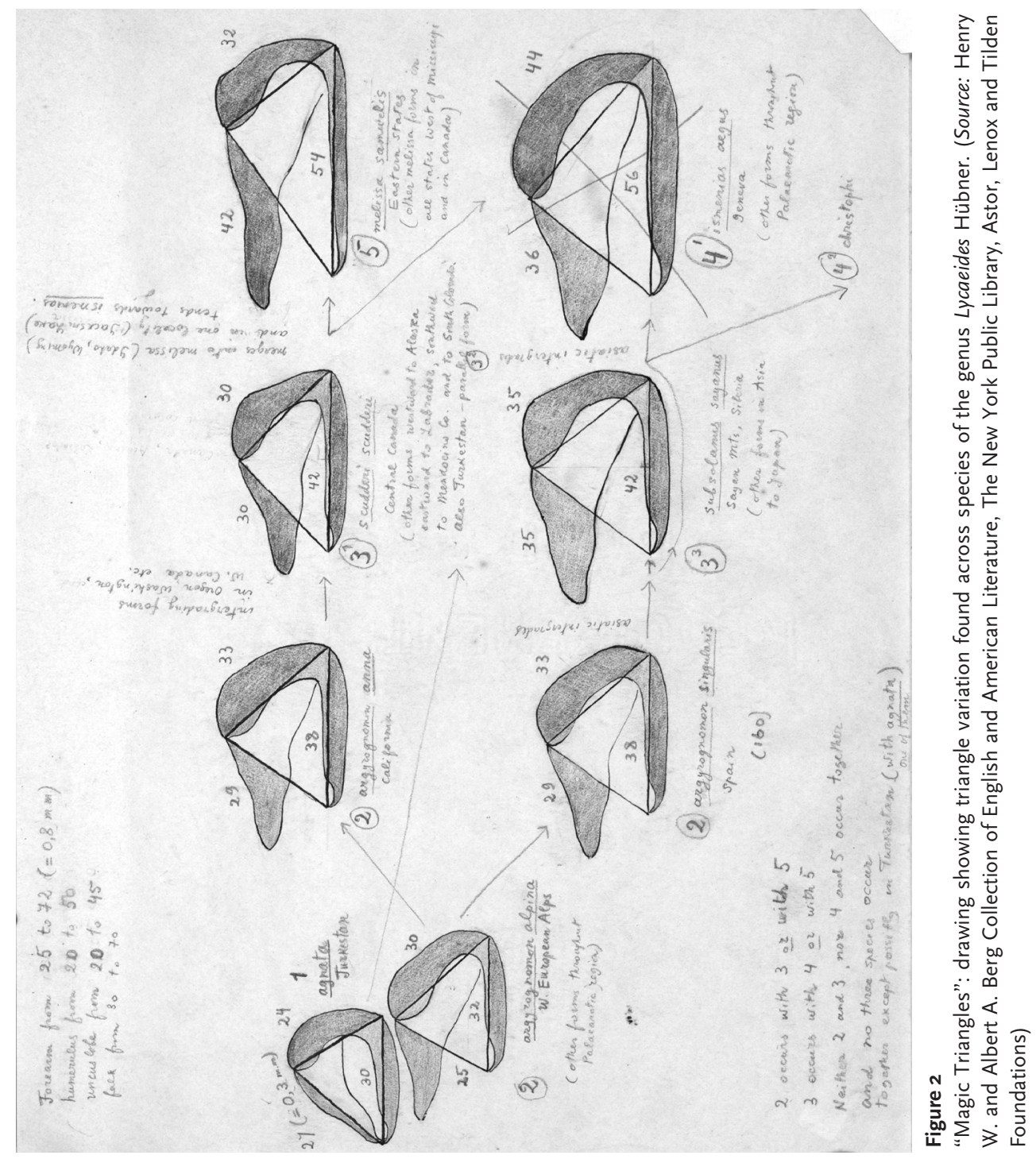


the several decades since Nabokov did that work, surpassing even his own ambitions for them. ${ }^{12}$

Nabokov's emphasis on form, or what he called "the morphological moment," is telling. In contrast to the "biological" criterion of interbreeding, knowledge of morphology requires microscopic study, attention to minute detail, and comparison of various facts. (Even today, DNA analysis does not supplant morphology in determining separate species. $)^{13}$ In other words, it incorporates more empirical data than establishing whether two creatures can or do produce fertile offspring. It is also more practical, of course, because animals can be more easily dissected than caught in copulo. And in those cases where mating pairs resist detection, by mating, say, only in the forest canopy, the morphological approach removes arbitrariness and speculation by focusing on concrete data. (Nabokov did, like other biologists, allow the question of interbreeding to enter considerations after morphological judgments had produced their results). Morphological features themselves are amenable to one of the distinguishing traits of the human mind: the ability to collect and systematize perceptible details. These details, in turn, can be viewed and interrelated in a variety of ways, providing the examiner with a multifaceted web of data. As a result, the scientist's knowledge of what a species is both deepens and broadens. It includes a certain aesthetic (qualitative) element, related to the perceptive acuity and sensitivity of the scientist: the ability to see beyond the accumulation of measurements (as, for example, the "magic triangle").

The other result of a focus on morphology relates to what is actually seen under the microscope and described by Nabokov. What he reports is great variability of form, even within a single species. Nabokov describes the size ranges for parts and wing markings, as if the variations within, and intergradations between, any given species or subspecies constitute the main point of interest, so that the gist of Nabokov's last large lepidopteral work, "Nearctic Members of Genus Lycaeides Hübner," is formulated thus: "According to my present views, argyrognomon is represented in North America by ten multiform intergrading subspecies which may be grouped in three geographical arrays...," and "the other species, Melissa, consists of a Western nearctic group of four multiform intergrading subspecies .... and of a monoform, isolated Eastern nearctic subspecies (samuelis)." 14 The variations themselves relate to discussions of the similarities of distinct species or subspecies, and Nabokov seems most delighted of all when he can detect what looks like a continuous movement of variation across an entire group of species, with all the intermediate forms preserved, because it creates a simulacrum of nature in flux 
across time: "From Alaska southwards and eastwards alaskensis imperceptibly turns into scudderi, the delicate underside maculation becoming clear on a grayish or whitish ground and the female upperside becoming of a brighter blue with more or less developed aurorae." 15 What most intrigues Nabokov is the development of change itself, the fluid sweep of species variation. He writes of one creature "becoming" another, as if such a metamorphosis actually takes place when an insect crosses a particular geographical boundary. His picture of intergraded species represents also a kind of play with the interaction of time, space, and the progress of life. We imagine a series of forms that look as if they move chronologically, progressing from one extreme to the other as time advances-and in fact they might have evolved that way, although in reality Nabokov is talking about simultaneously existing species, not about a proposed evolutionary sequence. Nabokov draws attention to the dangers of such metaphors, which create the illusion of grasping the mysteries of time by means of spatial variation: "This scheme of course is not a phylogenetic tree but merely its shadow on a plane surface, since a sequence in time is not really deducible from a synchronous series. What seems certain, however, is that scudderi in its actual structure stands about midway between argyrognomon and Melissa ...."16 These intergradations-almost like the frames of a film-between forms among living organisms become an emblem of the processes of life as they continue beyond our efforts to describe them in the shape of individual species.

In contrast, the traditional species description based on a single individual leads to a deceptively static picture of nature. After reporting that Nikolai Kuznetsov denied the real existence of species, Nabokov wrote that "if [species] do exist they do so taxonomically as abstract conceptions, mummified ideas severed from and uninfluenced by the continuous evolution of data-perception, some historical stage of which may have endowed them at one time with a fugitive sense. To adopt them as logical realities in classification would be much the same as conceiving a journey in terms of stopping places." ${ }^{17}$ In other words, a species is active in time, mobile: Nabokov worked to perceive species holistically, in the full context of their imagined evolutionary development and interrelationships. And while it was his responsibility and his passion to describe and classify, he also kept in mind and transmitted a vivid sense of nature's fluidity and mutability, its lively ephemerality. In this way, Nabokov's scientific work never ossified in the enumeration of measurements, but rather always reached out to consider the breadth of nature's motion. His articles emphasize the active, productive capacity of nature; the evolution of forms (wing patterns, 
reproductive armatures), compressed in time as if viewed by the narrators of Transparent Things, ${ }^{18}$ becomes the sensuous movement of life itself.

The "general public" has always felt that there is something absurd and even a bit indecent about the passionate study of butterflies, Nabokov relates. ${ }^{19}$ A boyhood fascination with butterflies and moths (which exist in greater variety in Nabokov's European homeland than in eastern North America), ${ }^{20}$ and even a more mature scientific interest in them, seems natural enough. However, the fact that Nabokov came to be obsessed with lepidoptera tells us important things about him and his relationship to nature, and it also has significant consequences. It tells us, first of all, that he felt a direct response to the rush of nature surrounding the family estate in Vyra. ${ }^{21}$ What began at age seven as the collecting of butterflies quickly became their study and the absorption of information from various guidebooks. Nabokov gives us a sense of his feelings about butterflies in his description of Fyodor's childhood as a curieux, in "Father's Butterflies," and also in Speak, Memory. Here too, we see a blend of different aspects of consciousness brought to bear upon the perception of the natural object. For those of us who are not, and never have been, either collectors or amateur lepidopterists, the question arises: what causes the fascination that Nabokov felt for these insects? Their frequent beauty and color are obvious attractions, but that is not enough-and many of Nabokov's favorite creatures are not at all eye-catching. Knowing Nabokov's other passions, we can surmise that it was the intricacy of design, the great variety of forms, and the apparent ingenuity of many of those forms that seduced him (along with the lure of becoming the first to see, perceive, and name a piece of nature). The consequence of his passion was a lifelong devotion to discovering the details of nature's secret workings, a devotion that surely nurtured, and was fed by, his sensitivity to uniqueness and intricate detail in all spheres of life. It is also significant that butterflies and moths, in their great variety, represent nature at its most dynamic. The profusion of forms, adaptations, and devices_more than 160,000 species $^{22}$ — put the world of nature's flux at Nabokov's direct disposal, and from an early age he began to see things like mimicry as emblematic of special and mysterious powers behind nature's ebullience. As Nabokov would learn during his years as a professional researcher, that variety and its implications are even greater than he imagined in his youth.

All this exposure to the many species of lepidoptera produced in Nabokov an acute awareness of the generative power of nature, and he was clearly persuaded that life was evolving. As is well known, Darwin's theory of evolution by natural selection was in the ascendant, although it was 
undergoing significant revision and challenge during Nabokov's childhood and early adulthood. His notorious distaste for Darwinian theory is in fact exaggerated by many writers-even by himself. There were several reasons for this antipathy, but the most important was grounded in the popularized theory's emphasis upon utility for survival as the main, perhaps only, determinant of a feature's evolutionary preservation. For historical and philosophical reasons mentioned in the Introduction, Nabokov objected to the notion that utility should be a fundamental determinant of anything in the world. (Some of these reasons are probably related to the parodic view of Darwinism that Tolstoy's Anna Karenina expresses during her final emotional catastrophe: that all people should hate and attempt to destroy one another). ${ }^{23}$ Natural selection as Nabokov understood it clashed with his liberal-idealist leanings and his strong aversion to all material-based explanations of phenomena, an aversion surely deepened by materialism's victory in the Bolshevik revolution. Whether or not natural selection is a purely materialist theory, Nabokov clearly saw the inevitability of its exploitation by materialist thinkers and its incorporation into "dialectical materialism." ${ }^{24} \mathrm{He}$ subscribed to the liberal (Kantian) outlook according to which the individual person is an end in itself, and he seems to have generalized this notion to apply as well to the phenomena of nature (within limits: specimens-e.g. butterflies—could be caught for the sake of human knowledge, and such study is part of the progress of nature). To subordinate an entity to a system of "struggle for existence" is, he felt, to reduce it to its "utility" and to deny its fundamental value as an "end in itself," as an integral part of nature as a "whole," or as an object of consciousness. The other flaw in Darwin's theory, from Nabokov's point of view, rests in its emphasis on the process of elimination over the process of creation..$^{25}$

So, whereas Nabokov accepted evolution as a "modal formula," ${ }^{26}$ he rejected the materialist implications of the theory in the form that was well-known during the years leading up to his own empirical research. Curiously, he did not propose any other method of species development in his professional scientific writings, although he did put forward a theory of speciation in the abandoned second addendum to The Gift, "Father's Butterflies." At least into the 1940s, he shared with The Gift's fictional scientist a conviction that nature is far too creative and detailed in its forms, that it seems too well aligned with the precise needs and whims of human consciousness, to be fully described by a system that centralizes chance and strife. Nabokov and his fictional scientist Godunov-Cherdyntsev both focus on mimicry (and object resemblance more generally) as a key example of nature's surplus of creativity, likely perceptible only to 
the human eye. (It has since been shown that many predators possess very keen vision, at least as far as their prey is concerned, so that this argument of Nabokov's has become dated.) $)^{27}$

Irrespective of this claim's validity, it is worthwhile to explore exactly what it shows us about Nabokov's approach to nature. The argument is developed in greatest detail in "Father's Butterflies," a fictional work which nevertheless has much overlap with Nabokov's nonfiction comments about mimicry. Most often, passages describing extraordinary or even unlikely feats of mimicry are connected to the idea of design in nature and indeed in human life, and to the relationship between such design and the perceptive abilities of human consciousness: "Certain whims of nature can be, if not appreciated, at least merely noticed only by a brain that has developed in a related manner, and the sense of these whims can only be that-like a code or a family joke-they are accessible only to the illuminated, i.e., human mind, and have no other mission than to give it pleasure. ..."28 Sometimes, these patterns and designs are linked with the notion of a pattern-maker, implying some variant of a creationist worldview. However, we need to be careful not to take metaphysically intoned suggestions in Nabokov's fiction as direct statements of a proposed outlook or (pseudo-) scientific theory. After all, Fyodor warns us that "so far, all this is but an approximate image, in the same way as it would be purely allegorical for us to start affirming that the initial division of all earthly specimens into two groups were a separation of two halves under the influence of centrifugal force." 29 These "miracles" of nature, or of life, do seem to indicate a designing presence, but that they seem to do so is, as Kant demonstrated, a necessary part of the way human beings perceive the world. ${ }^{30}$ Examples of nonutilitarian mimicry-or any other nonutilitarian phenomenon of nature-would demonstrate the gaps in natural selection's explanatory power. They were, or would have been, particularly vivid banners for those lacunae. ${ }^{31}$ In short, they were part of Nabokov's effort to suggest that nature was not purely mechanistic and driven by causality. There must be, he felt, alongside or even above selection and competition, another force behind nature: one that drives the development of life and its intricacies in the first place.

His skeptical attitude toward natural selection was not only philosophically motivated: it also had scientific grounding that was shared by other biologists of the decades leading up to Nabokov's work. ${ }^{32}$ Even the great Russian entomologist (and translator of Goethe) Nikolai Kholodkovskii, imagining yet unknown elements hidden behind nature's veil, wrote that "natural selection is a controlling and choosing factor, but not a creative 
one: it concerns itself, so to speak, with the expediency of changes taking place within organisms; it does not create those changes." 33 And so when Nabokov, through Godunov-Cherdyntsev, comes to offer a vision of evolution-the diversification of life-he focuses not on the forces that drive the elimination of species but rather on those that drive the generation of new forms. His fictitious offering is a "spherical" theory, according to which forms of life arise in bubble-like groups from some unknown generative source behind all of nature, the "wind" that "animates the dance of the planets." 34 This process, as he describes it, has certain self-reinforcing traits (feedback) inherent to it, which contribute to its development and its complexity. Strikingly, he does not deny natural selection in all its forms, but he does refuse to give it central attention in a story that is, to him, really about the generation of nature's immense variety and of consciousness itself. The fact that nature, life, and consciousness seem intertwined and mutually reinforcing produces a vision of the world that attempts to comprehend it as a whole. It is not scientific in the Newtonian sense: In Nabokov's view, the quantitative analysis is ancillary to qualitative judgment. ${ }^{35}$ Such vision is not amenable to quantification because it does not break down the object under study (the natural world [universe] as embraced by consciousness), but rather attempts to view it and understand it as a whole. Significantly, this is precisely the kind of approach to nature that was taken by Goethe, to whom we will return in the next chapter. ${ }^{36}$

\section{Mechanism versus Essence}

The key to distinguishing Nabokov's scientific thought and practice from that of mainstream scientists rests in the difference between the study of mechanism and the study of essence. This is the same distinction that fascinated Goethe, and he (perhaps first among modern scientists) came to doubt the Newtonian emphasis upon mechanistic analysis of natural phenomena and its primary tool, mathematics. The dominant form of scientific study is based upon mechanistic assumptions-the knowledge that causality is an effective heuristic by which to analyze and understand all natural phenomena that take place at the mundane level-that is, the level that aligns well with classical, Newtonian physics. To some extent, even quantum and relativistic phenomena fall within this model, with the proviso that they represent extreme cases where mathematical truth departs from the fiction of physical appearance. However, the modern culture of scientific knowledge, which accounts for all but a tiny fraction of scientific 
work, abjures by necessity questions concerning the ultimate origin, cause, or essence of the materials and patterns of change it studies. Because causality, for the scientist, represents a closed system (except in certain disputed quantum cases, and perhaps in the black hole), units other than links in the chain of cause and effect are hard, if not impossible, to fit into the explanatory system. Such units could include concepts that transcend the boundaries of a typical causal agent-for example, a diachronic view of a given line of evolution; or ideas about forms or patterns in the universe or in biological nature; or the complexities of human mind, perception, and psychology. These phenomena all relate to the recently popular theory of emergence-the appearance of complex forms, structures, and systems that could not be predicted using known causal laws and accessible data. Secondarily, patterns may also be discovered among lapses in apparent causality, if one admits the possibility of such lapses. These are, by definition, heretical within the Newtonian system, with the result that an experiment that fails to produce a conclusive result relative to mechanistic effects is simply considered a failed experiment, its results discarded. ${ }^{37}$ Thus, to take natural selection as our example, Darwin repeatedly mentions the inability of his theory to make any claims whatsoever about the causes of species mutation, or the causes or origins of life itself. ${ }^{38}$ Instead, his study focuses precisely upon the interface between living organism and environment, proposing causal relationships between environmental facts and organismic consequences. His interest lies in the great variety of extant forms and in their evolution from earlier, similar forms, as a result of ecological interactions or pressures. But he is explicitly not interested in the concept of form itself, in the patterns behind interrelations of an organism's parts, nor in any larger questions of what, as it were, propels the flow of natural forms. Nabokov was interested in most of these questions, and his science shows it.

If we look at Nabokov's most important research articles, we find a distinct attention to the manner in which species relate to each other. His main guide in this research was form, or morphology, which he gave priority over the possibility of biological reproduction. ${ }^{39}$ In his 1944 article on the genus Lycaeides, Nabokov-in marked contrast to his fictitious scientist-vividly demonstrates his preference for the evolution and morphology of genitalic structures as markers of relatedness within genera, species, and subspecies. His reasons for this choice derived specifically from his understanding of natural selection and its action upon exterior form: as he writes, in "Notes on Neotropical Plebejinae," “Adaptation to surroundings, to climate, altitude, etc., and hence 'natural selection' in its simplest 
sense, certainly had no direct action whatever on the moulding of the genital armature, and we know nothing of the physiological processes of which that elaborate sculpture is the structural overflow. [ . . . Hence the conviction that there is some phylogenetic link where there is a recurrence of similar genitalic characters and that certain groupings- the new genera to which we now must turn-may be so devised as to reflect the natural affiliations of the species." 40 Thus genitalic forms demonstrate a part of the animal that is protected from natural selection in the "simplest" sense, and yet which does change and evolve. Even within these minute structures, Nabokov comes to differentiate between the parts that are more and less "prone" to morphological mutation:

I view evolution in Lycaeides as a twofold process of growth: 1. as a generic growth-involving the whole of the male genitalic structure, so that the absolute size of the uncus (independently from the size of the wings) in its general graduation from the most primitive structures $(\mathrm{F}+\mathrm{H}+\mathrm{U}=$ about $0.9 \mathrm{~mm}$. $)$ to the most specialized ones $(\mathrm{F}+\mathrm{H}+\mathrm{U}=\mathrm{about}$ $1.8 \mathrm{~mm}$.) is doubled at the maximum limit of development; and 2. as a specific growth-a process acting upon the relation of parts $\mathrm{F}, \mathrm{H}$, and $\mathrm{U}$, attacking one part more strongly than the other, whereupon the latter tends to catch up with the former, producing at a certain stage stabilization and equilibrium, which eventually are again broken by unequal growth.... [T] here is also a difference in the rhythm of the specific growth; and that throughout the general process stunted by-products occur (holarctically), reduction in absolute size of structure synchronizing here with reduction in size of wings. ${ }^{41}$

The structure, if viewed through various examples within a species, provides a visual representation of the rhythmic motion of evolution in a place where it is least affected by environmental pressures. He goes on to identify six "peaks of speciation" within the genus, and up to 120 subspecific forms "clustering around the main peaks" (see figure 3, pp. 36-37). We see here how Nabokov attempts to determine an atemporal sense of organismic change, which in turn defines the essence of what constitutes a species or a genus. What differentiates Nabokov from other taxonomists of his day is his effort to perceive and define this mobile aspect of species' and genera's essence, asking his reader to imagine the flow of mutations one into the other as a species evolves. "Nature is motion and growth," as Van writes in $A d a .^{42}$ 
Likewise, in his study of wing patterns, Nabokov seeks out evidence for the forces guiding species change, especially in the distribution of macules (spots) and lines across related species' wings. ${ }^{43}$ It was in this area that he invented his (briefly controversial) scale-line system for mapping the precise location of wing imagery, thus removing certain subjective flaws from the research method..$^{44}$ But notice how in this area, too, as well as in the "Notes on the Morphology of the Genus Lycaeides" paper, he departs from the accepted practice of providing a detailed description of an accepted holotype (authoritative representative) of a species, moving to a synthetic description of a species' varietal range across its geographical range. In the following passage, Nabokov proposes rhythm as the defining trait of a polytypic species: "'Rhythm' depends on the following: if B, L, P, $T$ represent in one species of Lycaeides certain combinations of characters as revealed by definite subspecies, and if in another species the combination $\mathrm{L}$ fails to be represented at all, while on the other hand $\mathrm{P}$ is not represented by a single definite subspecies, but is spread over several, these omissions, gaps, fusions, and syncopatic jerks will produce in one species a variational rhythm different from that of another." ${ }^{45}$ Nabokov's goal is to discover "differences in rhythm, scope, and expression, the total of which would produce the synthetic character of one species as differing from the synthetic character of another." ${ }^{46}$ This is the same "synthetic character" that he imagines following a species in its journey through time, an image he projects upon the hidden history behind modern forms of Plebejinae in the New World: "Going back still further, a modern taxonomist straddling a Wellsian time machine with the purpose of exploring the Cenozoic era in a 'downward' direction would reach a point-presumably in the early Miocene-where he still might find Asiatic butterflies classifiable on modern structural grounds as Lycaenids, but would not be able to discover among them anything definitely referable to the structural group he now diagnoses as Plebejinae. On his return journey, however, he would notice at some point a confuse adumbration, then a tentative 'fade-in' of familiar shapes (among other, gradually vanishing ones) and at last would find Chilades-like and Aricia-like structures in the Palearctic region." ${ }^{47}$ An individual butterfly is not just a butterfly: it is a member of a species. But a species is not a static unit; rather, it is an ephemeral manifestation of nature's growth and development through time, and the attempt to visualize the rhythmic form that characterizes the evolution of species is typical of Nabokov's approach to science. It is a holistic approach that strives to surpass quantitative analysis (even though it may have quantitative 


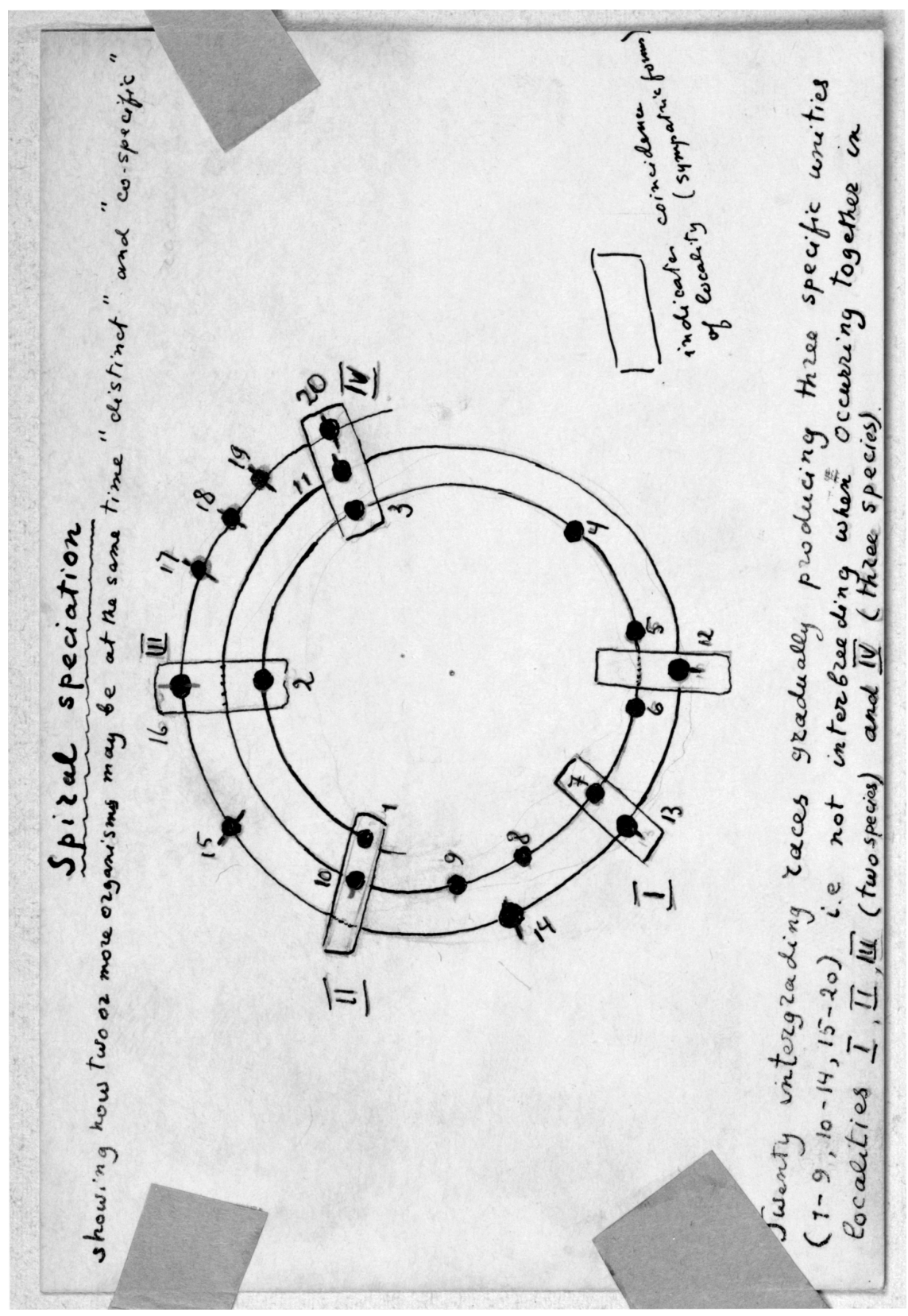




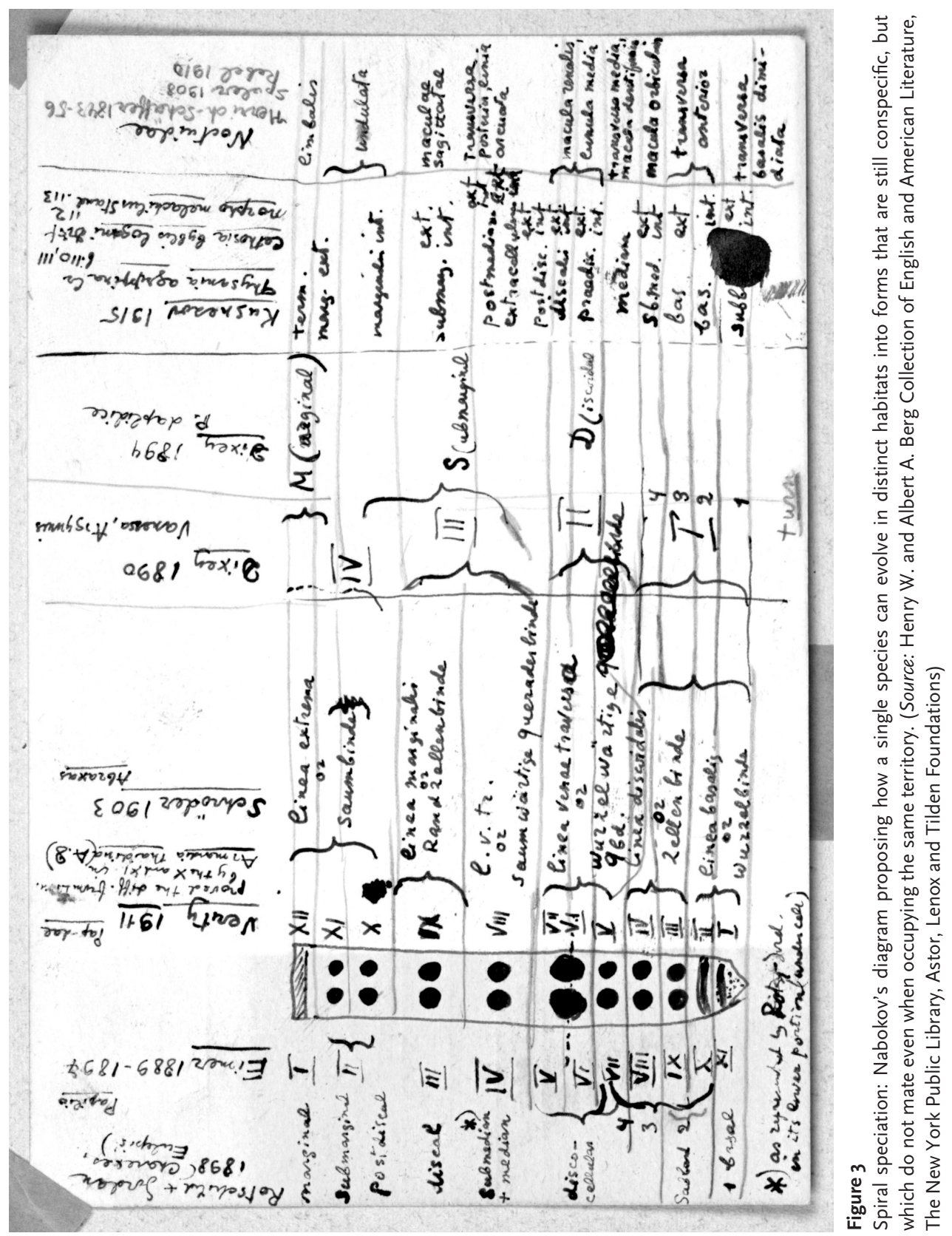


components, such as the size of various structural parts or the number and position of wing-scales). The value of this method, although questioned by F. Martin Brown at the time of its first use, was confirmed by its ability to produce accurate revisions in the classification of butterflies and moths.

\section{Mimicry}

The most renowned-or notorious-part of Nabokov's thought about nature is his view of mimicry. ${ }^{48}$ In his informal lexicon, mimicry refers both to classical mimicry between species (such as the Viceroy's apparent mimicry of the Monarch), and also to what is more technically called "object resemblance" or "protective coloration." Thus, in his works, moths can "mimic" leaves or flowers, and caterpillars can mimic roots (or roots caterpillars!). There is a fascinating and clear distinction between what Nabokov wrote about mimicry in his fictional or memoiristic works and what he wrote as a professional lepidopterist. Although he submitted an article on mimicry to the Yale Review and spoke regularly on the subject during 1942 and 1943, ${ }^{49}$ and although he envisioned for a while composing an exhaustive work on mimicry "with a furious refutation of natural selection," 50 there remain no traces of this radical thought among Nabokov's preserved scientific notes and publications. What we do see, however, is a special attention to occasional similarities between species that are usually caused by chance or else by deeper forces of nature that natural selection may not explain. ${ }^{51}$ For example, in some notes from 1944 defining the term "homopsis" (inter-generic resemblances within a family), Nabokov differentiates this term from mimicry: “... mimetic forms [are] forms belonging as often as not to different families and moreover linked by a (still inexplicable, in my opinion) coincidence between mimetic aspect and mimetic behavior and mimetic habitat, this coincidence being as impossible to explain satisfactorily either by blind accidental causes or by the blind coordination of accidents termed natural selection (even if the protective value of mimetic resemblance is proved)." 52 False resemblance (of which some cases might be mimicry) and false dissimilarities must be extremely rare, and he implies that existing mimetic relationships far exceed the number that could be achieved by chance mutations. The text or notes from those 1940s lectures have been lost, it seems, and there is no record of what his lecture "Mimicry in Theory and Practice" contained. From the minutes of the CEC meeting of April 12, 1943, we know only that the talk was distinguished by "entertaining informativeness and 
clarity," followed by "considerable stimulating discussion." ${ }^{33}$ Although Nabokov remained interested in composing a scientific compendium on all forms of mimicry as late as 1952 , there are no documents or notes that shed any particular light upon his views at that time (unless we consider his informal anti-Darwinian comments in his memoir Conclusive Evidence [1951]). Kurt Johnson has proposed that Nabokov may have eventually destroyed his mimicry materials, perhaps having decided that his arguments were too clearly disproved by advances in evolutionary biology after the 1940s. ${ }^{54}$ To be sure, it is strange that there is nothing in his papers that brings us any deeper into his thought about mimicry-a topic of such fascination for him!- than the few passages in The Gift, "Father's Butterflies," Conclusive Evidence/Speak, Memory, and the slight traces in his literary lectures. Be that as it may, his cause would not have been helped by the fact that his most stunning examples of nonutilitarian mimicry were either erroneous or fictitious. ${ }^{55}$ It does seem, to judge from the published articles, that he came to find sufficient source for wonder even in the nonmimetic forms of nature to support his views on the merely partial scope of natural selection. His personal scientific emphasis was on the creative side of evolution, nature's generation of new forms, rather than on the selective reason for the success of one form over another, and nonutilitarian mimicry had simply provided him with an especially vivid example of such an exception. He must have known that in order to convince active biologists of nature's "non-utilitarian delights," ${ }^{56}$ he would have had to rely upon far more sophisticated and subtle arguments. Kurt Johnson has argued that Nabokov's inability to prove the limits of natural selection would not have forced him to "give up [...] the 'magical' view of the world, so evident in his fiction," and that neither would acceptance of the Modern Synthesis. ${ }^{57}$ His magical sense of nature could have been retained and nurtured by other concepts, including by his synthetic, Goethe-like sense of nature's mobility. However, within his lifetime, as within Goethe's, it may have been a losing battle as far as the mainstream scientific community was concerned. Although in the past fifteen to twenty years there has been some increased interest in "Goethean" holistic science, in the 1940s and 1950 s this was not the case. ${ }^{58}$

\section{Science into Fiction}

Although the fragment known in English as "Father's Butterflies" portrays a theory developed by a fictitious scientist, we should pay it some 
attention as a legitimate expression of ideas that Nabokov was considering during his years composing The Gift and the quickly ensuing shift to professional lepidoptery. We do not need to claim that these ideas were all conclusively accepted by Nabokov to take them seriously as authentic scientific thought, if only in the domain of hypothesis. It is well known that Nabokov's and Godunov-Cherdyntsev's opinions about mimicry as a refutation of natural selection were nearly identical (although the fictional character has the advantage of being able to refer to more perfect and conclusive examples-which, as it turns out, are as fictitious as he is). Nevertheless, the scientific material in "Father's Butterflies" is challenging, rigorous, and engaged with real controversies of the day; its contents are based upon Nabokov's authentic and deep knowledge of evolutionary theory, lepidoptery, and nature; and the speciation theory it proposes has its own authenticity and significance as it stands. As a whole, it helps us to understand more clearly how Nabokov saw the role of scientific thought in approaching true knowledge of the world, by elaborating in the clearest possible terms the link between idealist philosophy and idealist science. ${ }^{59}$

Why did Nabokov include such a detailed speciation theory within this fragment? And why as an afterthought, a possible addendum to The Gift, rather than as part of the novel itself? Close reading of the text (and examination of the manuscript) reveals that Nabokov approached this section with the same intensity, care, and preparation that he did The Life of Chernyshevsky, Fyodor's scandalous book in The Gift proper. This should come as no surprise: after all, Godunov-Cherdyntsev Sr. was proposing a theory that was intended to sweep away all previous approaches to evolution and speciation-first and foremost natural selection, but other explanations as well. His "spherical” species theory was revolutionary, incomprehensible to nearly all contemporary scientists, and yet, within the logic of the fragment, true almost beyond question. No doubt the discovery of such a radical truth was a passionate dream of Nabokov's: remember that "furious refutation" he was preparing, as a scientist, in 1941. We are made constantly aware of the theory's significance by a series of allusions to revolutions in two other branches of science, astronomy and physics.

Godunov-Cherdyntsev's speciation theory is uncompromisingly idealist, and it starts out by setting up systems of analogies that highlight its difference from materialist explanations. The most important consequence of this approach is that the theory avoids all mention of causality as a force driving species change. Fyodor's summary asserts that “by 'species' he intends the original of a being, nonexistent in our reality but unique and definite in concept, that recurs ad infinitum in the mirror of nature, creat- 
ing countless reflections; each one of them perceived by our intelligence, reflected in that selfsame glass and acquiring its reality solely within it, as a living individual of the given species." ${ }^{0}$ This platonic-sounding introduction is merely the opening gambit in a rhetorical strategy that repeatedly draws attention to aspects of the species idea that are not captured by mechanistic treatments and that exist-or seem to exist-alongside causal relationships. Not only does Godunov-Cherdyntsev play down the materiality of a species; he also focuses (like Nabokov) upon the concept of variability. His "spheres" are ideal figures that express the relationships between a number of organisms with a common heritage; they demonstrate, in time and in space, how a species occupies an extended conceptual space through its variety. The species is not static and it is not unitary; it represents and expresses a certain ideal content that transcends its physical manifestations. This approach to a species' essence focuses on its overall state of being, its quality, its variety, its status in nature as a temporally located, partially complete fulfillment of an idea. It posits that there is an ideal reality to this holistic and fluid approach to the conception of species, even though it is "non-existent in our reality." While not denying the mechanistic and causal relationships between and within biological organisms, Godunov-Cherdyntsev's theory suggests that this shadow-like essence is more fundamental and more important, just as Nabokov himself would later focus on the "synthetic character" of species. His idealist model proposes that even the very phenomenon of species, as a collection of related and similar beings, had to "evolve," and that this phenomenon's ideal evolution is itself fundamental, behind the scenes of empirical reality. "Just as an increase in the brain's complexity is accompanied by a multiplication of concepts, so the history of nature demonstrates a gradual development in nature herself of the basic concept of species and genus as they take form. [...Q Q] uite literally, in the human, cerebral sense ... nature grows wiser as time passes ... The only nit that can be picked is that we do not know what we imply when we say 'nature' or 'the spirit of nature." 61

This discussion of species is particularly striking in its similarity to Nabokov's metaphorical treatment of other aspects of reality in various works. It can also be related directly to Nabokov's interest in Andrey Bely's diagrams of lyric poetry: in these, poems are found to cast an ideal, negative pattern based on the position of unfulfilled stresses, something of a graphic "shadow" of the poems (see figures 4 and 5). Richer poems reveal richer patterns. Bely, a symbolist theoretician as well as literary artist, suggests that these patterns are in some way connected to the hidden value of a work (and hence to its ideal existence or essence). Nabokov was 


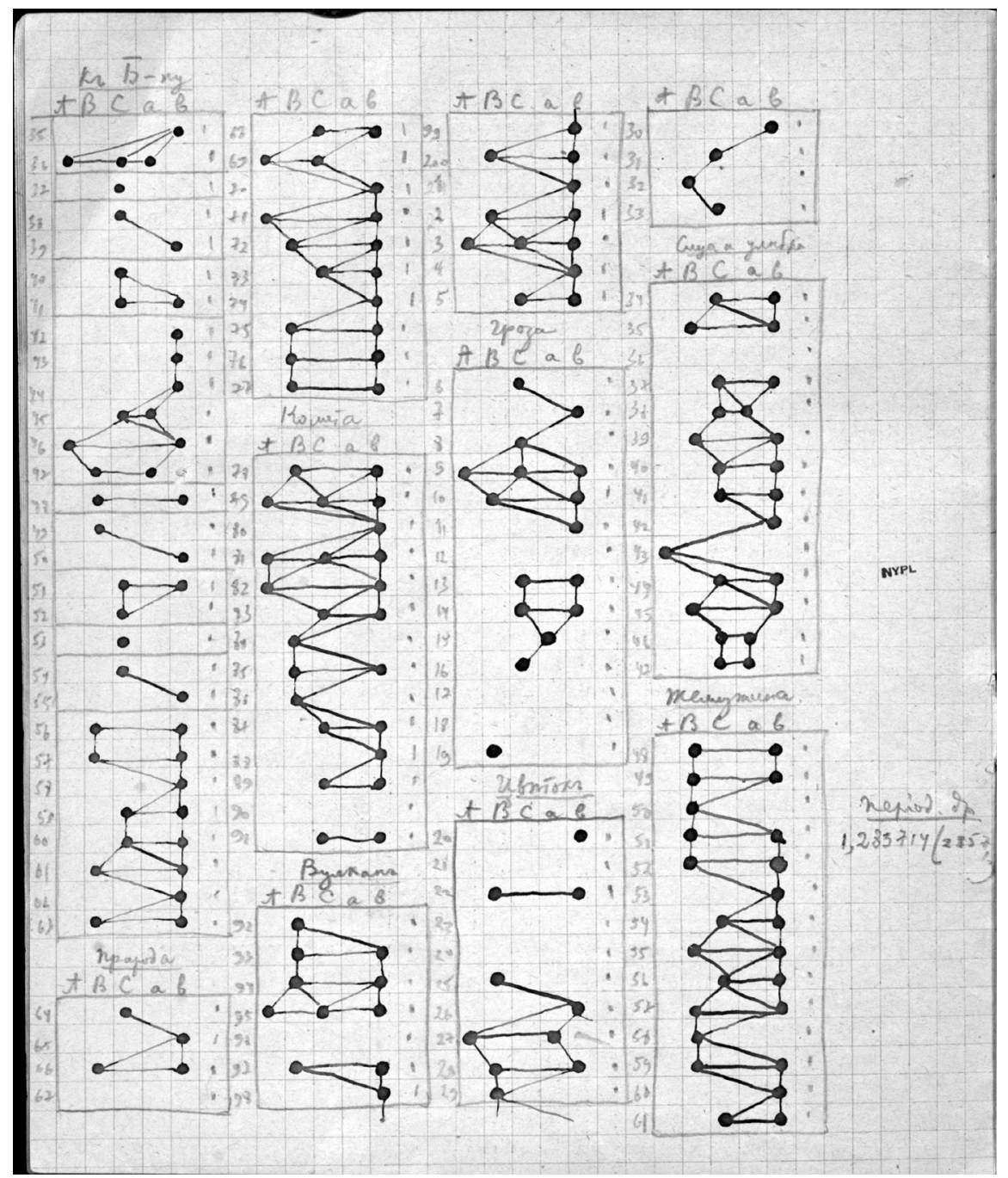

Figure 4

Poetry diagram, showing patterns made by mapping the "missed" beats in the poetry of Evgeny Baratynsky. (Source: Henry W. and Albert A. Berg Collection of English and American Literature, The New York Public Library, Astor, Lenox and Tilden Foundations)

fascinated by these patterns from his youth onward, and he filled many notebooks with such schematic analyses of Russian poetry. As he describes in Speak, Memory, Nabokov even tried composing poetry starting from certain interesting shadowgrams-a process that, in tacit conformity with Bely's thesis, did not work very well. ${ }^{62}$ We can see how these diagrams offer a model for suggesting how a phenomenon (poem or species) can 


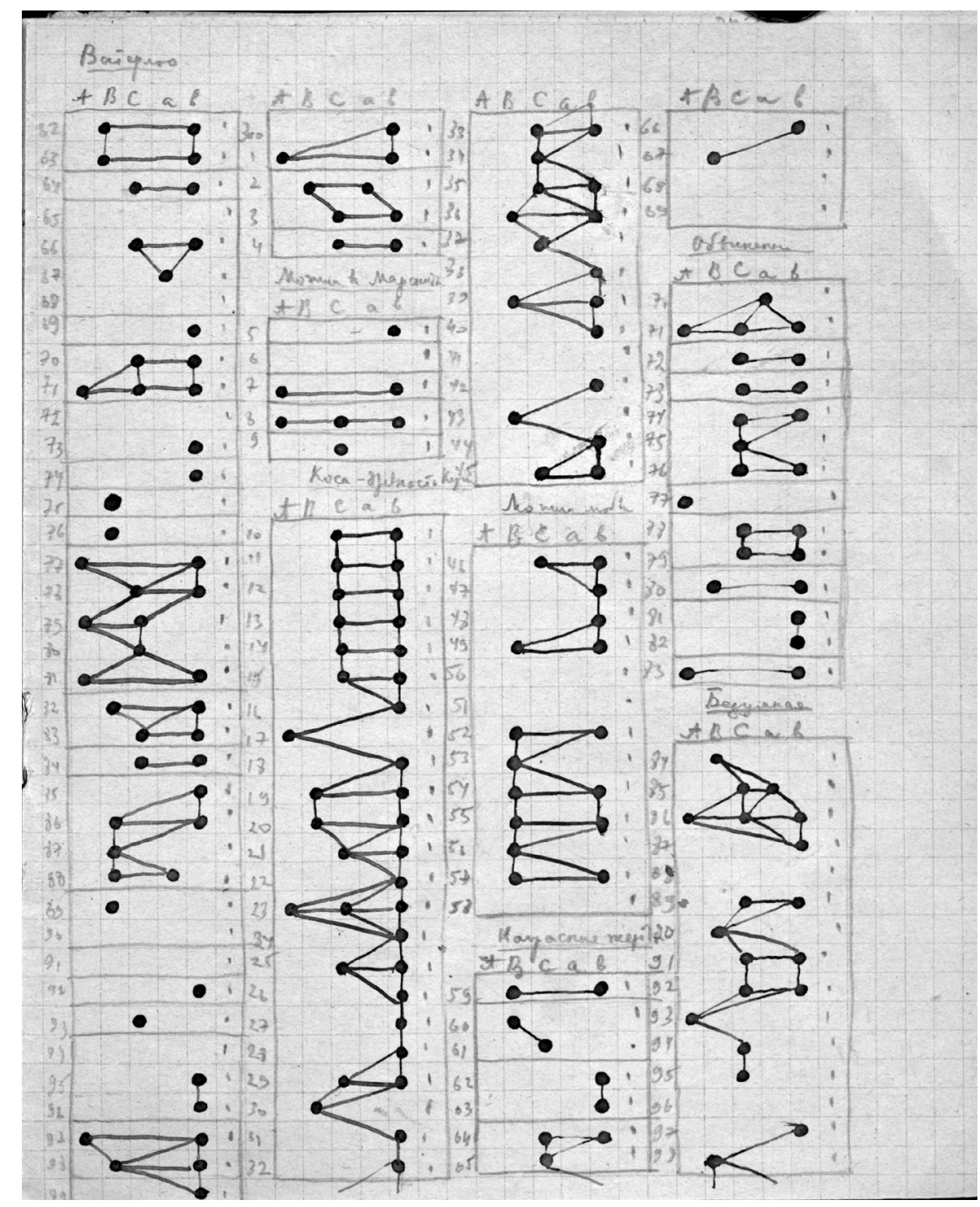

Figure 4 continued

exist in both "real" and "ideal" phases. As we saw, Nabokov's discussion of species also includes references to such negative components-unfulfilled spots in the species sphere, or the rhythmic interplay of presence and absence in a species' phylogenetic realization-as important characteristics for our understanding of the "real" species state relative to its ideal core. We will return to these patterned absences in chapter 6 . 


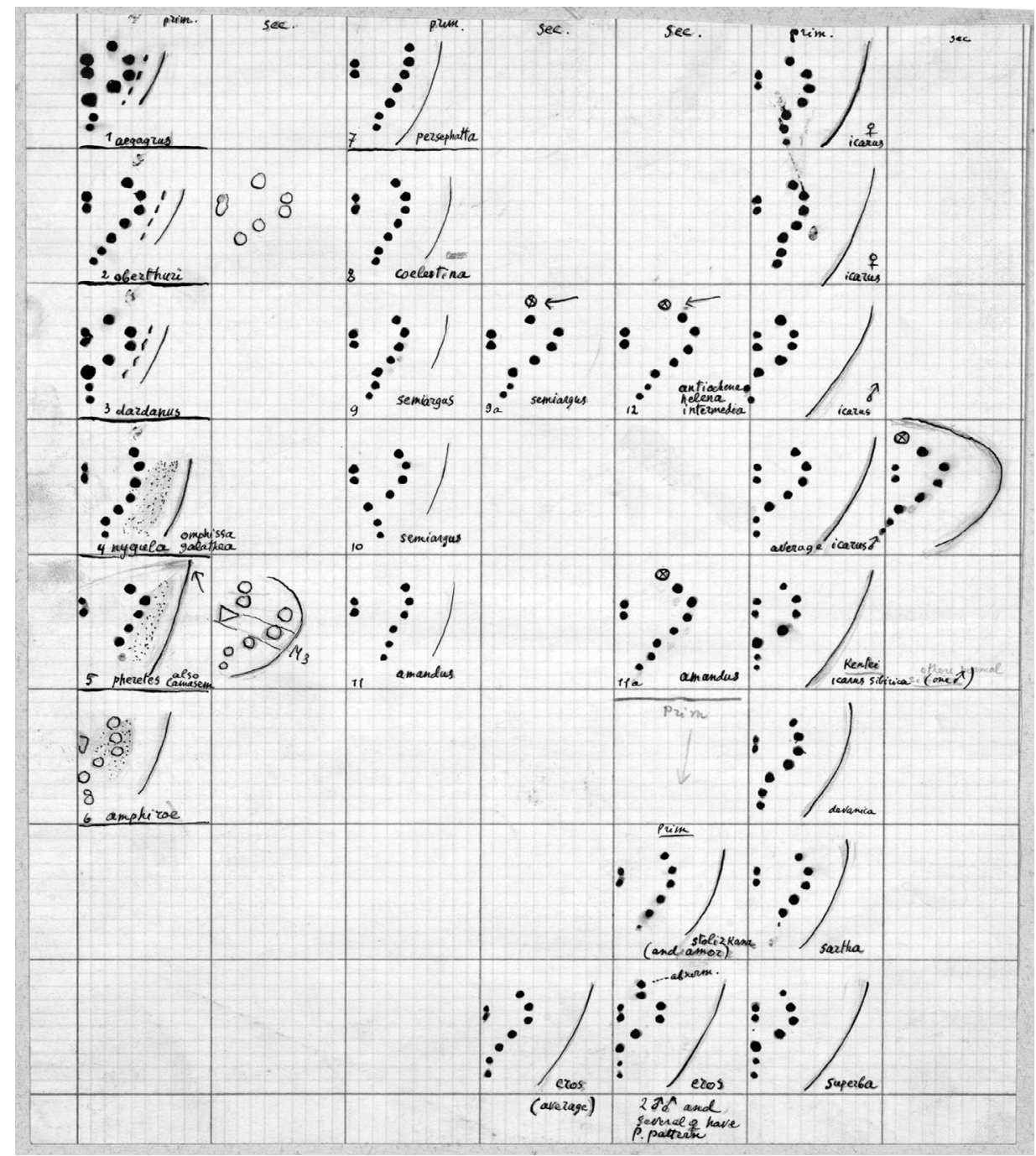

Figure 5

Wing spot diagram, showing progressive location of spots across the wing of related butterflies of two genera of blues, Lycaena and Polyommatus. (Source: Henry W. and Albert A. Berg Collection of English and American Literature, The New York Public Library, Astor, Lenox and Tilden Foundations) 
The next step in Godunov-Cherdyntsev's idealist exposition of speciation is to establish as fundamental this analogy between "nature" and mind. In doing so, he follows Coleridge and Emerson as well as Goethe and the German Romantics. ${ }^{63}$ Nature, in his usage, refers to whatever is the ultimate mysterious essence, the underlying source of reality as we know it, even though "we do not know what we imply when we say 'nature' or "the spirit of nature." 64 It is, clearly, a definition that does not shy away from metaphysics. Fyodor summarizes:

\begin{abstract}
Reaching again into the basket of generally accessible examples, let us recall the analogy noticeable between the development of individual and species. Here an examination of the human brain can be most fruitful. [...] In the course of life we learn, among other things, the concept of "species," unknown to the ancestors of our culture. Yet, not only is the history of mankind parodied by the developmental history of the writer of these and other lines, but the development of human ratiocination, in both the individual and historic senses, is extraordinarily linked to nature, the spirit of nature considered as the aggregate of all its manifestations, and all the modifications of them conditioned by time. How is it conceivable, in fact, that amid the huge jumble containing the embryos of countless organs $[\ldots]$ nature never included thought. ${ }^{65}$
\end{abstract}

It is here that Godunov-Cherdyntsev offers his mimicry argument, according to which the details of disguise exceed the perceptive acuity of the predator. Now, considering the fact that mimicry turns out, after all, to protect creatures from extremely perceptive predators, and thus has at least one mission aside from giving pleasure, his (and Nabokov's) theory would seem to be disproved. However, in fact only the old-fashioned, teleological side of the argument is disproved: the idea that things in nature exist exclusively for human benefit or enjoyment. It remains the case that recognizing, and even finding wonder and humor in, mimetic disguises is an ability reserved for a certain development of consciousness, so far known only in humans. Godunov-Cherdyntsev's key point is not that feats of mimicry seem gratuitous (although he does argue this), but rather that consciousness, as a product of nature, detects in nature signs of its own creative principles, hence, signs of consciousness underlying nature itself. Such an argument-an idealist one to be sure-can be made successfully with or without gratuitous mimicry, although the latter would make it easier to couch the case within empirical discourse. ${ }^{66}$ Even there, however, it is not strictly necessary, because it is possible to find nonutilitarian muta- 
tions, or to discuss the generative, rather than regulative, side of evolution (and besides all this, within Kantian empirical discourse, such appeals as Godunov-Cherdyntsev's to metaphysical underpinnings are banned from scientific argument while also being a necessary part of human consciousness). The fact that nature evolves and constantly develops more complex forms and variety is deeply mysterious (at least, Darwin thought so); that humans (as products of nature) partially recognize and understand nature's dynamism is more mysterious still.

Continuing his analogy between the development of mind and the evolution of nature, Godunov-Cherdyntsev insists that "the appearance of species is unarguable; and neither the evolutionist 'how' nor the metaphysical 'whence' can be answered until we agree to admit that it was not species that evolved in nature, but the very concept of species." ${ }^{67} \mathrm{He}$ is equally interested in the nature of species differentiation, which on the one hand he views as becoming less and less likely as the "species concept" itself becomes more distinct and as existing species acquire firmer delineations. There is a crucial moment in the process of differentiation where the emergence of new species from the variations of an existing, fading species "contradicts the limits of the concept of species." 68 The point is quite obscure, but Godunov-Cherdyntsev seems to imply that in its own evolution, the species concept reaches a stage where mutation is no longer active; new species, as such, cease to develop from existing species. However, the result is not stasis in the natural world: a "leap" takes place ("somewhat similar to what we find when we compare mechanical and animal motion") whereby the multiplication of diversity shifts from the outer world to its representation in consciousness: thus, after centuries of unified identity, a species comes under human scrutiny, reveals hidden divergences that define some of its members, and suddenly where there was one species now there are two: "suddenly our eyes open wide, and how could one ever have overlooked those very traits that, with such elegant precision, now distinguish the two butterflies." 69 Thus the play of diversification that had worked itself out on the field of phenomenal nature continues in the increasing refinement of human consciousness. Nabokov's proposal in Speak, Memory that space, time, and thought are connected is prefigured here in the suggestion that worldly mechanical evolution achieves its natural extension in the increasing complexity and creativity of human conscious activity.

One of the surprising features of Godunov-Cherdyntsev's theory is that despite what some would call its romantic, fanciful, even quaint attempt to create a vision of natural progress not founded upon mechanistic causality, 
it employs an insistent stream of analogies from the physical sciencesespecially astronomy, and also particle physics. Indeed, the progression of metaphors may be seen to trace the course of planetary analogies in the study of subatomic structure during the years 1907-13 by Ernest Rutherford and Niels Bohr. The sequence is compelling: early passages draw our attention to the fact of the solar system, and the planets' orbits, reminding us of the radical shift in perception that took place following the "Copernican revolution" and its refinement by Johannes Kepler. Visions of space filled with stars and "the dance of the planets" continue to accompany the argument, telling us that "spherical classification" brought about "delirium and confusion," just as would "the measurement of the earth or the laws linking it to the other planets, if humanity had not already had an inkling of its roundness and rotation." The analogy of thought becomes one of form, too, as the species and genera themselves begin to appear with "annular principle" and "ringlike pattern forming new ringlike systems." Similarly, the theory itself possesses "stellar elegance" (zvezdoobraznyistroinyi), but due to its novelty and science's lack of preparation for it, it is "eclipsed by its own explosion." ${ }^{0}$ When the discussion finally reaches the concept of "genus rings," a subtle shift in terminology occurs: the central or type species of a genus sphere suddenly becomes the "nucleus" species. The connection to atoms, rather than cells, becomes clear when we read that "the number of satellites revolving around the central nucleus is expressed in the even numbers four, six, and eight-and, as far as it has yet been possible to determine, does not exceed the highest of those." 71 The planetary model of atomic structure was proposed by Ernest Rutherford in 1907 and refined by Bohr by 1913, so that a well-read anglophile scientist likely would have been aware of these theories by 1917 (the year Godunov-Cherdyntsev set off on his final journey and Rutherford received the Nobel Prize). The restricted variations of satellite counts are especially reminiscent of the specific numbers of electrons in each fixed orbit.

There are a number of ways we might interpret this sequence of metaphors, which, we are told, first occurred to Godunov-Cherdyntsev in his last year (1917). He had been studying and classifying organisms for decades; he possessed a vast wealth of data and experience from a wide variety of ecosystems. Significantly, he was not looking for any theory during the years of his fieldwork: he simply applied the existing schemes of classification, imperfect as they were, because he was too busy describing new species and their habitats. And yet "something lurking behind the mental capabilities he called on for the straightforward investigation of haphazardly accumulating materials suddenly manifested itself. [...] The 
hour had come when my father suddenly sensed a truth had matured that he had not consciously sought but that had harmoniously grown out of an internal association of elements he had gathered. The mystery was only in the very act of association, and akin to capillary attraction-happening, as it were, independently of the gatherer's will." ${ }^{\prime 2}$ Thus in some hidden but innate way, Godunov-Cherdyntsev's insight emerged as a spontaneous outgrowth of his conscious scientific work. The new theory is meant to be understood as radical, virtually incomprehensible, and undeniably "true" (he "sensed a truth"). That the theory bears strong analogies to other major discoveries (of the solar system, and of atomic structure) might be meant as a sign of its rational accordance with other revolutions in the scientific world. ${ }^{73}$ Or it might be meant to suggest that this pattern of spheres, satellites, and orbits is in some way indicative of hidden unities within the "spirit of nature," as he calls it. In both cases, the metaphorical development reminds readers of the history of intellectual innovation, of the pattern of human discovery as it shatters old worldviews and envisions new ones. This process is founded upon the ability of consciousness to overcome its own creations and tear down its own scaffolding as it achieves greater and greater insight into "nature"; this conscious activity is the natural extension of evolution as Godunov-Cherdyntsev understands it.

\section{The Artist and the Explorer}

It is telling that Nabokov was a naturalist, not an experimentalist. Rather than "torturing nature," as Baconian and Newtonian scientists were wont to do (devising experiments with conditions that would never obtain in nature), Nabokov chose simply to observe and study nature at ever increasing levels of detail. ${ }^{74}$ Whether climbing mountains or digging among forgotten collections of specimens in a museum's vault or examining thousands of minute organs through a microscope, he was traversing space and matter as nature presents them. In these efforts, he was attempting to find what had previously been hidden, to discover uncharted ways, to spot unnoticed relationships or undiscovered beings. He was, in this sense, an explorer, and it is perhaps through the figure of the explorer that we can best understand Nabokov as a scientist and grasp the scientific component of his artistry. This is why the main image we find in Nabokov's works is of the individual looking for something: whether it is the artistic principle behind life, as in The Gift, or the essence of human identity and kinship, as in The Real Life of Sebastian Knight. It is not that experimental sciences 
are invalid, but that they are sterile, by design and by necessity: they are free of life and its vicissitudes, deliberately immune to chance. They strip life of its messiness and characteristic features. Nabokov and his surrogates strive to discover whole essences with their context, like a butterfly on its host plant in its special environment. Even characters whose efforts lead them toward more destructive or self-destructive ends demonstrate this crucial difference: Humbert Humbert wants Lolita in his personal possession—not in her full natural glory (notwithstanding his quasi-scientific study of her features and environment). He is like Nabokov's despised German butterfly collectors and traders who care only about possession, not about knowledge. ${ }^{75}$ Kinbote in Pale Fire likewise wants to colonize the poetry of John Shade, rather than learn whatever might be his secret or appreciate his art.

The analogy is brought to its clearest form in The Gift, where the main protagonist is both an artist and a would-be lepidopterist and explorer. As an artist, Fyodor explores the souls of others: he projects himself into them and attempts to imagine them completely. As he says, he recreates not just the color of their eyes, but also the color behind the eyes (tsvet zaglaznyi). ${ }^{76}$ He can, so he thinks, imagine the inner worlds of other people and discern the patterned essence of their lives. This imaginative daring is akin to his fantastic accompaniment of his father on explorations of Central Asia: based on anecdotes, the works of various explorers, and his father's own texts, Fyodor creates an entire world that hovers before him as he contemplates and writes it down. His (and Nabokov's) researches into Chernyshevsky's life are similar in their exhaustiveness; like a lepidopterist in the field, Fyodor immerses himself into the world of his object, reading masses of socialist literature, theory, and propaganda, along with diaries, letters and autobiographies, and based on that experience produces his work of art. Fyodor's book on Chernyshevsky is exceedingly self-conscious in its use of device and baring of device, which is roughly analogous to the way science uses and discloses its tools and methods. The artist must be an explorer, Nabokov suggests, a discoverer of new or unknown phenomena-including mental phenomena, images of the world reflected in consciousness: the artist's own and those of others.

The scientist, too, can choose to view an object holistically, rather than reduce it to a list of components and rules governing them. This, in effect, is what Godunov-Cherdyntsev does when he produces his "supplement," the result of his years of experience observing and classifying butterflies and moths. Not content to rely on the mechanism of natural selection to understand speciation, he intuits a deeper essence in the emergence and 
proliferation of species. The fact that his "outline" fills thirty incomprehensible pages, and "Murchison's" (fictional) exegesis attains more than three hundred, demonstrates the notion of the incommunicability of phenomena at a certain level of complexity and abstraction. We are told in Fyodor's summary that the figures used are an "approximate image" of what is really happening in nature, which his father has apparently perceived in full depth and complexity, but which can only be seen through a fullness of vision like his own, not through reading his or anybody else's report of it. (Such irreducibility is reminiscent of Schopenhauer's and Tolstoy's comments about their own work, which Nabokov himself echoed in an interview.) $)^{77}$

\section{Devices and Wholes}

The interconnections of art and science relate to Nabokov's awareness of his creative and intellectual environment in the 1920s and 1930s. The school of literary criticism known as Formalism was expanding its influence and its range of concepts during the years of Nabokov's artistic formation. Developing a self-consciously scientific approach to artworks of all types, Formalism sought to identify universal principles and artistic units-devices, functions - that would allow full dissection and systematic study of a narrative or a painting. Some of the most famous of these early formalist works invoke explicitly scientific language, like Vladimir Propp's Morphology of the Folktale. The mechanisms whereby literary works incorporate components of their precursors became objects of "scientific" literary study; they were cultural and psychological facts and principles, which could be applied toward a scientific understanding of how artworks fit into the flow of human culture, viewed objectively and mechanistically as a part of a naturally evolving behavioral system. Propp's choice of the term "morphology" occasions some chance irony, because the term was invented by Goethe without any intent to explore mechanistic or even quantifiable aspects of nature. ${ }^{78}$

Nabokov's interest in formalist writings has been clearly demonstrated by others, as has the fact that he made use of their texts and ideas for his own purposes-(illustrating a principle that perhaps eluded the formalists' view: the exploitation by art of criticism and theory itself). ${ }^{79}$ Considering his commitment to natural morphology (at both large and small scale), it is logical that Nabokov should find some congenial elements in this Formalist method. After all, why shouldn't an artwork of any sort be compared 
to a living organism? Why shouldn't it be made up of identifiable components, systems, have a genealogy? We have already seen how Andrey Bely, who inspired some of the earliest methods of Formalism, devised a scheme for analyzing poems based upon their unfulfilled stresses. Nabokov discovered in Bely's analyses a tool for probing and studying secondary patterns in art and nature. Nabokov's own discussions of other artworks explore details and structural principles of novels and stories; they also employ biological metaphors like "heartbeat." But, echoing Bely, still more important for Nabokov is the concept of the "missed heartbeat," or the gap or quirk in visible nature, in life, or in literature. The artifice or "madeness" of literature (as in Boris Eikhenbaum's classic "How Gogol's 'Overcoat' Is Made") is a constant theme for Nabokov, and it is in order to underscore these gaps and discontinuities, rather than to claim that "all is language," that Nabokov repeatedly inserts traces of authorial craft throughout his fiction. A thing is "made" out of parts, components, rules. But there is one more component, both in the biological prototype and in the artwork: the whole, or life itself.

Whether or not a novel or story is "made"-Nabokov also invoked the romantic notion that he merely transcribed, as accurately as possible, something that existed independently of his conscious creation ${ }^{80}$ — such an artwork, like a living organism, comprises parts, systems, and rules. But to insist on the primacy of mechanistic relationships among these elements, without paying any attention to the life of the work, to its living coexistence within an intellectual ecosystem made up of thinkers, artists, consumers, and tradition is the same as supposing that a mounted butterfly and its scientific description represent all there is to know about it. Nabokov insisted that a lepidopterist must spend many years in the field observing the actual life cycles and behaviors of a creature before having any hope of understanding it. ${ }^{81}$ What is that understanding, once achieved? How can such an experience be communicated? By definition, it can't-it is so complex and multifaceted that it can only be lived, and it has no substitute. In short, one can collect and count as many facts as one likes, but without life the facts remain incomplete, barren, meaningless. ${ }^{82}$ It is the same for a novel or any work of art: it can be dissected and described, but its full essence can only be lived in actual aesthetic perception. One of Nabokov's purposes in engaging the concepts and methods of Formalism surely was to demonstrate that a work of art is much more than the sum of its parts. This holistic attitude characterizes Nabokov's thought about art and about nature as well: a species is not a static unity, but rather a mobile multiplicity. Formalism, like positivist science, draws attention to what can 
be quantified and communicated neatly and accurately; but it downplays the things that can't be tidily encapsulated. Like much positivist science, it enshrines a myth of certainty and of communicability that requires the erasure, the willful overlooking, of that which cannot be communicated or quantified. Nabokov, in contrast, constantly reminds his audience of the presence of the undetectable, the incommunicable, the unknown; and his works, like all art, cannot be condensed or explicated without sacrificing what is most essential in them. As a scholar, translator, and lecturer, too, Nabokov attempted to indicate the nature of the irreducible elements of an artwork, insisting upon the perceptual effort and struggle of each individual who confronts a novel or story in its entirety.

Science for Nabokov is always some form of approach to the world, "reality," visible nature. As a fundamental human activity, one that expands our conscious awareness of our inner nature and our natural environment, science can be evoked whenever we attempt to confront the world in some new way. But science can also be inverted or perverted, inasmuch as it may set up faulty schemes, use flawed or broken devices, or lose sight of its own contingency. Those works of Nabokov's that demonstrate the breakdown of rational powers may be related also to the problems that science has in establishing knowledge of the world. In either case, science provides a tentative confirmation of the world's shape as it is known at any one time. The coming chapters will explore how discoveries and insights from three scientific domains give shape to the themes and structures of Nabokov's art. 


\section{Nabokovian Science and Goethean Science}

NABOKOV MADE surprisingly few comments about Goethe. He did publish a translation of the dedication to Faust for the centenary of Goethe's death; and a decade later he mentioned the "streak of poshlust ["philistine vulgarity'] running through" the German poet's masterpiece. ${ }^{1}$ Aside from that, a handful of allusions to Goethe's work have been found in Nabokov's prose, but not much else. ${ }^{2}$ However, as fellow artist-scientists, the two share a unique place in the parallel histories of literature and of science. Considering them together, we can begin to suggest characteristic traits for the artistic scientist. As I juxtapose these authors' scientific work, I will focus on commonalities in their empirical approaches to data collection, in their thought about the subjective nature of observation, in their shared emphasis on facts over theory, and in their mutual interest in holistic, dynamic studies.

One of the goals in this book has been to demonstrate that Nabokov's artistic and scientific aims were fundamentally related and, by corollary, mutually illuminating. In his scientific work, Nabokov strove to find accurate ways to describe specific phenomena of nature, to establish a sense of their fluid development over time. In his literary art, he sought to offer varying models of the way human consciousness embraces and contributes 
to its world, its "reality," which is made up of specific empirical phenomena, including numerous consciousnesses interacting with those phenomena and with each other. Because Nabokov's scientific practice stood apart from the mainstream of his time, and because of his suspicion of purely quantitative and statistical analysis, it is essential to characterize how his work relates to that of previous thinkers.

The best, and perhaps the only, analogue to be found for Nabokov's integration of scientific and literary work is Johann Wolfgang von Goethe. Goethe's contribution to the sciences was surely broader than Nabokov's: he lived the life Nabokov might have lived, had he not been forced into exile. But Goethe's passion to know and understand the world of nature drove him to study it in exhaustive quantity and detail. He collected enormous amounts of sample materials for his mineralogical, osteological, and botanical studies. He believed in and practiced a strict empiricism, based upon the accumulation of very large quantities of evidence. His theoriesof archetypes and metamorphosis, of color-were arrived at only after minute analysis of his samples. For his color theory, he "collected" an encyclopedic array of the possible manifestations of color as known to human perception, including physical or chemical colors as well as physiological and subjective-psychological colors. And Goethe's theory of theories-that every fact, or empirical observation, is already theory-laden-resulted in his extreme caution concerning the place of major, abstract theories in the determination of research programs. It was a scientific method that Nabokov would surely have found to be both rigorous and honest-even, perhaps, inspirational.

Although there is no clear evidence that Nabokov read Theory of Color, or Metamorphosis of Plants, or On Morphology, there can be little doubt that he read about these works and was aware of Goethe's broad scientific activity. One need not suppose that Nabokov was influenced in any way by Goethe's scientific methods or style: it is just as likely, and probably more revealing, that Nabokov's scientific style was as much a part of him as his creative drive. Looking at these two artist-scientists side by side, we can begin to develop an idea of how an aesthetically and qualitatively oriented scientist may differ in outlook from a nonartistic, quantitatively focused one. Because of this innate kinship, a review of how historians and philosophers have come to understand Goethe's approach to nature will offer a partial vocabulary for framing and describing Nabokov's synthetic work. Goethe's scientific output, although different in scope and ambition from Nabokov's, provides an essential context for assessing the interrelations of Nabokov's scientific and artistic activities. 
Artists, or at least some artists, ought to make for excellent scientists: they have keen observational skills, an eye for detail and pattern, the drive to represent and preserve something from the world in durable form. An artist is a person who wants to, and does, express something by selectively using the full literal and figurative power of a language (verbal, musical, tactile, and/or visual). A scientist is someone who wants to discover a secret, some pattern or mechanism, hidden in nature. Artists may feel driven to discover things, too, but often they are seeking truths within themselves, or in a transcendent realm, and they tend to believe that the truths they seek cannot be expressed directly. The artist-scientist should be a person who has both urges: to learn nature's secrets, and to express various discoveries or insights. In such a person, the scientific work will be colored by the holistic, aesthetic sensitivities of the artist, and the artwork will include traces of the scientist's urge to collect, analyze, experiment, and synthesize. It might even be imagined that artist-scientists offer us the most complete ability to envision and describe nature, precisely because of this dual sensitivity and drive. Nevertheless, their work has been viewed with suspicion by the scientific community, in large part because of their willingness to challenge the basic assumptions that underpin mainstream research. The effort by an outsider to discredit Newton or Darwin can appear quixotic, raising doubts among those who do not question established orthodoxy.

Goethe presents a convincing parallel for Nabokov in part because both authors demonstrated a passionate affection for the phenomena of "reality," especially as expressed in nature-even while exhibiting strong idealist tendencies that might seem to de-emphasize or discount the physical realm. It will be useful to summarize what is known about Goethe's practice and philosophy of science, and by necessity I will rely almost exclusively upon existing scholarship to do this. ${ }^{3}$ A great deal has been written about Goethe's science that is worth rehearsing here. Rather than interrupt at each opportunity to claim "Nabokov too!" I will for a time rely on the reader to keep in mind the specifics of Nabokov's scientific methods discussed in chapter 1 .

From the outset, Goethe was an unorthodox scientist. He was not formally trained in any branch of science; he was not an experimentalist, and his empirical approach was highly suspicious of theories and hypotheses as guiding forces behind discovery. Instead, he continued the tradition of extensive observation and collection of natural details, whether in the sphere of physical objects such as plants or that of psychological phenomena like colors. Distinguished by its attention to form and to extensive, 
cumulative observation, Goethe's research relied on the perceptual power of human consciousness, rather than on the quantitative power of mathematics. ${ }^{4}$ His interest in form as a continuous and guiding feature of the natural world led him to create the term "morphology," giving voice and unity to a diverse set of empirical interests across traditional scientific boundaries; ${ }^{5}$ it led him to focus on the discovery of the natural archetype, the Urphaenomen, or the commonality behind the formation and evolution of various species and other natural phenomena.

Goethe did not hesitate to question received wisdom, or even to challenge the titans of science. In his Metamorphosis of Plants, he took on Karl Linné's system of classification, suggesting improvements and modifications in the great taxonomist's methodology; in his osteological studies, he overthrew the dominant view of human skull-structure and argued for the morphological kinship of humans, apes, and other vertebrates (thus providing strong evidence in favor of transformation of living forms, or evolution); ${ }^{6}$ in physics, he rejected Newton's claims to have exhausted scientific knowledge of color and severely criticized the scientist despite-and to some extent because of-his mythic stature. ${ }^{7}$

Goethe has been credited with fostering a holistic approach to the study of nature. ${ }^{8}$ Accordingly, in an essay from the collection On Morphology, he wrote: "[W]e often think the best way of gaining an insight into the relation between [natural objects'] inner nature and the effects they produce is to divide them into their constituent parts. ... But these attempts at division also produce many adverse effects when carried to an extreme. ... Thus scientific minds of every epoch have also exhibited an urge to understand living formations as such, to grasp their outward, visible, tangible parts in context, to see these parts as an indication of what lies within and thereby gain some understanding of the whole through an exercise of intuitive perception. It is no doubt unnecessary to describe in detail the close relationship between this scientific desire and our need for art and imitation." 9 This emphasis on the whole as a context that conditions not just our perception, but the situational reality of the parts, gives Goethe's science a quality that requires the kind of back-and-forth across levels of perception, or synthesis, that human consciousness can provide, but that instruments or mathematical formulae generally cannot. Similarly, Goethe was aware of the tendency of science to study and quantify objects as if they were static, whereas in fact they are always moving and changing. In his words,

$[\mathrm{N}]$ othing in [organic Gestalten] is permanent, nothing is at rest or defined-everything is in a flux of continual motion. 
If something has acquired a form it metamorphoses immediately to a new one. If we wish to arrive at some living perception of nature we ourselves must remain as quick and flexible as nature and follow the example she gives.

$\ldots$ the ever-changing life of nature $\ldots{ }^{10}$

Goethe thought of the human cognitive-perceptive ability as itself an organ and a refinable tool of scientific investigation-in fact, as the most sophisticated tool available. ${ }^{11}$ By extension, one part of the power of cognition lies in the affinity between consciousness (or self) and any natural observed object: not only is human perception uniquely suited to discover certain kinds of pattern and regularity in nature, but it is so because it is immediately of nature. Subject and object are interrelated and even interpenetrating (they make and shape one another). The categories of reason are an expression of nature in consciousness; by means of them, the human mind grasps and understands the nature that produced it.

This intimate relationship between subject and object forms the core of Goethe's subtle philosophy of science. One of the dominant characteristics of Goethe's approach is his unflagging awareness that one cannot ignore or wish away the presence of consciousness as a defining constituent of any act of observation (a formulation that anticipated Ernst Mach's assertion that one cannot imagine a completely isolated object, because the imagined observer violates the isolation), ${ }^{12}$ a position he lays out in the essay "The Experiment as Mediator between Object and Subject." His main criticism of so-called "objective" science arises from what he calls its error, whereby the scientist "loses the yardstick which came to his aid when he looked at things from the human standpoint; i.e., in relation to himself." 13 The quest for "objective" knowledge-knowledge fully independent of a subject's perception-is fraught with dangers and also with fallacies, because the individual consciousness, with all its baggage, can never be fully suppressed and eliminated from the field, although it is easy to pretend that it has been. The effort to produce objective knowledge is valuable, but its limits are real and inescapable: the scientist "must be his own sharpest critic where no one else can test his work with ease, [...] he must question himself continually even when most enthusiastic-it is easy to see how harsh these demands are and how little hope there is of seeing them fully satisfied in ourselves or others." ${ }^{14}$ It is for this reason that Goethe is often described as a phenomenological scientist, that is, one who saw every empirical observation as theory-laden, never losing sight of the fact that all observations are taking place in a context of phenomena 
accessible to sensation and cognition as well as intellectual expectation and response. ${ }^{15}$ The best antidote to the pitfalls of objective science, Goethe suggests, is to be found in collaborative work and the complete sharing of all information, as early as possible: "no scientific edifice should be built until the plan and materials of its structure have been widely known, judged and sifted." 16

As a result, Goethe's preference for inductive science emerges from these very concerns, and a concomitant suspicion of theory guides his scientific endeavors. When theories arise from collections of data carefully amassed, they are valid, useful, and a "tribute to their author's intelligence"; but these same theories often take on a life of their own, suppressing or twisting the collection and observation of new data, as "with undue applause or protracted support they soon begin to hinder and harm the very progress of the human mind they had earlier assisted." ${ }^{17}$ This, to Goethe, was the fate of Newton and his theory of colors expressed in Opticks: the great man had let a tacit theory regarding likely outcomes guide his research, and he selected only a few experiments that would confirm this theory, rather than striving to present an exhaustive account of how colors exist and function within the world and human consciousness. ${ }^{18}$ Although Goethe's attack on Newton and his scientific method did not win him followers in the nineteenth century - the practical utility of Newton's discovery was too powerful for Goethe's critique to win many allies - it was recognized in the twentieth as a perspective that had certain value in establishing approaches to scientific knowledge not based exclusively upon reducing phenomena to quantifiable constituents. ${ }^{19}$

The key to understanding nature, for Goethe, was the extensive accumulation of detailed evidence: "We cannot exercise enough care, diligence, strictness, even pedantry, in collecting basic empirical evidence; here we labor for the world and the future. But these materials must ... not [be] arranged in some hypothetical way or made to serve the dictates of some system." ${ }^{20}$ Evidence (details) first, theories (generalizations) second, he continues: "once the sequential evidence of the higher sort is assembled, however, our intellect, imagination and wit can work upon it as they will." $\mathrm{He}$ is confident in the ability of a large number of collected facts to outweigh the tendency of the human mind to "unite all external objects known to it," ${ }^{21}$ but suspicious that theory-driven science is prone, even doomed to become despotic and misleading. This is what happened with Newton's Opticks, he felt, producing over a century of slavish imitation and no legitimate extension or refinement of the original work. ${ }^{22}$ 
Goethe's color theory was dismissed in its day, but a century later some scientists began to recognize the value of his approach along with the important distinctions to be made between the proper subjects of Newton's and Goethe's researches. For Newton was examining, specifically, properties of light-especially, its composition from different colors whose "refrangibility" varied, as proved by his prism experiments. Goethe, on the other hand, was focused on color itself in its various manifestations, including physical, chemical, and physiological. ${ }^{23}$ Goethe paid particular attention to the effect of context on color, such as the way the surrounding background may affect the perceived value of a color, or the changes of color when under shadow. Newton, of course, was aware of these phenomena, but he made no effort to bring them into his system, which concerned only the physical behaviors of light, particularly in its refractions when passing through glass lenses and prisms, rather than the multifarious phenomena of color as experienced by humans. To Goethe, Newton's choice represented a careless neglect of color in its fullness as phenomenon (or a group of phenomena), a willful refusal to explore all the facets of color's manifestation in nature-including human nature. Although Goethe was wrong about the value of Newton's theory within its own sphere, he was right about its narrowness and its inability to account for much of what color actually does in everyday life. Today, Goethe's work is valued especially for its insights into the physiology and psychology of color perception. $^{24}$

Another aspect of Goethe's career that hindered his scientific reputation was his intimacy with major proponents of German Natürphilosophie, the idealist philosophy of nature developed and espoused especially by his friends Schelling and Schiller. Contemporaries firmly associated Goethe with these metaphysically inclined colleagues who had, finally, no credentials in empirical science. However, Robert J. Richards has argued that although Goethe was attracted, and at times committed, to some aspects of Schellingian idealism, he was in the end too much of an empiricist, intensely drawn to the reality of nature, to accept a fully mystical-idealist interpretation of the world.

One of the most famous episodes in Goethe's connections to Romantic nature philosophy occurred during his first extended conversation with Schiller, in which the latter, having heard Goethe's theory of the archetypal plant or Urpflantz, retorted, "that is not an observation from experience. That is an idea." ${ }^{25}$ At the time, Goethe regarded himself as a thoroughgoing realist: he even felt that his intuited "symbolic plant" was part of 
perceived reality. He was suspicious of the idealist philosophers' outlook, and he was quite nearly offended by Schiller's suggestion that his experiences were not "real" after all. But the ensuing debate established a working détente between the two, as well as a close friendship that endured until Schiller's death in 1805. The solution to the apparent contradiction in Goethe's thought, Richards suggests, is to be found in Natürphilosophie's debt to Spinoza's pantheism: “A Spinozistic monism, in which natural processes have a mental counterpart that can be recognized through careful experimental procedure and that can be captured at a higher level of cognition-these assumptions seem to lie behind Goethe's methodological pronouncements. 'The simpler powers of nature,' if thus resident in an external world, would remain inaccessible to a Kantian mind. Herein would lie the attractiveness of Schelling's idealistic Spinozism, which took its departure from Kant, yet which spoke of a nature that did not lie irrevocably hidden in a noumenal world but was continuous with our very selves." 26 Thus through the inherent connection of mind and nature, the reality of archetypes is reasserted; physical, empirical objects- "nature"exist within and beyond mind in a way that surpasses the Kantian phenomenon, because human beings have an immediate intimacy, even a unity with that world (the one "beyond mind"). Such a solution allowed Goethe to remain grounded in his love of physical nature while feeling that his "ideas," or intuitions, were also part of nature's own reality.

Goethe's understanding of nature as a changing, evolving domain is of obvious interest from the standpoint of Nabokov's scientific outlook. We have seen above how Goethe views the archetypes of nature as a "flux of continual motion," how "if something has acquired a form it metamorphoses immediately to a new one." Nature is "ever-changing": this epithet refers not only to dynamics of ecology and the lifecycle, but also to the fact that forms themselves evolve towards greater complexity and (as Goethe the good teleologist thought) perfection. Hence, "creatures gradually emerge in two opposite directions toward perfection, with the plant finally reaching glory in the tree, perduring and rigid, and the animal in human beings, the epitome of mobility and freedom." 27 Acknowledging adaptation of form to environment, Goethe mentions the seal, "where the exterior has grown quite fishlike even though the skeleton still retains all the features of a quadruped." 28 For Goethe, these transformations are driven by a vital force, guided and constrained by the archetype and the inherent relation of idea to empirical form and environment.

The status of the archetype as empirically "real" brings Goethe and other idealists into conflict with Kant's third Critique, since there the 
teleological principle suggested by the archetype has hypothetical value as a regulative principle, but lacks actual valence in reality. As Richards summarizes: "The Kantian biologist, then, should only deploy archetypal notions heuristically, as if organisms had been the products of an ideal plan, while yet searching for proper mechanistic causes. Schelling and Goethe-and those biologists following their lead—countered that if archetypes proved a necessary methodological assumption for the biologist, then there was no reason-especially on Kantian grounds-to argue that nature was not intrinsically archetypal, that is, essentially organic rather than mechanistic." ${ }^{29}$ As we shall see, both the archetypal consequences of this stance and the anti-mechanistic ones resonate powerfully with some of Nabokov's scientific formulations. The archetypal view of nature has not, with a few notable exceptions, found much support among modern scientists. Rather, science has focused on causality, on mechanism, and on the local interplay of physical or ecological forces. Goethe wanted to demonstrate the value of an approach that considers mechanistic systems as part of a larger whole that includes guiding archetypes. It was easy enough for scientists to dismiss this approach, because its results tend to be neither clean nor distinct: that is, they lack the black-and-white quality that post-Newtonian research has come to expect. The adoption by modern science of the Newtonian-Kantian mechanistic methodology has had its own set of serious consequences, which Goethe's followers today are attempting to counterbalance. ${ }^{30}$

Goethe's conception of evolution would thus not be entirely mechanistic, that is, driven exclusively by the cause-and-effect of environmental pressures. Life is change, and change occurs along various defined pathways in concert with the requirements of physical survival in an environment. Hence the seal's-or, more dramatically, the dolphin's-mutation into a fish-like form, while it still retains the archetypal skeleton and organs of a mammal, as Goethe discussed in "Toward a General Comparative Theory." Aquatic life fosters the emergence of certain hydrodynamic modifications in marine mammals, while the underlying structures continue to exhibit a family resemblance with land mammals, rather than (re)converging with fish. To put it another way: if a species is bound to change and metamorphose, following a law of nature, then it is problematic to say that any particular stimulus has caused that change: it has simply directed the change that must inevitably occur. What looks like cause and effect on the local level looks like the details of an integrated process when seen from a broader, holistic perspective. Such a perspective does not deny the existence of causes and effects, but it does attempt to move 
beyond a point of view that considers causality to be the only legitimate lens through which to study nature's progress. We will see a very similar inclination in Nabokov's scientific exploits.

For Goethe, nature did not progress mechanistically (or, at least, not only mechanistically), but rather through its own inner, creative force. He thus embraced a view of nature as creative, with human consciousness both expressive of and participant in that creativity: "We ought to be worthy, through the intuition of a continuously creative nature, of mental participation in its productivity." ${ }^{31}$ In the creativity of nature itself Goethe also found a source for the kinship of art and science, his two passions, so that intuition and imagination are not wholly alien to discovery of nature's secrets but rather enhance them in the context of human consciousness and creativity. ${ }^{32}$ Such a view also implies that scientific and artistic activity are not radically distinct; rather, they reflect and respond to a common essence-an implication easily discerned in Goethe's assertion that "there is an unknown, lawlike something in the object that corresponds to an unknown, lawlike something in the subject." ${ }^{33}$ It also hints at a deep commonality between art and nature, helping to suggest a new meaning for the ambivalent phrase "art for art's sake," so often misinterpreted as a license for decadence or meaninglessness. Both art and science involve intuitive discovery of hidden truths. When differentiated from his idealist companions, Goethe offers an example of a thinker who sees nature and art as expressive of the highest truths, but who refuses to accept that those truths exist independently from the nature and art that embody them. An abstract, metaphysical "spirit" or platonic "ideal," somehow superior to or independent of a subordinate nature, was as alien to Goethe as was Kant's "noumenon," for it appeared to devalue the significance of empirical reality and nature.

This partial overview of Goethe as a prototype of the artist-scientist gives us a rich context within which to consider Nabokov's own doubleedged career. Especially in view of the strong indications we have of Nabokov's idealist sympathies, the Goethean point of view provides special tools for interpreting some of Nabokov's most elusive scientific and philosophical observations.

We can see at the outset that Nabokov's scientific work shares much in common with Goethe's. In his speciation theory-never given explicit form, but suggested in his papers on lepidoptery and in the fictional "Father's Butterflies"-we find an interest in the progress of nature and its inescapable motion: Nabokov saw nature as "in flux," claiming that an overweening attention to species as a static form is like conceiving a journey only in 
terms of stopping points. Although interested in finding new species-as demonstrated in his poem, "A Discovery" ${ }^{4}$-Nabokov was always even more focused on the connection between any species and its relatives and subspecies. A polytypic genus, or even a group of genera, presents a broad picture of nature's varied development, the profuse emergence and variation of many forms within a relatively small corner of the natural world. Following upon his "journey" metaphor, Nabokov tends to survey large groups of related species, thinking of the whole as a continuum in which various species and subspecies serve as snapshots of an organic, continuous process. He also, somewhat illegitimately (but with self-conscious irony), pretends to view these contemporary creatures as if they present the image of a chronological evolutionary series. The point, however, is that he writes about groups of butterflies like the subfamily Plebejinae as if they were an organism in their own right, changing, mutating, evolving in ways sometimes predictable, sometimes surprising. In "Father's Butterflies," we witness how, in a fictional setting, Nabokov creates a theory that expresses the organic nature of life's systemic developments by means of Godunov-Cherdyntsev's "spherical” speciation theory. That theory, by the way, is not strictly locked away in the world of fiction, for we see traces of it in Nabokov's own scientific writings, too. ${ }^{35}$ His "magic triangles" (see chapter 1) are akin to Goethe's archetypes, governing the development of forms within a certain species or genus.

Does philosophical idealism guide Nabokov's science? GodunovCherdyntsev, in "Father's Butterflies," asserts that a species is an "idea" reflected in the "mirror of nature." This is, no doubt, an unabashedly idealist claim. It is some of these hints, along with Nabokov's public opposition to Darwin's theory of natural selection, that have raised doubts among some scientists about Nabokov's acumen and his commitment to empirical science. ${ }^{36}$ These passages are some of the most difficult to interpret in all of Nabokov's fictional oeuvre, because of the philosophical weight the metaphors are forced to bear. In contrast, we do not find anything resembling idealist statements in the research papers themselves, a fact that demonstrates Nabokov's willingness to practice science within accepted Kantian boundaries. The Goethean perspective helps us to discover the common ground between these two poles in Nabokov's thought.

Nabokov's attack upon Darwinian theory-upon classical natural selection-echoed Goethe's attack on Newton in that he implicitly accused the theory's proponents of overlooking or ignoring counterevidence. Nabokov does hint at the inadequacy of a mechanistic model of evolution, such as Darwin proposed, when he states in one article that he is "not satisfied 
with any of the hypotheses advanced in regard to the way it works." 37 In this rather subdued critique, Nabokov merely refuses to endorse the Darwinian as well as any other theory of speciation: that is, he appears to be concerned that the theory had come to control and distort the perception of data-that hypothesis, rather than empirical observation, was driving science. We saw in chapter 1 how he was repelled by the utilitarian whiff of the "struggle for survival" and expressed contempt for causality as the exclusive engine of natural history and life. There can be no doubt, however, that Nabokov accepted the basic premise that evolution allows and fosters the production of forms better suited to survival, as when he wrote that "the zebroid [wing] patterns, peculiar to certain groups in certain environments, suggest specialized protective adaptations rather than primitive designs." 38 His hoped-for proof against natural selection's universality—nonutilitarian mimicry—can be viewed as a particular failed hypothesis about nature: that some case(s) of mimicry or object resemblance can be proved to confer no survival benefit to its owner. However, even without such a silver bullet, Nabokov's apostasy was intellectually valid, for Darwinism was and is a hypothesis concerning how new species develop from old ones when faced with varying environmental pressures. The theory's core concept, mutation, was a phenomenon without an explanation, and Darwin himself readily and frequently admitted that its cause was absolutely unknown. To Nabokov, Darwinism-especially in its Spencerian guise-left out the most important part of nature's story by ignoring the entire question of origins, and by accepting discernible adaptations as a substitute for other missing knowledge about evolution. Like Goethe's aversion to Newton, Nabokov's rejection of Darwinism constituted a refusal to accept the universality and comprehensiveness of a partial theory. If natural selection is assumed to be "all-powerful," as Weissman claimed it was, then it could be presumed to answer every conceivable question about life. Put another way, Weissman's version suggested that henceforth living nature could only be questioned with the tools of natural selection. $^{39}$

We do know that Nabokov's envisioned “Animal Mimicry” project would have presented the kind of data set that Goethe deemed essential to good science. It is striking how extensively Nabokov presents his morphological data concerning butterfly variation, whether relating to the structural components of genitalia or to wing markings. If one follows his argument, there is a suggestion that the wing patterns vary across subspecies and species in a way that seems governed by laws of predictable development, as by an archetype, even while it is not clear that any 
of the variations upon a given theme has a survival advantage over others. ${ }^{40}$ And his opinions concerning the morphology of butterfly genitalia are even more remarkable for their Goethean overtones. Nabokov distinguishes between the external features that are more likely to take on new forms when faced with a new environment, and the internal ones, like sexual organs (Goethe's example had been skeletons), that are not directly confronted with environmental pressures. These hidden forms are much slower to change, and hence preserve the marks of specific kinship far longer than external features do. And even when external features and internal features vary distinctly, Nabokov, like Goethe, relishes most of all the family similarities between distinct organisms. Compare, for example, the following passages, in which both authors consider continuous resemblances between diverse groups of animals:

\section{From Goethe:}

What a gulf between the os intermaxillare of the turtle and the elephant, and yet an intermediate series of forms can be found to connect the two! What none would deny of the entire body could here be shown in a small part of it. ${ }^{41}$

\section{From Nabokov:}

Indeed a loss in thickness less than the difference between, say, southern and northern individuals of the Cascade Mts. forms of [Lycaeides] argyrognomon, together with a weakening of the hook, would be enough to change [Lycaeides] argyrognomon longinus (holotype) into [Lycaeides] melissa. As will be seen further, in the Jackson Lake region such intergradation actually does occur, [ . . . A this point of its development argyrognomon does turn into melissa (from which, however, only 300 miles to the west, it is sharply separated in all characters). That it wavers here at the crossroads of evolution and may select another course, is proved by the ismenias-like genitalia of the paratypes. ${ }^{42}$

\section{And:}

A complete sequence of intergrades (more complete than I originally thought) exists between argyrognomon and scudderi in the palearctic branch and between argyrognomon and subsolanus in the nearctic one ... ${ }^{43}$

Nabokov sees the continuity of forms across closely related taxa as a matter of primary interest when considering nature's development and its 
constant movement through various states. This sustained attention to these dynamic, large-scale natural phenomena implies a belief that such metaphenomena are themselves expressive of certain realities hidden within nature. Such a viewpoint cannot be attained without the careful amassing of data and their comparative analysis, with an eye toward secondary patterns to be found among "gaps" and "syncopatic jerks" encountered in the diversified species. From the standpoint of modern evolutionary theory, considerations of this so-called "synthetic character of a species" and its emerging patterns would have given Nabokov a better platform than mimicry from which to view secrets of evolution that go beyond natural selection.

Mimicry itself serves a dual function within Nabokov's broader outlook: first, as a conjectured proof that not all dramatic morphological changes take place due to a survival benefit; and second-and far less scientifically_as evidence of an artistic principle embodied within nature itself. This essentially romantic view of nature is not surprising, but it is telling that Nabokov, an exhaustive empirical researcher, thought that he had discovered a way to prove nature's extension beyond the law of causality. Nabokov is not the first serious post-Darwinian scientist to propose creative or artistic components of nature's dynamic process. The physicist and philosopher Ernst Mach also felt that some investigative behaviors of chimpanzees reflected gratuitous curiosity, unrelated to the potential utility of the object of attention. ${ }^{44}$ Simeon L. Berg had summarized several putative examples of non-utilitarian mimicry in $1922 .{ }^{45}$ And Nabokov's interest in Henri Bergson's vitalism is quite well-known. ${ }^{46}$ One could certainly counter that the continual emergence of new forms in nature does not need to be proved useless in order for it to have deep affinities with art (and nonutility is surely as hard to prove objectively as any other "negative feature" might be). At any rate, we see vividly expressed throughout The Gift and "Father's Butterflies" the affinities between nature and art, including even natural anticipation of the materials of human painting, displayed on the wings of a moth, in the spot "resembling a dab of gilt redolent of turpentine, [which] must therefore be copied (and recopied!) in such a way that the painter's work transmits, besides all the rest, a resemblance to the work of a painter!" 47

Consciousness itself is a part of nature as Nabokov and Goethe both understood so well, and its own creative acts are, likewise, part of the world's natural development. Nabokov believed in the creativity of the individual artist, and in the necessity of allowing artists to produce their work unimpeded. At the same time, he recognized certain limitations on 
creativity, which are most easily discerned in his statements about "transcribing" his novels as if from a transcendent or ideal state. This second claim appears to be in direct conflict with the first, so it is worth pausing for a moment to sort them out. After all, what kind of creativity is it that merely transcribes an existing form? When we consider anticipations like the gilt wingspot or the alleged preexistence of consciousness in nature's storehouse as described in "Father's Butterflies," it is tempting to conclude that, indeed, Nabokov was proposing a dualistic, platonic structure where the "real" reflects concepts from transcendent or noumenal reality. We should bear in mind, however, Fyodor's warning that "these are only an approximate image." ${ }^{48}$ A Goethean interpretation of this artistic credo might provide a more satisfying, and less contradictory, solution. Recall that Goethe, following Schelling and Schiller, felt that the subject and the object are fundamentally continuous, and that human consciousness is intimately part of and unified with the development of nature-the worlditself. That unity gave Goethe a sense of his own ability to perceive nature in both its superficial and its hidden (archetypal) essence, and allowed him to define his experience of hidden, "ideal" phenomena as immediate and direct. What the artist perceives and expresses cannot but be part of the world's natural development: as Kant put it, "genius is the inborn mental trait through which nature gives the rule to art." ${ }^{49}$ The imaginative individual may have immediate access, through conscious or unconscious intuition, to emergent phenomena or archetypes. What these intuitions reveal may be incomplete or unclear, and the artist communicates as distinctly as possible- "with the utmost accuracy and perception" 50 - that which emerges from the darkest recesses of inner consciousness for, as Goethe had written, "our mind stands in harmony with the deeper lying, simpler powers of nature and so can represent them in a pure way." 51 The problem for the individual with such intuitive powers is that whatever is so perceived, if it is in fact a new creation of nature, has never before been expressed in human language or art. Therefore, its appearance in art or science is likely to be both disturbingly unfamiliar and, for a time, incomprehensible. For this very reason, Nabokov asserts that authors create their readers. ${ }^{52}$ In his informal, non-scientific moments, Nabokov suggests that the patterns and compositions in nature and within a human life are indicative of something hidden or transcendent, "the underside of the weave," "other climes of this world," life's "unusual lining," "Person Unknown." 53 These tentative metaphysical gestures, “approximate images," appearing mostly in artistic or autobiographical works (and in a few scientific texts as "Mother Nature" and perhaps also visible in the "synthetic character" of a species 
explored in "Notes on the Morphology of the Genus Lycaeides"), give an unusual context for appreciating the form of Nabokov's empirical science. They, like Fyodor's musings in "Father's Butterflies," demonstrate the possibility of grounding an empirical, objective approach to phenomena in a noncausal, nonmaterial interpretation of nature's sources. Idealist tendencies do not preclude good science, but we see in Nabokov's case as in Goethe's how they may shape the contours of the scientist's agenda. The discoverer's task leans toward detecting and understanding nonmechanistic phenomena that relate to larger, intuitable but perhaps unprovable essences.

Nabokov's approach to color also shares important affinities with Goethe's. Although Nabokov never attempted to create a science of color, he was fascinated by color from childhood on. A painter's sensitivity to shading, shadow, and hue accompanied his early thoughts of becoming a landscape painter. Goethe's own effort to develop his theory of colors emerged from his journey to Italy, which was originally undertaken in order to study the art of painting. It was precisely the artist's intuitive grasp of color's variability and complexity that led him to his experiments in the psychology of color. Nabokov the writer was acutely sensitive to the play of various shades in his works and the importance of distinguishing between closely related hues. We see this theme developed most explicitly in Pnin, where the adolescent Victor, an aspiring painter, has already learned to discern the shadow-colors of different objects.

Nabokov comes close to exploring a partial science of color in studying his own, and later his wife and son's, “colored hearing": in his nineteenth year, and again in his forty-seventh, he mapped out the precise color associations provoked by each sound and letter, distinguishing carefully in detailed charts between the sounds of English, French, and Russian phonetics. ${ }^{54}$ This special cognitive feature and family trait was a source of pride and fascination for him; evidence of blurring across perceptual categories, which he called "drafts and leakings," 55 intimated possibilities of still higher forms of perception, related to phenomena generally inaccessible to human sensibilities. ${ }^{56}$ The experience of such perceptual interpenetrations reinforced Nabokov's sense of mind's essential inscrutability.

Taken broadly, Nabokov's scientific endeavors conform to the Goethean conception of science. The same impulse can be seen in his unrealized dreams as a scientist. He envisioned, planned, and in some cases even substantially completed four encyclopedic works: a complete guide to the lepidoptera of Europe (largely complete, except photography); the same of North America (partially complete); mimicry in the animal king- 
dom (one article written and apparently lost); and butterflies in art (some materials collected). Each of these projects exhibits the same urge to collect a voluminous amount of data over a period of years, arrange it properly according to detailed analysis, correct errors in earlier publications by less attentive researchers, and thus create the possibility of surveying large subdivisions of nature with a comprehensive, synthetic eye. Such a resource would assist scientists in discerning those most Nabokovian phenomena, pattern and syncope (elision, absence).

An exhaustive account of mimicry in nature, if it went according to his hypothesis, would have presented at least a few examples of possibly gratuitous mimicry or object resemblance (as, say, when there are no predators found to hunt a particular quarry). It would also have illustrated how extensively and exuberantly nature likes to copy itself, and how the idea of detailed imitation and representation was already built into the natural world long before human beings created their version of art. As butterflies and moths embody for Nabokov nature's artistic impulse, a compendium of lepidoptera in art would show the tradition of human beings appreciating the connection between their own activity and its natural origins. The possibility that such connections may have transcendent or idealist implications need not be dismissed just because it is not subject to scientific investigation-just as the butterflies and moths portrayed in human art are not rejected because they lack scientific accuracy. Such inaccuracies should be noted, but they do not disqualify a painted butterfly from the history of art, or from the history of human perceptions of nature.

Whether Nabokov studied Goethe's scientific works is impossible to determine. It would be convenient to rely upon the generally held opinion that Nabokov read everything, and thus was likely to have read everything by Goethe, too. But it is not really so important. We do know that he read and thought about Goethe in general, and to honor the centenary of the poet's death in 1932 he even published a Russian translation of the dedication to Faust. ${ }^{57}$ The Russian émigré communities in Berlin and Paris were significantly involved in celebrations of Goethe's art, and commemorative events were announced in the newspapers frequently throughout the year. Lectures on "Goethe and X" were ubiquitous: there was even a Russian presentation called "Goethe and the Law" in Berlin. Aside from his literary works, Goethe's autobiography and his conversations with Eckermann were available in Russian (as well as English), and Nabokov certainly read them; both of these volumes include significant references to Goethe's scientific studies. The most important indication we have that Nabokov was reading widely in Goethe's nonfiction writings is the title of his lecture 
"Pushkin, or the Real and the Plausible," delivered for the centenary of Alexander Pushkin's death in $1937 .{ }^{58}$ This essay discusses the impossibility of creating a true biography of any historical figure-especially a poetand, more broadly, the very problem of truth in representation. Written in French as "Pouchkine, ou le Vrai et le Vraisemblable" [Pushkin, or the True and the Verisimilar], the title is certainly an evocation of Goethe's essay "On the Truth and Verisimilitude of Art," and it also echoes Goethe's theoretical concerns about the nature of historiography and biography more generally. ${ }^{59}$ Despite Nabokov's suggestion that Goethe's Faust contained a significant vein of "poshlust," 60 he most likely saw Goethe the scientist as a kindred spirit, if he ever took the time to consider the matter. Nabokov was surely also intrigued by the art-science crossover made by the admired Russian lepidopterist Nikolai Kholodkovskii, who was the leading translator of Faust into Russian.

It is ironic that one of the criticisms leveled by Nabokov's detractors in the 1930s was his supposed un-Russianness, and especially an un-Russian indifference to nature. ${ }^{61}$ While planning to write a novel near the end of The Gift, Fyodor tells his mother that it will contain all the hallmarks of great Russian literature, including "descriptions of nature.” When nature appears in Nabokov's works - in lepidoptera, orchids, the effects of light and color, or in other physical phenomena like rolling beads of water or undulating grass blades - it does so with the aid of the author's precise attention, as part of a complex network of artistic and naturalistic components. It is the interconnection of all of these levels, ranging from the natural to the psychological to the metaliterary, that most evokes Goethe's vision of the oneness of nature. Such a sense of unity emerges as an explicit part of Nabokov's aesthetics and even his philosophical outlook, in what he called "cosmic synchronization" and illustrated in the following oftquoted passage: "And the highest enjoyment of timelessness-in a landscape selected at random-is when I stand among rare butterflies and their food plants. This is ecstasy, and behind the ecstasy is something else, which is hard to explain. It is like a momentary vacuum into which rushes all that I love. A sense of oneness with sun and stone. A thrill of gratitude to whom it may concern-to the contrapuntal genius of human fate or to tender ghosts humoring a lucky mortal." ${ }_{62}$ Nabokov here argues that both despite and because of science, simply being in nature, deeply known, offers access to mysteries "hard to explain": intensely real, beloved, but not amenable to objective analysis. 


\section{Utility and Futility}

\section{NABOKOV'S BIOLOGICALETUDES}

The wondrous growth on Nigabsi defies explanation: everything on this island appears enormous and alien. For instance, in the island's interior, butterflies (species Vanessa) were observed whose wingspan was established as being approximately $1 \mathrm{~m} 75 \mathrm{~cm}$.

—-"The Wondrous Island Nigabsi," Berliner Illustrierte Zeitung, 1 April 1925, p. 445. Translation by Daniel Magilow. (See image, overleaf.)

THE BIOLOGICAL FOUNDATIONS of Nabokov's science contribute to many of his literary works' themes, and even more significantly to their forms. "Biology," as the broad rubric to be discussed in this chapter, includes the organic world of living nature. It comprises conceptual matters like evolutionary theory, and more specific concerns like the structure and habitat of a particular butterfly or flower. Nature's apparent artistry and generosity are frequent visitors in Nabokov's work; on the other hand, so also is the paradoxical force of (generally human) sexuality, which at times creates profoundly un-beautiful consequences. Implicit throughout Nabokov's work is the tension between the practical utility of any physical or behavioral feature and the extent of its inutile capacity to produce idle pleasure or ecstasy. Among nature's products are human consciousness (which will be discussed more fully in the next chapter) and, through it, art. In his effort to discredit pure Darwinian theory, Nabokov draws explicit connections between artworks-objects not particularly beneficial to physical survival-and their origins in, and emergence from, nature. We notice this almost exaggerated attention on Nabokov's part to the definition of his artworks: they "serve no moral purpose,"1 nor, we are encouraged to believe, any practical purpose either, like a "violin in a void." 


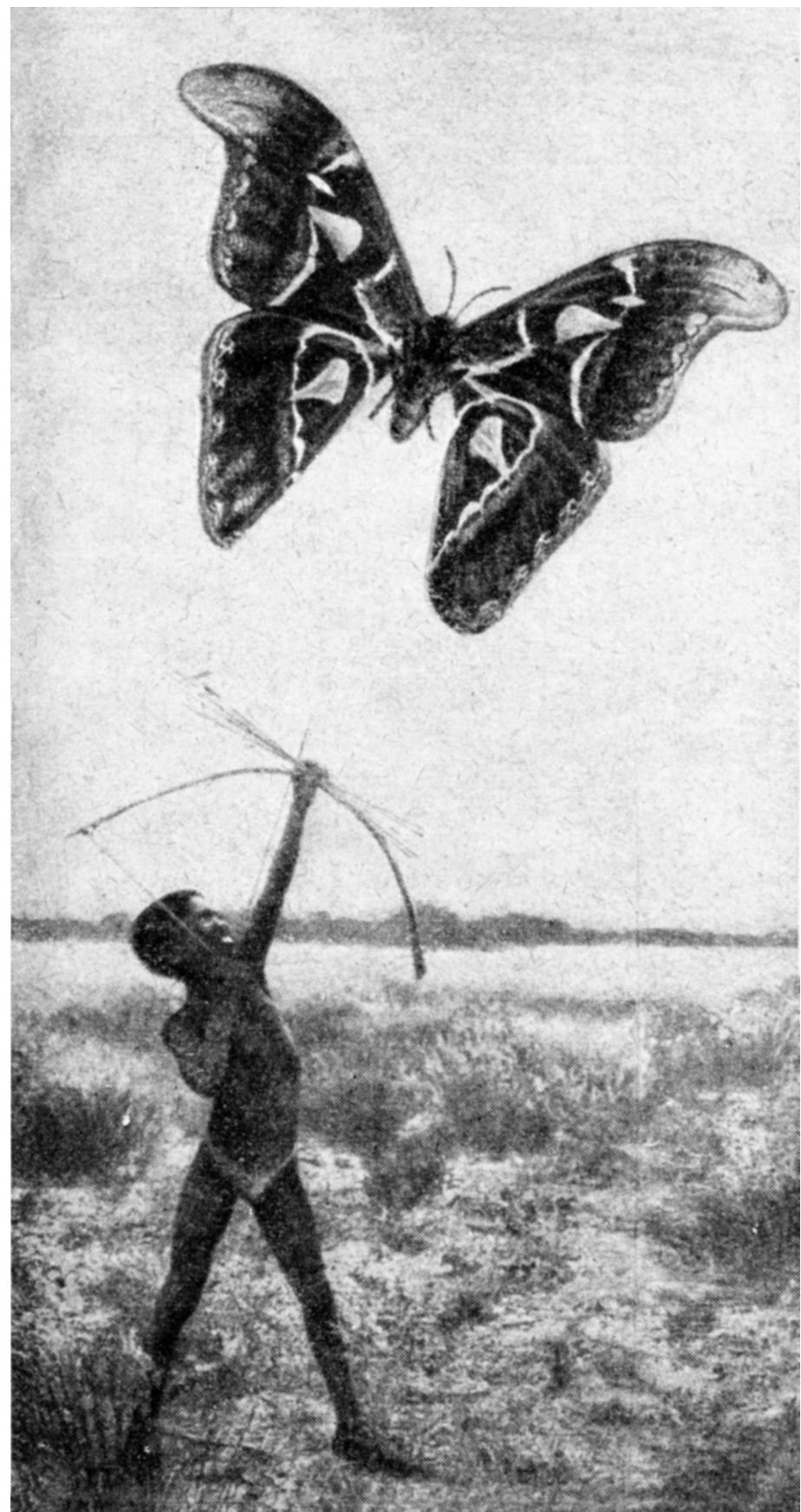

Overleaf: Figure 6

April Fools' image printed with a mock-scientific report from Polynesia originally in Berliner Illustrierte Zeitung, 1 April 1925 (445), which was included in the Soviet journal Krasnaia nov' as real news, as reported in Rul', June 21, 1925. The butterfly is identified as a 1.5-meter example of the Vanessa genus. 
Nabokov, echoing Pushkin, claimed to write for his own pleasure and to publish for the money. ${ }^{2}$ The existence of higher sorts of intellectual pleasure-aesthetic bliss-depends upon the possibility of escaping, if only briefly, from the struggle to survive. This question of "purpose" and its absence therefore grounds our understanding of Nabokov's approach to living forms and evolutionary change.

As we saw in the preceding chapters, Nabokov viewed living nature as a domain of boundless creativity. It is this creativity that animates his view of life in the broadest sense-and most likely his view of the physical realm generally. Creativity by definition requires freedom as well as constraint; and thus it implicitly contradicts mechanistic and deterministic hypotheses. There is, in nature as in Nabokov's works themselves, an enigmatic tussle between freedom and necessity ("the choice that mimics chance"). ${ }^{3}$ Nabokov accepted evolution (as any scientist surely must), and he even accepted the mechanism of natural selection up to a point: his articles acknowledge the adaptive advantages of certain features produced by evolution, and so it cannot be said that he was blind to the play of cause and effect in complex systems. However, selection, as we saw in chapter 1 , is by one definition a controlling factor, not a creative one, and like several other late nineteenth- and early twentieth-century scientists, Nabokov considered that the force impelling life to expansion and variation was fundamental, whereas the selective power of Darwin's theory was secondary. ${ }^{4}$ Whether recalling Henri Bergson's élan vital or some other impetus, nature's continuous expansion and variation is to Nabokov emblematic of the principle of innovation through the free development of organic form.

Consciousness plays an essential role in this story of evolution, both as its most exciting known result, and as a hypothetical background for its development. When The Gift's Konstantin Godunov-Cherdyntsev argues that consciousness, "in the storehouse of the bestower," ${ }_{5}$ preexists its manifestation in human form, he exposes himself to the charge of teleological thinking - the idea that nature is predestined to achieve an end in consciousness (in its human or some future guise); and also to the charge of creationism, as his claim suggests that nature arbitrarily delivers forms from the transcendent to the phenomenal realm. However, there is another way to interpret Godunov-Cherdyntsev's image, more in accord with Nabokov's scientific outlook and his idealist leanings: consciousness may be seen as a mode or principle of being (like an ultimate substance, say, or like the laws of physics), which manifests itself in the forms that emerge within its progress, but not predefining all possible phenomena that can be 
generated out of it. It thus would be part of the stuff of nature, constantly appearing, not the goal as such.

There is a semblance of inconsistency in Nabokov's approach to these concepts, but careful consideration reveals a self-consistent set of principles. It is not immediately clear, for example, how a nature that produces its forms with the "aim" of amusing human beings can be said to be free (here freedom from mechanism becomes enslavement to the telos of conscious amusement). In Speak, Memory (but notably not in his scientific articles), Nabokov emphasizes the "nonutilitarian delights" of nature, suggesting its innate freedom, although one might note that nonutility and freedom are not necessarily synonymous. Godunov-Cherdyntsev, in "Father's Butterflies," proposes a designing "Nature" that creates—not by a plan but freely-the overall patterns of life's flow (even if this is "but an approximate image," and "allegorical"). ${ }^{6}$ Within this model, it is not the constituents of nature that are necessarily free, but rather the animating drive behind them. ${ }^{7}$ Time and causality themselves come into question, as sequence defers to form and structure (as in the back-and-forth structure of Pale Fire's numerous cross-references). Events may relate to one another in identifiable ways, but causal chains can also conceal other constructive or creative principles at work behind nature's surface. If consciousness confers a kind of freedom upon its possessors, that freedom might not relate to everyday interactions with the physical world in its concrete form. If nature is free (i.e., not fully mechanistic or predetermined) in some hardto-detect way, then phenomena within nature, including the phenomenon of evolution, can exist in ways not fully explained by efficient cause. ${ }^{8} \mathrm{On}$ the other hand, artworks, as free products of the mind, represent nature's freedom within the bounds of what is knowable by human consciousness. Such is Nabokov's philosophy of nature and art, and these principles shine through all of his works. Thus we find in his art many images taken from organic nature (usually as emblems of nature's free creativity, with a hint of its consciousness-like undercurrent), and the fiction itself is structured by analogy to this outlook. ${ }^{9}$

Biology is concerned with the growth, reproduction and interrelations of living organisms as well as with the evolution of life forms on the planet. The novels that most extensively and explicitly broach biological themes are The Gift and Ada, but these topics appear insistently throughout Nabokov's works, and not only in the form of butterflies and moths. Once we take into account Nabokov's passionate interest in questions about life's ultimate essence (and especially the question of its possible roots in free creativity or in mechanism), we begin to see biological concerns hidden 
in unexpected contexts. (As early as The Eye [1930], Nabokov alerts his readers to his, and his narrator's, zoological training in a discussion of Linnaeus and problems of species and subspecies classification. ${ }^{10}$ The corollary to his conviction about nature's creativity is his belief in, and sustained attempt to demonstrate, the inadequacy of natural selection as the causal agent behind all evolution. Among scientists, efforts to supplant Darwinian theory came from multiple directions, including purely mechanistic explanations of species variation over time (as, for example, orthogenesis, the law-governed development of form), and, of course, renewed Lamarckism (the heritability of traits acquired during life). But Nabokov's concerns were precisely not with any mechanistic components of nature: he believed, rather, that nature conceals within itself gaps, fissures, rents and flaws in reality's tapestry, a metaphor that Nabokov probably borrowed, with polemical intent, from Alexander Herzen's My Past and Thoughts. Donna Tussing Orwin has shown the importance of this metaphor in Tolstoy's reflections on the relationship between Darwinian biology and history. Tolstoy had written to Herzen objecting to his "carpet" image, in which individual selves are both "woof and weaver" in the context of a free-floating history where "there is no master, there is no design, there is only the warp (foundation) and we all alone by ourselves." ${ }^{11}$ In his redeployment of this figure, Nabokov takes what had been for Herzen an image of mechanical construction, pattern-making, system, and organization, and instead focuses on another side of metaphor's realistic potential: gaps in interspaces, flaws, foldability and surprising, super-imposable patterns, and the existence of an "underside of the weave" or "lining" of life. ${ }^{12}$ Nabokov subverts Herzen's metaphor by foregrounding the fine structure and discontinuity of textile. The irregularities found there offer another figure for the limitations of materialist analogies.

The essential first move in Nabokov's gambit is to take on the concept of utility, in nature and also in human life, which he recognizes as a development of nature. Against the Darwinian postulate that randomly acquired features are retained by nature if they serve some purpose benefiting individual and hence specific survival, Nabokov argues that nature creates novel features not randomly but freely, and that some features can persist despite their uselessness. In the 1930s he would have argued that certain extravagant designs in nature demonstrate this principle; even to the end of his life, he held that consciousness represents the prime example. At the same time, it is important to remember that as someone who, at the least, considered idealism a plausible metaphysical stance, Nabokov apparently felt that consciousness might offer access to states of being 
that are removed from the vicissitudes of physical existence. Consequently, physical survival is not a priori the most desirable outcome, as he illustrates in The Defense, Invitation to a Beheading, Bend Sinister, and Glory, to give only the most vivid examples. ${ }^{13}$

The short 1931 novel Glory (in Russian called "Podvig"—a high deed or exploit) begs for such a discussion, inasmuch as its protagonist's main foil is named Darwin. ${ }^{14}$ This Darwin, not a biologist but a war veteran and a writer of short stories, embodies practicality (especially the stereotypically English variety), strength, sensibility, virility, wit, attractiveness-all the features that suggest fitness for survival and the successful rearing of progeny. In his Cambridge years, however, Darwin's fiction and his actions are iconoclastic and pointedly nonutilitarian. Yet survive he does, having settled by novel's end into the comfortable life of an established journalist who speaks of "success, of earnings, of splendid hopes for the future" and is "particularly interested in the sepulchral-sounding 'moratoria,' whatever they were." ${ }^{15}$ Darwin is winning his struggle, but this type of victory is meant to strike the reader as hollow. It is Martin Edelweiss, the sensitive, intelligent, but aimless and ungifted Russian émigré, who animates the novel's creative core. He does not really provide much of a plot or energize the narrative. The novel is perhaps Nabokov's most understated, and in a Chekhovian way it reflects the undramatic, even anticlimactic nature of Martin's life, while at the same time surrounding his existence with an enchanting texture of natural environment, emotion, and richly lived imagination.

Aleksandr Dolinin and Grigorii Utgof note the thematic significance of the novel's juxtaposition of the "weak" character Martin with the "strong" character Darwin, suggesting that natural selection is refuted by the fact that Martin undergoes greater spiritual growth during the novel. ${ }^{16}$ In fact, the novel's anti-Darwinian currents run much deeper than that, although indeed the tension between the two protagonists creates a focal point for Nabokov's struggle with "struggle." Curiously, in the translation's foreword Nabokov describes Glory as his only novel written with a "purpose." 17 That purpose was contrarian: describing a time of great purpose, of passionate struggle for political and economic survival, Nabokov chose to emphasize the opposite principles: idleness and uselessness. In the heat of the Russian civil war, while many Russian acquaintances enlist and fight to regain their homeland, Martin dreams and fantasizes, chases romance, and studies Russian literature. As a student at Cambridge, he does not even attempt to find a career for himself. 
Given this lack of practical drive, it is intriguing that Martin is especially drawn to competition: he is skilled in tennis, soccer, and boxing. He particularly likes to be overmatched, even if it means near-certain defeat, because the goal of winning is not a trophy, but a feeling (and preferably also an unlikely, Herculean achievement). In a telling exception, during the University soccer championship Martin hopes his game-winning saves at goal will impress the elusive Sonia, perhaps winning her heart; but Sonia is indifferent and bored by the whole affair, leaving the game early. ${ }^{18}$ Similarly, when Martin and Darwin engage in a boxing match, in part spurred by competition over Sonia, the fight leads not to some prize for the victor-the maiden's hand, which neither of them achieves-but to a renewed sense of camaraderie, as if the competition's sole purpose were to eliminate its own putative goal. The bloody fight has a sublime quality to it, as well as a cathartic one, but even this most explicitly biological duel over a desired mate winds up having an entirely unpredicted and unproductive result. Senseless, the match is its own reward.

The consequences of active striving come into full relief in Martin's reflections upon the death of Iogolevich, a Social-Revolutionary activist who had snuck across the Soviet border several times on mysterious antiBolshevik missions. Having read the obituaries, Martin is struck by the way his world of anti-Bolshevik struggle has reduced the man (and others like him) to a public cliché, a "true toiler" who "burned with love for Russia"; these words "somehow debased the deceased" in their universal applicability. Martin thinks of Iogolevich's idiosyncrasies, "his gestures, his beard, his sculpturesque wrinkles, the sudden shy smile, the jacket button that hung by a thread, and his way of licking a stamp with his entire tongue before sticking it on the envelope and banging it with his fist. In a certain sense this was all of greater value than the social merits for which there existed such easy little clichés . ..."19 The ability to notice and appreciate such minutiae, like the minutiae themselves, lacks any particular utility, and yet for Martin the details and their perception are of "greater value" than patriotic valor. What Martin calls Iogolevich's "originality" (svoeobrazie) ${ }^{20}$ represents one of life's greatest treasures, and one that, as the obituaries demonstrate, is too quickly neglected even by Russian Liberals. The emergence of such values, and what they imply, demonstrates for Nabokov that not all aspects of life are utilitarian. Martin, whom Nabokov calls a martyr in his foreword, proves his own freedom from life's struggle by perishing for the idea of uselessness. True, he will leave no progeny, his bloodline is ended; but Nabokov wants his readers 
to consider the aesthetic, fantastical structure of Martin's life, akin to something Nabokov found in nature, as a beguiling tale of a life lived for its own end, with its own mysteries. Such considerations fill Darwin's final moments in the novel as he pauses on the forest trail.

Martin spends his entire life trying, as it were, to enter the picture over his childhood bed and explore its mysterious forest path, much as Konstantin Godunov-Cherdyntsev in The Gift enters the base of a rainbow. He yearns to perform some high deed of great risk and no purpose-a romantic exploit-and for this reason Nabokov's working title for the novel was “The Romantic Age” (Romanticheskii vek). Martin's chosen act-a choice reinforced for him by certain mysterious, fateful signs-is afterwards decried by his friends and acquaintances as pointless and even absurd (not to mention suicidal): to cross from Latvia into Soviet Russia, spend the night, and return across the border. Martin has no ulterior motive, and the glorious, gratuitous danger of the proposed feat constitutes its only rationale. Martin tells no one of his plans except, just prior to his departure, Darwin himself, whom he meets almost by chance in Berlin while preparing to set out. ${ }^{21}$ By this point, almost three years after their time together at Cambridge, Darwin has become even more stolid and evolutionarily secure (secure from both danger and imagination: he has given up writing fiction). Why does Martin confide precisely in Darwin, and not in, say, Sonia or some chance acquaintance-or in no one? The purpose, from a narrative point of view, is to put the Darwinian notion of fitness in direct contrast with the dramatic demonstration of futility and its consequences. Darwin, the character, is forced to confront the entire complexity of Martin's design and its implications. Martin surely perishes at the hands of the Soviet border patrol while wending his way through some forest path like the one above his childhood bed; and Darwin winds up on another wooded trail, attending closely to sounds of surrounding nature (gurgling water, a bird). Martin's image merges with the natural scene and environs of his youthful imagination; Darwin, the survivor, quietly reflects upon-what? We do not know, but we are convinced that something in his consciousness is moved, has taken on a new form.

It may be, as Charles Nicol has suggested, ${ }^{22}$ that the result (but not the purpose) of Martin's exploit is a reawakening of artistic sensibility in Darwin. That almost sounds like a causal explanation, which would be problematic in light of the contention that Nabokov's goal in this novel is to demonstrate a noncausal principle in nature and life. (This noncausality is underscored as well by the patternings in Martin's life, and by the fact that his dreams tend to come true. ${ }^{23}$ These events seem supernatural, 
if they are not simply amazing coincidences; they suggest a principle of composition in life that stands outside cause and effect: they are subtle flaws in the surface texture of life.) Part of the response to that dilemma lies in unpredictability: Martin does not know that his deed will eventuate in Darwin's change. But it is not just Martin's deed that acts on Darwin; it is also the particulars of the setting where the car slides into the ditch and Darwin faces, unknowingly, a scene much like the one hanging over Martin's bed and also much like a passage in Pushkin's Ruslan and Ludmila. And within that scene, what is it that affects Darwin? Is it the water? The wicket? The gray snow? Perhaps, indeed, nothing decisive has happened within Darwin's mind-we are given no strong sign that it has-but rather he has been opened, like the wicket, to new courses of action, to possible creative responses that may or may not take shape. Nicol shows how "Darwin has now both entered Pushkin's universe and taken the path that Martin had been on since he was a child." Martin's dreams and fantasies are fulfilled; he fades away into fantastic imagination. Darwin is left behind to contemplate the meaning of life and death, the struggle for existence or for glory, while readers (who know much more than Darwin does) are left to ponder the beauty of uselessness and the meaning of a life sacrificed for nothing. The deceptive first impression left by Glory is of the simplest and least overdetermined of all Nabokov's works; ${ }^{24}$ its facile surface conceals a depth that makes it perhaps Nabokov's most haunting novel.

\section{Sexual Selection and the Survival of Species}

One may struggle to survive or one may seek glory, but in order to participate in evolution any animal needs to mate. Outside Russian émigré circles, Nabokov became famous because of the troubling role of sexual desire in his third novel in English. Lolita is primarily devoted to the psychological profile of its pathological narrator and the harm he does to his victim. The novel is less about sex than it is about abuse and enslavement, and also about the psychological condition of solipsism-to name only the most prominent of its themes. ${ }^{25}$ However, the sexual component is real, and it forms the basis for Humbert's obsessive passion and his ability to destroy, almost blindly, the life of another human being. Viewed from the perspective of biology and evolution, Humbert's sexuality takes on an additional nuance: it is directed at a girl who is, according to his precise definition of nymphet, not yet capable of conceiving a child. ${ }^{26}$ Hence, like 
homosexuality, it cannot be viewed as a reproductive sex drive. It is a beguiling choice on Nabokov's part: he had been toying for two decades with the idea of the child-bride, borrowed from Dostoyevsky, Poe, and Dante and deployed as early as Camera Obscura in 1932 (and reappearing in Invitation to a Beheading, The Gift, The Enchanter, Bend Sinister, and Transparent Things). There are a number of ways that one can read this pedophilic passion symbolically, most of which are encoded and mocked within the novel itself. The emblematic case appears in the "return to childhood" theme implied by the "Annabel Lee" narrative at the novel's beginning. There is, however, something far too comfortable and convenient about the Annabel story and its conventional Freudian causality. It has the feeling of a handy alibi, but not much more. Humbert's sexual peculiarity stands independently from the Annabel episode; it is, as far as we can tell, a distinct part of him, one that may be innate in him just as "normal" sexuality is innate in someone else. By all indications this is what Humbert is, and at least as far as his passions are concerned he cannot be any other way (but he can, and in moments of strength sometimes does, find ways to redirect his deviance). His arguments about the acceptability of very young brides in some cultures are quite beside the point: these nymphets will always grow up, but Humbert will remain besotted by their departed, youthful, infertile form and its repetitions all around him. ${ }^{27}$

Thus, on a certain level Humbert's proclivity represents a nonproductive mutation, a diversion of sexual energy, fated always to be directed toward infertile objects. It is a Darwinian dead-end, rather than a causally evoked Freudian short-circuit of the sexual mechanism. And yet, Humbert is more than his sexuality, and this seems to be especially true at the time that he composes his "confession." He is, at the very least, a display piece: he puts himself on display, if not with complete honesty or even self-knowledge, at least with a degree of sincerity and a demonstration of certain sensitivities and weaknesses. If we believe at the end of the novel that Humbert's narrative contains something valuable, that he has, even in his rather smug and self-serving, obfuscating way, communicated something vital about Dolly and his exploitation of her, and presented us with an artistic image - perhaps even unwittingly_of the ugly reality of certain habits or traits of consciousness, then he has transcended his criminality, his defect, and his biological uselessness. If the novel's tragedy contains an element of truth, and if Humbert's perception of it contributes both to the novel's own truth and to its tragedy, then his artistic existence is validated in a way that his biological existence never can be, at least in Darwinian terms. This is likely why Nabokov grants him a "green lane in 
paradise" and yearly furlough from eternal punishment, while "hell shall never parole" his precursor Hermann Karlovich Hermann from Despair. ${ }^{28}$ Humbert, for all his crimes, exhibits through his narrative some necessary traits of humanity and even an embryonic indication of the ability to love. Despair's Hermann, in contrast, subordinates everyone around him to his own solipsistic, self-aggrandizing fantasy. In his mind, he is the only possible love object. ${ }^{29}$

When Nabokov centralizes sexuality in a novel, he tends to choose a variation on the typical reproductive urge and presents a version of human carnal passion that excludes even the possibility of offspring. In this way, the physiological sex drive is explicitly torn away from the survival of the species. Despite his open aversion to homosexuality, Nabokov must have become aware of the fact that it represents a phenomenon inexplicable in Darwinian terms. Although it passes fleetingly across the façades of several works (perhaps due to the existence of at least two homosexuals within his close family), homosexuality does not make a central appearance until Pale Fire. ${ }^{30}$ Kinbote's sexuality is famously exaggerated, but what is especially interesting in the novel's formulation is its variegated play with concepts of fertility, fertilization, conception, and birth, as figured against a background of John Shade's life at Wordsmith College, on the one hand, and of the frolicsome, sterile escapades of "Charles Xavier Kinbote" on the other.

The sexual drive has a special place in Darwinian theory as the force that propagates and preserves many species. ${ }^{31}$ Building upon this fundamental biological fact, Freud and his followers explained various sexual "perversions" as mechanistic consequences of various childhood protosexual mishaps or Oedipal malfunctions-explanations that Nabokov largely rejected. ${ }^{32}$ In fact, it may have been more congenial for Nabokov to view nonprocreative sexual urges as innate, rather than as causally and psychologically motivated. The unbridled sexuality in Kinbote's life, with no clear aim besides carnal pleasure, puts into distinct relief the human idolization of sensuality, of sexual desire, in complete isolation from any reproductive motives. ${ }^{33}$ That something so central as the sexual urge can be fully detached from the service of procreation and evolution must have struck the zoologist Nabokov-expert in butterfly genitalia!-with particular force. ${ }^{34}$ His creative response to this enigma is intriguing: rather than demonstrate the evolutionary futility of such a variation, he uses the occasion to model the transition from nature to consciousness when "suddenly our eyes open wide," as outlined by Godunov-Cherdyntsev in his "Supplement" (in "Father's Butterflies," discussed in chapter 1). ${ }^{35}$ 
Kinbote displays, even flaunts his sexuality in his tales of his lost kingdom of Zembla. We can have no idea to what extent his fantasy corresponds to any possible reality; we cannot know whether the Zemblan homosexual escapades and his unconsummated marriage to Queen Disa have any basis in the character's "real" biography, as opposed to in his fantasies. As far as we can tell, Kinbote does have an active, albeit frustrating, homosexual sex life during his stay at judge Goldsworth's house. Accepting his homosexuality as diegetically "real," along with his casual acquaintance with his poet-neighbor John Shade, we witness a very strange tale in which sex and sexuality play a confounding role. Kinbote's creation-the story of Zembla and King Charles' flight from it—is in many ways a tour de force. Ignoring for the moment the complex relationship between his story as it develops in the commentary and Shade's poem "Pale Fire," we can appreciate the drama, the humor, the suspense, and the pathos of Kinbote's narrative. Yet, standing on its own, it hardly has the makings of a great novel or long modern poem. The tale is not truly autobiographical (since Charles Xavier does not exist as such in the novel's outer reality), but it does create what Shade calls "a brilliant invention" that takes the place of Kinbote-Botkin's "drab and unhappy past." ${ }^{36}$

Kinbote relates the life story of Charles Xavier, which reaches its first major complication when the young prince becomes king and is expected to wed and produce an heir. Charles is sexually repelled by women, and despite his wife Disa's beauty and some conscientious effort on his part, he is unable to perform his biological role in extending his dynasty. Brian Boyd has connected Disa's name with the orchid Disa uniflora, which is the "flower-of-the-gods" orchid King Charles brings when he visits her in the Riviera. As Dieter Zimmer has revealed, the genus Disa comprises mostly orchids that are visited only rarely by the necessary fertilizing insect, and thus many members of each new generation die without producing offspring. ${ }^{37}$ Hence Disa's barrenness is situated within a biological subtext, which in its own way reinforces the theme of evolution gone awry: what survival purpose could possibly be served by a failure to attract fertilization, hence procreation ${ }^{38}$ Her situation is all the more puzzling, as her beauty and, as far as we know, fertility (further enhanced by her social advantages) should assure her the chance to pass her genes to future generations. Clearly, something has derailed the normal functions of individuals within the evolutionary machine. The alpha male has abdicated his Darwinian throne. ${ }^{39}$

Shade's daughter Hazel is also doomed to de-facto infertility, but for different reasons: it is her external appearance that makes her unlikely to 
find a mate. She is, however, intellectually superior, creating a Darwinian paradox (should not higher intelligence enable her to overcome her superficial obstacle? If the intelligence of homo sapiens is a selected adaptation, should not intelligence itself be a trait that increases survival and reproductive likelihood?). Moreover, aside from her mundane burdens, she is privy to otherworldly communications from her Aunt Maude and seems also to stir up a poltergeist in the house. Such a combination offers yet another evolutionary quandary: if advanced abilities (mental and maybe even psychic) coincide with a weakening of fertility, what evolutionary goal is served? Certainly none, from a Darwinian perspective. The standard adaptationist reply would be that these psychic mutations, if real, are random and are just as likely to occur in a physically attractive package as in an unattractive one. However, this reply discounts the value of such individuals as ends in themselves, ${ }^{40}$ while justifiably dismissing the unverifiable hypothesis that consciousness might present a special phase of evolution, some sort of bridge to unknown states of being. However, such dismissal leaves important-to Nabokov, at least—questions unexplored. What takes place in the minds of individuals with "enhanced" consciousness may have some bearing on aspects of reality that are not commonly perceived. In a vision of the world that scoffs at causality and the struggle for survival, such gifted individuals make special contributions to human life aside from the procreative. These may be artistic, scientific, or spiritual, Nabokov suggests. It is precisely such contributions that he highlights as markers of where life, through consciousness, might be heading next.

Pale Fire, after all, sprouts from infertility, from biological dead ends. ${ }^{41}$ For even John Shade and his wife Sybil, although happily married and fertile themselves, do not manage to project their lineage into the future. Their gifted daughter sinks into the lake through melting ice and, like Ophelia, meets her end. According to Boyd's analysis, however, Hazel's influence on the world of Pale Fire does not end with her physical life. And we need not take a purely occult standpoint concerning her influence over Kinbote during his Zemblan storytelling. Even without such ghostly interpretations, Hazel haunts Shade's poem as well as Kinbote's version of Shade's recent life. If, as Kinbote suggests, he has a strange kinship with Hazel (whom he has never met), that link may itself be enough to justify the various invocations of her that we find in the Zemblan narrative. And yet, this convergence of John Shade, Hazel, and Kinbote is credited with producing something like Pale Fire, a novel of great complexity and many intertwined strands of meaning. Where this artistic product might lead its 
readers in consciousness is a question that trumps the concerns of heredity and biological fitness. It leads, Nabokov suggests, to Zembla (the last item in the index), to all the riches of imagination and art.

\section{Intelligence, Creativity, and the Limits of Evolution}

If there were any doubt that Nabokov's oeuvre traces the biological theme through its creative permutations, Ada should lay them to rest. Written just after Pale Fire, in a sequence interrupted only by Pnin, Ada presents the culmination of Nabokov's erotically oriented art. It also brings to a dramatic conclusion his play with counter-evolutionary sexuality. Having already examined pedophilia and homosexuality, Nabokov combines incest with physiological sterility in his most ardor-laden novel. Van and Ada, whose mutual passion is born when he is fourteen and she twelve, learn early on that they are biological siblings (even though in law they are cousins). Once an adult, Van learns to his delight that he is perfectly sterile. This situation resolves the obvious problem of contraception, and the slightly less obvious one of the genetic consequences associated with incestuous procreation. What are we to make of this baroque tangle of evolutionary missteps, in which infertility becomes a good thing because it prevents mutant offspring? There is yet another twist: not only are Van and Ada both passionately, eternally enamored with their sibling (something that evolution should select against, of course); they are also both at the far extreme of human intelligence (if such distinctions are important, they are probably even more highly developed than Hazel in Pale Fire).

In this structure, Nabokov is working along several different tracks at once. Ada (unlike her brother) is an amateur lepidopterist, and also a student of plant biology, especially in the very diverse species of orchids. These flowering plants fit into Nabokov's biological narrative in several ways: through various ornate mechanisms (including mimicry of insects), they lure creatures to pollinate them and facilitate procreation-and in this regard they seem to embody the survival principle in nature. The varieties of orchid are extremely numerous, demonstrating the success and creativity of this particular natural lineage. ${ }^{42}$ And they are very frequently phallic (rather, both phallic and testicular): the flowers, themselves often resembling the testicular sack, often grow on a thick shaft. The name orchid comes from the Greek orchis, testicle, revealing their ancient totemic associations. Their pollination strategies are highly diversified and often include self-fertilization. They are the procreative urge incarnate, both in 
themselves with their extruded and dominating reproductive organs, and from an anthropomorphic perspective in their false mimicry of human reproductive organs. Finally, they demonstrate the creative power and deceptiveness of nature, as well as its complexity and ornate beauty. ${ }^{43}$

All this, in a novel that begins with genealogy and a family tree (a tree designed at once to highlight and obfuscate biological links) and ends with the fading away of a pair of sterile sibling-lovers, who, rather than concluding their narrative in any conventional way, fade into a blurb describing the very novel in which they feature as lead characters. ${ }^{44}$ They by necessity leave no offspring, and they spend their final four decades (we presume) engaged in little more than constant, happy, mutual love, which eventually culminates in the creation of Van's memoir (which is also Nabokov's novel). The lack of story once they are finally and forever united develops logically from the original, unmutilated form of the Tolstoy misquotation that opens $A d a$-namely, that all happy families are happy in the same way and thus make for banal storytelling.

$A d a$ is more sexually elaborate than its sibling novels: the two main characters are granted insatiable libido, and their prodigious lovemaking is surely meant as yet another jab at Darwinism. (At one point eight-yearold Lucette queries, "could a boy bee impregnate a girl flower through something, through his gaiters or woolies or whatever he wore?") ${ }^{45}$ The novel also nurtures some very different concerns in its deepest core, for the ethical considerations raised by the siblings' treatment of their half-sister Lucette are distinctly subtler than those in Humbert's "confession." Nevertheless, Ada is similar to its predecessors in its emphasis on the transformation of a particular biological, or physical, problem into an artistic, or ideal, solution. The "problem" is the breakdown of biological procreation; the "solution" is the expansion of human consciousness into a truly creative entity and the "reality" of its creative products.

This solution is figured, to some extent, in Ada's paintings of orchids, in which she takes nature's designs and extrapolates according to her own artistic sense in harmony with her sense of nature, as when "she combined one species with another (unrecorded but possible), introducing odd little changes and twists that seemed almost morbid in so young a girl so nakedly dressed"; or her painting of "the marvelous flower that simulated a bright moth that in turn simulated a scarab." ${ }^{46}$ And, most obviously, it becomes manifest in the shape of the novel itself, which is their collaborative memorial to life, love, nature, consciousness, and passion. The novel elaborates Nabokov's notion of a progressive consciousness, as well, in its figuration of Antiterra and Terra which, although utterly 
separate "worlds," do come into contact through apparent aberrations in consciousness, at least in Ada's world (we do not know whether these revelations are mirrored on Terra). But the parallel, skewed existence of these two worlds is more closely related to advances in physics, which we will visit in depth in chapter 5 .

\section{Novelistic Structures: Art as Organism}

Nabokov intends his novels, stories, plays and poems as exemplars of organic artistry. That is, they are to be viewed as somehow natural, organically produced works in which the various parts and the whole coexist in a naturally connected way that transcends the mechanics of construction. Such a conception of art dates back at least to the Romantics, and it stems from the view of the artist's inherent unity with nature. Although Nabokov would likely have embraced this outlook, in his works we find a situation complicated by the onslaught of modern life, genocide, and warfare. Significantly for their era of composition, all of Nabokov's works appear to imply a unity of being upholding life, unlike the fragmentation and discontinuity embodied in much modernist and especially postmodernist literature. Even while exploring some of the anxieties of modern existence, Nabokov's novels and stories follow coherent trajectories of development, and when they are not strictly linear, or when the narrative seems to decay into discontinuity, these are instead parables of the seeming fragmentation of existence within a larger unifying context. For example, while the shifting narrative voice of The Gift might be seen as an emblem of the fragmented subject, alongside similar strategies used by other authors in the early twentieth century, it in fact merely represents the multiple sides of a single creative person whose life synthesizes these fragments into a larger whole. Lolita erects many layers of defense around its central significance, and it still surely holds many surprises. Nevertheless, the novel projects a definite, if elusive, oneness; at its most basic level, it represents the failings of one man and the sufferings of one little girl as if these things matter in any imaginable frame of reference. Pale Fire, perhaps the most superficially incoherent Nabokov novel and the hardest to pin to any particular version of "reality," nevertheless remains grounded in the linked fates of its two main characters and their loved ones. Its development, although erratic, does follow the course of one character's innate creative urge and inner tragedy. It is that sense of mattering that unifies Nabokov's oeuvre, that promotes the notion that things in the world have meaning despite their 
apparent senselessness and randomness. In their mimicry of-we might instead say simply isomorphism with_organic phenomena, Nabokov's works underscore their commitment to an ideal, value-laden substrate beneath the development of natural life. ${ }^{47}$

There is nothing particularly new in the suggestion that an artwork is the organic product of consciousness. This idea harks back to the Romantic age and its emphasis on nature's divinity, reinforced by ideas of art's connection to higher realms of truth and spirit. ${ }^{48}$ In Nabokov's case, however, with his emphasis on nature's creativity as a counterweight to Darwinian theory, it is worthwhile to examine the figuration of an artwork's development as an outgrowth of this specifically creative procession.

Nabokov's primary focus, in nature, lived life, and art, was pattern. ${ }^{49}$ The existence of unlikely patterns at all three levels, discernable by human consciousness, is evocative of a creative force, but not necessarily a creator, behind life. And it is by now a truism that Nabokov constructed his works, with their layers of concealed patterns, as an embodiment of this principle-some would argue, as signs of the designer behind the design. As Brian Boyd has shown, the reading and rereading activity they encode mimics the process of living life with full, energetic, and creative consciousness. ${ }^{50}$ But such mimicry (and even pattern itself) is only one part of the creative cycle at nature's disposal. We should expect to find in Nabokov's works other signs of art's kinship with a creative evolutionary process, and in fact we find such markers both within individual works and running through his oeuvre taken as an organic whole.

\section{Mimicry}

Nabokov's favorite among nature's tricks, mimicry is the most frequent biological analogue embodied in his works; it stands as the prime example of nature's most persistent feature: deception. Mimicry represents for Nabokov the natural equivalent of human artistic practice: the reproduction of existing forms or their transposition into a new context. In other words, mimicry is the adoption of a pattern or design from one area of nature as camouflage to conceal some other creature. One might say that mimicry is the dominant biological mode in such genres as parody or travesty, although in parody the main emphasis is perhaps one of difference rather than similarity. This is true in nature, too, as it is only external appearance or behavior that is subject to mimicry. Likewise, travesty preserves essential surface formalities of a genre, while replacing its under- 
lying content. It becomes a mock repetition of the original form, while the intent is actually subversion. (Parody and travesty may be said to be parasitic in this way, in addition to being acts of pseudo-mimicry). ${ }^{51}$ Significantly, a parody's intent and identity are not concealed as they would be in forgery. Mimicry can also be said to lie behind all efforts at artistic conformity, and behind innovation when it emerges through slight differentiation. This focus on imperfect similarity explains the use of the term mimesis in discussing art, going back at least to Aristotle (artworks not only mime nature; they also mime the accepted modes of miming).

Mimicry, as the creation of an illusory or camouflaged surface, relates to the description of The Gift's architectonic principles as discussed by Irina Paperno and then later by Marina Kostalevsky and greatly extended by Dieter Zimmer and Sabine Hartmann. ${ }^{52}$ In this case, the larger, complete text is meant to appear organic, original, and internally continuous, whereas Paperno demonstrated how Nabokov used principles of mimicry (crypsis) to conceal the foreignness of cited texts within the flow of the novel. In effect, the same principle is active whenever Nabokov inserts an intertextual reference that might go unnoticed by a reader without an encyclopedic memory. Rather than rely exclusively upon overt references to other authors, Nabokov encodes many such references in a way that makes them appear to be a natural part of the ongoing narrative-as in fact they are, on a different level. This is true of verbatim quotations as well as of the importation of imagery and other cultural motifs.

By using this artistic analogue of biological concealment, Nabokov is able to increase the cultural and linguistic density of his works without obstructing the flow of the narration itself. The result allows for another kind of mimicry, albeit metaphorical: a work constructed with adequate complexity can mimic the multilayered reality of human culture as well as the intricate and interdependent patterns of nature. This is the line of inquiry pursued by Savely Senderovich and Yelena Shvarts, especially in their synthetic work, "Approaching Nabokovian Poetics." ${ }^{33}$ On this view, Nabokov is attempting to encode both nature's and culture's systematic complexity in the fullest way attainable within the narrative form.

Mimicry appears in all artistic works in some ways, with varying degrees of intent on the part of the author. In Nabokov's case, nearly all acts of mimicry can be viewed as conscious artistic decisions. ${ }^{54}$ In particular, on the level of intertextual or cultural echoes (where special intertextual words mimic "ordinary expressive" words), the mimicry can be said to pervade almost every sentence of Nabokov's prose. Another type of mimicry occurs when a text contains a first-person narrator, whose 
psychological profile it then mimics. Novels like The Eye, Despair, The Real Life of Sebastian Knight, Lolita, Pale Fire, and Ada fit this mold, because we know that the author does not in fact share the personalities and biographies of the given narrators. In The Gift and Pnin the situation is somewhat different, because the narrator is a writer not very unlike Nabokov himself (one can only mimic what one is not), so that the mimicry effect is essentially suppressed by the play of distortion and parody. This theme reaches its fullest expression in Look at the Harlequins, where the narrator is an explicit self-parody and the novel a mock-autobiography of its real-life author.

Genre mimicry is also a significant component of Nabokov's palette: Pale Fire could be said to mimic the form of the annotated scholarly edition, although such an identification is problematic because the mimicry is so radically imperfect. Strictly speaking, it is a travesty, because just the form of scholarly notes is retained, while the content only occasionally bears any resemblance to conventional annotation. John Shade's poem should properly be said to mimic an American narrative poem of the twentieth century (Frost is typically invoked), ${ }^{55}$ in that it was written not as a poem in its own right but purely as part of the novel and as the launch pad for Kinbote's wild commentary. Another Nabokov poem falls into this category: in the notorious "Vasily Shishkov" affair, in which Nabokov fooled Georgy Adamovich, leader of the anti-Nabokov "Paris" circle of writers, into praising his poem "The Poets" published under the name of V. Shishkov. Apprised of his mistake, Adamovich called Sirin "sufficiently talented to mimic genius." ${ }_{6}^{6}$ What Nabokov had really done in "The Poets" was to mimic the kind of poetry Adamovich most admired and to trick his erstwhile adversary into public praise of the bogus verse. (Ironically, one could view this prank as part of a literary "struggle for survival," as Adamovich was Nabokov's most respected and eloquent detractor in the emigration, accusing the novelist of a preponderance of "style" over serious content, among other failings).

Other novels may mimic, or seem to mimic, various types of literary models. Lolita may be seen to mimic the detective novel; it explicitly mimics a literary confession and perhaps also a Freudian case history. Ada at least purports to mimic a "family chronicle" (the moniker that forms part of its subtitle); the idea that it could in fact be a family chronicle in the traditional mould is fairly outrageous. I have suggested elsewhere that Glory mimics an apophatic tale (in which "nothing much happens") while in fact concealing hidden messages and significance that its form appears to deny. Fyodor's "Life of Chernyshevsky" in The Gift mimics a biography; and 
the posthumously published chapter 16 of Conclusive Evidence mimics a book review.

Mimicry receives a different sort of embodiment in Despair, where the narrator thinks that he and his chance acquaintance Felix are perfectly alike. Although the case is complicated by the fact that the resemblance is actually slight or nonexistent, Hermann's use of Felix to mimic his own corpse carries a distinctly utilitarian slant, in that he hopes through this ruse to collect his own life insurance and escape from his collapsing chocolate business. In contrast to Hermann's, Nabokov's own celebration of mimicry centers on the idea of the nonutilitarian copy, especially the one that far exceeds in detail and perfection the acuity of its intended dupe. In this regard, Hermann's botched "perfect murder as work of art" attempts to suggest the emptiness of mimicry and struggle enacted solely for utilitarian purposes of survival and self-enrichment.

\section{Metamorphosis}

Just as some creatures mimic not just the appearance but also the rhythms or movements of their targets, artworks can represent and also embody the pattern of specific natural lifecycles. One of the most amazing events in nature, and for Nabokov one of the most fascinating, is the metamorphosis of butterfly and moth larvae that transforms them from something utterly earthbound into something airborne, often colorful, and emblematic of the free spirit. This extraordinary change and rebirth apparently signals to Nabokov an eloquent hint of humanity's own future prospects, and we find that nearly all of his mature works are structured around a thematic or narrative metamorphosis of one sort or another. Thematically, the most obvious of these are in Invitation to a Beheading and Bend Sinister, in which characters who seem to escape a sordid reality enter into an afterlife accompanied by images of a special moth. In Invitation, the moth escapes the captors' cleaning efforts as Cincinnatus is led to his execution; in Bend Sinister, the "author" greets a moth that lands on his window screen just as Krug is granted insanity and release from his hellish world. More covertly, we see textual metamorphoses occur in such novels as The Gift, The Real Life of Sebastian Knight, Pale Fire, Lolita, Pnin, Transparent Things, and the story "The Vane Sisters"- - among others. In these works, the narrative produces doubts about itself and its point of origin (for example, the identity of the narrator) - usually at or near the end of the first reading. This happens in The Gift, when Fyodor announces that he is distorting 
his experienced world in his novel about it; in Pnin, we learn in the final chapter that Pnin's story has been composed by an unreliable source-and hence everything we have read needs to be reconsidered in light of the new information about our subjective informant. In Lolita, the date-counting anomaly has caused similar transformations in readers' approach to the novel's events and their import (reading Lolita also induces other transformations, such as well-known shifts in the reader's sympathy for and complicity with Humbert).

This type of metamorphosis reaches its zenith in Pale Fire, where the reader comes to doubt, through successive readings and meditations on the novel, first the narrator's main story (of Zembla), then his secondary story (of Kinbote), and finally the very source of the poem occasioning the commentary, as when readers begin wondering which "author" created which "character." But all of this unhinging does not indicate an arbitrary, meaningless world (at least, for Nabokov it does not): it simply gives rise to an entirely different level of contemplation, a new, perhaps confusing, but by no means senseless representation of the novel in consciousness. The metamorphosis is radical: what begins as an ostensibly straightforward text-and-commentary model becomes, with time, a reflection on how the text, preface, commentary, and index present one version of a story while hinting at an entirely different version, with details that emerge specifically from the surprising interplay of the novel's parts. At the same time, the suggested role of transcendent beings-ghosts-in both the novel's action and in its genesis calls forth yet another degree of complexity, as readers model and consider variations on the putative generation of the fictitious text. Nabokov's artistic practice in his novels includes the deployment of numerous small puzzles with specific solutions (often based on literary allusiveness), but as these are solved, they tend to generate further possibilities for interpretation of the text in hand. These broader metamorphoses, it seems, increase and multiply and are not meant to resolve into a single, permanent, and defining solution. We have already seen in chapter 1 how such representations in consciousness are themselves proposed as part of the evolutionary process. The novel's phenomenal form is no longer limited to the narrative's evident content, but expands to include the various metamorphoses it undergoes over time (as well as multiple figurations of the concept of metamorphosis itself).

It is worth considering for a moment why metamorphosis is an important element of Nabokov's artistic thought and philosophy. It is not simply a matter of a sentimental analogy between a caterpillar's transformation and human ascent to a higher spiritual state after death. Whether Nabokov 
believed that death itself necessarily leads the human soul to a higher state remains uncertain. However, as a figure, the concept and example of lepidopteral metamorphosis is extremely powerful in its implications for life's potential development, particularly in the realm of human consciousness. As he demonstrates in his lectures, Nabokov was interested in the different modes of apprehension that a literary work can traverse. In relation to nineteenth-century novels, he notes the chronological and linear track imposed by the act of a first reading: "When we read a book for the first time the very process of laboriously moving our eyes from left to right, line after line, page after page, this complicated physical work upon the book, the very process of learning in terms of space and time what the book is about, this stands between us and artistic appreciation." ${ }^{57}$ Even in texts that do not themselves challenge conventional realistic representation and chronology, Nabokov urged a mode of reading that violates not only the linear-chronological form of a book, but also the underlying causality that marks its superficial law of progression, as when he demonstrated the chronological flaw in Anna Karenina. ${ }^{58}$ In other words, his proposed practice of reading, through multiple rereadings, is intended to transform a linear, causally grounded experience into one that is nonlinear, noncausal, in which the rules of progression, pattern, and form-the active "laws of nature"-are subordinated to the live work of the experiencing consciousness. The reader's creativity is aligned, potentially, with the writer's. The "metamorphosis" is one from linearity, causality, and passivity, to multidimensionality (unpredictable freedom), consciousness, and activity. It is perhaps a charming coincidence that we think of caterpillars as linear creatures restricted to the two-dimensional world-with the inch-worm as epitome-while butterflies and moths are "free," nectar-drinking creatures of three dimensions. Although with regard to nineteenth-century works Nabokov needed to create explicit guidelines for enacting the transformation, in his own works he built the stimulus to transcend the linear text right into his narrative structures.

Nature prefigures some of the later possibilities of its evolution: thus mimicry foretells representational artistry, and the emergence of new species anticipates authentic conscious creativity. Creative engagement with a novel, and the transformative progress from linear reading to multidimensional rereading, echoes the shift within nature from the evolution of species to the evolution of consciousness and knowledge of nature. Likewise, metamorphosis within a single life form holds out the possibility that human consciousness, at some unknown point, might undergo its own extraordinary transformation. 
Transformations, however, are subject to arrest and derailment. Lolita is in large part a novel about a metamorphosis that the hero desperately wants not to happen. Humbert is rather well read in the science of puberty, but he wants to catch that moment in its first transitional stages and freeze it forever. He yearns for a timeless and changeless Lolita, an eternity of nymphetry in perpetual service of his carnal passion. This resistance to change and development, to the "fugitive" reality of life and human experience, is the strongest sign of Humbert's error. His monstrosity is not simply a misdirected sexual urge; it is a metaphysical quest to thwart time and the universality of change. Humbert struggles against all of nature. Recognizing his error and his crime, at the novel's end Humbert tells us why he has undertaken his "confession," which offers in compensation a surrogate metamorphosis into what he calls the "local palliative of articulate art." ${ }^{59}$ Humbert, mentally accepting the mature Dolly Schiller (whose pregnancy further underscores her successful metamorphosis), acknowledges the depth of his error and understands its consequences. He believes, or wants to believe, that he can take his past and transform it into an artistic embodiment of the very metamorphosis he had fought. If the novel ends on a distinctly ambivalent note, it is because there can be no suggestion that it was "worth it" (notwithstanding John Ray, Jr.'s crass assertion that had Humbert averted his tragedy, "neither would there have been this book." ${ }^{60}$ His aestheticized confession is, simply, the best Humbert can do in expiation of his tragic desire to possess and freeze in time an innocent little girl. But it can never be enough.

\section{Nature, Creativity, and Artistic Evolution}

To state that Nabokov's works embody creativity as a natural tendency or force is to broach tautology. Are not all artworks by definition "creative"? However, I want to argue that Nabokov strives for an art that is not only creative in a general sense, but is also formally, even morphologically creative and expansive. If his passion as a naturalist responds to the amazing diversity of forms and the apparent creativity driving their emergence, his works explicitly recreate that natural principle. They do not simply tell a new story, or tell an old one in a new way or from a new perspective. Nabokov regularly attempts to produce entirely new kinds of literary form, and he does so on a variety of levels, ranging from narrative structure to intertextual density. This commitment to innovation suggests an effort to create art that realizes the highest available potentials of nature- 
in-consciousness. It is an art that strives to produce, as it were, new species of artistic creation. However, this creativity is not unconstrained: unlike his predecessors in the Futurist movement, Nabokov did not want to toss Pushkin from the "ship of modernity" and destroy or discard the literary tradition. ${ }^{61}$ His creative principle is analogous to evolution in nature (but not, of course, Darwinian evolution), and thus it makes use of all that comes before and builds upon it in architectonically valid ways, as implied by Kant's definition of genius. ${ }^{62}$ Artistic mutations emerge from existing forms, within certain limits of variation, limits that are necessary in order for them to continue to stand as "art" within the culture at large. ${ }^{63}$

If we think about how Nabokov's works relate to one another from the standpoint of evolutionary development, we witness a general trend toward greater complexity. Also significant is Nabokov's frequent practice of linking the various novels through migrating characters, thereby foregrounding, almost exaggerating the organic connections between them. From within each work, it is not particularly important that its characters also exist in a different text, but from a broad perspective on Nabokov's creative output, it encourages us to confront the entire corpus as a single interconnected whole.

In the earlier works, it is not always easy to see the evolutionary principle in action. There is not an obvious development in the transition between Mary and King, Queen, Knave, or between the latter and The Defense. Upon closer inspection, however, we can identify at least one crucial step that each subsequent novel takes beyond its predecessor. King, Queen, Knave, for example, differs from Mary in its focus on German characters, rather than Russians or émigrés. (This could be viewed as a predicted organic move inasmuch as Ganin abandons his Russian pastembodied by Mary—on the station platform, and boards a train for other parts, leaving behind the Berlin émigré community). The Defense departs from the previous two novels in its incorporation of a main character with an anomalous-some would say deranged-psychology, and also in its explicit play with the concept of a life's pattern. (The Defense also introduces Nabokov's first major temporal discontinuity, in the chapter 3 elision between Luzhin's childhood and his adult years.) $)^{64}$

In each novel, several of the devices from previous novels are present; they do not simply accumulate and expand, but rather occur in various combinations-with always some new narrative structure or device generating the novel's core artistic energy. Thus, the anticipatory comments first introduced in The Defense become a regular feature in Glory and The Gift. This phenomenon may help explain some of the superficial similar- 
ity among Nabokov's novels, as was noted in an interview with Herbert Gold when Nabokov replied that "artistic originality has only its own self to copy." 65 The point is not that Nabokov's art is repetitious because he repeatedly mined the same old veins, but rather that those plot elements where he was repetitious were not the focus of his innovation, but were rather signs of the organic relatedness, the base from which the various mutations evolved. This biological analogy for novelistic innovation makes sense, because when a new species emerges, it will be more similar than dissimilar to its "parent" species. ${ }^{66}$ Or, to return to Nabokov's scientific work, a collection of subspecies will have a "synthetic character" expressed in the patterns of presence and absence of specific features.

These formal modifications occur in tandem with thematic novelties. As we have seen especially in the case of Lolita's heroine, these new formations often have a hidden history within earlier works. We can trace thematic genealogies within Nabokov's oeuvre and discover where new compositional elements arise, and in what ways they have emerged from earlier forms. ${ }^{67}$ Thus it appears that Nabokov approached his artistic creativity as, itself, a kind of changing, transforming agent of emerging consciousness. One can look at his output as a single organism gradually revealing its ontogeny, or, from a different perspective, as a series of related organisms expressive of nature's creative impulse. ${ }^{68}$

We see Nabokov's playful engagement with an analogue of such change in John Shade's favored game, "Word Golf," in which the player starts with a given word and attempts, changing only one letter at a time, to produce a series of real words leading to a prespecified goal. Thus: "lass to male in four moves," or "live to dead in six moves"; "hate to love in four." Nabokov worked out several of these on his note cards as he was writing Pale Fire. ${ }^{69}$ The similarity between this model and natural evolution is striking when viewed graphically. For example, lass to male: lassbass-base-bale-male. The particular examples Kinbote has chosen are both extreme and paradoxical, but the point is not the logical or biological propriety of the chosen sequence. It is rather the principle of innovation through gradual, constrained change, along with the creativity of discovering amusing sequences. From an evolutionary point of view, each newfound transformation is new as a whole, as is the game itself. The principle of evolution in consciousness is revealed in the conscious production of a novel game modeling evolution. The "purpose" is not the target word (it is not the "telos"), but rather the delight occasioned by amusing new discoveries (thus, perhaps, disarming the suggestion that Nabokov's view of evolution is design-oriented or teleological, as the start-finish structure of 
the puzzles might suggest: here, the game's directionality serves the aim of aesthetic pleasure).

A telling passage from The Gift brings together letter-based or anagrammatic play with the themes of evolution and metamorphosis. In his letter to his mother near the novel's end, Fyodor describes the strange mutations a word can undergo in consciousness during focused scrutiny: "You know, like taking a simple word, say 'ceiling' and seeing it as sealing or sea-ling until it becomes completely strange and feral, something like 'iceling' or 'inglice." 70 The possibility for ordinary words like "ceiling” to veer away from established, orderly language to become untamed and wild represents a precipitous step beyond the evolutionary adjustments of Kinbote's word golf. This final, irrational step-like the one into a rainbow?-communicates a metamorphosis into a new phase of lexical being: not merely logical and legal anagrams, but suggestive neologisms that might expand human consciousness and expressivity. Fyodor immediately observes, "I think that some day that will happen with the whole of life."

Clearly, such fancies represent transformations that are derived from, but are not strictly of a kind with, those that occur in nature-either between species (as evolution) or within them (as metamorphosis). A butterfly does not look like a caterpillar, but it is after all a development of the exact same creature. Nevertheless, if nature can prefigure its future forms - in the "dab of gilt" on a butterfly's wing or in a "death's head" on a moth - then the metamorphosis from larva to imago might someday find a fantastic elaboration in "the whole of life," as Fyodor puts it. ${ }^{71}$ A speculative point, to be sure, but one that clings to the open and unknowable possibilities of the future. In their evocation and recapitulation of natural forms, Nabokov's works gesture toward the "unlimited possibilities" 72 of human and natural creativity. Consciousness itself is one of the primary sites for such potential fantastic leaps; accordingly, Nabokov's novels embody many striking transformations of human mental life. In the next chapter we will explore Nabokov's engagements with the potentials and realities of nature's most complex and inscrutable product: mind. 


\section{Anti-Psychological}

All novelists of any worth are psychological novelists.

[...]

Every original novel is "anti-."

_Interview with Alfred Appel, 1970'

Berlin's first psychoanalytic clinic has opened in a former sanitarium in Tegel. ${ }^{2}$

—“Chronicle," Rul', April 12, 1927

NABOKOV BELIEVED in evolution, and he also believed in the mystery of mind. In one of his lectures, he wrote: "Let us not confuse the physical eye, that monstrous masterpiece of evolution, with the mind, an even more monstrous achievement": whose achievement, exactly, is left unsaid. ${ }^{3}$ In Bend Sinister the philosopher-protagonist describes his son: "a fusion of two mysteries, or rather two sets of a trillion of mysteries each; [ . . ] thus formed and then permitted to accumulate trillions of its own mysteries; the whole suffused with consciousness which is the only real thing in the world and the greatest mystery of all." 4 Such statements put the goal of understanding mind in the far, far distant future, if not beyond human abilities altogether. Nevertheless, the science of psychology existed, ambitiously, throughout Nabokov's career.

Since the early twentieth century, psychology has been the most disunited of scientific enterprises. Competing schools have successively attempted to redefine the nature of psychological study in an effort to create a science as stable and objectively valid as physics, biology, and chemistry. From Nabokov's perspective as a young man, the most visible branches of the growing discipline were Freudian psychoanalysis, behaviorism, and to a much lesser extent functionalism and Gestalt psychology. The first 
two of these branches seem diametrically opposed, since psychoanalysis explored the world of the unconscious through the code of dreams and neuroses, whereas behaviorism attended only to outwardly measurable actions, objectively observed during a formal experiment, without any recognition of mind or consciousness at all. But they both shared in common the presupposition that the object of study (mind or behavior) could be translated into a finite logical system that would explain the phenomena in causal terms.

Gestalt psychology and functionalism were less concerned with determining mechanistic laws of mind or behavior. Nabokov may have known something about Gestalt psychology, which was prominent in Berlin before 1933 and in the United States when he arrived there. He is less likely to have had direct contact with functionalism, which grew from William James's eclectic evolutionary approach to mental life. In both of these schools, the scientist's aim was to understand a system holistically, as something that is greater than the sum of its parts. Gestalt psychology, in particular, explored "higher-order units of thought perception," irreducible to lower-level components. ${ }^{5}$ This desire to see conscious behavior as a series of emergent wholes, and not strictly as a mechanism, may have failed to generate great quantities of statistically verifiable data, or clear answers to questions about causality. ${ }^{6}$ But we can easily see how, in its methodological dispositions, it offers a congenial fellow-traveler for Nabokov's anti-Freudian, anti-behaviorist convictions. Thus, when in the coming pages I refer to his psychological approach as holistic and nonreductive, I am highlighting parallels with specific schools that existed within psychological science during Nabokov's creative life. Far from being forgotten or rejected false trails in psychology, both Gestalt psychology and functionalism have been partially incorporated into the discipline's modern form. ${ }^{7}$

Freudianism, in its popularized form, became a special target of Nabokov's constant mockery. This sparring has garnered nearly all of the attention of critics exploring Nabokov's responses to academic psychology during his career. However, he also demonstrates an unmistakable animus towards experimental behaviorism, especially in the first three novels written in the United States (Bend Sinister, Lolita, and Pnin). When Nabokov creates his characters' lives as complex and psychologically unpredictable, he is advocating a particular epistemology of mind. The tenor of his character portrayals also urges that empirical psychology be held in constant proximity to philosophical reflections upon the nature of mind. In this regard, Nabokov resisted the schism between the two disciplines that accompanied the rise of experimental psychology. 
Unlike the other sciences discussed in this book, the very essence of psychology has remained controversial since its inception. Various of its "schools" have been, not infrequently, the butt of humor (including Nabokov's own humor at Freud's expense). Beginning over a century ago, and continuing even in recent years, there has been debate over whether psychology can even be called a science. William James called it "only the hope" for a science in 1892; a century later, former academic Stephen B. Wilcox claimed that institutional psychology was merely "a giant welfare program for psychologists." ${ }^{8}$ More recently Raymond Tallis wrote that "we are not yet able to explain human consciousness," and The Economist proclaimed that "consciousness awaits its Einstein." 9 The object of study has changed over the years, traversing sensations and perceptions, introspections concerning mental phenomena and mental states, observable behavior, and organism-environment systems-to give only a very condensed list. ${ }^{10}$ Nabokov's relationship to this inchoate science was distanced, filtered through his own readings and philosophical commitments. While a few of his attitudes about psychology leap off the page, his core psychological convictions remain essentially latent. Generous attention has been paid to his disdain for Freud, and Nabokov's antithetical views respecting the falsity of generalizations and the freedom of the individual from any mechanistic or mythical laws of personality have been thoroughly illustrated. However, to paint Nabokov's psychological interests as a Freud/Not-Freud polarity is to neglect the varied scientific context that forms the background of his art. Nabokov in fact becomes much more interesting when we recognize how his psychological portrayals of characters' actions reflect some of the twentieth century's major scientific and philosophical conceptions of mind.

As Nabokov entered adulthood, psychology as a scientific discipline was undergoing tremendous change. This transformation was occasioned in part by the rise of Freudian psychoanalysis, in part by a shift among non-Freudians away from introspectionist accounts of mind and toward behavioral and causal explanations of psychological regularities. The need for a "scientific," experimental psychological practice was felt especially by those who saw psychoanalysis as a near-mystical threat to the science of mental phenomena. ${ }^{11}$ There was pressure in some quarters to extinguish from psychology consideration of such things as consciousness and mind, focusing instead exclusively on behaviors and responses that could be measured quantitatively. The new approaches considered the human mind as a mechanism-Freudians, a mechanism of mental objects; the behaviorists, a mechanism of physical nerve pathways, sensations, and reactions. Fading 
out of the mainstream was the introspectionist psychology practiced by Edward Titchener and others with its inherent acceptance of mind as an investigable scientific entity. The behaviorists, led by John B. Watson and developing lines of inquiry opened up by Russian physiologist Ivan Pavlov, worked to establish the laws governing human behavior's physiological roots in its environment, often by means of comparative studies in animals. Those who continued to study mind and consciousness, for the most part followers of and defectors from Freudianism (in the 1910s and 1920s), were also attempting to analyze the mind's functioning into component parts and causal systems (such as Freud's ego, super-ego, and id). But the problem with a science of the contents of mind was that no matter what form it took, it could not be tested scientifically: there was no way to provide objective access to information that could only be retrieved or produced by an individual's introspective narration. ${ }^{12}$ Thus, on the one hand, we have scientific denial or willful ignorance of mind; on the other, a scientifically untenable (and for Nabokov, personally objectionable) explication of mental life. One of Nabokov's goals in his works is to present varieties of psychological phenomena in consciousness that allow readers to ponder the existence of various sorts of mind. Human mind and consciousness, after all, feature in "Father's Butterflies" as the current pinnacle of evolution, the "greatest mystery of all," and as such the most exciting area of scientific research-even if we do not necessarily possess all the tools necessary to understand the object of study. By extension, creativity and art, as products of mind, are psychological phenomena-a fact not lost upon Freud, of course, and well illustrated in some of Nabokov's readings.

Nabokov used his art to advocate the continued importance of introspectionist psychology, by placing at the forefront of his concerns the irreducible mystery of human consciousness. His characters become a gallery of individuals_- "finite individual selves"-whose actions can be partly, but never fully, explained by possible or likely causal sequences. In creating this gallery, Nabokov expanded his effort to emphasize the reality of qualitative phenomena that resist explication in quantitative terms, but which nevertheless can be collected and described in some detail. In this chapter, after exploring the background of Nabokov's psychological commitments, I embark upon a discussion of how Nabokov's view of human psychology becomes manifest in a variety of his characters, in tension with the competing Freudian or quantitative fashions.

Nabokov's works are primarily devoted to exploring how individual minds perceive, interact with, shape and are shaped by the worlds around them. His human subjects range from the super-intelligent to the average 
(or worse), from the highly creative to the purely destructive. Nabokov presents to us vividly imagined, complex individuals who, usually in their own first-person narratives, demonstrate the intricacies of how mind and world interact. Before we embark on an examination of how Nabokov's works embody his psychological interests, we need to establish what, to him, was the proper object of psychological study. ${ }^{13}$

\section{Psychology versus Psychoanalysis}

In choosing his approach to individual characters as psychological specimens, Nabokov had to decide what he intended by the concepts "consciousness," "mind," "self," “individual." Philosophy had struggled with the status of these notions since at least Descartes' time. In the nineteenth century, empirical psychology began the attempt to put the discussion on solid ground. Some researchers chose to deny the reality of metaphysical entities like "soul" or "spirit" standing at the core of personality, offering instead theories of mind grounded in the mechanical development of the nervous system as part of the evolutionary process. These explanations, with their often materialist presuppositions, tended more and more to view consciousness and personality as accidents of animals', and finally primates', interactions with their environment and each other. ${ }^{14}$ Most renowned among those who preserved a place for a "soul," despite his Darwinian slant in Principles of Psychology, was William James. James also drew attention to the metaphysical assumptions underlying materialist accounts, pointing out that idealist theories accepting existence of the individual "soul" were in no way logically inferior to mechanistic discourse, even though they could not be accommodated within the scientific method. ${ }^{15}$ Another influential component of Nabokov's heritage was the pre-twentieth-century tradition of considering psychology together with philosophy, as exemplified in the prominent Moscow Psychological Society-a group which was, in the main, devoted to idealist philosophy (and several of whose members were close to Nabokov's father). ${ }^{16}$ Nabokov's affinities with this group were reinforced later by his friendship with Iulii Aikhenvald, who had been the society's research secretary from 1895 to about 1902 .

Judging from all of his artistic output and other comments on the matter, it is quite clear that Nabokov was inclined to accept the existence of a mysterious, inaccessible, individual self, which might be called a "soul," and which might or might not imply immortality and survival apart from 
the body. There is no evidence that he credited the possibility that conscious selves are illusory side effects of brain activity. The self thus becomes the first principle of all his compositions. As a result, the concept of the autonomous individual consciousness plays a crucial role in Nabokov's explorations of psychology_of human behavior and its possible explanations-and of "Psychology"- the formalized study of human behavior that took shape during Nabokov's lifetime.

\section{Dismissing Freud}

With a cautious wink toward Freudian psychoanalysis, we could say that Nabokov's characters serve as "case histories." Throughout his career Nabokov famously locked horns with Freud and his legacy. The reasons for this antipathy have been in dispute: some say it was because Nabokov feared that Freudian interpretation would reveal his deepest personal secrets and he must therefore disarm it in advance; some that he despised and mocked the reductive sexual implications of Freudian psychoanalysis. ${ }^{17}$ Still others have proposed that he saw in Freudianism a dominant cultural opponent with which he had to contend if his own, contrary views about personality and mind were to gain any attention in their own right. ${ }^{18}$ What is certain is that the Freudian movement was entering its heyday around the world when Nabokov entered Cambridge University in October of $1919 . .^{19}$

Freud's sexuality-based theory might never have achieved such dominance had it not appeared at the end of the Victorian era, with its repressive attitude toward the human body and especially toward sex. ${ }^{20}$ No doubt, Freud's success was in part also engendered by his own narrative skill and energy; by the quantity of his output and the strange familiarity of his cases; and by the public's attraction to the theory's clear and simple, story-like yet positivistic explanations of human nature. The method's practical applications and apparent clinical successes produced a cultural maelstrom that by 1920 had generated discussion groups, psychoanalytic societies, and spin-off publications-in short, an industry. For much of the twentieth century, "psychology" was synonymous with "Freudianism" in the popular imagination. And it was largely against this popular behemoth that Nabokov directed his polemic and parodic wit. ${ }^{21}$

Nabokov evidently knew Freud's work when he attended a talk by one "Mlle. Ioffe" at the Tatarinova-Aikhenvald circle in 1926, referring to the

topic ironically as a "most pleasant theme" beforehand, and afterwards 
calling Freud a "witchdoctor" (znakhar'). ${ }^{22}$ By 1931 his anti-Freudian animus was fully charged, producing that year the essay "What Should Everyone Know?," a mock-promotional text hawking "Freudianism for All," a tonic to assuage all maladies. ${ }^{23}$ The same year saw the beginnings of Despair, Nabokov's first virulently anti-Freudian fictional work. It is surprising that he turned down a request from Gleb Struve in 1931 to write something on Freud for the newspaper Rossiia $i$ slavianstvo, presumably in connection with the theorist's seventy-fifth birthday celebrations, but Nabokov suggested that he was weary of the topic for the moment. ${ }^{24}$

Notwithstanding such fatigue, the Freudian theme became a leitmotif in Nabokov's oeuvre, as well as a permanent fixture in the forewords to his translated Russian and reissued English works. However, this recurrence does not by itself embody a psychological aspect of Nabokov's art-although Jenefer Shute has argued that it tells us about Nabokov's anxiety regarding Freud's cultural dominance. ${ }^{25}$ Rather, the Freudian battle has to do with the theory of mental symbolism and how artistic creations relate to their authors' childhoods. The anti-Freudian polemic represents an ideological argument opposing the reducibility of all human behaviors and pathologies to sexual causes-or to causality in general. ${ }^{26}$ It lays the groundwork for the development of a different kind of psychological exploration than Freud's, one that holds that the human mind is too complex, mysterious, and surprising to be defined by a single underlying cause, such as childhood trauma, sexuality, or the urge to reproduce.

Given that psychoanalysis, like literature and unlike experimental psychology, focuses on individuals and their stories, and recognizing how quickly its methods were applied to literature even by Freud himself, it is quite natural that a literary writer would be competing with Freud, for in important respects they shared and competed for the domain of human narrative. ${ }^{27}$ The key distinction between them, for Nabokov, is expressed by Ardalion in Despair, when he says "what the artist perceives is primarily the difference between things. It is the vulgar who note their resemblance," 28 a direct jab at a theory that quickly attempted to generalize from individual cases to universal laws. Nabokov's view of human psychology was based on the belief that unique individual traits are more important than commonalities or developmental laws, and that even in the case of abnormal behavior, generalized answers will not suffice. His crusade against Freudianism enacted a twofold strategy: open mockery of the theory's sexual reductivism, and the generation of a series of counterexamples, human beings of various types-some normal, some not-whose personalities cannot be adequately explained by means of psychoanalytic 
paradigms. A covert side strategy was to draw continual attention to the fact that it is impossible for one person to know all the phenomena taking place in another's mind (even with the aid of a confession), implying that without this knowledge, conclusions about universalities and psychological causality are premature. This inaccessibility of others' inner life was an important artistic challenge for Nabokov, one that he found treated carefully in William James's Principles of Psychology. ${ }^{29}$

James's encyclopedic work gave Nabokov vigorous preparation for his future battles. It surveys in impressive detail all the then-known elements of mental life, including its many aberrations. ${ }^{30}$ What must have struck Nabokov with particular force was James's ability to describe the systems of cognition and behavior from a point of view that simultaneously respected Darwinism and its implications for the evolution of human behavior and also preserved belief in mind's essentially secret nature. ${ }^{31} \mathrm{He}$ surely was fascinated by James's emphasis on the stream of thought within consciousness as the primary data of personality (and he proudly credited Tolstoy with inventing "stream of consciousness" narration in Anna Karenina a decade or so before William James coined the term). ${ }^{32}$ At the same time, by regularly demonstrating the necessary limits of empirical knowledge about the human mind and its behaviors, James provides strong support for anyone unwilling to ascribe a provable, mechanistic nature to mental life. ${ }^{33}$

Such a background, combined with likely exposure to Moscow Psychological Society writings on the philosophy of mind and self, made Nabokov well-equipped to think carefully about consciousness and its mysteries. ${ }^{34}$ And his study did not end there. The few glimpses we have of his psychological readings indicate that he read broadly and eagerly in this field, which was so close to his own artistic practice. Various sources confirm that he read Freud, Havelock Ellis, Cesare Lombroso, Élie Metchnikoff, and Grigorii Aleksandrovskii; he is very likely as well to have read Herbert Spencer, Remy de Gourmont, Théodule Ribot, Hyppolite Taine, Otto Weininger, and Veniamin Tarnowski, whose books were widely known and also held in his father's ample library. ${ }^{35} \mathrm{He}$ also had probably read at least some works of Karl Jung and Otto Rank by the late 1930s, most likely earlier (he mentions Jung explicitly only in Pnin, while Jungian traces have been found in Despair). ${ }^{36}$ To this list we can add a series of books and research papers listed in notes made during the creation of Lolita, Pnin, and Pale Fire. Considering that our documentary glimpse of what Nabokov read or had available to him amounts to merely a few 
snapshots, it is fair to conclude that he also read significantly beyond the mentioned titles. ${ }^{37}$

\section{Nabokov's Psychology: Subjects and Objects}

While Nabokov was conversant with the main directions in modern psychology, his works focus on the internal phenomena of consciousness, on the nature of the stream of thought and its relation to memory. This emphasis makes sense, given Nabokov's humanistic commitment to the individual, the self, as fundamental principle and axiological center. In practice it means that Nabokov's main artistic impulse in his works is to create fully developed individuals whose psychology appears plausible and self-consistent, if not always perfectly coherent or obedient to discernable causal laws. Although there are many peripheral characters in his novels who are psychologists or psychiatrists, only one of his narrators, Van Veen in $A d a$, takes on this profession (and the reason he does so is apparently driven by his interest in paranormal Terra-related phenomena, evoking William James's interest in what is now called parapsychology. ${ }^{38}$ The hypotheses of other psychologists in his works are suffused with irony, usually by association with caricatures of Freudian or behaviorist theories (such as Luzhin's doctor in The Defense [1929, Nabokov's third novel], the inhuman behaviorist experimenters in Bend Sinister [1947], and Eric and Liza Wind in Pnin [1957]). ${ }^{39}$

Breaking down the psychological plane of Nabokov's work into scientists and those they study, we find that the first group presents several variations on the theme of the crank or charlatan, while the second group offers a much larger and more diverse collection of types. This imbalance reflects Nabokov's partiality to the variety and inaccessibility of individual selves, and his disdain for the efforts of psychoanalysis to "explain" consciousness and the essence of self or mind, and of behaviorism to reduce human mental life to a collection of external manifestations. Given this evident bias, it might be argued that Nabokov was in fact opposed to psychology as a science, in that he rejected his era's dominant approaches to the study of human nature, personalities, and pathologies. But it would be more accurate to say that his approach to mind was roughly aligned with other schools-especially Gestalt and functionalist psychology-that were less visible to the public than psychoanalysis and behaviorism, but whose effects upon the science's development were no less authentic or enduring. 
Nabokov's psychologists, with the exception of Van Veen, display varying degrees of Freudian influence, and this fact betrays Nabokov's concern that Freudianism was overwhelming the study of human mind. Beginning with Luzhin's doctor, psychoanalytic buzz words are the hallmark of this role. This psychiatrist is presented to us as an unalloyed Freudian whose method for achieving Luzhin's recovery is to get him to experience a "rebirth," a gradual re-entry into life, from which all the disturbing elements that led him to obsessive chess playing are deleted. While apparently successful at first, the treatment is also implicated in the chess master's last mental breakdown. At least that Freudian thought he was doing good; his patient's well-being was his aim. In Bend Sinister, Nabokov creates an explicitly harmful blend of Freudian and behaviorist psychology in an incompetent team of experimenters for the totalitarian Ekwilist regime. The logic of scientific research meets the institutional rejection of the individual's moral value (a rejection that was realized in Soviet practice). Their experiments involve studying the ameliorating effects of child-torture and murder on the subsequent behavior of the violent criminal.

A more sophisticated but no less parodic incarnation of a modern psychologist appears in John Ray, Jr., author of the fictitious "Foreword" to "Lolita, or, The Confession of a White Widowed Male." Ray has written a prize-winning book called "Do the Senses Make Sense?"- a title raising curious questions about the relation between the world perceived through the senses and the "sense" within the consciousness that may or may not be "made" by them. Ray's moral relativism parading as philosophical sophistication appears in his assertion that "'offensive' is frequently but a synonym for 'unusual'; and a great work of art is of course always original, and thus by its very nature should come as a more or less shocking surprise" - a view which in some Nabokovian contexts would be laudable, but here reeks of "poshlust" (vulgarity). Our suspicions of his ethics are meant to be deepened by his platitudinous praise of the confession's moral dimensions: "they warn us of dangerous trends; they point out potent evils. 'Lolita' should make all of us [... ] apply ourselves with still greater vigilance and vision to the task of bringing up a better generation in a safer world." 40 If this is the best response psychology can give to Humbert's narrative, Nabokov suggests, then the discipline has reached a blind alley. ${ }^{41}$ Lolita also includes several parodies of behaviorist experiments, including one in which participants are paid to spend a whole year walking on hands and knees, consuming only bananas.

The series of mock(ed) Freudians continues with Eric Wind, in Pnin, who represents a jumble of Freudian and post-Freudian psychoanalytic 
trends. He and his wife, Liza (also Pnin's ex-wife), attempt to raise their son Victor guided by these theories, doing "their best to impersonate Laius and Jocasta" (that is, Oedipus' parents). ${ }^{42}$ Wind propounds that "pregnancy [is] really the sublimation of a death wish." ${ }^{43}$ Lastly, although Ada does include some lightly veiled mockery of Freud ("Dr. Froid of SignyMondieu-Mondieu”) Van Veen stands apart from other Nabokovian characters due to his primary focus on mental aberrations associated with paranormal phenomena and the mysterious Terra. "As Van Veen himself was to find out, at the time of his passionate research in terrology (then a branch of psychiatry) even the deepest thinkers, the purest philosophers, Paar of Chose and Zapater of Aardvark, were emotionally divided in their attitude toward the possibility that there existed 'a distortive glass of our distorted glebe." 'Van's clinical experience led him to compose his novel, "Letters from Terra," derived in part "from his own reports on the "transcendental delirium' of his patients." ${ }^{44}$ Echoing William James and his era, Van is as much philosopher as psychologist, composing the erudite, playful, and challenging essay "The Texture of Time" that becomes the novel's Part Four. However, there is no indication that Van as psychologist really understands any of his patients (despite having "a passion for the insane as some have for arachnids or orchids"). ${ }^{45}$ Notwithstanding his extreme intelligence, he is equally insensitive to the psychological needs of his halfsister Lucette. But this lack of insight is more a function of individuality's secrets than of his incompetence.

\section{"Trillions of Mysteries"}

Nabokov's works present individuals whose minds are to be explored as if from the inside, through a vicarious introspection, not analyzed from without or associated with predefined causal mechanisms, mapped out in convenient dream sequences. There is nothing surprising in this emphasis: after all, as Nabokov insisted, psychology is often the main content of literary art. Nabokov wrote to Gleb Struve that the many writers who eagerly made plots based on Freudian themes were not producing literature. ${ }^{46}$ Considering carefully what kind of psychology Nabokov practiced in his works, we find that he explored the human mind not by searching for its unknown motivations and sources, but by presenting a mental portrait as complete as possible, no matter how contradictory in nature. $\mathrm{He}$ was inclined to study how the active mind chooses to act-that is, how it engages purposively with the world around it. Not all actions can be 
explained causally, either through self-interest (as Chernyshevsky and the radicals would have it) or through Freudianesque chains linking childhood traumas to adult psychoses.

Nabokov's novels and stories do not seek out causes to explain why a character behaves one way or another. In this respect, he is an essentialist who, as noted above, believes in the utility of the autonomous self as a working hypothesis, if not as a certain reality. This belief may bring accusations of mysticism, as it did to William James: characters act a certain way not because of laws of personality or revealed psychological development, but for reasons that are essentially hidden. ${ }^{47}$ This obscurantist perspective suggests that we cannot know why people (including criminals) behave as they do.

Sometimes, Nabokov's characters seem to offer hints of a causal mechanism behind their actions. If we think of Axel Rex in Laughter in the Dark, of Franz and Marta in King, Queen, Knave, of Hermann in Despair, and to some extent of Humbert in Lolita, there is a common strand that makes up the background for the criminal act or its attempt that readers may consider to be an underlying cause. Nabokov himself said that criminals lack imagination-specifically, the inability to imagine a life behind bars. ${ }^{48}$ Maybe so. Even more significantly, they lack respect for the dignity and autonomy of others in general (they may also lack the ability to love, within Nabokov's world). But this lack too must have its origins; and these are nowhere to be found among causal chains in Nabokov's works. We do not know why Hermann in Despair is so narcissistic; we do not know why Humbert is for so long blind to his own destructive acts; we do not know why Franz and Marta in King, Queen, Knave come to believe that Dreyer's life is expendable. In Despair and in Lolita, there are tempting hints at Freudian causal explanations. But these hints do not bear out: in both cases, Hermann or Humbert could have acted much differently if there had been a desire to do so. There was not. Why they desired specifically to act as they did is a matter of personality, perhaps of perversion. (Nabokov did believe that a mind could follow a perverse path, although it is not clear that he felt all such paths led to harmful, criminal, or murderous acts). His dissent from causality as a universal system meant he could argue that, perhaps, such paths are chosen by the individual for unknowable reasons. It is not a very scientific perspective, but it does bring attention to the possible limits of scientific psychology. "We shall never know ... the nature of thought." ${ }^{49}$ He was in good company: even James, the father of modern psychology, preserved space for the mysterious and unknowable elements of the individual's self-things that were not accessible to the scientific method. 


\section{Serial Selves}

One of the best ways to get inside the mind of a character is through a first-person narration, and Nabokov adopted this method surprisingly late in his novel-writing career: in The Eye (Sogliadatai, 1930), his fifth novel. Smurov, the main character, is also Nabokov's first unreliable narrator characterized by dubious mental stability. Not surprisingly, the short novel contains many psychologically suggestive themes. The most immediate anomaly to present itself is actually concealed during most of a first reading of the text: the narrator, who apparently shoots himself after a thrashing he receives from his lover's jealous husband, goes on narrating "from the beyond." It is from this otherworldly perspective that he takes up his role as an "inner spy" of the events surrounding his former existence. It eventually becomes clear that he is not dead, but is in fact experiencing a kind of dissociation, viewing himself and his interactions with others as if from the outside, making his "self" the focus of an objective, rather than subjective, analysis.

The origin of Smurov's malady or mental state can be linked in part to the psychological concept of dissociation, which appears as well in a Freudian-sexual context in Despair. Nabokov likely derived this concept from reports of injured war veterans who believed that they had died, and looked upon their bodies as something dead and completely separate from their surviving psyche. ${ }^{50}$ This connection is all the more likely in light of Smurov's claims of military derring-do in the Russian Civil War (191821), compounded by the violence precipitating his suicide attempt. ${ }^{51}$ As we learn from Olga Skonechnaia's commentary to the short novel, it includes many references to sexual and cultural realia from Silver Age literature (ca. 1890-1916). ${ }^{52}$ Smurov's somewhat ambiguous sexuality, and also his name, alludes to the protagonist of Mikhail Kuzmin's 1907 novel Wings, which contained openly homosexual themes (homosexuality had ideological and even mystical significance in symbolist and decadent intellectual circles). His "afterlife" experience leads him to believe that everything around him is "only my imagination, only a mirror," 53 including his love interest Vanya (a sexually ambiguous but generally masculine name), the young woman who is also another man's fiancée. On the one hand, other people and the world do not exist, except as part of his otherworldly solipsism; on the other-he himself does not exist, except as reflected in the minds of others ("You see, I do not exist—all that exists are thousands of mirrors, each reflecting me"). ${ }^{54}$ In the end, of course, Smurov's psychological aberration amounts to existential angst, driven by his failure to integrate his "inner" self with its "outer" perception by others. ${ }^{55}$ Yet it 
also seems that his dissociative state is to a certain extent willful. If this is so, then the tale presents a counterexample to the influence of repressed or subconscious mental phenomena. If Smurov's strange experience is essentially a creative act, it suggests other sources besides the unconscious for altered or anomalous mental states. However, Smurov's case is not pushed very far; Nabokov appears to have been engaged in exploring the narrative potential of self-conscious solipsism and the relative realities of mind and world, rather than in examining insanity. As for minds truly at odds with their environment - these Nabokov had already begun to study from a third-person perspective in the shady area between extreme intellectual gifts and troubling mental deviations.

\section{Genius or Insanity?}

Nabokov confronted the basic problem of genius and its possible proximity to insanity in the work of Cesare Lombroso, which he placed on his Crimean reading list in $1919 .{ }^{56}$ As an artist who felt the distance between himself and the world around him, Nabokov was certainly ready to explore the psychology of genius, and also to turn a critical eye to its reception in a typical human environment. The linking of genius to mental disorders conformed to a growing quest among psychologists for demonstrable, empirical components of consciousness. If the primary mode of modern psychology was to establish causal processes that would explain various human behaviors and personality traits, perhaps including genius, then Nabokov's direct engagement of that mode entailed an effort to discredit the alleged causal chains. ${ }^{57}$ In part such a project relates to his neoidealist affinities and a corresponding commitment to the autonomy of the individual, which presumed the existence and autonomy of an inherently mysterious willing self. We see this effort most distinctly in The Defense, Despair, Lolita, Pale Fire, and Ada, but it also forms a subtle undercurrent in Glory, The Real Life of Sebastian Knight, Pnin, and Transparent Things. It even causes a few ripples in The Gift and elsewhere. When we speak of causes, we imply effects, which in this case are the acts of individuals. Why characters do what they do-why they murder, rape, commit suicide, or write books-is a question that psychology might hope to answer, assuming that behaviors and the mind can be found to obey laws of cause and effect. But throughout his career, Nabokov crafted examples of why the explanatory urge is doomed to fail when it comes to the secrets of the individual mind. 
The beginnings of this search for noncausal aspects of mind appear in The Defense (1929). The novel is designed, from one perspective, as an explicit argument against the idea that anything in Luzhin's childhood has brought about his adult "misfortunes"-beginning with his obsessive chess-playing, and ending with his developing paranoia and flight from life.

Luzhin's mental life comes to us in phases, with special attention to his pre-chess youth, his transitional period, and his adult state, when little exists for him outside the world of chess forces. The child who was a frightening enigma to his parents first notices only, among the details of his transition from home lessons to secondary school, that there he will be called "Luzhin" rather than "Vanya." Only some days later, during the return journey to the city, does he recognize that so many beloved features of his regular existence would be canceled by this change. When he runs away, he "played for a while with a beetle nervously moving its feelers, and then had quite a time crushing it beneath a stone as he tried to repeat the initial, juicy scrunch." His adjustment to school is unsuccessful, in part because of other students' response to his singular nature. During recess, he always escaped to an unobtrusive wood pile in order to evade torment: "He had chosen this spot on the very first day, on that dark day when he had discovered such hatred and derisive curiosity around him that his eyes had automatically filled with a burning mist, and everything he looked at-out of the accursed necessity of looking at something-was subject to intricate, optical metamorphoses. The page with criss-cross lines grew blurry [ ... ] and his desk neighbor, an insidious brute with down on his cheeks, would say with quiet satisfaction: 'Now he's going to cry.' But Luzhin never once cried." Meanwhile, little Luzhin developed a deep love for the stories of Conan Doyle, in the form of two books given him by his aunt, and "only much later did he clarify in his own mind what it was that thrilled him so about these two books: it was the exact and relentlessly unfolding pattern." This affection transfers onto the practice of magic, and he also daydreams about abstract mathematics, "and he lingered long in those heavens where earthly lines go out of their minds." 58

Nabokov takes some pains to convey the workings of little Luzhin's observational and imaginative life during his early immersion into chess, as in this passage describing his response to the ephemera of an idle day out of doors, a day without access to an opponent or new chess ideas:

That day Luzhin junior was in low spirits. All the games in the old magazine had been studied, all the problems solved, and he was forced to play 
with himself, but this ended inevitably in an exchange of all the pieces and a dull draw. And it was unbearably hot. The veranda cast a black triangular shadow on the bright sand. The avenue was paved with sunflecks, and these spots, if you slitted your eyes, took on the aspect of regular light and dark squares. An intense latticelike shadow lay flat beneath a garden bench. The urns that stood on stone pedestals at the four corners of the terrace threatened one another across their diagonals. Swallows soared: their flight recalled the motion of scissors swiftly cutting out some design. Not knowing what to do with himself he wandered down the footpath by the river, and from the opposite bank came ecstatic squeals and glimpses of naked bodies. He stole behind a tree trunk and with beating heart peered at these flashes of white.... Afterwards, lolling on the drawing room couch, he drowsily listened to all manner of slight sounds, to an oriole's cry in the garden, to the buzzing of a bumblebee that had flown in the window, to the tinkle of dishes on a tray being carried down from his mother's bedroom-and these limpid sounds were strangely transformed in his reverie and assumed the shape of bright intricate patterns on a dark background; and in trying to unravel them he fell asleep. ${ }^{59}$

It is a curious moment: Luzhin engages sensuously with the world around him, transforming it partially into chess imagery, partially into other sorts of mysterious patterns, in a way that appears to be vaguely comforting to him. That very evening, his father returns having learned of Luzhin's extraordinary talent, and the prodigy's childhood effectively ends: he is quickly submerged in the world of tournaments. When we meet him as an adult, aged thirty, he has much more trouble interacting with the realia of everyday life, and his future bride is perhaps the only person to have interacted with him on this level in almost eighteen years. He emerges from the "usual murk" of his life, and he "noticed with surprise that he was actually talking with her." She is "so unexpected and so familiar, and ... spoke with a voice that had been sounding mutely all his life and now had suddenly burst through the usual murk." He begins "with a series of quiet moves ... his own peculiar declaration of love." When he finally proposes, most strangely ("And therefore in continuance of the above ['above' appears to refer to their trite discussion the day before] I have to inform you that you will be my wife, I implore you to agree to this, it was absolutely impossible to go away, now everything will be different and wonderful"), ${ }^{60}$ he then bursts into tears and makes various awkward physical gestures while his beloved attempts to adjust to her situation. Who would have expected such an emotional outburst from 
a man wedded to chess? Exactly how and why her voice had "sounded mutely all his life" is not revealed. But this persistence of his openness to love, even his latent desire to love and be loved, his sensitivity to certain details of a person, his desire to give and receive affection, all show us a man who cannot be glibly dismissed as an insane chess master. Nabokov provides Luzhin's psychic life with a degree of worldly texture, precariously perched above the abyss of pure chess ideas. None of these facets of personality is explained. Despite the apparently predestined fate toward which Luzhin is driven, there is much about his mental life that remains outside the ominous patterns that coalesce into his vision of a malevolent opponent.

Nabokov presents a carefully wrought story of a maladjusted boy who becomes a maladjusted, asexual man-who also happens to be a chess genius. The causes of his first and second breakdowns have been a matter of considerable debate, a fact which bespeaks the psychological motivation behind the book. It makes us ask the questions: why does Luzhin have mental breakdowns; and why does he go mad and decide to "leave the game" at the novel's end? From one perspective, it may seem that Luzhin's breakdown is caused by the emotional imbalance, rooted in his childhood, that manifests itself in his chess addiction. Consequently, Luzhin's final insanity and suicide are caused by his inability, even after treatment, to escape hints of the "chess world" that reclaim him (the roll-up board, Valentinov). Alternatively, Luzhin's collapse in the championship may have been brought about by the conflict between his new, human interest (his future wife) and his burgeoning chess abilities; his final paranoia and suicide, by his treatment itself, even by Mrs. Luzhin's overzealous complicity in it. Nabokov structures the novel carefully to give readers ample opportunity to look for Freudian causes in Luzhin's childhood-for example, his father's barely concealed affair with his wife's second cousin, his mother's consequent hysteria-and, in general, what appears to be his parents' inability to nurture Luzhin in an effective, healthy way. It is on this dysfunctional childhood that the novel's Assyrian-bearded psychiatrist blames Luzhin's obsessiveness and his nervous collapse. The doctor's efforts to discover these roots meet with failure:

"Let me imagine your house-ancient trees all around . . . the house large and bright. Your father returns from the hunt. ..." Luzhin recalled that his father had once found a fat, nasty little fledgling in a ditch. "Yes," replied Luzhin uncertainly. "Some details," asked the professor softly. "Please. I beg you. I'm interested in the way you occupied yourself 
in childhood, what you played with. You had some tin soldiers, I'm sure. ..."

But Luzhin rarely grew enlivened during these conversations. On the other hand, constantly nudged by such interrogations, his thoughts would return again and again to the sphere of his childhood. ${ }^{61}$

The iconic references to Freudianism are unmistakable, as is Luzhin's lack of receptivity to this method. The novel refocuses vividly upon Luzhin's childhood, which now takes on an utterly different significance in his own reminiscences than it might in a psychoanalytic interpretation. His recollections evoke in him a feeling of warmth; even his once-dreaded governess, whose entrapment between floors in the elevator Luzhin often relished in youth, is a fond presence in remembered childhood. And yet, strangely and even paradoxically enough, this memory with its "tender constriction" 62 comes back empty, just like the elevator that has taken her as if up to heaven. Luzhin's nostalgia for his truncated childhood cannot bring it back. The glimpse of it we are given suggests that, although unconventional, Luzhin's childhood experiences carried a value and perhaps also a magic in them that-although in the past, lost-represents a positive significance in his life, rather than a source for neurosis.

The remainder of the novel consists of his wife's efforts to protect Luzhin from all reminders of chess, while the chess world inevitably, relentlessly finds its way back to him, apparently causing his final panic and escape out the window. This presents readers with two choices: (1) Luzhin's demise is caused by chess and, most immediately, by his "chess father" Valentinov; or (2) it is caused by the psychiatrist and his prescription for Luzhin's recovery. It might seem most logical to assume that Nabokov would wish to pin the blame on Freud, whose disciple has driven the vulnerable character to insanity through his manipulations: "Horror, suffering, despair,' said the doctor quietly, 'those are what this exhausting game gives rise to.' And he proved to Luzhin that Luzhin himself was well aware of this, that Luzhin was unable to think of chess without a feeling of revulsion, and in some mysterious fashion Luzhin, melting and coruscating, and blissfully relaxing, agreed with his reasoning." 63 Our attention is frequently drawn to the professor's "agate eyes" and his soothing tone, and one really wonders whether he might be hypnotizing Luzhin ("he proved to Luzhin ... ; Luzhin ... agreed"). Most likely, Luzhin is in a suggested state of suppressed chess-interest, and his surreptitious, confusing, and incomplete emergence from this state finally combines with a disjointed vision of life's relentless patterning, causing him to seek an 
escape. Much of the evidence points in this direction. Although such a solution also amounts to a causal explanation of Luzhin's actions, it does not explain his chess gift or his predilection for seeing patterns and repetitions. The causal chain might be rather compared here to a game of chess itself, where each action evokes an unpredictable reaction.

Luzhin's decision to "leave the game" relates to how we interpret the construction of his character, and how that character experiences and responds to the world around it. One of the key assumptions that has guided most critics' readings of The Defense is the notion that the best outcome for Luzhin is for him to live a happy, balanced life, perhaps regaining his chess abilities, perhaps not, but in any event experiencing a loving relationship with his spouse, Mrs. Luzhin (who has no other name in the novel). It is a tempting vision-after all, it is what most people want for themselves (substituting some personal interest in the place of chess, and adding perhaps a child or two). However, there is nothing in the novel that would suggest to us that such an ordinary, bourgeois existence is inherently desirable, or that it is in all situations the best alternative. ${ }^{64}$ Indeed, the bourgeois existence of Mrs. Luzhin's parents is subjected to significant irony throughout the novel. Luzhin's case is very special, and the novel forces us to question whether he is at all suited to such a life. We need to explore what his options really are.

The beginning of the novel offers us a peek back into the chessmaster's childhood, through the memories brought on during his convalescence (this relationship between a childhood experience and its future recollection is one of Nabokov's favorite themes). What we find recalled is a childhood that, for all its strangeness, seems essentially sweet and wondrous, as we see in these memories of Luzhin's governess:

Many years later, in an unexpected year of lucidity and enchantment, it was with swooning delight that he recalled these hours of reading on the veranda, buoyed up by the sough of the garden. The recollection was saturated with sunshine and the sweet, inky taste of the sticks of licorice, bits of which she used to hack off with blows of her penknife and persuade him to hold under his tongue. And the tacks he had once placed on the wickerwork seat destined, with crisp, crackling sounds, to receive her obese croup were in retrospect equivalent with the sunshine and the sounds of the garden, and the mosquito fastening onto his skinned knee and blissfully raising its rubescent abdomen. A ten-year-old boy knows his knees well, in detail-the itchy swelling that had been scrabbled till it bled, the white traces of fingernails on the suntanned skin, and all those 
scratches which are the appended signatures of sand grains, pebbles and sharp twigs. ${ }^{65}$

It was, to him, a cherished and safe existence, despite his fragile makeup; so that the news of his having to leave home and the regular routine of life with his governess (whose initial acceptance by him had been equally turbulent) causes him great distress. "His daily morning walks with the governess - always along the same streets, along the Nevsky and back home, by way of the Embankment, would never be repeated. [ . . . ] Finished also were his agreeable after lunch musings on the sofa, beneath the tiger rug, and at the stroke of two, his milk in a silver cup. [ . . . In exchange for all this came something new, unknown and therefore hideous, an impossible, unacceptable world. ..." Not, perhaps, an extraordinary childhood, but one filled with many pleasures and with a high degree of sensitivity on little Luzhin's part. But already we see signs of danger: his parent's fear of him, his difficulty adjusting to change around him, his preference for losing himself in abstractions like mathematics. In addition, he inherently attracts "hatred and derisive curiosity" from other boys; there is no hope of him fitting in, or becoming a normal part of childhood or grownup social structures. Only when he discovers chess does he begin to acquire an existence that seems commensurate with his own inner life: "'It must be a great pleasure,' his father had said, 'to assimilate music in its natural state.' It was a similar pleasure that Luzhin himself now began to experience as he skimmed fluently over the letters and numbers representing moves." There are signs that chess is for Luzhin more than a mere obsession. Consider the first time he ever plays, with that same aunt with whom Luzhin Sr. is having an affair: when she repeatedly attempts to put him off and delay the lesson till another time, Luzhin exhibits his surprising passion: “'No, now,' said Luzhin and suddenly kissed her hand. 'That was sweet of you,' his aunt said softly. 'I never expected such tenderness. . ..'” Even before he has played the game, he watches his classmates, "feeling vaguely that he understood the game better than these two, although he was completely ignorant of how it should be conducted." Once his chess "vision" is unveiled, he is able to read the notation of chess moves, "perceiving their melody mentally through the numbers and signs." Luzhin's chess activity is described as a kind of contact with another dimension, the world of "chess forces" and concepts. He enjoys playing blindfold, because "one did not have to deal with visible, audible, palpable pieces whose quaint shape and wooden materiality always disturbed him and always seemed to him but the crude, mortal shell of exquisite, invisible 
chess forces. When playing blind he was able to sense these diverse forces in their original purity." During his match with his archrival Turati, this world of pure chess forces encroaches further and further into everyday life, leading finally to his delirium during the suspended game (there is a certain logic to this formulation: it makes sense that Luzhin might find it impossible to step out of the chess world in the process of unfinished play). Nabokov encourages us to believe that Luzhin is indeed in a transcendent state of mind, one where pure ideas-in this case, the interactions of chess forces-are the most immanent reality. This is a world of beauty, not unlike music - as Luzhin is told by the violinist who first shows him the chessboard, echoed by Luzhin's attraction to a game's "melody." If we accept that this portrait of Luzhin's mind is accurate, then we are left with a mystery: why is Luzhin a "chess genius"? 66

Is Luzhin's final unhinging caused by the psychiatrist, or by his wife, or by his "chess father" Valentinov? Let's examine once again the contributing factors. The psychiatrist, with Mrs. Luzhin's complicity, attempts to expunge chess from Luzhin's life as if it were a mental cancer. Certainly this course of action sets the stage for Luzhin's rediscovery of chess and the inexorable slippage in his mind between its ethereal world and the physical world around him. Valentinov, so urgently attempting to have Luzhin reenact his match with Turati, completes a pattern that Luzhin recognizes as a repetition. In Nabokov's works such patterns often have meaningful implications, and in this case Luzhin descries an analogy between patterns in a game of chess and patterns in his life.

Luzhin is one of the few characters in Nabokov's novels who observe these meaningful repetitions, and his ability to notice them is surely related to his chess gift-just as Fyodor's ability is part of his artistic one in The Gift. Luzhin, however, is more extreme: his engagement with the world of ideas and concepts is so intense that it removes him from his ordinary life (as does Fyodor's when he is writing). Already on two occasions, he has had attacks of delirium: at his first achievement of fame as a child chess prodigy (which caused him to run away from home), and at his championship match with Turati. In short, Luzhin is by nature easily overcome by the world of concepts. ${ }^{67}$ The ordinary world has only a tenuous hold on him; he is more at home on the plane of chess forces and ideas: "he accepted this external life as something inevitable but completely uninteresting." His situation is not unlike that of Cincinnatus in Invitation, who is vividly out of place in his slapdash surroundings. In other words, Luzhin's perception of and affinity with an ideal realm, exemplified by chess forces, makes him ill-suited for the world around him, which is generally so much 
more concrete than the one of abstract "chess forces." In the prosaic tournaments Valentinov relentlessly had guided him to, Luzhin's chess abilities gradually seemed to decline, despite a continuing inner creativity: "the bolder his imagination, the livelier his invention during his secret work between matches, the more oppressive became his feeling of helplessness when the contest began and the more timidly and circumspectly he played." His decline from the very top, superstar level into a "cautious, impenetrable, prosaic player" seems to have to do with his performance at matches - that is, in the world-rather than with his harmony with "chess forces," which was now manifest only during "secret work between matches." 68

His fall from preeminence is unmistakably associated with his exploitation by Valentinov, whose concerns are exclusively prosaic and materialistic. Valentinov "had a peculiar theory that the development of Luzhin's gift for chess was connected with the development of the sexual urge, that with him chess represented a special deflection of this urge, and fearing lest Luzhin should squander his precious power in releasing by natural means the beneficial inner tension, he kept him at a distance from women and rejoiced over his chaste moroseness." ${ }^{69}$ This obviously Freudian interpretation of Luzhin's psychology turns out to be patently false within the novel's own logic, for the appearance of a beloved woman in his life coincides with the reemergence of his abilities. If we accept that Luzhin's early relationship with his fiancée is meant to demonstrate a positive mental development, then we witness a process, truncated in the novel's world, whereby Luzhin's chess play and his emotional connection to another become mutually reinforcing. However, Luzhin and his wife are not the novel's only characters, and all others conspire to squelch the grandmaster's consuming passion. In such a world, Luzhin's very existence becomes impossible.

That is not meant to imply that Luzhin's end is predestined in any specific way, but rather it is likely to come sooner rather than later, given his incongruity with his environment. In a certain sense, by taking his own life Luzhin fleetingly regains earthly control, just before losing it. However, the nature of his psyche makes it very unlikely that Luzhin would be able to remain apart from his beloved chess realm, and this attraction in itself works against his physical survival. Luzhin's mind is drawn to patterns, as it had been even in his earliest childhood before he had heard of chess; these patterns, through chess, alienate him more and more from the world of physical embodiment. It is not a matter of cause, but rather one of essence, which is why at the last instance-while falling-Luzhin recog- 
nizes that he cannot really escape from the play of chess forces; they are too much a part of him.

Mrs. Luzhin also has significant psychological depth: she is not simply a person who latches onto a pitiful creature out of an irrepressible drive to nurture-although that drive is part of her makeup. Her attraction to Luzhin is subtle, finding in him "something pathetic, a charm that was difficult to define but that she had felt in him from the very first day of their acquaintance"; "She wanted to make his acquaintance, talk Russian-so attractive did he seem to her with his uncouthness, his gloominess, and his low turndown collar that for some reason made him look like a musician"; there was "no time to sort out" her previous attractions to men, for "too much space had been taken up by this taciturn, fantastical, enigmatical man, the most attractive of all the men she had known." And when she has wordlessly (or at least internally) accepted his proposal, she wonders "how she could show this man to her father and mother, how could he be visualized in their drawing room-a man of a different dimension, with a particular form and coloring that was compatible with nothing and no one." In this way, she exhibits a particular, almost uncanny capacity to sense the value, or authenticity, or goodness, of people around her. She recognizes Luzhin's superior cultural sensitivity, in spite of his basic ignorance and lack of education. She feels the falsity of her Soviet visitor (at first the nameless visitor seems "interesting," but fairly soon Mrs. Luzhin concludes that her "opinions were false and stupid-but how prove it?"). ${ }^{70}$ Perhaps most significant, this special perceptive capacity comes along without any particular evidence of intelligence. Mrs. Luzhin has goodness, and the ability to perceive goodness or truthfulness in others, despite the unabashed if well-intentioned poshlost' of her father and mother-and the overt anti-Semitism of the latter.

Her unusual sensitivity comes into special relief at the party she hosts in order to bring Luzhin into contact with what she hopes will be positive intellectual influences. There appears a "plain looking man" who had just been listening to a journalist's "tortuous idea," and we learn that Mrs. Luzhin

liked him very much, and precisely because of his plainness, the neutrality of his features, as if he were himself only the outside of a vessel filled with something so sacred and rare that it would be a sacrilege to paint the clay. His name was Petrov, not a single thing about him was remarkable, he had written nothing, and he lived like a beggar, but never talked about it to anyone. His sole function in life was to carry, reverently and with 
concentration, that which had been entrusted to him, something which it was necessary at all costs to preserve in all its detail and in all its purity, and for that reason he even walked with small careful steps, trying not to bump into anyone, and only very seldom, only when he discerned a kindred solicitude in the person he was talking to did he reveal for a moment-from the whole of that enormous something that he carried mysteriously within him-some tender, priceless little trifle, a line from Pushkin or the peasant name of a wild flower. ${ }^{71}$

This is an excellent example of Nabokov's reformulation of Gogol's mock-classical digressions. But whereas in Gogol the comic asides trail off into humorous nonsense, here, this long, irrelevant passage actually goes straight to the heart of what matters for Nabokov. He allows his text to convey the idea of a person who, although outwardly unremarkable, carries a hidden truth, an "enormous something" that is completely concealed by his demeanor. Here we see Nabokov giving his purest impression of essentialist psychology. This Petrov—strikingly, one of the very few named characters in the novel-makes no other appearance in the story, he has no depth of character beyond what appears in this single, unusually penetrating description. We, as readers, are expected to accept, unquestioningly, the truth inherent in the passage about him. But his existence in the novel is not so important in itself: what is important, for an interpretation of The Defense, is that Mrs. Luzhin intuitively appreciates his "sacred and rare" interior or essence. The scene reinforces, just before the novel's end, the notion that she too, despite her flaws and her lack of intellect, nurtures a connection to some sort of "truth." It serves to validate her attraction to Luzhin, her love for him, and her sense of his superiority to his surroundings. Yet this fact does not mean that she is infallible, or that she understands the things she intuits. Her too-easy acceptance of the bearded psychiatrist's prescription helps set in motion the sequence that leads to Luzhin's paranoia and death. She remains a complex mix of personal traits: pity, tenderness, intellectual gullibility, and at the same time an indefinable sensibility. Nabokov wants readers to sense this strange, irreducible blend and notice Mrs. Luzhin's not-quite predictable actions. But he does not hint at anything that might explain where these traits come from.

The novel comes across as neutral in regard to Luzhin's plight. Are we to regret his abandonment of the "real world"? Perhaps, to an extent: it did hold some charms and delights for Luzhin, at times, as it does for so many of Nabokov's characters. Yet somehow, despite the potential joys of living, Luzhin seems likely to have difficulty being at home among ordi- 
nary human beings with their material concerns, callousness, and occasional cruelty. After all, the world of pure chess concepts appears beautiful to Luzhin, as well as terrible. When he awakes in the hospital, we are told that "the heavenly void in which his transparent thoughts floated was being filled from all sides." 72 We can feel sorry at Luzhin's breakdown, and we can understand why he chooses certain acts, based on our understanding of his personality and psychology. But we cannot explain-based on the novel's evidence-why Luzhin is the way he is, nor where the line between genius and insanity may fall: his individual mental essence lies in that domain that is impenetrable to the eyes of science.

\section{The Psychological Causality of Crime}

In considering the presentation of Luzhin's inner life and its consequences, we had the advantage of an unbiased, omniscient third-person narrator. The psychological situation is much more complicated in Despair and Lolita (as also in The Eye) because our only source of information is the very character whose mind and motives we want to understand. Even worse, these characters report having committed serious crimes. Their narratives serve as an effort to justify the crimes or ameliorate the reader's judgment (or possibly, in Humbert's case, as an act of atonement). Thus we have, really, no reason to trust what they say, and we must read everything as if it has been shaped with an eye toward manipulating our response. As a result, a reading of each text becomes, by default, a reading between the lines, an effort to discover places where the villain's real concerns or actions seep through the stylistic veneer. Each story is therefore double: we read the confessional narrative, and from the way it communicates its content, we draw conclusions about the teller. We attempt to reconstruct the man from traces and tracks left in the narrative; this image may have little in common with the one we actually read about. It is worth keeping in mind Nabokov's fond topic of the distorting character of even a supposedly faithful autobiography, as in Fyodor's plan to "twist" his own story to render its autobiographical content invisible. Hermann and Humbert have as much motivation as any author might to manipulate their readers' impressions.

The psychological crux of Lolita resides in the following three questions: what does Humbert want his narrative to do; why does he want this; and does he succeed? There are several possible aims Humbert might have in mind: he wants to evoke sympathy in his imagined reader or judge; 
he wants to get revenge (for his abandonment); he wants to transfigure his deformity into a work of art as a sort of penance (as he implies). The question of sympathy relates to how his rhetorical strategies attempt to provide a rationale, hence a cause, for his behavior, with this specific text. If he can diminish a judge's sense of his responsibility for his acts, then he has succeeded in securing sympathy. The aim of this tactic might be to receive a reduced sentence; it also might be to salvage a modicum of self-respect. As for revenge-well, Humbert's pursuit of Quilty is a rather straightforward tale of revenge, although whether it reflects Humbert's "reality" remains questionable, if we also accept his moral epiphany as "real." His recognition of his acts' horror, and his evident self-accusation following Dolly's disappearance, opens the way to considering as well how the work might function if it is not intended to exculpate the criminal.

We can't know whether Humbert's self-respect is served by his confession, but to judge from decades of criticism, his effort to evince sympathy is largely successful with first-time readers. How does he do it? As is well-known, he adopts a two-fold strategy: first, he offers stories from childhood that have allegedly affected his sexual development; second, he attempts throughout his story to suggest Lolita's own culpability and her moral failings, and to hint that she is not quite civilized, depraved, even. ${ }^{73}$ The second of these has been well rehearsed in recent criticism and need not be presented here. Although mitigated near the novel's end, its net effect is to suggest that she is the cause of his and her own downfall, which is in a way but a variation on the questions of causes (hence, excuses) we turn to next.

We do not know, but we can accept that Humbert is earnestly interested in discovering the source of his obsession with pubescent girls. The hypothesis that he maps out rests on three components, all of which have a Freudian resonance: his mother's early death ("picnic, lightning": he was three); his aunt's "fatal rigidity" in certain undisclosed matters ("Perhaps she wanted to make of me, in the fullness of time, a better widower than my father"); $;^{74}$ and his "fatal," unconsummated affair with the doomed (typhoid fever) Annabel Leigh. He thus proposes a series of psychological "causes" for his misfortune. And just in case we are not Freudians, he keeps the "F"-word concealed, appealing instead to our mystical inclinations, saying he is "convinced, however, that in a certain magic and fateful way Lolita began with Annabel." This waffling between deterministic and predeterministic arguments evokes similar equivocation by Grigory Pechorin, the manipulative lady-killer who wrote "The Fatalist" in Lermontov's A Hero of Our Time, which Nabokov was teaching while writing Lolita. 
In case we are not fatalists, either, Humbert elaborates his theory of "nymphets," whose "true nature is not human, but nymphic." 75 Freud, McFate, or Magic: he has his bases covered. The point of all this is to show how Humbert repeatedly suggests that his predilection is out of his control and that it has a cause. It may well be beyond his control, but his effort to pin it to a source is belied by the sources' variety, and he is equally unconvinced by all of them-and for precisely this reason he is driven to write his narrative. In truth, he has no idea why he is the way he is, and neither do we. Nabokov hopes that we will recognize, through various smokescreens, that there is no way to determine why Humbert is a pedophile. Nabokov suggests that the psychology of crime can be just as mysterious as the psychology of art. And he asks us to imagine whether a criminal can be an artist, and if so, to ponder the significance of that fact.

Viewing the confession as both work of art and penance becomes plausible when we recognize that Humbert cannot excuse or justify his acts even to his own satisfaction, but he can at least (and at most) make a go at self-punishment. An important part of his controversial "moral apotheosis" is his claim that, after Dolly's disappearance, he came to recognize his crimes: he had "inflicted" "foul lust" upon her; she was "deprived of her childhood by a maniac"; he was "despicable and brutal."76 He ruefully confesses his own willed ignorance of her inner life. He does not even propose that his confession might atone for his acts, only that it is a "treatment for [his] misery," a "very local palliative." This repentance, if we accept it as such, raises a special problem. Humbert the individual can both hold within himself a cruel and brutal monster who subjects his victim to living hell; and he can be a person who acknowledges his foul deeds and feels extreme pain and remorse at what he has done, using his last strength to generate something "good," a work of art honoring LolitaDolly, from what he has learned.

This possibility is real in the novel, even if it does not convince all readers, as we can judge from Nabokov's statement that Humbert becomes a "moral man" at his story's end. If we accept that Humbert's "Lolita" represents an act of contrition, and perhaps of penance, then we must accept the extraordinary psychological enigma of a deeply intelligent, gifted, eloquent individual, with a powerful imagination, who can simultaneously harbor a capacity for deeply inhuman behavior. We must also accept that such an egotistical monster can somehow achieve a capacity for love and respect for others. In the works of many authors, as in Dostoevsky, this kind of transformation is presented within Christian structures; accordingly, Humbert mentions his attempt to adopt the Catholic faith, but he 
"was unable to transcend the fact that whatever spiritual solace I might find, ... nothing could make my Lolita forget the foul lust I had inflicted upon her."77 Humbert's escape from his solipsism precludes him from finding actual solace. In rejecting what faith might offer him, Humbert nevertheless turns to what might be seen as ascetic self-flagellation in composing his confession, forcing himself to relive the moments that constitute his guilt and shame-a thunderous echo of Coleridge's ancient mariner (and by coaxing readers to side with him in his exploitation, he forces them to glimpse the fragility of their own presumed normality). But even if Humbert's post-crime actions, including his misery, make a certain kind of sense, we remain completely ignorant of why he is a pedophile, and of how he can be both monster and artist. Despite these apparent contradictions, Humbert remains a remarkably plausible character.

Similarly, in Despair we are offered various hints that might explain Hermann's obsession with having a double, but we have no real sense of why he comes to believe that murder can be an art. Compared to Lolita, Despair offers a slightly clearer boundary between fictional "world" and narrator's narcissistic self-aggrandizement-his "light-hearted, inspired lying" notwithstanding. ${ }^{78}$ Hermann, luckily, is not a psychiatrist-manqué; however, he does employ a dizzying variety of Freudianesque imagery to accompany his tale. At the historical time he is "writing" (around 193031), Freudianism was already a cultural industry, and we cannot exclude that Hermann himself, like Humbert, uses psychoanalytic discourse to create an attempted justification for his acts. However, he is to the end unapologetic: he does not seek to exculpate himself, but rather takes pride in his deed until his error-the overlooked walking stick-is brought to light. Since Hermann does not seem to be attempting to offer a Freudian alibi for his actions, the novel's phallic and mythological dimensions belong to the implied author's sphere of influence, not Hermann's; they serve as the author's method for aligning Hermann's thought process with that of a discredited social fad. By filling the murderer's surroundings with mock-sexual tokens, giving him, in effect, a phallic obsession that he seems not to notice, Nabokov may be suggesting that Hermann has a perverse sexual fixation that makes him akin to Freud. Hermann himself mentions, but seems not to dwell upon, certain childhood events that might be given a psychoanalytic twist: "for such sweet lying my mother would give me a cuff on the ear, my father thrash me with a riding whip which had once been a bull's sinew. That did not dismay me in the least-rather, it furthered the flight of my fancies. With a stunned ear and burning buttocks, I would lie on my belly among the tall weeds in the orchard, and whistle 
and dream." Nabokov tempts us with the possibility that poor parenting might have caused Hermann's amorality, but he simultaneously mocks this idea: after all, Hermann could be lying even now. ${ }^{79}$

There also lurks beneath the surface his wife's affair-perhaps it is just sexual play-with Ardalion, her "cousin," from whom Hermann seems to want to escape. But we do not really have enough biographical details about Hermann to distinguish, a), why he should have a phallus/castration complex as the novel's imagery implies or, b), why he should choose murder as a solution to his financial problems. ${ }^{80}$ The novel's shock comes not so much from the idea that Hermann resorts to desperate measures like murder and insurance fraud, but from his conviction that such an act could be considered art. He too, like Humbert, considers his meeting with Felix to be a sign of fate, a mechanism that continues its work as time passes: "But what, above all, gave me delight, delight of such force and ripeness that it was difficult to bear, consisted in the fact that Felix of his own accord, without any prompting from me, had reappeared and was offering me his services; nay, more: was commanding me to make use of his services and, withal doing everything I wished, was relieving me of any responsibility that might be incurred by the fatal succession of events." ${ }^{81}$ Nabokov here openly parodies the revulsion and fatal mechanism found in Dostoevsky's Crime and Punishment, but with a twist. Like Raskolnikov, Hermann swears off his aim ("what a fascinating thought; to take the advice of fate and, now, at once, leave that room, forever leave and forget, and spare my poor double.[ ... ] I was now superstitiously keen to turn away from temptation for ever").${ }^{82}$ When he thinks, erroneously, that Felix has come to find him at his home, right when he most fears to see him, he tells the maid to send him off. But when he discovers his mistake, that it was not Felix after all, the error changes his mood. Unlike Raskolnikov, whose passion was rekindled by an actual coincidence (he hears a merchant discussing the pawnbroker just when he has given up his horrible thought), Hermann is spurred by a noncoincidence-a coincidence that occurs in his mind but not in reality-thus emphasizing the purely inner source of his depravity ("My passion for my double was surging anew"; "One day something very like somnambulism took me to a certain lane I knew well, and so there I was moving nearer and nearer to the magnetic point that had become the peg of my being") ${ }^{83}$ Hermann's brief wavering, whether based on morality or simple squeamishness, is the only sign we have that he perceives the horror of his plan. Considering the cold-blooded assurance with which he follows it through, one wonders that he wavered at all. 
Hermann's repugnance is tangible, but its cause is elusive. His author endows him with a variety of psychological deformities: amorality, sexual deviation, narcissism, and aesthetic blindness. He also makes him an atheist and Soviet sympathizer, a rather ironic position for a business proprietor, albeit a failed one. However, these psychological traits are not organized to show a causal relation: rather, it seems that they are lumped together as if inherently united. Hermann's fixation on having a double, his inability to notice or value individuals and differences, derives from his innate makeup. His lying, from childhood on, and his indifference to the needs or feelings of people around him, suggest rather a fundamental flaw, a manifestation of essential evil in the guise of an educated and sophisticated man, one who for the most part manages to pass himself off as decent. Humbert, for all his crimes, appears not to be amoral. Hermann, in contrast, simply cannot value the existence of another human being, a trait that Nabokov, by repeated association, connects to the imagery of Freudian-style sexual obsession. Nabokov wants to suggest that Freudianism itself is like Hermann, despite its respectable public appearance.

\section{The Nonanalyzable and the Limits of Psychology}

If in Despair the concern with Freudian theory is latent but central, in Pnin it comes out into the open, while also becoming peripheral. Written immediately after Lolita, Pnin exhibits Nabokov's most elaborate confrontation with the psychoanalytical establishment; it is his first novel with analysts as significant characters. Nabokov read scholarly books and research journals in producing his parodic image-a parody which is nevertheless drawn straight from actual scientific journals. The main character, Russian Professor Timofey Pnin, is the ex-husband of a devoted student of Freudianism. She left him for another Freudian, with whom she had a son, Victor. This poor lad, we discover, becomes the object of his parents' passionate Oedipal expectations, and he is brought up in accordance with all the latest psychoanalytic theories. Remarkably, Victor fails to conform to Freudian or any other norms, and also fails to be emotionally harmed by the extraordinary pressures his parents have brought to bear on him. $\mathrm{He}$ is an artist, and his psychic world appears to be directed more from the inside than from the outside. Subjected to a gamut of psychological profile tests, Victor's personal essence remains inaccessible to the scientist's quantifying probes. For his part, the narrator seems to encourage a sense of mockery directed at these tests. Victor is "tested psychometrically at 
the Institute," where he undergoes a whole battery of tests, some possibly invented and some derived from sources Nabokov was consulting while at work on the novel. ${ }^{84}$ The tests are apparently meant to demonstrate the absurdity of psychoanalytic_-and much psychological—study of the preceding half-century. ${ }^{85}$

This shared mockery, however, conceals an irony that is lost on the narrator himself. For he is, or appears to be, just the kind of "psychological novelist" whom Hermann mentions during Despair. The narrator, V.V., wants to define Pnin for his readers, to create a definitive image for them. This puts him in an awkward position. He seems to feel that his credentials for producing such a portrait would be strengthened if only he could demonstrate some kind of personal closeness with Pnin. Having rescued Pnin, perhaps, from the grotesque distortions of Professor Cockerell's impersonations, the narrator wants to have his own way with him, and to do so with Pnin's consent if not with his blessing. However, unlike Lermontov's Pechorin from A Hero of Our Time, Pnin does not hand over his notebooks and invite his chronicler to peer into his soul. If the narrator's remarks are to be believed at all, Pnin does not even allow V.V. to get a good look at him, much less speak to him, as he leaves Waindell in the closing pages. Pnin is unwilling to be defined by anyone-even as a unique individual. ${ }^{86}$ His actions, as far as we can gather from this somewhat unreliable narrator, seem profoundly "normal" and free of any sort of neurotic or pathological component. Nevertheless, the narrator cannot really get close to a picture of the inner man. The thoughts and feelings he projects onto Pnin are creative and plausible-he imagines Pnin seeing the ghosts of deceased friends and family before his lecture at Cremona, in chapter 1 , and he imagines his pain on remembering Nina Belochkin in chapter 5-but they do not dip into deeper strains of psychological motivation, such as why Pnin refused to work with him, or why he continues to love his vapid, exploitative, unfeeling ex-wife (he cannot love Betty Bliss because "his heart belonged to another." ${ }^{87}$ In this way, the narrator shows the limits of his ability to imagine, respectfully, the inner life of another. Of course, there are most likely reasons behind this reticence that relate as well to the narrator's own desire for privacy (he conceals, or pretends to conceal, his own affair with Liza Bogolepova-Pnin-Wind), and so his desire to protect himself makes it impossible for him to explore Pnin as fully as he might.

Pnin was born as an "Anti-Freudian story." On one note card, Nabokov focuses on the creation of a character who defies Freudian stereotypes and, like Victor Wind in the novel, is "not even a nail-biter." Even the epithet 
"impregnable" appears in both notes and novel, as do most of the initial comments about Victor's “abnormality." ${ }^{88}$ Pnin's ex-wife Liza and her second husband Eric Wind are co-authors, with Dr. Albina Dunkelberg, of "Group Psychotherapy Applied to Marriage Counseling." This fictitious study derives from the real article "Group Therapy in Sexual Maladjustment," 89 which Nabokov called in his notes "one of the most grotesque and hilariously funny 'papers' I have ever seen"; he produced five full note cards for future reference. The fact that both Liza and Eric remarry during the novel further undermines the value of their psychoanalytical work as marriage specialists.

The narrator is clearly well aware of these ironies, and he shares Nabokov's scorn for the mass-culture phenomenon of Freudian psychoanalysis. He appears more interested in the rule-bound aesthetic shape of Pnin's life, as opposed to a Freudian explanation of his personal quirks. After all, Pnin is not described as having any particular neuroses. Young Victor Wind is "abnormal" only in his resistance to Freudian or Jungian categorization. If the narrator has chosen Pnin as an attractive, idiosyncratic character for a "type" portrait, he is interested in the determinism of personality as such, but not in seeking formulaic causes for individuals' traits. He seems to accept and take an interest in Pnin's personality, in his individual self, even if this self is set within a network of causal relationships that determine its actions in varying degrees. In this approach he follows William James, at least as he expresses himself in Principles of Psychology. Pnin's desire for privacy is, in part, Nabokov's own-but it is also representative of that fundamental inaccessibility of anybody's inmost self to all outside observers, no matter what the approach (as Nabokov had discussed in "Pushkin, or the Real and the Plausible"). V.V. may have hoped to be able to offer his readers a glimpse of "The Real Life of Timofey Pnin," but his effort fails, just as disaster miscarries in his first chapter. Except in its most basic elements - as an explanation of details of sensory perception and other physiological phenomena-psychology, for Nabokov, does not reveal the secrets of self. The secrets-or "mysteries," as they are called in Bend Sinister-always escape, even when the investigator is not a Freudian.

Pnin falls in with those works that steer clear of exploring the actual psychological functioning of their characters, despite, or perhaps because of, their anti-Freudian intent. Others in this group include Ada and Transparent Things. Ada is certainly Nabokov's least psychologically nuanced first-person narrative, an irony made all the more acute by Van's career as a psychiatrist. The closest thing Van provides to any sort of psychological self-revelation is in his description of his aesthetic and erotic responses to Ada's physical being. We are invited to form an ethical judgment of his and 
Ada's actions toward Lucette, but there are no psychological treasures hidden here. The lovers' behavior is guided by their narcissism, and its apparent consequence-Lucette's death-brings them real remorse. However, except perhaps as demonstration studies for Lombroso's parallel between genius and mental disturbance (if we assume this narcissism to be such a disturbance), Ada and Van do not offer readers much psychological grist. They love; they frolic; they (especially Van) become jealous; they produce creative works; they separate and reunite. They blindly spark Lucette's feelings for Van, which seem to be a blend of erotic and romantic love.

Lucette's obsessive love in her adult years is somewhat mysterious, and it presents the novel's most authentic psychological riddle. Was her love for Van caused by witnessing her siblings' intimacy when she was eight years old? Was it deepened by Van's gift of a book of poems, given as a distraction so he and Ada could have their own fun away from her "cucumicolour eye" ?90 Why, finally, is it such a despairing love, such that Lucette decides that if she cannot possess Van at least physically, her life is not worth living? Readers of the novel know essentially nothing about Lucette's inner life, a surprising fact considering the central role she plays in the novel's architectonics as defined in the most powerful readings of it. ${ }^{91}$ According to Brian Boyd, Lucette is the fulcrum on which the work's ethical balance pivots; she is the selfless counterpoint to the immeasurably self-absorbed Van and Ada. Of course, our ignorance as readers must be a reflection of Van's own-he is our only guide to Antiterra. For a psychiatrist, he is surprisingly reticent about his own and his sisters' conscious or subconscious motives.

In fact, we cannot know why Lucette takes her own life-and Van's refusal to attempt a more complex but nevertheless fictitious account of her psychology suggests his recognition of its essentially secret nature. In this sense, Lucette's act is kin to some other suicides in Nabokov's works: like Hazel Shade's in Pale Fire, or Luzhin's in The Defense, or the boy's in "Signs and Symbols," there are partial explanations in certain causal chains, but no complete revelation of why the suffering mind decides it must escape. ${ }^{92}$ Causes may be as plentiful as we like, but psychological reasons can still remain beyond reach, mysterious.

\section{The Minds of Others}

Lucette, like the Shades and like the Vane sisters, appears to be able after death to influence the living, and this strange fact has its own implications, perhaps deriving from Nabokov's understanding of how minds relate 
to each other and exist in ways that go beyond the individual's discrete, cranium-bound existence. Usually, this lingering influence is interpreted by critics as essentially spectral, as in Vladimir Alexandrov's Nabokov's Otherworld, and there is every reason to believe that Nabokov had such readings in mind (whether or not he believed in such phenomena as "real"). But he also, most likely, entertained other possibilities-versions which he expressed more directly in the 1920s and early 1930s. In at least two compositions, his commemorative piece on Iulii Aikhenvald (1928) and The Eye (1930), Nabokov made suggestions about the continued existence of the deceased within the minds of those who knew them.

In "In Memory of Iu. I. Aikhenvald," Nabokov expresses his grief over the untimely accidental death of his dear friend. The commemoration exudes not only respect but also love, combined with the bitterness of loss. "Iu. I. is no more," he writes, but he then revises that sentiment to suggest that Aikhenvald continues on in the minds of his friends, acquaintances, and even readers. "Oh yes, there is an earthly possibility of immortality. The deceased continues to live, in detailed and varied form, in the souls of everyone who knew him [ . . . ] And each acquaintance has assimilated an individual version of the person, so that the deceased remains on earth in many forms, sometimes harmoniously supplementing one another." ${ }^{93}$ This passage, perhaps out of sentimentality, perhaps out of an unwillingness to let go, or perhaps simply out of conviction, strongly suggests that this lingering existence is not exactly a mere memory. It proposes that something more substantial takes place between two minds when they know one another, and that others' imprints in our minds are permanent and carry with them tangible psychological consequences. This same thought is echoed by Smurov in The Eye (1930), who, having shot himself, already believes himself to be nothing but this lingering presence in others' minds, through the inertia of life that carries the mind past the boundary of death. If the "ghosts" in works like Pale Fire and Ada are of this type-mental fragments, as it were, of the departed, rather than creatures of a more traditional "otherworld," it would represent a striking hypothesis on Nabokov's part: that an individual's mind, or psychology, is composed of layers of impressions left by others, in addition to whatever might be identified as a fundamental "self." From this perspective, one person's psychology takes on even more "mysteries" than had been hinted at in Krug's musings in Bend Sinister. Maybe Lucette lives on in her reflections in Van's and Ada's minds; but if she does, then those minds are not quite the unitary agents that their owners feel them to be. These possible figments of others' selves lurking in each person's consciousness complicate the task of defining one 
individual's psychology, as they multiply the number of influencing factors present in the mental foreground and background..$^{94}$

This is the very problem that animates Pale Fire, in which several characters appear to have significant influence upon the mental lives of others, even from the grave, as it were. As Charles Kinbote composes the commentary, foreword, and index, there are three dead characters, only one of whom he knew directly-John Shade. This novel seems to offer a composite of two stories: the story of Shade's effort to understand and appreciate his own life and his daughter's death; and the story of Kinbote's fantastical invention of a world called Zembla. In each case, the reader is confronted with direct narration by the person in question-Shade in his poem, Kinbote in his commentary. Both narratives have a blatantly psychological purpose: the poem is Shade's verbal exploration of his own sensations and responses to life's trials; the commentary is Kinbote's complicated effort to transform his deepest anxieties into a completely new verbal texture-to present his life history in a new form and associate it with great poetry. His need to do this derives in part from his homosexuality, a trait which gives him significant unease, especially during his dreams. ${ }^{95}$ Curiously, his story does not suggest any cause for his homosexuality. Indeed, there is little or nothing we can derive from the story about the "real" KinboteBotkin. That he is homosexual, we can be confident: the Zembla story has all the markings of a wish-fulfillment fantasy, depicting a land where male homosexuality is unconstrained and even an elite practice. In its flagrant libidinousness, the narrative short-circuits any Freudian investigation: there is no coded language, no hidden message of illicit sexual urges here. Everything is in the open. This novel, like Despair, is bursting with false trails for psychoanalytic interpretation (such as the long tunnel the King uses for his escape-formerly used for his ancestor's trysts with an actress; the red caps; the Steinmanns). But in the end, like all such trails, they lead us nowhere, and we are left in near total ignorance of the "real life" of the scholar "V. Botkin," Kinbote's alter ego. If we presume that KinboteBotkin's acquaintance with Shade was an important source of a tenuous inner equilibrium, the latter's death marked the end of such balance, and it is all he can do to finish writing his "commentary." Shade's murder, which Kinbote feels he has indirectly caused, has undone him, removing his only access to the creative investigation of self. He finds another outlet in the commentary, which sustains him until it is complete. Of his psychological underpinnings, we can only say that he seems to lack the "indecent" optimism that Nabokov himself experienced. ${ }^{96}$ Nevertheless, despite our general sense that Botkin-Kinbote's sexuality has something to do with 
his suicidal tendency and his need to create an alternate reality, we do not really have any access to the person who generates these phantasms, and it is hard to see how the texts he has left us give us conclusive insight into his psychological being.

Hazel's path is just as mysterious. Although the immediate precursor of her death is her rejection by Pete Dean, it is hard to accept that this character would kill herself merely because she cannot be physically attractive to men. One might criticize Shade for heightening her opportunities to face rejection in a world that values surface appearances. But can it really be true that the Shades have been so fully swayed by popular norms that they collude in destroying Hazel's self-esteem? Can the intelligent Hazel have set such a high value on those norms? It seems unlikely, although her chosen doom is particularly unnerving. Still, Hazel could have other reasons that would motivate, reinforce, or confirm her decision to depart this world, having more to do with her tendency to have spectral encounters than with her looks. Hazel may leave the world because she feels out of place in it-like Cincinnatus, but without his worldly attachments. But we cannot really say with confidence: we only know that Shade feels despair at her physical deformity.

\section{Artistic Psychology: The Fragility of Genius}

Alongside these various psychological studies of variously "normal" and "abnormal" individuals, Nabokov presents as well the psychological portrait of the creative type, from two essential points of view: the psychologically "normal" or balanced, and the "abnormal" or mentally ill. A curiosity about the mental conditions of artistic creation was fundamental to Nabokov's thinking from early on; his 1918 reading list included both Cezar Lombroso's Genius and Insanity and Grigorii Aleksandrovskii's On the Psychology of Poetic Creation. On one side of this equation, the likes of Hermann, Humbert, Van, and Kinbote all create something while in variously compromised mental states, although they do not all qualify as artists. By contrast, Fyodor in The Gift, Sebastian in The Real Life of Sebastian Knight, John Shade in Pale Fire, and Vadim Vadimich in Look at the Harlequins! are presented as artists first and foremost, albeit with varying degrees of perceived "sanity."

Nabokov's interest in the psychology of the artist would probably have led him to explore works by Freud and by Otto Rank in this connection, and it also reminds us of his reading of Joyce's A Portrait of the Artist as 
a Young Man. Rank's Art and Artist came out in English in 1932, offering its vision of the emergence and meaning of the artist-hero type in modern culture. It also presented the concept of the neurotic as an artist-manquéan image so important to both Despair and Lolita. ${ }^{97}$

The Gift's Fyodor is both the most autobiographical and by far the sanest of these artist-characters, and for this reason it is not surprising that his method of perception and composition anticipates Nabokov's own memoir, Speak, Memory, in many ways. What we see in Fyodor is Nabokov's portrait of how an artist with stable and reliable senses and mind perceives the world and transforms it into art. And that is almost all he does: everything he perceives in the course of the novel is material for future works, finally coalescing into the novel itself, in a strange, distorting way.

As a psychological portrait, The Gift leaves us without any sense of initial causes, and this is just what the novel's title leads us to expect. In effect, the novel seeks to prove the inexplicability of Fyodor's creative urge, and in doing so it reenacts possible psychological investigations. The first chapter includes a lengthy recapitulation of Fyodor's first published book of poems, written in a Proustian mode of recovering childhood. One remarkable feature of these poems is how they demonstrate the translation of the ordinary into the artistic: lost and found balls, trips to the dentist, the winding of clocks. Events that might constitute the trivia of any young life become the stuff of poetry and enhanced vision. They are the possibilities offered at every step to the alert consciousness with an eye for pattern. The novel, as we read it and reread it, comes to express this idea of consciousness as the creator of its own artistic reality. We learn that Fyodor believes that "there is something" behind his reality, even though there is "no one to thank" for the riches of existence, or for this artistic sensibility that allows him to appreciate those riches. ${ }^{98}$

What might be called the abnormalities of the artist's personality come out during moments of intense creative work. While thinking up verse on the street, Fyodor wanders blindly into traffic where, thankfully, "something preserved him"; about to leave for a masked ball to meet with Zina, he hesitatingly takes up his pen to correct a word in his "Life of Chernyshevsky" - and when next he looks up, the ball is over and Zina's door angrily slams, his own mask lying unused beside his manuscript. ${ }^{99}$ Fyodor also turns out to be subject to mild hallucinations, or enhanced imaginary conversations with the image of his poetic rival, Koncheyev. On the whole, however, he possesses many features of a psychologically normal, optimistic, and likeable character, even though Zina will at times "be wildly unhappy" with him. ${ }^{100}$ This image probably comes fairly close to how 
Nabokov saw himself as a human being and as an artist-although his foreword suggests that Koncheyev and Vladimirov are nearer approximations. ${ }^{101}$ Pale Fire's John Shade is but another version of this same concept, Nabokov's assertion of the plausibility, contrary to Freud and Lombroso, of a normal artist.

But such a creature's existence did not reduce the fascination of the less balanced artistic types, and so it is no surprise that the latter are also important Nabokovian characters. In The Real Life of Sebastian Knight, the title character is a writer with a significantly gloomier outlook than Fyodor's. He is unable to find happiness with the kind, loving, and devoted Clare Bishop, and he is passionately drawn to a rather superficial Russian femme fatale who severely undervalues him (and he her, she suggests). V., his brother and the book's narrator, calls Sebastian's thinking “a dazzling succession of gaps"; ${ }^{102}$ he is, apparently, significantly more mysterious and also stranger than Fyodor. Nevertheless, it is not this one love that defines him-and in the end, a major point of the novel is that Sebastian cannot be captured biographically or psychologically.

Vadim Vadimych of Look at the Harlequins!, inasmuch as he is a parody of the public misperceptions of Nabokov's biography and character, possesses many traits that invert the ones Nabokov confesses as his own in Speak, Memory, Strong Opinions, and in letters to friends. Somewhat comically, Vadim is obsessed with a mental deficiency that prevents him from imaginatively spinning on his heel after a short stroll and retracing his steps through a landscape, a trait that indicates his imaginative onedimensionality. He continues to write novels and poems, becomes famous, has three unsuccessful marriages and finally, late in life, finds his true love, a young woman his daughter's age-while also coming to doubt the independence or reality of his own existence. These doubts, of course, are quite well-founded within the novel's logic — he is a parody, after all-and in the end readers are not left with the sense that Vadim Vadimych is an artist on the same level as Nabokov, Fyodor, or Sebastian Knight.

In the case of Vadim as well as of Kinbote-Botkin, Nabokov toys with the idea that a character's consciousness may exist in a state of dependence upon another mind. ${ }^{103}$ As we have seen, Nabokov was interested in phenomena of multiple personalities as well as in claims of "possessions" or channelings of the dead. We can trace this interest as far back as The Eye (1930) or even The Defense (1929), ${ }^{104}$ but in his known readings this interest reached a peak in the 1950s and early 1960s. The cases Nabokov read about in Donald James West's Psychical Research Today involved mostly examples of subordinate personalities that emerged and took over 
spontaneously or in the process of "automatic writing" (notably "Patience Worth," a seventeenth-century English persona who appeared in the automatic writing of a midwestern American, Pearl Curran, 1883-1937; and Ansel Bourne/A. J. Brown). ${ }^{105}$ There is nothing in his notes that proves that he either accepted or rejected a "supernatural" explanation of these phenomena: while he marks for further study certain phenomena that were demonstrably faked, he also intended to read affirmative accounts of the Patience Worth case. ${ }^{106}$ What we can say with certainty is that in many of his works, most vividly in Pale Fire, The Real Life of Sebastian Knight, and Look at the Harlequins!, Nabokov sets up the idea of the secondary personality as an exploration of the nature of consciousness.

\section{Nested Personalities}

Much has been made of the narratorial play in Pale Fire. Quite an astonishing amount of debate has taken place concerning the relative "reality" of the narrating characters. For not only is it a book with two ostensible authors (the poet and the annotator), but one of those authors is demonstrably insane-or is pretending to be. Kinbote's instability, his fantastic imagined life as King of Zembla, and his "real" identity with V. Botkin, combine with various hints in Shade's poem "Pale Fire" to suggest that perhaps the mad commentator is simply Shade's invention. The reversethat Kinbote, or rather Botkin, has in fact invented Shade and all the other characters-has also been argued forcefully and not without solid evidence. More recently, Brian Boyd has attributed many of the text's strange features to the intercession of ghosts (Hazel's and Shade's) behind the scenes, while arguing the individuality of both Shade and Botkin (who is, or generates, Kinbote). ${ }^{107}$ More recently still, suggestion has been made that all main characters besides Shade are fragments of his own personality, shattered by a stroke or other neurological trauma-and occasionally taking over his "body" to produce the poem plus commentary structure. ${ }^{108}$ And Dmitri Nabokov reported in 2008 that his father told him that "it does not matter much; let's just say that each invented the other." 109 That a personality can split or develop a secondary form is scientifically known, and Nabokov would have read about these phenomena in William James's work as a young teenager, decades before his preparations for this novel. ${ }^{110}$ But in Pale Fire, Nabokov explicitly mixes these psychological realities with more controversial events, like alleged poltergeists and barn hauntings. Furthermore, if Shade's poem bears traces of Hazel's otherworldly 
hand, while Kinbote's commentary contains Shade's ghostly imprint, then the workings of a secondary personality within a single living mind take on a fully ambiguous significance. How can one discern between the influence of a ghost and that of a lasting imprint of another's personality within a mind or soul, as Nabokov had written at Aikhenvald's death? What are the sources of artistic inspiration? What sorts of causes can obtain at the outer reaches or deepest recesses of the mind? In producing such a tangle of consciousnesses- "imaginary" or "real," worldly or otherworldly, healthy or deranged, visible or camouflaged-Nabokov creates an insoluble conundrum. There are so many possibilities, all or mostly open, that the interpretive path followed by Freudian psychoanalysis stands out in its narrowness and apparent confidence. Nabokov presents his readers with many more questions than answers, and like William James he does not propose to have even approximate knowledge of what makes a consciousness function, or what makes it change.

Insanity has its own links to a "beyond" in Nabokov's worlds. Hazel is strange to say the least, and her strangeness is explicitly linked to her participation in paranormal events-a trait she shares with many Nabokov characters. Nabokov never commits to the "reality" of the worlds perceived by his troubled characters; those supernatural or metaphysical glimpses remain ambiguous, ephemeral, uncertain. And yet he also refuses to dismiss or mock their possible veracity. The gaps and breakdowns in the texture of an individual's consciousness are natural features of a world where thought itself may form the closest link to "higher truths"-if one embraces idealist philosophy-even though, ordinarily, the mind is oblivious to those truths' proximity. The nested, or secondary, personality is an extremely apt representation of this problem, for if the embedded personality is unaware, as Kinbote appears or pretends to be, that its thought and essence are sharing a brain with another personality, then that second self exists within a larger, hidden and unknown, mental context or reality. In William James's exposition of such cases, the secondary personality is usually a "shrunken" version of the original, a personality possessing some, but not all, of the characteristics of the primary one. ${ }^{111}$

As if in illustration of this Jamesian, shrunken secondary self, Vadim in Look at the Harlequins! intuits or catches glimpses of a larger, "primary" self at various times during his waking and semi-conscious life. These glimpses are like flaws in the texture of his existence: mistakes in his speech (he once calls his daughter "Dolly," confusing her with a former lover and a Lolita he never knew) ${ }^{112}$ and in that of those around him; his own feelings of uncanny precursors; his spatial-imaginative disability. 
Vadim's psychological limitations and discontinuities serve as an embodiment of the epistemological concerns that permeate Nabokov's oeuvre. His sudden, lengthy blackout near the novel's end gives him a view of his other or outer self-the "real" Nabokov, the implied author of Vadim's text. As in many other examples we have seen, Vadim's revelation hints at the idealist notion that consciousness sustains reality in ways beyond the purely subjective. Significantly, his ambivalently spatial or temporal problem, occurring exclusively within his thought, brings us back to the spacetime-thought dialectic proposed in Speak, Memory, in which thought is proposed to warp outward into a "special space" or other transcendent dimension. It does not matter whether Nabokov literally believed that space, time, and thought were in fact dialectically continuous. The point is rather that he finds the idea intriguing and even plausible-(in Kantian formulation, space and time are the a priori forms of human cognitionthey are, as it were, the contours or manner of sensuous thought about the phenomenal world). ${ }^{113}$ As a variation on his idealist leanings (if not convictions), this formulation enacts Nabokov's attempt to find principles of thought itself subtending the development of reality. His works suggest that the exploration of mind may offer the most likely pathway toward the discovery of deeper realities, because mind itself is more clearly reflective of those depths than are the behaviors of material bodies (whether planets or photons) moving through space and time.

Vadim's mind in Look at the Harlequins! seems to be if anything too connected to "physical" space and time: he cannot manipulate them mentally, just as he cannot imaginatively turn about and retrace his steps. His memoir, as a parody of Nabokov's own Speak, Memory, differs radically from that original in its slavish attachment to chronological and spatial directedness. Aside from a few passing anticipatory references to "You" and a handful of other upcoming life elements, Vadim holds strictly to his life's spatio-temporal trajectory. Unlike Nabokov's, his metaphors do not create bridges between past and future, between local present and distant past. ${ }^{114}$ Unlike the chrono-clastic Fyodor in The Gift who says, "I seem to remember my future works," Vadim constructs his works whole in his mind and then memorizes them, as composed. ${ }^{115}$ Vadim Vadimych is stuck within linear causality, whereas Nabokov proclaims his own freedom from it ("I do not believe in time").

Nabokov's works ask us to maximize our conception of what psychology is, and what it can be as the science of the human mind. In some respects, psychology represents a natural field for the scientific method Nabokov espoused, for, as in his studies of butterfly morphology, each 
individual realization of the human mind offers its own unique, not necessarily generalizable, set of features. Writing at a time when Freudian psychoanalysis and its popular literary incarnations came to dominate public discourse on the mind (and the unconscious) while behaviorism dominated the rest of the field, Nabokov fought against what he saw as a radical and false narrowing of the domain of psychological inquiry. His own works embody a great diversity of mental phenomena-some with causal explanations, some quite mysterious. Artists, geniuses, dreamers, pedophiles, psychopaths, suicides, quirky professors, even relative mediocrities: every character is presented as a complete world, each containing "a trillion of mysteries," as Adam Krug puts it in Bend Sinister. ${ }^{116}$ Nabokov explores the idea that at its outer limits, where sanity frays into other, problematic variations on consciousness, mental life may catch glimpses of a reality that extends beyond the one we usually perceive- a theme he revisited again and again. To Nabokov, popularized (a word used advisedly) Freudian psychoanalysis did the exact opposite: it narrowed the field of psychological interest and inquiry to a particular material problem (sexual development-hence, reproduction) and glibly claimed to eliminate the mysteries of mind. In striking contrast to William James, psychoanalysis worked to apply the tools of causality to the farthest reaches of mental life (hysteria, neuroses, dreams). Most tellingly, it turns our attention to cases that confirm its claims, ignoring those that do not (while also functioning in a manner not subject to refutation). ${ }^{117}$ Nabokov's psychological portraits insist that there must be more to human consciousness than Freud's work suggests, and for this reason he presents his readers with a variety of believable types whose actions are not easily reducible to Freudian sexual causality. His ventures into the fringes of science, parapsychology and "psychical" studies may well demonstrate not superstition or a confident belief in ghosts and spirits, but an elaborate metaphor for the kinds of unpredictable, irrational phenomena that could linger just past the fringes of consciousness. That something is there, Nabokov appears to have been quite sure. ${ }^{118}$

One of the ways that Nabokov responds to modern psychology and psychoanalysis, with its stress on the unconscious component in storymaking and other human behaviors, is to use his works as a demonstration that intentionality, consciousness, and conscious creation are possible-not necessarily given or automatic, but nevertheless accessible to the species at 
large. Thus we can call Nabokov's texts hyperconscious, in that they make use of imagery, language, and various bits of other authors' narratives in a highly deliberate, artistic way. ${ }^{119}$ It is also true that Nabokov recognized the possibility of unconscious inspiration, the presence of a mysterious element even in the context of deliberate creation. As he wrote to Carl Proffer regarding the latter's Keys to Lolita, "many of the delightful combinations and clues, though quite acceptable, never entered my head or are the result of an author's intuition and inspiration, not calculation and craft. Otherwise why bother at all-in your case as well as mine." ${ }^{120}$ This disclaimer corresponds to what Nabokov puts into the philosopher Krug's mind: that each individual is a combination of trillions of mysteries. From such a perspective, any discussion of discovering the causal root of anyone's psychology sounds misguided.

Nabokov's psychological explorations were not particularly scientific, although they might be considered a kind of imaginative taxonomy (and he was, after all, a taxonomist). Nevertheless, they take a place alongside the science of the mind as it progressed through the twentieth century. While many researchers and practitioners, especially within psychoanalysis, were interested in establishing root causes for various psychological problems, Nabokov was conducting his own detailed expositions of how deranged or gifted minds might work, and how even their self-knowledge can be limited by overgrown departments of mental life- by obsessions, passions, or an inability to see the world around them. Nabokov wants his readers to recognize in his characters new species of mental being, individuals whose behavior seems grounded in an irreducible self rather than in a causal chain. The list of things we can only guess at is a long one. Whether consciousness is "soul" or else something emergent and spontaneous, discovering little-known types of mental life is at least as valuable as determining some of the knowable laws that govern human thought. Moreover, new unique incarnations continue to appear, giving constant expression to the mysterious power of nature, which "one cannot afford to despise," as William James wrote, and as Nabokov spent his artistic career illustrating. ${ }^{121}$ 


\title{
Nabokov's Physics
}

\author{
PARTICLES, WAVES, AND UNCERTAINTY
}

A lecture on Einstein's theory was scheduled at the New York Natural History Museum. A crowd of several thousand people, which had gathered outside the hall due to the lack of seating, broke through a police cordon and entered the hall. The auditorium was significantly damaged. This is the first time public disorder in New York has been caused by the thirst for knowledge.

—-Khronika," Rul', January 11, 1930

Broadly speaking the task of physical science is to infer knowledge of external objects from a set of signals passing along our nerves.... The material from which we have to make our inferences is not the signals themselves, but a fanciful story which has been in some way based on them. It is as though we were asked to decode a cipher message and were given, not the cipher itself, but a mistranslation of it made by a clumsy amateur.

- Sir Arthur Eddington, New Pathways in Science, 1935'

THERE IS LITTLE controversy in accepting Nabokov as a naturalist, and hardly any more in supposing that he was a serious student of human psychology. But physics? As we have seen, he told an interviewer that although he had "little physics," he was not inclined to believe Einstein's "slick formulae." 2 This flip dismissal conceals Nabokov's intense and abiding interest in the progress of modern physics and its implications for his world outlook. In his lectures on Chekhov and on tragedy, composed in 1940-41, Nabokov gives the first explicit indication that he was aware of recent advances in subatomic theory and their eerie consequences. Looking closer, we find traces of that interest going at least as far back as Invitation to a Beheading (1934). ${ }^{3}$

In the early 1940s, Nabokov claimed that in the works of Anton Chekhov, "we get a world of waves instead of particles of matter, which, incidentally, is a nearer approach to the modern scientific understanding of the 
universe." ${ }^{4}$ We see this same interest developing into a critique of general conceptions of Newtonian physics. Composed around the same time as his Chekhov lecture, his lecture "The Tragedy of Tragedy" included the following collection of statements identifying the ancient Greek genre's central weakness:

[T]his imagination of ours is regulated by a sound logic, and this sound logic of ours is so hypnotized by the conventionally accepted rule of cause and effect that it will invent a cause and modify an effect rather than have none at all.

[T] he old iron bars of determinism . . . have imprisoned the spirit of playwriting for years and years....

[Tragedy is composed on] the illusion that life and thus dramatic art picturing life should be based on a steady current of cause and effect driving us towards the ocean of death. ${ }^{5}$

Nabokov felt confident enough in his understanding of nature to propose that causality is not a complete description of the world's workings. He does not reveal what might displace or supplement mechanistic causality, but he calls tragedy, with its dependence on cause-and-effect devices, a "clockwork toy made in Greece that little children wind up and then follow on all fours." 6

It appears that Nabokov took a serious interest in the advances of physics throughout the 1920s and 1930s and that this interest began to give specific shape to his art no later than $1934 .^{7}$ The two essays discussed above, both composed between 1941 and 1943, reveal Nabokov's particular interest in the underlying essence, shape and structure of the universe. It might seem inappropriate, even naïve for a literary figure to apply metaphors from physics to his works-and worse, to make claims about physics' findings. ${ }^{8}$ However, there is nothing particularly new about seepage of specialized terminology across professional or conceptual boundaries, and such osmosis moves in both directions. We find a fascinating illustration of a reverse trend in the writing of Cambridge astrophysicist Arthur Eddington, whose eclipse-viewing expedition in 1919 played a major role in confirming Einstein's theory of general relativity. In New Pathways in Science (1935), Eddington wrote:

Our sensory experience forms a cryptogram, and the scientist is a Baconian enthusiast engaged in deciphering the cryptogram. The story teller 
in our consciousness relates a drama-let us say, the Tragedy of Hamlet. So far as the drama is concerned the scientist is a bored spectator; he knows the unreliability of these play-writers. Nevertheless he follows the play attentively, keenly alert for the scraps of cipher that it contains; for this cipher, if he can unravel it, will reveal a real historical truth. Perhaps the parallel is closer than I originally intended. Perhaps the Tragedy of Hamlet is not solely a device for concealing a cryptogram. I would admit-nay, rather I would insist-that consciousness with its strange imaginings has some business in hand beyond the comprehension of the cipher expert. In the truest sense the cipher is secondary to the play, not the play to the cipher. But it is not our business here to contemplate those attributes of the human spirit which transcend the material world. We are discussing the external world of physics whose influences only reach us by signals along the nerve fibers; and so we have to deal with the story after the manner of a cryptogram. ${ }^{9}$

Recalling the theory that Sir Francis Bacon in fact authored Shakespeare's works, Eddington's analogy is amusing, instructive, and at the same time highly ironic (and it also, perhaps, relates to the elaboration of the Baconian motif in Joyce's Ulysses): taking Shakespeare's tragedy as his model of the phenomenal universe, the Baconian sleuth who reveals cryptograms in the text-that is, as hidden messages and patterns pointing (perhaps) to the text's real source-is the equivalent of a scientist who uncovers hidden regularities and recurrences in nature and with their aid constructs pictures or mathematical descriptions of the world's implied inner workings. The irony, of course, is that the Baconian cryptograms in Shakespeare may be nothing more than the fancy of those who seek them out, and Bacon himself may have had no role in the plays' creation. Eddington, surely consciously, chose to emphasize a fashionable and well-known cryptographic topic that demonstrates not only an aspect of the scientific method, but also the vulnerability of scientific theorizing to false pathways.

Suggestively, Eddington then backs away from his analogy, offering a different perspective on it. For Hamlet may (or may not) contain cryptograms of this or that historical truth; but it is also, unquestionably, a play, producing aesthetic, intellectual, and emotional responses in the individuals experiencing it. This is a momentous concession: Eddington suggests that all of these intellectual-aesthetic aspects of the play's reality are "primary" - are, in a sense, the real truth of the play as a work of art. Similarly, the phenomenal world as it exists in and of itself (as perceived by the mind) is also primary; the cryptograms and the scientific theories are 
secondary discoveries or appendages, things that may happen to be true but are not part of the experiential truth of the whole ("consciousness with its strange imaginings has some business in hand beyond the comprehension of the cipher expert"). But such truths, whatever they are and however real they might be, Eddington calls "attributes of the human spirit which transcend the material world." Scientists have agreed to a set of rules and practices that restrict them to deciphering the cryptogram.

It is refreshing to see one of the twentieth century's most eminent physicists refer to his own work as analogous to wildly speculative, not to say crack-pot, textological scholarship. For readers of Nabokov, such a comparison has even greater significance, as so much of his work contains cryptogrammatic elements. When Shakespeare wrote "All the world's a stage" - a theme which recurs throughout his dramas-he surely did not foresee his plays representing the world in quite this way. Eddington's decision to offer great literature and its study as his analogy for the nature of the universe and our knowledge of it demonstrates the epistemological intersection of art and science. He could not make the point he wished to make within purely scientific discourse, which shuns the metaphysical. He thereby concedes the limits of that discourse and the constraints of the scientific enterprise. Nabokov's own interests in the natural world were based on scientific passions and a desire to describe, with accurate detail, certain parts of it. But clearly, he was always curious about the foundations of nature, and this curiosity led him to craft his own work in a way that corresponded to discoveries and puzzles then shaking the world of physics. Given his anti-materialist bent, it is no surprise that he would have been encouraged by the advances in physics in his early adulthood; these corresponded comfortably to his efforts to demonstrate exceptions and contradictions to Darwinian evolution within the world of natural mimicry, and to suggest a noncausal essence at the heart of consciousness.

\section{Nabokov and the "New Physics"}

Einstein's theory of general relativity received its first decisive confirmation in November 1919, based on results from Eddington's trip to observe the effects of solar gravity on a distant star's light during an eclipse. ${ }^{10}$ The results showed that the star's light was, in fact, bent the predicted amount by the sun's gravity, and the finding upended the world of physics. London's Times screamed "New Theory of the Universe" and "A Revolution in Science!" Classical, Newtonian laws were no longer adequate to 
describe reality, and the new laws made it seem as though the reality we perceive may have little in common with what the world actually holds. Einstein became an overnight sensation, receiving the attention of a pop star in nearly all his activities from then on. Discussion groups formed to analyze relativity from various perspectives and to consider its philosophical implications. ${ }^{11}$ It was, in short, a cultural phenomenon, and it spread widely as interpreters of science attempted to bring the new theory to the masses. There was a steady barrage of books and articles explicating relativity (both special and general), and it was not long before relativistic themes began to appear in the arts. Works by James Joyce, Virginia Woolf, William Faulkner, T. S. Eliot, and others incorporated relativityrelated themes. ${ }^{12}$ And in 1925, Nabokov's friend Iulii Aikhenvald reviewed a Soviet publication of May Sinclair's story "The Finding of the Absolute," writing that she "not without humor and not without philosophical depth, in literary form makes interesting suggestions" about Einstein's thought on space and time, with reference to Kant. ${ }^{13}$ Nabokov had ample opportunities to hear and read about relativity, including from his friend Vladimir Tatarinov, a science and political writer at Berlin's Russian newspaper $\left(R u l^{\prime}\right)$, where Nabokov's father had been a founding editor. ${ }^{14}$

Similar sources would have brought Nabokov into contact with advances in quantum theory. Initiated in 1900 by Max Planck, quantum theory was not as famous as its precocious younger sibling, but it was perhaps even more momentous a hypothesis in its ultimate development. Various innovations were announced in the press and described in some detail to the lay reader; in addition to Einstein and Planck, the names of Niels Bohr, Ernest Rutherford, and Louis DeBroglie were familiar fare (they all received Nobel prizes between 1908 and 1929), and newcomers Heisenberg and Schrödinger also made appearances in the Russian émigré press. ${ }^{15}$ Despite their less sensationalized reception, the theories of subatomic structure and mechanics raised questions that were equally alluring to Nabokov as possible ammunition against a purely mechanistic philosophy. It is from descriptions of this branch of physics that he derived his understanding of the "wave-like" nature of matter, which finds vivid expression in the popular and semi-popular accounts of the day. ${ }^{16}$ These same accounts offered quantum theory-especially in its post-Heisenberg, "uncertainty" or "Copenhagen" variant-as proof that classical causality was not active at the fundamental levels of matter, and hence was not fundamental. Arthur Eddington was "the first influential author to call [Heisenberg's uncertainty] relations a "principle." "17 To an author committed to discrediting materialist thought, a better scientific resource could 
hardly be desired. Articles such as "Atoms and Stars" by Tatarinov further help to explain the sources for analogies in "Father's Butterflies" linking speciation to both atomic and solar-system structures. ${ }^{18}$

It would have been virtually impossible for Nabokov to avoid exposure to the new ideas in physics, and there is fleeting evidence of a response to relativity even in Mary and King, Queen, Knave. Nabokov's early notebooks and poems demonstrate that he mused over the idea of inhabited worlds orbiting far-off stars and our place in the vastness of the cosmos, even before Einstein's meteoric fame. ${ }^{19}$ But such reflections were of a general, essentially romantic and slightly metaphysical character, not really shaped by the spirit of astronomical inquiry.

\section{Materialism versus Idealism: New Physics in The Gift}

Nabokov's serious encounter with the new physics was most likely spurred by his research into the life of Nikolai Chernyshevsky and reflections upon the materialist tradition he helped popularize in Russia, leading finally to the Bolshevik overthrow of the liberal Provisional Government in November of 1917. Conceived as the core of The Gift in 1933 with roots going back to the Soviet codification of Socialist Realism in 1932, the "Life of Chernyshevsky" reinterprets the socialist icon and critiques his philosophy, positivist materialism (or naïve realism). Sergei Davydov called this chapter an "aesthetic exorcism," which it certainly is, but it is more than that. ${ }^{20}$ By creating a fictitious, deconstructive "portrait" of Chernyshevsky, one that draws constant attention to the ironies and contradictions in his life and thought, Nabokov attempted to concoct a powerful antidote to the image celebrated by the Bolsheviks and even by their liberal opponents. The fact that materialism is closely linked with scientific positivism, one of socialism's most important ideological anchors, led Nabokov to take an increased interest in the changes science had undergone since the turn of the twentieth century. Reading voluminously (starting in about 1932) in the socialist polemics from Chernyshevsky's day to Lenin's, Nabokov was led by the great revolutionary himself to one of the key figures in relativity's rise: Ernst Mach. ${ }^{21}$ The famous nineteenth-century physicist and philosopher of science is Lenin's main opponent in the latter's Materialism and Empirio-criticism, a work which establishes "Machism" as a major heresy within the socialist movement—a kind of science-based idealism, as Lenin saw it, that sought to deny the existence of the real-world "thing in itself." It was Mach, Nabokov would have elsewhere learned, who first 
questioned on scientific grounds Newton's absolute time and space, laying some of the earliest foundations for Einstein's new theories. ${ }^{22}$ From this inception, Mach, Einstein, and other proponents of the new theories subtly wove their way into The Gift's dense fabric. ${ }^{23}$

But there was a detour along the way: after completing a draft of The Gift's chapter 4 (and apparently without having written a line of the other chapters), Nabokov was suddenly moved to write another book, Invitation to a Beheading, in what he later called "a fortnight of wonderful excitement and sustained inspiration." ${ }^{24}$ Possible signs of relativity in Invitation are ambiguous at best. We do not have, as we do in The Gift, any distinct textual markers that point to specific scientists or their work. What we do have is a preoccupation with geometry (especially triangles and circles), time running amok, and a distinct departure from the ordinary laws of nature. The geometrical theme, combined with the fact that so often the novel's geometry seems to be distorted, calls to mind Nikolai Lobachevsky, the Russian co-discoverer of non-Euclidean geometry. We know that Nabokov grew interested in Lobachevsky while working on the Chernyshevsky chapter, where he even quotes the radical's derision of the great mathematician. ${ }^{25}$ And just as the spatial features of Cincinnatus's world do not conform to our expectations, its time flow is also erratic and occasionally even circular-although it does progress, relentlessly, to its promised end. The laws of classical physics are largely discarded, albeit not in a way that refers specifically to relativity or quantum theory (the novel follows what Nabokov elsewhere calls "dream-logic"). ${ }^{26}$ As an investigation into concepts of philosophical idealism, the novel also proposes that the qualities of reality and its laws are in some ways dependent on the quality of the minds that support them in thought. While having nothing to do with Einstein's famous theories, such an imaginative leap can be seen as a logical improvisation on the limits of the relativity concept in its barest form. Working on The Gift, Nabokov conceived various philosophical and scientific ideas to explore and test, and Invitation became a part of that lengthy process.

Even before the Chernyshevsky chapter, he had written the story "The Circle," which he later referred to as a satellite orbiting The Gift, from which its characters are drawn. ${ }^{27}$ The story itself-written before the rest of the novel but portraying events after the novel's time frame-enacts a circular structure, and when we take into account the same geometrical device in the novel as a whole and in several of its parts, it becomes immediately clear that the circle is a guiding structural principle in this work. That initial impulse would continue to develop, in chapter 1's "triangle in 
a circle" and chapter 4's "spiral within a sonnet," expanding to encompass planets, spheres, exploding stars and atomic nuclei in the speciation theory presented in the "Second Addendum [Father's Butterflies]." Judging from its fitful and disorderly start, there was something about this novel that resisted the usual method of beginning a project at the beginning. ${ }^{28}$ No doubt part of that something was the desire to use ideas from the new physics as a covert support for the novel's anti-materialist thrust (layered on top of what Nabokov had learned about thought and memory from philosophers and psychologists).

The novel's playful engagement of relativity begins with the very first sentence, in its mock-precise establishment of the time of action. "Towards four in the afternoon, April 1st, 192-": the April fool's joke is on us, of course, because Nabokov interrupts both the sentence and the year with a lengthy parenthesis on the "honesty" of Russian authors who withhold precise dating of their novels. The plot begins on the street, as a married couple watches as their belongings are carried by a pair of movers from a van to their new apartment-which happens to be in the same building as the narrator's new abode. Moving, or motion generally, is one of the novel's chief concerns, for a variety of reasons (emigration, a father's adventurous travels across Asia, Chernyshevsky's exile in Yakutsk). Everything is in motion, and when characters do sit still, it is with the purpose of contemplating the motion around them, or imagining still greater departures and arrivals.

The moving van itself turns out to be a cipher for relativity: its inscription is "Max Lux," painted in blue Latin letters shaded in black, "a dishonest attempt to climb into the next dimension." On the van's side the illicit next dimension is depth, but the phrasing also reminds readers of the existence of the fourth dimension, time (as had been famously discussed by Hermann Minkowski and Albert Einstein). The name "Max Lux" calls to mind a crucial part of relativity: that light (lux) moves at the maximum speed possible in the universe. If one treats a Cyrillic reading of the first word as another kind of "next dimension," "Max" would be pronounced “makh,” pointing to Ernst Mach, Einstein's revered predecessor. Nabokov hints that readers should make this shift by tweaking these same words across languages in the opposite direction: he tells us that their sound in German (or Latin) is like the Russian "Mak-s ... Luk-s, vasha svetlost"” and transforms the scene into a farmers' market: "What have we here? Poppies, sir. And here? Onions, your radiance" (in Russian the pun is more obvious: svet means "light"). The meaning of the words themselves is relative to one's linguistic point of view, and this play with Latin-Cyrillic 
coincidence recurs several times in the chapter (in Fyodor's landlady, Clara Stoboy [from Latin claritas, clearness or brightness + Russian s toboi, with you] and in the special words "mama" and "kakao" that appear the same in German and Russian). ${ }^{29}$

The couple whose belongings are being unloaded from the van are named "Lorentz"-introducing H. A. Lorentz, another of Einstein's most significant immediate predecessors. The vehicle's fan is star-like, reminding us of stars in general as hypothetical destinations or worlds, or as celestial objects producing - and bending - the very light that Einstein theorized about. That starry fan is said to be on the cab's forehead, Russian $l o b$ : at this point, it seems reasonable to suggest a reference to Nikolai Lobachevsky, whose non-Euclidean geometry was also crucial to relativity's discovery. Once departed, the truck leaves behind an oil spot with a rainbow in it. That rainbow brings us more light, now spread into a spectrum like the light that allows astrophysicists to measure the temperature, composition, and distance of stars. The spectrum is also a subtle reminder of that original (yet so unfashionable) natural philosopher, the discoverer of the laws of refraction, Sir Isaac Newton, who now, it seems, must wallow in the mire rather than play among the stars. Several more images in the chapter draw our attention to light's odd properties: a mirrored dresser's "parallelogram of sky" with a "human vacillation," and lindenshadows that "hastened headlong toward substantiation," to offer the two most prominent examples. ${ }^{30}$

The prismatic and reflective properties of light continue to play a major role throughout the novel. Near its end Fyodor, the novel's protagonist, even becomes light in this remarkable passage, while relaxing in the Grunewald: “The sun bore down. The sun licked me all over with its big, smooth tongue. I gradually felt that I was becoming moltenly transparent, that I was permeated with flame and existed only insofar as it did. As a book is translated into an exotic idiom, so was I translated into sun. [ . . . ] My personal I [ . . . ] had somehow disintegrated and dissolved; after being made transparent by the strength of the light, it was now assimilated to the shimmering of the summer forest." ${ }^{31}$ As light, Fyodor assimilates to the fragrant, sensuous world of nature around him, but then worries that "one might dissolve completely that way" - an ironic reference to Romantic or transcendentalist concepts of merging with the universe.

Pedestrian variations on relativity saturate the entire first chapter. Fyodor's new room, near his old one but on a crossing street, gives him an entirely new relation to this particular spot, which "had revolved and glided without any connection to him; today it had suddenly stopped; 
henceforth it would settle down as an extension of his new domicile." 32 The nature of the local space becomes a feature of the perceiving mind (if it is an attentive one), its former motion transfixed by Fyodor's entry into this new frame of reference. Nor is time forgotten, and in fact the chapter presents a curious series of transitions between Proustian/Bergsonian perceptions and relativistic mutations. Fyodor's rereading of his book of poems, which makes up the first large section of the novel, enacts its own temporal play, in both form and content. Fyodor makes two passes through the work, one as if at light speed: "he would skim in an instant the entire book, so that in the instantaneous mist of its madly accelerated music one could not make any readable sense of the flicking lines-the familiar words would rush past, swirling amid violent foam ...";33 and then, upon returning to his room, he reads with deliberate slowness, "as if in three dimensions, as it were, carefully exploring each poem, lifted out like a cube from among the rest and bathed from all sides in that wonderful, fluffy country air. . ." 34 The passage of time takes on a relationship not only to the speed of the reference frame, but also to the speed of thought; we shift from the "violent foam" of extreme speed to the protracted recreation of each moment of experience that entered into the poem's composition- “everything, absolutely everything" — thus reliving the pure duration of lost time. Nabokov then plays two jokes on Fyodor: his watch begins behaving erratically, "now and then" moving backwards-a reflection of Fyodor's occasional journeys into his past? Or his light-speed rereadings? Then, in his excitement to hear the supposed review of his poems at the Chenyshevskys' flat, he attempts to "dawdle," but in reality moves so fast that time seems to slow down, so that "the clocks he came across on the way ... advanced even more slowly," and he overtakes his acquaintance Lyubov Markovna “in one stride." 35 The frames of reference are rather muddled here from a strictly relativistic point of view, but these repeated manipulations of temporal flow combine with variations upon light and space to produce a poetic embodiment of the Einstein revolution.

The novel's attention to time, light, and space, and their possible transformations, constitutes its primary field of action, complemented by thought. ${ }^{36}$ Although consciousness itself is not a part of Einstein's physical theories, Nabokov's novel exhibits a driving concern with the relationship between these phenomena and the perceiving and imagining human mind. Spurred by the apparent revolutionary overthrow of some of Newton's laws, Nabokov explored the possibility that thought could, in its way, create other, more local violations of accepted laws of physics. Hence Fyodor's image of his father, who had recounted stepping into the base of a rainbow. 
By means of the same process, Fyodor recreates first his own past, then the central Asian itinerary of his father's explorations-even though he had never seen those exotic lands. Their scenery is transferred onto the ceiling and walls of Fyodor's room, where it is fully substantiated in Fyodor's thought (even more fully than the shadows of linden branches on the van's roof). Such habits also have practical applications: Fyodor, in his book "The Life of Chernyshevsky," describes in detail how his protagonist, who mocked Lobachevsky, was forced to traverse physically much of the terrain Fyodor covers in his armchair. Similarly, Fyodor is able to bend the straight lines of the Berlin streetcar system, turning a one-way ride into a round trip-although he often forgets to do this, not being very good at practical applications generally. ${ }^{37}$

The novel's poetics also seems permeated by a sense of subatomic theory and quantum mechanics. This awareness becomes helpful in Fyodor's effort to discredit Chernyshevsky's materialism, as "for those in the know, matter turns into an incorporeal play of mysterious forces." 38 This is indeed how the subatomic world was beginning to look even to those who discovered it. The Copenhagen interpretation of quantum mechanics, developed at around the time Fyodor and Zina meet (roughly 1926), resulted in Werner Heisenberg's famed uncertainty principle, which was wellpublicized by the time Nabokov began work on his novel (1934). This principle showed that for subatomic particles-like an electron-it is possible to know with arbitrary precision either the position or the momentum, but not both, because of the mathematical consequences of such particles' minuteness. This discovery meant that in the subatomic world, the future positions of particles are fundamentally unknowable, and not subject to typical analyses of cause and effect. This principle has also a psychological parallel in the troubled subject-object relationship: the subject readily imprints a part of itself onto any object (which is experienced as representation in the brain, after all), leading Konstantin Godunov-Cherdyntsev to his admonition not to let "reason [...] prompt us with explanations which then begin imperceptibly to influence the very course of observation and distort it: thus the shadow of the instrument falls upon the truth." ${ }^{39}$ This phrasing is quite similar to the way Niels Bohr expressed the problem in 1931, and also, as we saw in chapter 2, to Goethe's descriptions of scientific subjectivity. ${ }^{40}$ There is a difference, however, between obscuring the truth through subjective contamination and the unknowability that the uncertainty principle entails. It may well be that Nabokov had this latter sort of uncertainty in mind when he established the novel's inscrutable narrator, who shifts invisibly between first- and third-person voice, 
compounded by Fyodor's announcement that his novel will so "shuffle, twist, mix, rechew and rebelch everything ... [so] that nothing remains of the autobiography but dust." 41 If we decide that we know who the fictive author is, then we do not know his "real" biography; if we decide that Fyodor's life is accurately described, then the fictive author becomes an abstract concept. ${ }^{42}$ Whether or not the Schyogolevs' departure for Copenhagen is a gentle echo of Bohr's and Heisenberg's work, Fyodor and Zina's immediate future is also uncertain: will they or will they not gain access to the apartment? Will they discover they are keyless, and perhaps look through the mail slot and see Mrs. Schyogolev's keys lying there, star-like?

These intimations of the new physics, although not thoroughly grounded in the theories' detailed mathematical equations, perfectly intertwine with The Gift's primary concerns-the power of thought, memory, and art; the magical richness of worldly existence; the mysterious force of love-because they emphasize how strange and unknown the world really is at its deepest and grandest levels. The illusion of certainty promoted by Newtonian science gives way to the uncertainty of relativity and quantum mechanics, sparking hopeful play with (or playful hope for) the idea that matter is really subordinate to mind, that causality is conditional. And yet even while deploying these themes surreptitiously in his work, Nabokov was mocking those who imported the latest theories carelessly or simplistically. In the comically unbearable play by the hapless Busch, near the end of chapter 1, a chorus is said to represent both "de Broglie's waves" and the "Logic of History." 43 Busch's play serves as a warning of the difference between haphazard allegories based on scientific novelties and careful artistic reflections upon the new theories' significance.

\section{Mind over Matter: Bend Sinister}

In the works that immediately follow The Gift, the new physics motif becomes less central to the philosophical argument, while maintaining a distinct, if sometimes inconspicuous, role. After some strong echoes in "Ultima Thule" followed by a de-accentuation in The Enchanter and The Real Life of Sebastian Knight, ${ }^{44}$ the motif emerges again in Bend Sinister, which returns in part to the vexed question of the ultimate nature of existence, with a brutish and brutal socialist-materialist, anagram-crazed dictatorship—the "Ekwilist" regime—as its foil.

Philosopher Adam Krug is well aware of recent advances in subatomic theory, and in this sense Bend Sinister (composed 1942-46) is the first 
Nabokov work to bring the theme into the open. Although Krug had, for most of his career, been reluctant to probe the questions of nature's ultimate essence, the Ekwilist revolution and the steady disappearance of his friends lead him to do so. In a much-quoted passage from chapter 14, he ponders the relation between theoretical physics and ontology:

If (as some of the wiser neo-mathematicians thought) the physical world could be said to consist of measure groups (tangles of stresses, sunset swarms of electric midgets) moving like mouches volantes on a shadowy background that lay outside the scope of physics, then, surely the meek restriction of one's interest to measuring the measurable smacked of the most humiliating futility. Take yourself away, you, with your ruler and scales! For without your rules, in an unscheduled event other than the paper chase of science, barefooted Matter does overtake Light.

We shall imagine then a prism or prison where rainbows are but octaves of ethereal vibrations and where cosmogonists with transparent heads keep walking into each other and passing through each other's vibrating voids while, all around, various frames of reference pulsate with Fitz-Gerald contractions. Then we give a good shake to the telescopoid kaleidoscope (for what is your cosmos but an instrument containing small bits of coloured glass which, by an arrangement of mirrors, appear in a variety of symmetrical forms when rotated-mark: when rotated) and throw the damned thing away. ${ }^{45}$

Many features of this passage recall the same theme's more discreet presence in The Gift: Krug's circular name (krug is Russian for "circle"), which echoes the earlier novel's structural motif and its "satellite" story; the "measure groups" and "electric midgets"; the prismatic effects. Krug questions the value of a philosophy of existence based on this physico-mathematical theory and its unmeasurable consequences, because to his mind the analogies it evokes still require some sort of outside figure to rotate the kaleidoscope. Nevertheless, he clearly values the anti-causal implications of a world where measurement is futile, while causality and other purely material phenomena are subordinate and deceptive.

Preferring to stick to the purer ambiguities of idealist philosophy, Krug offers what is, to him, the best and only possible definition of human existence, which he derives from his love for his son: "A little creature, formed in some mysterious fashion [ . . ] by the fusion of two mysteries, or rather two sets of a trillion of mysteries each; formed by a fusion which is, at the same time, a matter of choice and a matter of chance and a matter of pure 
enchantment; thus formed and then permitted to accumulate trillions of its own mysteries; the whole suffused with consciousness, which is the only real thing in the world and the greatest mystery of all." ${ }^{46}$ In this way Krug overcomes the need for scientific-philosophical explications: he modestly asserts that the ultimate source and essence of existence is unknowable, and therefore all attempts to define it, whether through experiment, mathematics, or verbal probing, are doomed, pointless, and possibly even harmful.

The novel's main example of a harmful philosophy, as in most Nabokov works, is socialist ("dialectical") materialism along with its distorted version of positivist science. The Ekwilist regime's socialist dogma mirrors quite closely the actual utopian aims of places like the early Soviet Union, aims to be achieved here through the material and intellectual equalization of all members of the populace. When Krug is arrested, he relies on that positivist certainty of his captors, and their ability to act on it, when he argues to himself: "They will not harm the child. On the contrary, it is their most valuable asset. Let us not imagine things, let us stick to pure reason." ${ }^{47}$ This "pure reason" (is it also Kant's?) is the very logic of Paduk's regime, where strict cause and effect work out their determinist consequences. However, such logic and reason are useless in a world where each individual comprises "trillions of mysteries," and thus all predictions of human behavior and its consequences, even based on unalloyed self-interest (as were those of Marx and Chernyshevsky), are bound to fail at the crucial moment.

Stepping back from the novel's main action and its overt references to the mysterious substrate of physical being, we find some subtle reinforcements on an entirely unexpected plane: esoteric discussions of Hamlet. Chapter 7 presents the reader with a dense, arcane, and surprisingly long disquisition on the authorship, translation, interpretation, and staging of Hamlet. Brian Boyd called this chapter a "parody [of] the whole history of perverse misinterpretations of the play." ${ }^{8}$ Hamlet, Boyd reminds us, shows us Shakespeare at his best, and thus represents a vivid refutation of the Ekwilist doctrine of universal mediocrity. But it is also more than that. The play's role in Bend Sinister has another significance that relates as well to the posing of ultimate questions. This nuance should not be surprising, as the tragedy includes the bard's most famous soliloquy, Hamlet's "To be, or not to be." ${ }^{\prime 9}$ In the west-including Russia-Hamlet plays a key role in discussions about the meaning of existence, even if it fails to provide unequivocal answers.

Judging from Nabokov's use of this material, it appears all but certain that he had read Eddington's New Pathways in Science sometime after 
its 1935 publication, and that he intended to engage Eddington's cryptogram analogy, discussed at this chapter's outset, in Bend Sinister. Chapter 7 begins with a detailed description of three engravings that embody the Baconian hypothesis of Shakespearian authorship, including cryptograms:

"Ink, a Drug." Somebody's idle pencil (Ember highly treasures this scholium) has numbered the letters so as to spell Grudinka which means "bacon" in several Slavic languages.

Number two shows the rustic (now clad in the clothes of the gentleman) removing from the head of the gentleman (now writing at a desk) a kind of shapska. Scribbled underneath in the same hand: "Ham-let, or Homelette au Lard."

Finally, number three has a road, a traveler on foot (wearing the stolen shapska) and a road sign "To High Wycombe."

Ordinary interpretive or annotative scholarship is somewhat different from a search for cryptograms; as Eddington suggests, the play itself exists as something transcendent and contains hidden truths that are, perhaps, unutterable, but scholarship strives to identify at least the best approaches for glimpsing such truths. Of course, some efforts are better than others, and chapter 7 alternates comically between frivolous or self-serving interpretations and the serious, passionate, and honest mental work done by Ember. The first reinterpretation we encounter, by one "Professor Hamm," tells us that the play is not really about Hamlet at all, but rather about the recapture of the Danish throne by the house of Fortinbras, and proclaims that "to surreptitiously shift the stress from this healthy, vigorous and clearcut Nordic theme to the chameleonic moods of an impotent Dane would be, on the modern stage, an insult to determinism and common sense." 51 Note the "determinism," which is precisely one of the features of reality Eddington tells us we must forego. ${ }^{52}$ Krug then considers Ember's painstaking, loving translation work, which is like an "intricate piece of machinery which would $[\ldots]$ cast a shadow exactly like that of" the original. Of the translator's servile path, Krug wonders, "could this suicidal limitation and submission be compensated by the miracle of adaptive tactics ... or was it, taken all in all, but an exaggerated and spiritualized replica of Paduk's writing machine?" 53 To translate, or not to translate? As Krug notes, he too is better at finding the weaknesses in others' formulae than in creating his own clear and crisp doctrine. To question and criticize is easier than to create. Yet the magic of the play embraces Krug's 
existence, even without Ember's or any other commentator's help, and that is precisely the point that Eddington wanted to make.

In Bend Sinister, as in Invitation and The Gift, Nabokov works against a very specific philosophical system. In this regard, there is a logic driving the inclusion of advances in physical science, because they seemed at the very least to undermine the certainties behind materialist positivism and open various other possible explanations of reality, even idealist ones. ${ }^{54}$ In later works, Nabokov never again took on materialism so directly, although its challenge is frequently hiding in the wings. Nevertheless, references to innovative physical theories continue to proliferate, intersecting with various works' main themes in surprising ways.

\section{Struggles with the Material World in Pnin}

Pnin, the "anti-Freudian story," might seem a novel most unlikely to contain a physics-related undercurrent. Its endearing, moving story of a rather clumsy, if brilliant, émigré Russian professor who cherishes his privacy and dislikes his narrator seems far removed from Einstein's or Planck's worlds. A closer look reveals several significant references, beginning with relativity itself. Much like The Gift, Pnin opens with an exaggerated presentation of trains on time, and time on trains, and the shifting duration of similar trips. While traveling to give a lecture at Cremona college, carrying a "stone-heavy bag," Pnin takes a different train than the one suggested in the standard schedule: "I was thinking I had gained twelve minutes; now I have lost nearly two whole hours!" 55 Playing with time, it seems, can be a risky business. Pnin is aware of the vicissitudes of human time from Tolstoy, whose twinned story-plots in Anna Karenina apparently diverge, leaving them about a year apart when they recombine, deep into the novel-producing, as he calls it, "the best example of relativity in literature that is known to me." ${ }^{56}$ In his lectures on Tolstoy's novel, Nabokov proposes that it is due to the intensity and passion of Anna and Vronsky's love (the emotional equivalent of light speed?) that their clocks move faster (although, once again, Nabokov seems to invert the speed/ time relationship that would obtain between relative high-speed and lowspeed reference frames). ${ }^{57}$ However that may be-and in Tolstoy's pre-Einsteinian novel it is surely a simple accounting error-Nabokov's use of this poeticized version of "relativity" serves to heighten the connection between time and consciousness, suggesting ways that physics might open out beyond a purely materialist conception of the universe. 
In an ironic twist, the narrator of Pnin, V.V., appears to be a materialist, and his preference for Newtonian certainties and mechanical predictability becomes his chief weakness and flaw as the conveyer of Pnin's story. Tension between the narrator's story and the described world is drawn to the extreme, as our ability to believe in the teller's objectivity fades away to nearly nothing by novel's end. The narrator supposedly wants to convey an accurate biographical picture of Timofey Pnin, but he also wants a good story, and to him a good story obeys causality and determinism: "Harm is the norm. Doom should not jam. The avalanche stopping in its tracks a few feet above the cowering village behaves not only unnaturally but unethically." 58 That is, he has a belief in the quality and efficacy of a certain kind of story that excludes apparent miracles and happy endings. Pnin's world, by contrast, is one where causality is suspect, a principle we see illustrated when he washes the dishes after his party, and the dropped nutcracker does not shatter the crystal bowl beneath the suds.

Of all things, the inner life of a human individual is the least accessible to knowledge. The question of how to find and convey information about Pnin-his position and velocity, as quantum theorists would have it-is important to V.V., which is why he spends more ink following Pnin's movements (around Europe and around the United States) than he does conveying his thoughts. The narrator-a lepidopterist like Nabokov-struggles with his desire to fix Pnin scientifically and classify him within a logical scheme, but his observations and their expression do not allow him to do this. The challenge is exacerbated realistically by the fact that Pnin himself, perhaps like some imagined particle a scientist attempts to isolate, is aware that V.V. wants to tell his story, that he has already done so in part on several occasions, with gross distortions: he is "a terrible inventor." 59 Like the scientist's observations, the narrator's intrusions on Pnin's life change his course, so that when V.V. arrives to take a position as Pnin's superior at Waindell, Pnin simply drives off in his little blue car (while trying, with some success, to prevent all direct, unequivocal observation of his position and velocity and much more besides: he wants to keep secrets). When V.V. collides with Pnin's world, Pnin is ejected-he ejects himself-like a particle. Neither the narrator nor the reader knows where he will be minutes or hours from the novel's conclusion. (The fact that he turns up in Nabokov's next novel as a department head and "martinet" extends the irony of uncertainty). It is the very uncertainty of his final position that frees him from the narrator's mechanistic tyranny. ${ }^{60}$

Similarly, in a manner reminding us of The Gift and The Real Life of Sebastian Knight, as we become aware of the narrator's conflict of interest 
and his tendency to inject himself into the story, our uncertainty about the story's accuracy grows and grows, until finally we recognize that we have no idea, no way to be certain, where Pnin's “truth" might end and V.V.'s "fiction" begin. This extreme skepticism may not be a tenable position with regard to most of our own sensations of the world around us; but whenever there is an intermediary-an independent observer and tellerwe must become suspicious of that person's inclination to shape our picture of reality. Uncertainty-for Pnin, his impending unemployment-is preferable to somebody else's (pre)determined plan for us.

\section{Time, Space, and Thought in Ada}

If in Pnin relativity and quantum theory serve primarily as peripheral metaphors-for the mysteries of consciousness, for the undefinability of an individual person, for the problems inherent in acquiring and reporting knowledge-in $A d a$, these scientific topics move to the work's creative center, where they become subjected to complete poeticization. This is the novel that began with Nabokov's desire to explore the nature of time through fiction, a philosophical project which led him to confront the history of human conceptions of time. The work is necessarily informed by relativity, but by no means governed by it: for it was while working on Van's treatise that Nabokov attempted to develop a critique of relativity's temporal implications. In this novel, space, time, light, electricity, and mechanics are presented in a way that foregrounds their physical nature while simultaneously straining at the limits that each one implies. As a result, the novel gives the impression of striving to break through all of the laws of physics by finding weaknesses, loopholes, or, simply, more poetic or attractive descriptions of reality creatively derived from theoretical physics. Rather than simply creating "science fiction" based on imaginative extensions of recent discoveries- “Antiterra” as antimatter universe, say-Nabokov explores what it might be like if the laws of physics themselves were subordinate to mind, and could be transformed and molded in acts of aesthetic creativity, just as certain electromagnetic waves become the world of light, color, and the aesthetics of painting.

In other words, when we think about the laws of physics as revealed by relativity and quantum theory, we are led more and more to think: what if even these laws are contingent-as, in the end, they must at the very least be contingent upon the existence of the universe (and as color and other qualities are contingent upon mind)? What if these laws, or 
at least our experience of them, could be fundamentally different? This, in effect, is what Ada imagines when she develops her games with light, shadow, and time that adolescent Van finds so tiresome as a fourteen-yearold: "The shadows of [limetree] leaves on the sand were variously interrupted by roundlets of live light. The player chose his roundlet-the best, the brightest he could find-and firmly outlined it with the point of his stick; whereupon the yellow round light would appear to grow convex like the brimming surface of some golden dye. Then the player delicately scooped out the earth with his stick or fingers within the roundlet. The level of that gleaming infusion de tilleul [lime tea] would magically sink in its goblet of earth and finally dwindle to one precious drop." ${ }^{11}$ Consider the implications of this game: light, a transient presence between the shadows of leaves, metamorphoses into a liquid, a "golden dye." Ada's game suggests a completely new relationship between the senses and light, in which instead of an ethereal electromagnetic radiation, light takes on the substantiality of a body, to be weighed, touched, poured, counted. What would it be like to live in a world where the stuff that, for Einstein, helps define space and time (through its speed) could be stopped and held in a goblet? Such a transformation offers a glimpse of perspectives on the real beyond even those proposed by the new physics.

Water and light are the novel's two key natural elements, and they undergo various colorful transformations, playfully invoking light's centrality in modern physics. Alexey Sklyarenko has suggested that the first chapter contains a coded spectrum and that the entire novel is figured as a kind of rainbow-which is, of course, the spontaneous, natural generation of color from water-refracted sunlight. ${ }^{62}$ Light and water are intimately connected throughout the novel, most distinctly at its moments of greatest dramatic tension. Lucette's name openly recalls light, while her lineage (mother and aunt Aqua and Marina) evoke both water and the color produced by light shining in seawater. Lucette goes to her end in the ocean, her light thus swallowed up by water.

Light and water evoke thoughts of Antiterra's "L disaster," suggesting a motivation for its inclusion in the novel. The term refers to electricity and some calamity that ensued from its exploitation by humans-the "Lettrocalamity," as Van once calls it. ${ }^{63}$ The use of electricity is banned on Antiterra, its role taken over by hydraulics. Not electrons, but water molecules must provide the means by which to telecommunicate and perform other work-saving tasks. Water, however, fails to manage all of the functions of its precursor-Van laments the loss of tape-recorders-but apparently it serves some purposes, epitomized by the "dorophone." Lucette, as 
the novel's primary onomastic source of light shining through its watery medium, produces its multifarious rainbow effects. The waves into which Lucette sinks remind us also of light waves and the wave-like properties of matter, generating the rainbow of the text. The $\mathrm{L}$ disaster, in turn, represents the hubris of humanity's partially ignorant exploitation of the secrets of nature: it is dangerous to make a utilitarian device out of something that we will "never understand." Composing a novel which, on the one hand, is merely a family chronicle and, on the other, is also a source of beautiful prismatic effects in a "literal" sense, ${ }^{64}$ Nabokov strives to demonstrate the mysterious complexity of existence. This complexity, it should be noted, has a special character dependent upon consciousness, for as scientists beginning at least as early as Goethe observed (and as emphasized by other critics of Newton's work), there is no such thing as color outside of perception and representation. Without this field of consciousness, colors are nothing other than collections of electromagnetic waves of distinct amplitude and frequency. Thus color (produced when light is reflected or refracted, filtered or scattered, or when a source emits specific wavelengths) is the feature that defines the transformation of the world of radiation (light) into the world of consciousness. ${ }^{65}$

By the 1960s, Nabokov appears to have decided to give relativity closer, more critical scrutiny from a fictional point of view. Nabokov bridles at the limits set by light's speed, and also at time's apparent contingency upon relative speed. In his notes taken as he read philosophical and popular scientific treatises in preparation for writing $A d a$, he argues with relativity's tenets. In particular, as he worked on "The Texture of Time" (Van's philosophical treatise), he wrestled with the Minkowskian tendency to link time to space within a four-dimensional manifold. Van is a psychologist, novelist, and philosopher, and his abilities in mathematics are suggested when we learn that he could "solve an Euler-type problem" at the age of ten. ${ }^{66}$ Like Nabokov, Van read heavily in literature related to the science and philosophy of time after the appearance of relativity, and his background and intelligence are meant to suggest that he had the wherewithal to comprehend the most difficult aspects of this subject matter.

So when Nabokov read about time and relativity in the 1960s, and when he parried Einstein's version of the time-space-speed relationship, it is plausible to suggest that the conclusions he reached were colored by his effort to create his character's vision. "I suspect I don't" accept all of Van's conclusions, Nabokov said, but he values them as working hypotheses that challenge what had become a scientific orthodoxy. ${ }^{67}$ Such challenges were 
a part of the artist's and the philosopher's calling in an effort to continue the expansion of human knowledge.

In the spirit of this challenge, he wrote, "I have no use for the artificial concepts of space-tainted time found in relativist literature." 68 In the novel, Van's version became: "We reject without qualms the artificial concept of space-tainted, space-parasitized time, the space-time of relativist literature." Also: "What many cosmogonists tend to accept as an objective truth is really the flaw inherent in mathematics which parades as truth." His main concern appears to have been to recognize for time a reality apart from its use as a measure of change in the physical world. Van writes, "one can be a hater of Space but a lover of Time." ${ }^{69}$ Considering his opposition to causality and purely materialist philosophies, this is no surprise. Nabokov concludes that "contrary to the assertion [in Fraser, The Voices of Time] that in a world that had 'no natural change by which one state of the universe could be distinguished from any other' there would be 'no basis for a concept of time.' This is nonsense. Even in 'such a quiet world' time would exist and that is the trouble with time." other words, the "states" of the universe-here taken to be purely physical states, detectable with the help of various instruments-and their changes exist within or alongside of time, but do not constitute time through their processes of change. Whatever conception of time can be derived from mechanical change, it is at best a highly limited and narrow one, Nabokov suggests. Commenting on G. J. Whitrow's presentation of the idea of the "chronon," the hypothetical, indivisible base unit of time, and its source the proton, Nabokov remarks, in brackets, that " 'protons' and 'chronons' may prove to contain as many worlds of matter and time as there are atoms in the universe." ${ }^{71}$ This argument reflects an affinity with Romantic predecessors, and it echoes some of his own youthful musings about the universe. It expresses the desire always to explore past a given level of reality to its substrate or underlying components, onward, perhaps, to a regressive infinity. Van's treatise demonstrates a philosophically grounded refusal to accept a definably material basis for existence or for time. As we have seen elsewhere, Nabokov surmises that consciousness itself may have a closer connection with "pure" or "ultimate" time than does space or space-time-and this is why he rejected the idea that high-speed travel through space might have its own independent effect on the experience of personal time.

A conviction of time's independence from calculations of spatialmechanical change derived from Nabokov's sense that the universe may be more complex and mysterious than human mathematics can imagine; that 
whatever truths or even absurdities such calculations might produce, they still only represent a particular, limited structure, for which one can imagine an outside, encompassing or generating system. This intuition, that mathematics is a limited, closed but not complete system, puts Nabokov's thought close to Kurt Gödel's “incompleteness theorem," of which he could have read a popular account as early as 1958, which states, approximately, that all sufficiently complex mathematical systems must contain propositions that cannot be proved true or false-therefore, they are not complete. ${ }^{72}$ In one note, also recalling Heisenberg's uncertainty principle, Nabokov wrote, "There is indeed a profound connection between the reality of time and the existence of an incalculable element in the universe. An element of indeterminism and irreducible contingency in the universe."73 In his conviction that time and consciousness are not strictly subject to the mathematical laws of space and matter, Nabokov suggests that they are both signs of gaps through which the "outside," the "beyond"-the irreducible contingency—of the system can be hazily glimpsed.

This mode of thought was encouraged by J. W. Dunne, whom Nabokov was also reading while he worked on Ada. He noted approvingly the following statement in Dunne's The Serial Universe: "Classical science involves, employs, and asserts ... the view of every observer as an external potential interferer with an otherwise 'determinate' universe. . . . The determinist bogy - that alleged offspring of classical science-was never even conceived, and the birth certificate signed by the materialist was a fake."74 Dunne's rather esoteric argument relies on the regressive notion that all interfering observation (and all observation is interference) is embedded within a time-frame superior to the one which is observed and interfered with. These receding temporal vantage points produce receding perspectives wherein each level contains its own set of distinct "observables," no less real than the one we think of as empirical reality, but removed from our conscious awareness. These very concepts appear in greater relief in Transparent Things, where the metaphysically superior narrator and his colleagues see physical objects in their full temporal extension, from the present to distant past as dispersed molecules (but not very far into the future), demonstrating a partially causal chain upon which they, as otherworldly beings, can have only the slightest influence. A similar regression to a broader temporal perspective that recognizes a specific layer of significance, invisible within the ordinary chronological flow of events, can already be discerned in The Real Life of Sebastian Knight, for example, in the idea of the identical pattern created by two brothers' superficially contrasting styles of tennis play. ${ }^{75}$ 
Nabokov as a young boy was a mathematical prodigy, a gift he lost during a bout of pneumonia at the age of seven. ${ }^{76}$ As he begins his series of note cards on relativity, he opens by casting doubt on the ability of mathematics to express the very deepest truths of the universe and its essence. In a note anticipating his comment about Einstein's “slick formulae," he wrote: "The mathematical universe of Einstein et al is an unreal world, a jumble of symbols, a flourish of formulae." 77 In another card he seems to criticize Whitrow for accepting the physical consequences of relativity; the relativist "has discovered not an objective truth, but the flaw, inherent in mathematics, parading as truth ... An example of the mental monsters produced by mating 'light $=$ signals' with 'traveling clocks' by means of mathematical formulas [and not by hand as I suggest]." 78 That "flaw inherent in mathematics" once again, deliberately or by chance, echoes Gödel's theorem. Through several numbered cards from sets labeled "Relativity" and "Simultaneous Events," Nabokov lays out ways to contradict the time-traveling implied by relativity, and to reassert the notion of simultaneity, which relativity had effectively nullified on the grander scales of cosmology. ${ }^{79}$ "The world-as-observed at a given instant of individual time cannot be identified with the world-as-it-is at a definite instant of universal time. [it could if the observer were everywhere simultaneously]." 80 These considerations depend upon creating the concept of an observer who transcends the physical possibilities made available within the system-that is, the empirical universe with its physical laws, as known. To illustrate this idea, on another card Nabokov describes an enormous hand touching two remote points in the universe, and conveying information about each of them to the hand's owner, simultaneously. Van, in Ada, notices the difficulty of this line of argument: "will it not be touching both at the same time-or are tactile coincidences even more misleading than visual ones? I think I had better back out of this passage." ${ }^{81}$ Physicists reject such arguments because they have no relationship to anything we can possibly observe or know-and also because nerve signals are subject to speed limits. Indeed, such a large hand would be so massive-the size of untold numbers of stars- that its gravitational consequences would be profound, if not cataclysmic, for all objects in its gargantuan neighborhood-unless, of course, it were an immaterial hand, not subject to scientific observation or inquiry. Be that as it may, Nabokov's desire to exploit these apparent paradoxes reveals his insistence on the contingent and subordinate essence of what he called Visible Nature and its discovered laws.

Nabokov struggled with these relativistic effects, perhaps because he wanted to be able to refer to time as something that remained self- 
consistent in a way accessible to human consciousness, and also as something beyond deterministic causality. He seemed concerned that Minkowskian space-time might eliminate time as one face of the universe's mystery. In the end Nabokov, through Van, senses that his best strategy is to restrict himself to time as experienced, although he was constantly tugged-by the relativist literature as well as by personal predilectiontoward the far-off stars: he begins one late note, "Remote objects in extragalactic space," but then interrupts himself: "[but I am interested only in local time]," 82 as if recoiling from a constantly reappearing temptation. If he can limit his discussion to time as experienced locally, then at least he need not win an argument with physicists and mathematicians. ${ }^{83}$

The world portrayed in $A d a$ is not exactly our own: the action takes place on "Antiterra," a planet with a history similar to Earth's, but with significant differences in historical detail, geography, and chronology. The distortions have been interpreted in a variety of ways, but I suspect that the best approach, encouraged by the novel itself, is the suggestion that this might be an "anti-world," existing in some kind of secret relationship with its "Terra" partner. ${ }^{84}$ Nabokov's novel proposes that these two antiworlds might have some sort of access to one another through consciousness; such contacts, which are the object of Van's psychiatric research as well as of a cult of "believers" on Antiterra, tend to appear through a variety of mental instabilities. The differences-distortions, from our point of view-might be well explained by Nabokov's rejection of pure determinism, so that even if two worlds are twinned through obscure psychophysical channels, each is still free and independent of the other, within a certain set of constraints. ${ }^{85}$ In this way, Antiterra may represent the macroscopic consequences of subatomic indeterminacy in mirror-twinned worlds-as imagined by Nabokov.

It is highly unlikely that Nabokov knew of the many worlds interpretation of quantum mechanics, which was first proposed in an obscure paper in 1957 but not popularized until the late 1960s and 1970s. More likely, he derived his Antiterra concept from H. G. Wells’ Men like Gods (1923), a novel in which people travel between Earth and its parallel world, Utopia, or Murray Leinster's "Sidewise in Time." ${ }^{86} \mathrm{He}$ also made his own imaginative conclusions based on the advances in theoretical physics he had seen. It is extraordinary that Nabokov has Van consider the parallel existence of alternate realities, and the tree-like forking of a life's possible paths. This instability of causal pathways is a recurring feature in Ada, and sometimes reality metamorphoses from one face to another before our eyes. For example, after his father forbids the siblings' relationship, Van appears to 
attempt to shoot himself: "He pressed [the trigger]. Nothing happenedor perhaps everything happened, and his destiny simply forked at that instant, as it probably does sometimes at night, especially in a strange bed, at stages of great happiness or great desolation, when we happen to die in our sleep, but continue our normal existence, with no perceptible break in the faked serialization, on the following, neatly prepared morning, with a spurious past discreetly but firmly attached behind. Anyway, what he held in his right hand was no longer a pistol but a pocket comb which he had passed through his hair at the temples." 87 This formulation, focusing on the intersection between the boundaries of consciousness and the future's alternate possibilities, once again puts mind in a pivotal position in reality's progress. This "forking" model is closer to the many worlds interpretation of quantum theory than to the world- or dimension-hopping in Wells' or Leinster's novels. Nabokov's artistic intuition brought him to contemplate ideas very similar to those of contemporary physicists, in a remarkable demonstration of the common ground shared by artistic and scientific investigations.

Ada represents the artistic culmination of Nabokov's interest in physics, but the novels I have passed over, while not exhibiting the same degree of explicit play with physics-related concepts, all include quiet variations on the themes found prominently in other works. The Real Life of Sebastian Knight (written in 1938), with its questing researcher, V., who collects the facts of his brother's life, elaborates the concept of the problematic observer whose consciousness shapes the object while also being shaped by it, leaving the reader in a state of utter uncertainty about where the "real" boundaries of the novel's world lie. V. also refers to Sebastian's artistic practice in his novel The Doubtful Asphodel as a collection of themes that interact and communicate the book's hidden meaning through "a succession of waves"- - a phrase Nabokov echoes in his 1940 lecture on Chekhov and in "Ultima Thule." 88 Pale Fire (1962), which includes occult messages communicated by a circlet of light, is also structured so that in the midst of many puzzles and their solutions, the reader is left with utter uncertainty about the "real" ground for the novel's action. This uncertainty, or hints about possible or definite flaws in the descriptions we are given by various narrators, became one of the most common and varied structural motifs in Nabokov's work after 1934. The same impulse brought him to create Look at the Harlequins!, a novel that plays with metaphysical implica- 
tions of left-right symmetry on the molecular level, as Nabokov had come to know it from Martin Gardner's The Ambidextrous Universe and other physics books he read in the 1960s while working on Ada.

I have suggested that in every novel from Invitation to a Beheading on, a total of ten novels, Nabokov made major or minor use of concepts from twentieth-century advances in theoretical physics. Lolita might be singled out as a misfit in this group, but it activates many of the same uncertainties that we find in The Gift, The Real Life of Sebastian Knight, Pnin, and Pale Fire. These entanglements with modern physics often contribute to philosophically tinged aspects of Nabokov's works, echoing the fact that the leading early-twentieth-century physicists themselves all became philosophers interpreting their own theories. For a writer whose main theme has been identified variously as "the artist," or "nymphets," or "exile," or "the otherworld," or "individuality," this consistency is striking. It tells us that whatever dominant subject Nabokov may have placed at a work's center, he was always considering it within a series of expanding contexts that included a search for the hidden solutions to nature's cryptogram. It is especially characteristic that his engagement with these theoretical concepts is essentially playful, challenging, and even irreverent. For although relativity and quantum theory had rattled humanity's picture of the universe, Nabokov clearly thought that they were but signs of the incompleteness and mutability of knowledge. His own created worlds, likewise, are ones that keep us forever seeking and forever guessing. 


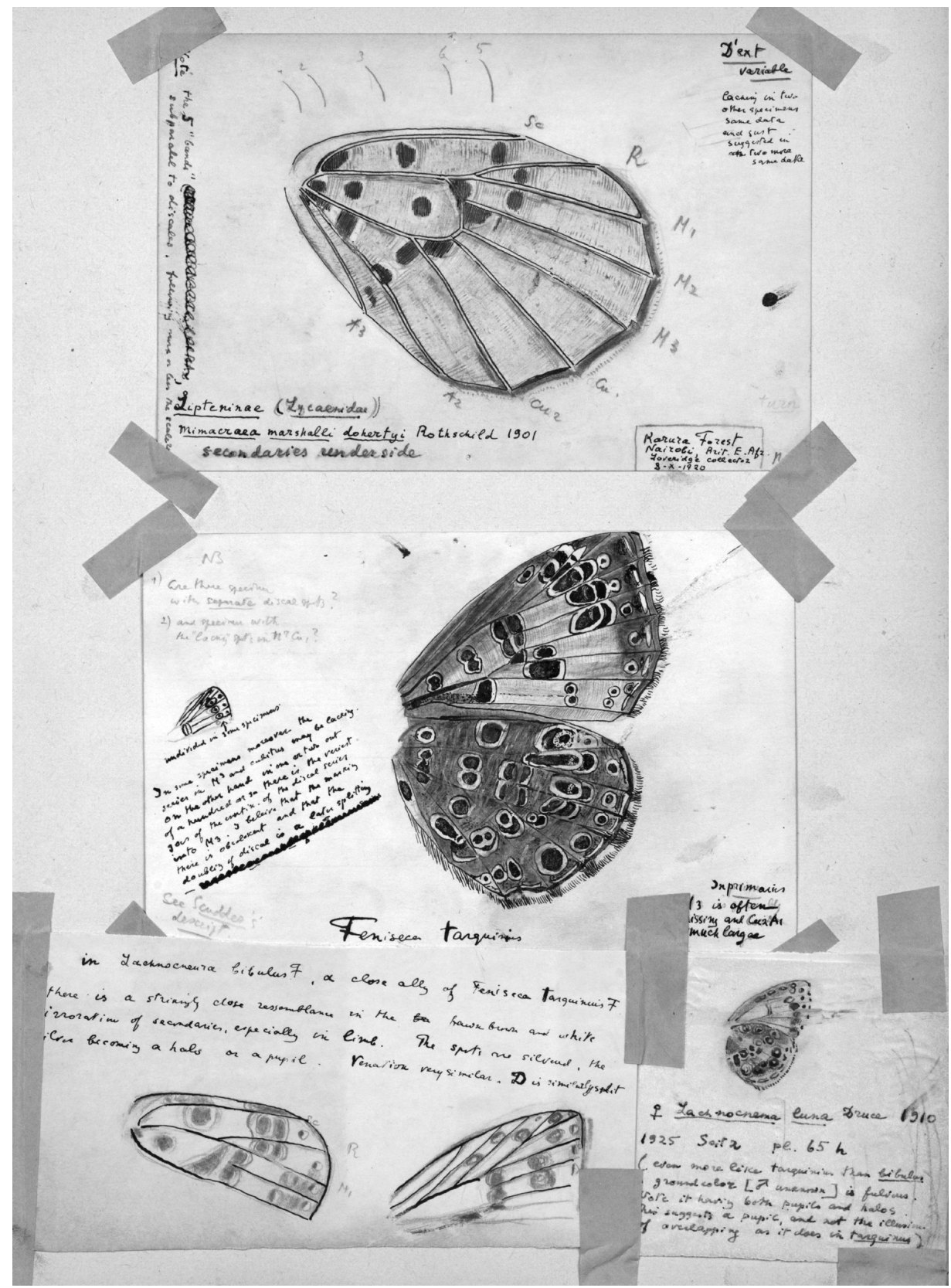

\section{Figure 7}

Wing diagrams. The middle image, labeled "Feniseca tarquinis," has an annotation on the left showing Nabokov's interest in absent features in nature. The paragraph begins, "In some specimens moreover the $\mathrm{M}_{3}$ and culitus may be lacking ..." and goes on to discuss how such an absence may be a sign of evolution. (Source: Henry W. and Albert A. Berg Collection of English and American Literature, The New York Public Library, Astor, Lenox and Tilden Foundations) 


\section{Minding the Gap}

\section{DISCONTINUITIES IN}

NATURE, ART, AND SCIENCE

His writing was a series of gaps, and you cannot ape a gap.

—Nabokov, The Real Life of Sebastian Knight, 1941

IN ONE OF HIS most quoted aphorisms, Nabokov once said, "Whatever the mind grasps, it does so with the assistance of creative fancy." ${ }^{1}$ The gist of this claim, and its usual interpretation, is that imagination plays a key role in determining "reality" as known and experienced by an individual. But in the passage, "fancy" transforms quickly into a scientific image: it is "that drop of water on a glass slide which gives distinctness and relief to the observed organism." Fancy is the medium of viewing, and thus it makes the viewing possible, gives it clarity and perspective. If the medium is adequate, the object can be observed distinctly. But let us take a step back to reconsider the phrase, "whatever the mind grasps": what about the things it doesn't grasp? Nabokov's essentially Kantian position on ungrasped things is apparent in his assertion that "we shall never know the origin of life, or the meaning of life, or the nature of space and time, or the nature of nature, or the nature of thought." ${ }^{2}$ This amounts to an insistence that there will always be a domain beyond the ken of human consciousness in its present form, and that it is in this unknown domain-the interspaces or beyond of knowledge-that the essence of these ultimate questions lies permanently concealed. Nevertheless, Nabokov presents the possibility in his work and outlook that by detecting irregularities such as 
patterns in the shape of a life, anomalies in the evolution of life (such as nonutilitarian mimicry), apparent ruptures or lapses in laws of physics, and, perhaps, inklings of "paranormal" phenomena, one can intuit the presence of "the reverse of the weave," or the world's "unusual lining"or, more simply, the existence of an invisible, unknowable, wider context for phenomenal being with which it is intimately connected. ${ }^{3}$ The question finally becomes whether one can perceive, even indirectly, gaps and tears in reality's texture. Science usually points away from its own blind spots; Nabokov wanted instead to celebrate them as places to seek intimations of deeper realities.

The common thread through the preceding chapters has related to Nabokov's apparent interest in the limits of science, in its revisability and reversibility. In all three areas of scientific inquiry that find some expression in his work-biology, psychology, and physics-Nabokov seeks out the insufficiencies at the farthest ends of possible knowledge: biological science, he thought, fails to explain some examples of mimicry and of beauty; psychology raises more questions than it answers; and physics seems to arrive at impossible conceptions of "time" and overemphasizes the power of mathematics. On the whole, he demonstrates suspicion of mathematical and psychological generalization and contempt for intellectual fashion. Thus at first Newton and Darwin, and eventually even Einstein, become emblems for systems of knowledge that are subject, on the one hand, to ossification, oversimplification, overconfidence, and blindness, and on the other-to expansion, subversion, even reversal. The case with Freud is somewhat different, as his writings represent (to Nabokov) not so much a scientific endeavor as an impressionistic theorizing based on a particular mass of collected data, an archeology of the unconscious mind as expressed in his psychiatric patients, in himself, in myth, and in literature. The central hypothesis of Freud's approach-that adult neuroses have their source in the mishaps of childhood sexual maturation-was not so much tested as applied en masse in the years following World War I and simultaneously adopted as the main ideology of the growing psychoanalytic community. As a cultural dominant and defined intellectual program, its theory of mind, self, and unconscious was equally vulnerable to the pitfalls of the "harder" sciences of biology and physics.

Nabokov occupies a unique place in modern intellectual history not only because of his dual status as an artist and a scientist, but because his scientific work left him skeptical about the ultimate ability of science to provide answers to questions that most concern humanity. This is not to say that Nabokov did not believe in the value of scientific work-he 
valued it very highly-but rather that he was ever wary of the ease with which scientific knowledge can turn into epistemological overconfidence, the development of political agendas, and the destruction of intellectual freedom. There is a specious irony in this juxtaposition of such skepticism with the "strong opinions" expressed in various interviews and essays. Specious, because many of those very opinions are the places where Nabokov warns most urgently against the dangers of certain knowledge and claims about "reality." Conversely, although he may have been intrigued by the uncertainty principle, that does not mean that Nabokov felt that all knowledge is radically uncertain or observer-dependent. Rather, his art and his science both demonstrate an instructive attraction to basing one's conclusions upon massively detailed empirical evidence, provided by the senses and available tools, and to preserving an awareness that any such conclusions are always tentative and partial, even when they appear unquestionable. Scientific research tests hypotheses about nature, and the validity of results is certain only to the extent that they can be replicated in experiment. Explanations of scientific data tell a story based on the specific facts of an experiment. But those data are always partial (sometimes more, sometimes less), and the mere existence of missing data, of hypothesized but unconfirmed phenomena, stands as an inescapable fact in the scientific grasp of the world. It is exactly that fact that is most easily ignored in a society where science can be appropriated as an engine both for progress and for political opportunity. ${ }^{4}$ Our knowledge of the world is inherently gappy and partial; science expands knowledge but does not change its fundamental incompleteness. It is this epistemological skepticism, combined with a passion for discovering what can be known, that defines Nabokov as an artist and as a scientist.

One distinct feature of Nabokov's intellectual stance is his consistent impatience with inaccuracy, sloppiness, generality, and dishonesty. In some notes for the "Butterflies of Europe" project, he observes that "The only other writer in the world whom I can think of, that constantly and with beautiful exactitude refers to butterflies in his works is Leon-Paul Fargue. It should be added that Aksakov's chapter on butterfly collecting is beneath contempt scientifically." ${ }^{5} \mathrm{He}$ ruthlessly critiques falsehoods and mistakes wherever he finds them, from Holland's "hopelessly inaccurate" The Butterfly Book to translations of Eugene Onegin. ${ }^{6}$ The point of this activity is that some things have been or can be discovered and established with reasonable confidence, if one thoroughly takes into account available information. When a lepidopterist misclassifies a species or genus of butterfly in a major reference work, Nabokov suggests, mistaken knowledge spreads 
throughout the community, taking the place of accurate knowledge. Likewise, to pretend to possess knowledge that is in fact lacking, or to present information that is mistaken instead of available information that is correct, is far worse than a glib confession of ignorance. In creating and perpetuating myths of truth, knowledge, and authority where none is present, good scientists along with fabricators and bunglers appease and foment the human expectation of such knowledge, abetting human complacency as a consequence of knowledge falsely won. Displacing established falsehoods is even more difficult than discovering new scientific truths, as Nabokov's own career shows, and each false trail that becomes dogma represents more than a simple misstep in the advance of knowledge. Notwithstanding the acknowledgment of limitations in most scientific articles, the human preference for even false certainty over ambiguity is deep-seated, meaning that when a mistaken theory is unambiguous and rhetorically powerful, it stands a decent chance of overwhelming reasonable doubts and equivocal counter-evidence, at least for a time. Such was the case with the Ptolemaic model of the solar system, or the early resistance to plate tectonics. ${ }^{7}$

In his own work as a lepidopterist, Nabokov not infrequently drew attention to the limitations of his knowledge as a researcher-to the limited number of specimens at his disposal, to the lack of corroborating data on a given preferred theory, to gaps in a projected continuous series of forms. We saw this in chapter 1 in discussions of speculative but probable intergradations between known species; in subspecies Nabokov had identified but which he admitted might in fact be hybrids; and in his reluctant hypothesis that members of the subfamily Plebejinae entered South America from Asia via Alaska, rather than by some other land bridge, even though no related forms existed in the alleged expansion route. ${ }^{8}$ Notice in the following passage from his drafts how he defines the quality of a taxonomic category in terms of the gaps separating it from other such categories:

Genus. The quality of a genus i.e. its natural or its artificial condition depends upon the gap between it and any other genus and also upon the interspecific gaps within it. The greater the intergeneric hiatus and the smaller the interspecific ones the more natural the genus appears.

But when-with a sigh of relief-we find a beautifully limited "natu-

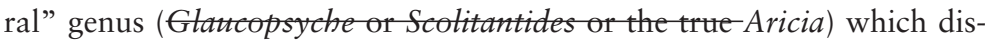
plays a number of species closely linked-and yet different-in pattern and structure, all having a most satisfactory air de famille,-we are, I am afraid, deceiving ourselves: this "natural" genus is but an extended 
species, and its representatives are so to speak fresh from the subspecific oven-they have just crossed the limit of specific alliance, of racial vassaldom-they are "good" species all right—but this rank has been acquired so recently that they still display exactly those conspecific features that we clutch at as being characteristics of a "natural" genus. The slender bridge between a species containing a number of well-defined subspecies and a well-defined genus containing a number of closely allied species is thrown over a stretch of very shallow water indeed. ${ }^{9}$

The gaps are crucial, because if there are none-if the series of forms is perfectly uninterrupted-then one is dealing with a "genus" that can hardly be distinguished from a polytypic species, and its absolute status is difficult to determine without the assistance of time. The presence of distinct gaps within a genus, or between genera, allows the taxonomist to create certain boundaries, but these delineations are always tentative. The synchronic approach restricts the scientist's ability to understand the status of a form or group of forms; diachronic study, if only it were possible, would free the observer from the illusion of fixed forms presently found in nature. ${ }^{10}$

As a taxonomist, Nabokov was fascinated by the equivocal status of forms whose position in the classificatory system could change based on human research: as he wrote, “... a monotypic species can turn into a polytypic overnight-it is a case of bibliography not biology." ${ }^{11}$ In regard to his own conclusion that Cyclargus Nab. was a monotypic genus (with ammon Lucas its only species), he wrote that "it is quite possible that someone else will 1) find that ammon produces well-defined local forms in some corner of Cuba or 2) [supplement these data] with facts which were unknown to me-and in result the monotypic ammon may revert without any evolutionary activity on its own part whatever to the polytypic aspect it had prior to this paper." 12 And of his most significant accomplishment, his revision of the more than 120 subspecies in the genus Lycaeides, he wrote to Edmund Wilson that its scientific authority would stand "for some 25 years, after which another fellow will show how wrong I was in this or that. Herein lies the difference between science and art." 13 The greater knowledge of the natural world, Nabokov recognized, was in constant flux. Gaps are discovered, others disappear, and still others go unnoticed, depending upon the tools and criteria used to measure and define discovered forms. Thus human knowledge of nature's processes remains, like nature itself, a flowing, changing entity, rather than a stable structure that expands as new units of information are annexed to it. It is for 
this reason that Nabokov insisted on basing that knowledge upon precise, detailed observation, and on allowing gaps in knowledge to remain visible.

Nabokov was aware that generalizations and abstractions are uncertain and transitory, but a detailed, specific observation has enduring validity: "Whatever the method employed and no matter the length and uniformity of his series, what he is describing is not an a priori geographical subspecies but the specimens he has before him. Only time assisted by several polemically minded first, second, third and Nth revisers, can settle the objective existence of this or that geographical subspecies, but this can in no way cancel or distort the particular meaning of a clear description based on the actual structure of any actual insect." ${ }^{14}$ Specific descriptions of individual specimens and the power of precise observation do not ensure a better theory, but they do allow access to facts. In his 1950 response to Martin Brown's critique of "Nearctic Members of the Genus Lycaeides" Nabokov demonstrates vividly how he considers specific judgments based on detailed knowledge of individual cases superior to, and more meaningful than, statistical presentations of general frequency or range of a given structural peculiarity. As he says, "I have been concerned with 'qualitative' subspecies (since I consider that merely 'quantitative' phenomena have no taxonomic status) and with trying to restore the qualitative approach to its position of honor, while placing at its service quantitative values to guide the next man ..."15 This distinction between qualitative and quantitative, and the subordinate status of the latter, is pivotal: seeing and perceiving are placed above measuring and counting, which are made to serve the qualitative evaluation. The fact that Nabokov did not appreciate statistics is an expression of his passion for the precise observation over the abstract, general rule. This principled stance implies a reluctance to neglect the individual case with its "qualitative" elements, and an abiding suspicion of the suppressive power of statistical generalization. Nabokov appears to be repulsed by the tendency of statistics to obscure or elide the data from individual cases in favor of an average value. His aversion to "generalities" (as he called them) may have prevented him from noticing the explanatory boost given by statistical information about baselines and ranges to serve as background for descriptions of particulars. ${ }^{16}$ Nowadays, we take for granted that statistical analysis is a powerful tool for understanding large amounts of data. But to the extent that statistical interpretation can come 
to take the place of looking with extreme care at new examples—of seeing groups not as "averages" but as sets of individuals-it is at least potentially misleading, from Nabokov's point of view.

Looking attentively at a particular butterfly reveals both positive and negative features. Nabokov was "interested more in what happens within a given interspace than in the wing pattern as a whole." ${ }^{17}$ But each of a species' traits can vary across individuals, and these variations create a different kind of pattern that seems to move observation from the synchronic to the diachronic level. As a conclusion of his "Notes on the Morphology of the Genus Lycaeides," Nabokov proposes a dynamic terminology for indicating the fleeting essence of a species. This terminology is based on "the specific repetition, rhythm, scope, and expression of the generic characters supplied by the eight categories discussed." 18 "Rhythm" is the most dynamic of these, so that when all the possible characteristics of a species are considered, their predictable or surprising presence or absence in various subspecies taken into account, "these omissions, gaps, fusions, and syncopatic jerks will produce in one species a variational rhythm different from that of another." This rhythm is itself a secondary phenomenon, a mobile pattern of presence and absence that is seen to characterize a species, without necessarily defining it. This is a purely metaphorical transformation of geographical diversity into an approximation of temporal flow (rhythm); Nabokov uses the irregularity of present-day species as an analogy for the fluid, changing nature of species across time as well.

\section{The Myth of Infallibility}

Nabokov's special perspective on science and its limits gave him a particularly contemptuous view of socialist positivism and its desire to construct a perfect society through the advancement of scientific knowledge. Of course, it might also be suggested that his personal catastrophe at the hands of the Bolsheviks was the cause of his critical, anti-positivist approach, but such a possibility looks very unlikely, in the context of everything known about his life. Growing up in a social context sympathetic to liberal humanism and to idealism-his father's Kadet party-Nabokov faced no immediate pressures to embrace positivism. His childhood reading of William James' Principles of Psychology, for example, would have only heightened his sense that scientific discourse is but a subset of broader discourse: it "answers to philosophy." James goes to great lengths to demonstrate that one can produce a scientific work that is strict in its attention to fact and 
observable laws, but at the same time expresses awareness of its limited sphere of application. Russia's transformation into a regime embodying epistemological assumptions absolutely antithetical to Nabokov's encouraged the extensive expression and artistic elaboration of an epistemological outlook that was already deeply held.

This struggle takes its most explicit, if not its earliest, form in chapter 4 of The Gift, Fyodor's "The Life of Chernyshevsky." This work sets out to demonstrate the hopelessly self-contradictory nature of socialist thought by creating a factual collage of telling events in the life of the famous radical. The most striking contradiction for Fyodor is that the "materialists" have a poor understanding of the natural world, one which is clouded by their utopian ideology. ${ }^{19}$ Fyodor inserts (and perhaps exaggerates) Chernyshevsky's quest to create a perpetual motion machine as an emblem of the materialists' social alchemy. He suggests that Chernyshevsky's ignorance of nature and erroneous approach to physics caused him to bump up against unforeseen obstacles in his life. This clumsiness forms the backdrop for the socialists' scientific program, which-one way or the other-was meant to assuage all of humanity's ills. This confidence in the ability to craft a new society based on rational principles and logical self-interest received its first public debunking in Notes from Underground by Fyodor Dostoevsky, not usually Nabokov's ally but in this case treading the same ground with him. It was the certainty, the Promethean impulse behind Leninism (combined with its abandonment of traditional, bourgeois values) that allowed the Bolsheviks to undertake the complete re-creation of society and humanity-with no regard for the cost in human lives.

Gaps in human knowledge are inevitable, but when they are denied the results can be disastrous. For Chernyshevsky and his followers, the desire to craft an all-encompassing worldview rendered the elision of gaps a practical necessity. But his own limitations are displayed in his (alleged) ignorance of the natural world; they receive a further dramatization when he is found to be reading a public lecture from "blank pages" in his notebook ("a gruesome symbol" is Fyodor's only comment). ${ }^{20}$ His near-sightedness makes explicit his inability to envision the minute details of the factual world around him-phenomena which really are there, but which he does not perceive. This limitation need not be taken as a special criticism of Chernyshevsky himself: his poor eyesight is analogous to the human condition generally, although his failure to recognize this flaw sets him apart. It is not only that the world's details cannot be seen, but also that they often go unseen even though they might, with care, be noticed: it is easy to overlook things one is not trying to see. Such tunnel vision 
anticipates Hermann's obsession in Despair. He not only finds his exact double where none exists-because he was looking for him-but he also overlooks the most important bit of incriminating evidence in the midst of his "perfect murder": the victim's engraved walking stick left behind in the car. Like Hermann, Chernyshevsky and his successors are implied to have overlooked the inevitability of gaps and shortcomings in their vision of the world, and as a result they paved the way to a political system that was bound to move from mistake to mistake as it produced an alternate reality of horrific proportions.

The problematic concept of mechanical perfection in the production of a utopian society receives special attention in Bend Sinister, in a device called a "Padograph." Bend Sinister is the only Nabokov novel that depicts in some detail the workings of a utopian state based upon a positivistic, materialist outlook on the potential of human progress. As such, it figures a regime which, like that of the Bolsheviks, aimed to create a fully rationalized society, where all behaviors were calculated and studied as potential components in the quest for equality. The novel's central image expressing this civic faith in human technology is the "Padograph," invented by the new dictator's father. This machine was designed to produce perfect forgeries of any handwriting, with the result that a person's script was no longer a trait of individuality. ${ }^{21}$ Now, while it may seem self-evident that there is more to individuality than handwriting, in Paduk's reasoning this device was the first step towards eliminating the unfair and pernicious differences among people's talents. The mechanical ability to mimic handwriting perfectly was thought to presage the triumph over individualism, as if such a mechanical feat, itself fairly simple, had profound consequences for the state's ability to manage and equalize various individual personalities. This overconfidence in the machine leads to illogical and impossible conclusions-and grim consequences. Like his logic, Paduk's ideology is flawed, and as a result it creates monstrosities in all of its further developments. It is not based upon a scientific view of the world but on an abstract theory (we may recall here Goethe's warnings about the dangers of theory), yet it becomes the guiding spirit of the nation's science, which like everything else in the Ekwilist state must forego excellence, because excellence is anti-egalitarian. As a result, the regime's doltish psychologists are more concerned to study the amelioration of criminal and violent natures than to protect and foster vulnerable children. (This bizarre distortion of logic appears to embody Nabokov's suggestion that once one has abandoned principles of reason and humanism, a situation arises where no result is truly illogical.) 
For Nabokov, the concept of knowledge of the world came to be connected with knowledge of specific phenomena and also with the possibility of accurate copying or representation of these phenomena. The "Padograph" is a travesty of such copying and also a parody of the repeatability of scientific experiments. The trope of copying is also relevant both intertextually, as a reminder of Gogol's "The Overcoat" and its copy-clerk Akaky Akakievich, and metapoetically, as an echo of Fyodor's, and later Nabokov's, claim to be copying down a text with its own transcendent existence. In his less guarded moments, Nabokov admitted that his contact with this transcendent artwork did not give him full knowledge of what possibilities were contained in each creation. ${ }^{22}$ This transcribing process can be assumed to be as accurate as human perception can muster, but it is not mechanical or all-encompassing: apparently, there can be gaps in the author's awareness of the creation's signifying power.

\section{Unrepeatability: Translation, Knowledge, and the Unknown}

Such incomplete transcriptions suggest an illuminating comparison with scientific work. Scientific observations must be repeatable; but that does not mean all forms of knowledge are, or can be, repeatable. Artistic inspiration may resist a single perfect transcription. The experience of that inspiration may be unrepeatable, and its expression in art does not follow the rules of science and may be incomplete. Sensitivity to such incompleteness characterized Nabokov's approach to science and, even more dramatically, his scholarly approach to literature. His translation with commentary of Alexander Pushkin's Eugene Onegin is a monument to the clash between the human desire for complete, reproducible knowledge and the reality of its impossibility. It is the same theme explored in Sir Arthur Eddington's comparison of the phenomenal world to a clumsy mistranslation of the physical world (quoted in the epigraph to chapter 5).

When Nabokov came to explore the problem of translation, particularly that of poetry, he approached the scientific notion of repeatability from a different angle. Although he had made some rhymed verse translations in the 1940s, when he began work on Eugene Onegin he became convinced of the impossibility of bringing the poem's full interplay of sound and meaning into another language. Thus the jerky, literal nature of his translation represents precisely the impossibility of creating a complete and perfect translation of the original. Such an absolutist goal may be dismissed at the outset as unreasonable and quixotic, yet it expresses 
and forces an important philosophical stance. It foregrounds the necessary humility of the human mind in the context of things that are beyond its reach. In this case, the exact specifics and complete form of Pushkin's poem are beyond the grasp of the English language and those who lack Russian; to conceal this inaccessibility behind a fluid translation, Nabokov suggests, is to exaggerate the power of language itself as a tool of knowledge. Even with its stripped-down goal of literal, semantic copying (no rhyme, no meter), the translation fails since it requires a commentary roughly five times its length to communicate the full semantic layer. Moreover the commentary itself, however extensive, cannot be exhaustive, and in a way it serves to underscore the incompleteness of all translations, no matter how extensive the apparatus and how diligent and perceptive the translator. This stance is the next logical step beyond the translation model discussed in Bend Sinister concerning Ember's versions of Shakespeare, which, as we saw, are like "shadowgraphs" of unbelievable complexity whose aim was to cast the same silhouette as Shakespeare's works, while not resembling them in primary form. If in that novel Nabokov has Krug question whether the result was worth the effort, by the time of his work on Eugene Onegin his priority is to trample the myth of epistemological confidence that readable, poetic translation implies.

The impossibility of translating a poetic work perfectly into a new language is an analogue for the translation of the world into our conscious awareness. "Reality is a very subjective affair. ... [A] lily is more real to a naturalist than it is to an ordinary person. But it is still more real to a botanist. And yet another stage of reality is reached with that botanist who is a specialist in lilies. You can get nearer and nearer, so to speak, to reality; but you can never get near enough because reality is an infinite succession of steps, levels of perception, false bottoms, and hence unquenchable, unattainable." 23 The theme of humans' limited ability to know the world takes various shapes throughout Nabokov's oeuvre. The 1930 novel Laughter in the Dark (originally Camera Obscura) contains one of the most explicit embodiments of this proposition, taken entirely out of any metaphysical context. When the protagonist Albinus-film critic and promoter of cinematographic innovation-goes blind after a car accident, he is forced to develop his conception of his surroundings from what he can touch, smell, and hear, combined with what he is told by his mistress Margot. She creates and narrates his imagined world, the views it might hold, its shape and contents-often with deliberate deceptions about vistas and colors: "The fact that the blind man was obliged to picture his little world in the hues prescribed by [her paramour] Rex afforded the latter exquisite 
amusement." 24 What she does not tell him-that in fact the two of them are not alone, but are accompanied by Axel Rex, with whom she is having an affair right under his nose-remains, for a while, outside of his consciousness. The gruesome comedy develops as Rex gestures, dances, and mocks Albinus within inches of his unseeing eyes. Gradually, Albinus's senses become more acute, and he starts to pick up on discontinuities: anomalous sounds, smells, and even intuitions that tell him that something is wrong with his world picture: "Soon it became quite difficult for Rex to come in or go out unnoticed. No matter how noiselessly he passed, Albinus turned his head at once in that direction and asked: 'Is that you, darling?" ${ }^{25} \mathrm{He}$ frequently stops and strains to catch clues to this mysterious presence. In Albinus's new dark world, Axel and Margot appear in the role of a malevolent demiurge, and the concealed, outer reality has almost nothing in common with Albinus's conception of it. His life becomes a living hell of his own making, a consequence of his own selfish and cruel behaviorthe abandonment of the ethical consideration of others whose lives he has made into hell (and his disillusionment is echoed in Despair by Hermann's rude awakening when he discovers the error in his "perfect crime").

Such a pessimistic picture of the relationship between the phenomenal world and ultimate reality is not typical of Nabokov's works, however. Albinus's ascent from a limited, erroneous consciousness to a higher state of awareness is a grotesque perversion of the enhanced consciousness of "multilevel thinking” espoused by Fyodor in The Gift. ${ }^{26}$ If Albinus's revelation is based on perceived flaws in the reality Margot has painted for him, Fyodor also finds many anomalies, coincidences, patterns, and delights that speak to him of a benevolent beyond that shapes the contours or somehow participates in his world: "the constant feeling that our days here are only pocket money, farthings clinking in the dark, and that somewhere is stocked the real wealth, from which life should know how to get dividends in the shape of dreams, tears of happiness, distant mountains." 27 He suggests that his father intuits the same metaphysical structure, which he sees in nature especially whenever he finds species whose existence is not justified by the struggle for survival. It is this vision that allows Konstantin to step into the base of a rainbow and its colored air, implicitly defying the laws of physics. Fyodor breaks similar laws when he transforms his tiny room into the expanses of central Asia, or turns a straightline streetcar ride into a circular one. These characters and their fictional kin perceive a basic goodness of ultimate reality through the fissures in ordinary life, even if they cannot know exactly what that "reality" is. 
These implied lapses in the continuity of "reality" —alleged nonutilitarian excesses in nature, or uncanny patterns in an individual's life ("coincidence")—connect to lapses in the laws of physics (remember Fyodor's erratically regressing watch and his ability to cross busy streets in a state of oblivion), and together these apparent flaws point toward the visible world's subordination to a larger context. Traditionally, following Véra Nabokov's famed revelation in the introduction to the 1979 collection of Nabokov's poems, this context is called "otherworldliness" (potustoronnost', from the poem "Being in Love"); but it might also be called the "not-yet-known," or the "unknowable"- the limitations and lapses of human mind. ${ }^{28}$ Whatever we call it, this simple formula becomes a regular part of Nabokov's narrative structures, and it is the main motivation for his use of concealed pattern in virtually all of his novels and most of his stories. But the patterns-the themes of a life, so to speak-are only one of the signs of this larger context. Nabokov also constructs his works so that there are deliberate gaps, flaws, and anomalies within the very texture of his created worlds and also in their textual substrate-the author's language - and these aberrations are intended to mimic the very imperfections that intimate the world's contingency. The relationship between these phenomena and mistakes is explicit-though inverted-in Despair and Laughter in the Dark, where the main characters are practically solipsists. It receives a positive, parodic, and exaggerated extension in Invitation to a Beheading, where the "cast" of characters "enacting" Cincinnatus's bizarre incarcerating world makes various sorts of mistakes, accompanied by a complete breakdown in the laws of language, logic, and even physics. Likewise, the socialist dictatorship in Bend Sinister is comically and tragically blunder-prone in its tyrannical pursuit of perfection through universal equality.

The mistakes of solipsistic "philistines" like Albinus, Hermann, Paduk, or Humbert are parodies of the wrinkles and fissures detected by the perceptive and curious. These benighted characters are subordinated to other sorts of textual patterns and anomalies that they do not recognize, but which the author allows readers to see (some sooner, some later). Such, for example, is the profusion of phallic and mythological imagery in Despair, which leads to the suggestion that Hermann is in the grips of an elaborate Freudian psychosis focused on castration anxiety. Likewise, Hermann is presumably unaware of the extent to which his own text parodies contemporary literature-literature that surrounds him with a subtext of mockery. ${ }^{29}$ 


\section{Discontinuities in Nature and Art}

Visible pattern, as a system of meaningfully interrelated moments, is only one aspect of Nabokov's integration of texture. The gaps or discontinuities in a character's conscious awareness, or in the reader's experience of textual meaning, drives Nabokov's work more and more toward the figuration of gaps at each available level of artistic material. Nabokov's conception of gap comes in part from his experience of literary science as expressed in Andrey Bely's "Lyric Poetry and Experiment," in the voluminous theoretical work Symbolism, published in $1910 . .^{30}$ In the Introduction, I proposed that there were affinities between this Belyan emphasis on prosodic gapsunfulfilled stresses-in verse and Nabokov's own interest in, for example, missing elements in the expected range of butterfly morphology. And in his own translation of Pushkin's Eugene Onegin, Nabokov drew special attention to the missing stanzas-some of which had been suppressed by Pushkin, some of which may have never existed-by granting them full blank pages, with line numbers telling us where the text would have been. No other publication of the novel employs this strategy. ${ }^{31}$ Such yawning discontinuities as these are characteristic of the world as Nabokov sees it; he sought and found them to be characteristic of Gogol's artistic outlook, as well (Andrei Bely had also drawn attention to the "negative" characteristics of Gogol's works, in his own Gogol's Craftsmanship). ${ }^{32}$ Nabokov clearly wanted readers to think hard about the fact that Pushkin has included these gaps in his "novel in verse." Of the missing stanzas XXXIX through XLI of chapter 1, he writes, "It is not unthinkable that this gap is a fictitious one, with some musical value-the artifice of a wistful pause, the imitation of a missed heartbeat, the mirage of an emotional horizon, false asterisks of false suspense." ${ }^{33}$ This emphasis is designed to suggest that the absences are crucial to a full understanding of the work, hinting also that they reveal a commonality between the two artists. ${ }^{34}$ The point for the scientist (literary or otherwise) as well as for the artist is that considering what is absent is just as important as examining what is present.

When he began work on Onegin in the 1950s, these kinds of fine-grain textual lapses were already a long-standing feature of Nabokov's artistic method. Beginning with Invitation to a Beheading, Nabokov deliberately included narrative anomalies that disrupt the regular flow of the reader's experience. These disruptions, or ruptures, are at first (as in Invitation) features of the characters' worlds, but by The Gift, they are integrated into the narrative form as experienced by the reader. ${ }^{35}$ The irregular, hidden shifting between narrative voices in that novel amounts to a series 
of almost undetectable, but momentous, ontological shifts, in which the reader is left in a state of constant uncertainty about the narrative status of the text. Whenever the reader's confidence is allowed to build, it is quickly dashed by another unnoticed shift in narrating perspective. It was probably such shifts that V. has in mind in The Real Life of Sebastian Knight when he asserts that Sebastian's writing is an inimitable "series of gaps." 36 This device-both obvious and hidden gaps in narrative flow-became one of Nabokov's most potent embodiments of his claim that one can only reread a novel, because the first reading gives such an incomplete and onedimensional picture of a work's multiple levels of meaning and their interconnections. A similar series of cognitive shifts takes place as a reader, in subsequent rereadings, comes to recognize blind spots in earlier readings, fragments from or references to other literary texts, and related hidden patterns, from which much of each work's mosaic is composed. The practiced and passionate rereader is looking carefully for tell-tale signs of these "cryptograms," to echo Eddington, just as Fyodor and his father look for similarly concealed anomalies in the natural world. The essence of the text is transformed from a system of unidirectional causal chains of story and plot into a network of hidden facts and their recursive discovery, in a way mimicking the scientific endeavor. ${ }^{37}$

It was a natural development for Nabokov to bring the text-reality analogy into the realm of explicit play and manipulation through the introduction of cryptograms, and this happens as early as the story The Vane Sisters (1951), although it was augured in the long-unpublished phrase "rhymes of nature," used to describe mimicry in "Father's Butterflies." 38 A related locution appears in The Gift proper, where during Nikolai Chernyshevsky's travels "a hole in the road loses its meaning of hole, becoming merely a typographical unevenness, a jump in the line." 39 And as we saw in chapter 5, the idea itself was echoed if not presaged in Arthur Eddington's New Pathways in Science in his comparison of the phenomenal universe to a cryptogram. But the idea achieves its fullest development in Lolita's "cryptogrammatic paper chase" and in Pale Fire's text-texture dichotomy, emerging from a metaphysical typo (mountain vs. fountain as parts of a near-death experience)-in fact, through a whole network of virtually invisible typos, as James Ramey has argued; ${ }^{40}$ and in Ada's alphabetical and typographical conundrums. In a string of text, a typographical error is a flaw or lapse, a break in the proper, rule-bound sequence of letters making up written language. It might be a chance event, or-as in Ada-it might be an otherworldly sign, but in either case, it is a place where the rules governing written language are interrupted by an external 
event, subject to a separate set of laws: the laws of neurological ability, typing and error rates, chance distraction of the typist, or the rules of otherworldly influence-whatever they might be. The point is that a typo is a simple mistake on one level, but if it is deliberately introduced by the author, then it is also a reference to a different ontological plane (the plane of authors, typists, and proofreaders). If the typo is also meaningful (part of an intentional pattern from beyond the inner story), then it opens up a connection between the two levels in the form of transcendent-not specifically defined-intrusions on worldly events. What these accidental yet meaningful (choice mimicking chance) events suggest within these works is that each level of existence is subject to effects from contiguous but usually unseen levels of being or meaning. Nabokov's works deliberately pursue metaphysically tinged structures that embody precisely this kind of layered significance (which is also reminiscent of J. W. Dunne's regressive approach to temporal existence in his The Serial Universe).

Certain kinds of intelligence-call it genius, like Krug's in Bend Sinister, or like an artist's or great scientist's—are highly anomalous within the spectrum of human abilities. Such aberrations in human mental features are themselves discontinuities in nature's expressiveness-irregularities that Paduk's Ekwilist regime wants to eliminate in order to create perfectly smooth, homogenous equality. This project is an excellent example of how an idea ("equality") can be misapplied to create a program completely at odds with the facts of reality (inequality, discontinuity, unpredictability). If one explores the world like a true scientist, examining individual samples and studying nature's extremes as well as its average representatives, one develops a sense for the system's complexity, the interrelation of all the parts and their dependence on one another. Equality, it turns out, is absolutely antithetical to nature, which is characterized by differentiation-a property Nabokov explored in depth as he studied extensive groups of subspecies. Nature is filled with bumps, flaws, and gaps; to eliminate them is to work contrary to reality and to ignore the beauty that nature's variety holds.

Of Nikolai Gogol's The Government Inspector, Nabokov wrote, "the play begins with a blinding flash of lightning and ends in a thunderclap. In fact it is wholly placed in the tense gap between the flash and the crash." This iconic illustration demonstrates Nabokov's fascination with the notion of a chasm between cause and effect. In the example he chooses, the pause, or "gap," is easily explained by the differing speeds of light and sound. Nevertheless, the delay cannot last two hours, or long enough to fit a play's duration. That apparent hiatus becomes emblematic for intuited 
or perceived fissures in all causal chains, no matter how self-evident the links between action and reaction.

Whatever may be the laws of causality and continuity in nature, a deeper law, Nabokov suggests, concerns interruptions, exceptions, and discontinuities. The essence of this law may be inaccessible to human perception and reason, but clues to the incompleteness of causality are evident to the careful and open-minded individual, his work suggests. Nabokov's intuition was confirmed, or at least shared, by physicists like Arthur Eddington, James Jeans, Niels Bohr, and Werner Heisenberg, and philosophers of science Emile Meyerson, Philipp Frank, and others. Constant awareness of this implicit, though inscrutable, law helps preserve scientists against excessive faith in the power of their methods and the infallibility of their discoveries-in other words, it protects them against hubris. In his combined aesthetic and scientific explorations of these meta-causal phenomena, Nabokov helps to establish guidelines for the best practice of science and the pursuit of knowledge. 


\section{conclusion \\ Science, Art, and Ethics}

Delo v tom, chto ischezla granitsa / mezhdu vechnost'iu i veshchestvomGone, in fact, is the break between matter and eternity ...

-“Oculus," 1939'

THROUGHOUT THIS BOOK, I have been encouraging the notion that Nabokov rejected determinism and even causality as fundamental principles of worldly existence. ${ }^{2}$ Evolutionary development, he suggested, depends not exclusively on the mechanisms of natural selection; the mind's history does not obey any deterministic laws; the known "physical" world tends to include patterns and discontinuities that are best termed metaphysical. I have argued that he had essentially idealist convictions, embracing possibilities that come from beyond the world of sense experience. These are not claims one expects to hear about a scientist, although as we have seen, Nabokov was preceded by other major scientists with a similar metaphysical bent (William James, Oliver Lodge, Arthur Eddington, and physicist-manqué Henri Bergson, to name just a few). In this Conclusion, I will explore the paradox of the anti-causal scientist, meanwhile placing Nabokov within the context of later discussions of science vs. anti-science and affirming Nabokov's place in the first camp, rather than the second. That accomplished, I will turn to a consideration of how this study's proposals affect our understanding of the most important interpretations of Nabokov's work, and what consequences these hold for readers and scientists alike. 
In the twentieth century's early decades, physicists working on subatomic and quantum theories came to deal first with the discontinuous nature of energy, then with the unknowability of complete data about subatomic particles, along with the wave-particle complementarity of matter. ${ }^{3}$ The results of these discoveries were so disconcerting and counterintuitive that even the scientists themselves had a hard time deciding what they meant. ${ }^{4}$ As several physicists began making popularizing or philosophical assessments of the new theories, debates arose about the ultimate tenability of the law of causality in view of the fundamentally indeterminate and unpredictable behavior of subatomic matter. Nearly all popular treatments of the new sciences included discussions of causality's fall or persistence: the demise of causality was emphasized by James Jeans and Arthur Eddington; in the strict context of subatomic phenomena Niels Bohr also cast doubt upon causality, while Werner Heisenberg and Einstein took the opposite point of view (although Einstein identified the anti-causal implications of quantum theory as early as 1917 , leading to his enduring doubts about the theory). ${ }^{5}$ These revolutions, combined with Einstein's relativity, set the stage for Nabokov's skepticism regarding the form and immutability of nature's "known" laws. ${ }^{6}$

Nabokov came to science from the standpoint of passionate observation and appreciation of detail. His approach to lepidopteral research began from an effort to identify undescribed species, which could only be accomplished by achieving a fine-grained sensitivity to the insects' morphological characteristics. While we know beyond dispute that Nabokov took great interest in evolutionary theory and was pleased to challenge natural selection, we do not know when, exactly, he read Darwin's works. Certainly he would have had significant exposure to them at the Tenishev School, where they would have been part of the biology curriculum, and where there were special materials and even exhibits on evolution and mimicry. ${ }^{7} \mathrm{How}$, exactly, Nabokov came to question the validity or comprehensiveness of natural selection remains unclear. His writings do not show definite signs of opposition until The Gift (unless one accepts my comments on Glory in chapter 2 as definitive). If we take literally the metaphysical expressions in a letter to his mother (about how the artist/writer, while primarily plagiarizing, adds bits of valuable new decoration to God's creation), ${ }^{8}$ they lay a clear groundwork for an idealist approach to nature. On the other hand, such effusions are rare enough that they could well be figurative, and there is simply not enough information in Nabokov's letters or private materials to conclude whether Nabokov was privately a deist-or even a theist. The formulations in "Father's Butterflies" clearly point toward an idealist, 
perhaps pantheistic version of nature's essence-but that is a work of fiction. Taken as a whole, Nabokov's fictional, autobiographical, and technical statements about Darwinism demonstrate a consistent effort to keep scientific, worldly knowledge enveloped within a larger context upon which it was contingent. In his suggestions that nature could be nonutilitarian, and hence escape the law of the struggle for existence (which he mentioned in another letter to his mother, in 1924), ${ }^{9}$ he appears to draw precisely on the noncausal potential foregrounded by the post-Copenhagen debates. Focusing on nature's excessive creativity, its element of surprise, Nabokov repeatedly draws attention to the possible existence of other laws-undiscovered and perhaps inaccessible to human reason-that may function on levels of reality that physics and biology cannot touch. ${ }^{10}$

Nabokov apparently felt, or hoped, that such a case could be made within biology proper. Nabokov's last, incomplete or rejected scientific projects offer a clue as to how it might have been done. Véra's description of his ambitious ideas for a comprehensive book on mimicry, collecting all known instances in the animal world, demonstrates his continued belief that mimicry, in its full development, would reveal nonutilitarian aberrations. ${ }^{11}$ And his large guides "Butterflies of Europe" and "Butterflies of North America" were to lay out species in their actual relationships with a completeness and precision never before achieved. Perhaps he felt that the explosion of butterfly species demonstrated variety in excess of the possible needs caused by competition for survival, or that such a massive collection of information would provide others with the tools to discover a nonutilitarian principle in nature.

It is telling that Nabokov did his most significant scientific work on the proper classification of groups of species-that is, on genera and subfamilies. His main interest was in seeing how various groups of related creatures formed different sorts of wholes: monotypic genera like Parachilades, or polytypic ones like Cyclargus. ${ }^{12}$ He takes natural selection as if for granted, but he does not give it pride of place in the examination of taxonomic relationships or the emergence of new forms. These groups of forms can form macroscopic, interspecific qualities or patterns, perceptible to the scientist, that have a certain phenomenal reality even though they can have no bearing upon species survival as such. This holistic envisioning of the qualitative aspect of nature asserts nothing more than the potentially valuable (to consciousness) existence of phenomena that may or may not be noticed, but that have no direct bearing upon utility or survival. Using his intellect to demonstrate the fascination of such phenomena, Nabokov proves by his own activity that the human mind as well is geared toward 
"non-utilitarian delights." 13 Such a "proof" recalls Ernst Mach's demonstration that some manifestations of curiosity have no possible purpose, but imply the appearance of a phase of life in which purpose, and with it cause-effect relations, is secondary. ${ }^{14}$

As for psychological commitments, Nabokov's relentless denigration of Freudian psychoanalysis, or at least of his own caricature of it, creates abundant interference surrounding his theory of personality and selfhood. As an essentially positivist, causally grounded account of human personality and neurosis, Freud's theory appears to have struck Nabokov as simplistic, reductive, and false. ${ }^{15}$ However, its power within the culture at large required him to wage constant battle against it. Thus the two most important aspects of selfhood to emerge in Nabokov's works are its essential mystery and its partial independence from positivistic causality. It would be absurd to suggest that there is no such thing as psychological causality, just as it would be foolhardy to deny all physical or biological causal chains. Yet Nabokov crafts his characters in such a way that the element of mystery is foregrounded, and causally obscure psychological events play a key role in a person's narrative. Willingness to be taken by surprise, and to consider a surprise as something essentially new and spontaneous rather than as something to be explained away, stands at the core of this vision of the world and of self. When the mind is bent toward the discovery and even the creation of new forms in the world, it is not "struggling for survival." In this very Schopenhauerian vision, aesthetic perception (of nature or of art) allows the product of nature-human consciousness-to escape, at least briefly, the deterministic law of cause and effect, to be free of "will” in Schopenhauer's sense. ${ }^{16}$ Like hypothesized nonutilitarian features of plants or animals, consciousness's pursuit of arcane knowledge or of aesthetic bliss does not confer any direct survival or reproductive benefit. It is primarily, though perhaps not exclusively, mind and the essence of human selfhood that Nabokov wants to pull out of the deterministic mechanism, suggesting that these contain secrets that lie outside causally linked pathways. As for causality in the world of physics and material objects, we can judge something of Nabokov's attitude from the way he frames the story in Transparent Things: this novel is narrated by a ghost (or ghosts), who describes the manner in which such beings are able, just barely, to affect the physical world and perhaps the actions of humans: "The most we can do when steering a favorite in the best direction, in circumstances not involving injury to others, is to act as a breath of wind and to apply the lightest, the most indirect pressure such as trying to induce a dream that we hope our favorite will recall as prophetic if a likely event 
does actually happen." ${ }^{17}$ Indeed, at the novel's end they try to impinge on the causality of Hugh Person's world in order to save him from the fire they foresee, but they fail because of his psychological independence from any acts they might perform, visible or invisible. ${ }^{18}$

But what can this mean, and how can a scientist seriously propose departure from causality in everyday life? After all, even the Copenhagen interpretation of quantum mechanics does not deny the causal predictability of events at scales larger than the subatomic. All this anti-causal rhetoric might lead one to accuse Nabokov of an anti-scientific or relativistic stance. The attention I have been drawing to Nabokov's suspicions of epistemological certitude, in science or in society, may suggest to some an allegiance with those who discredit the privileged role of scientific work in modern society. At times, indeed, Nabokov seems to do so-as in his lecture "The Art of Literature and Commonsense," where he explicitly downplays the fundamental value of mathematics and the sciences built upon it:

Man at a certain stage of his development invented arithmetic for the purely practical purpose of obtaining some kind of human order in a world which he knew to be ruled by gods whom he could not prevent from playing havoc with his sums whenever they felt so inclined. ... Then ... mathematics transcended their initial condition and became as it were a natural part of the world to which they had been merely applied. Instead of having numbers based on certain phenomena that they happened to fit because we ourselves happened to fit into the pattern we apprehended, the whole world gradually turned out to be based on numbers, and nobody seems to have been surprised at the queer fact of the outer network becoming an inner skeleton. ${ }^{19}$

Considering this passage together with his dismissal of statistics, his preference for qualitative over quantitative research, and his desire to overturn dominant theories like natural selection, we have a portrait of someone who rejects the scientific method and its results in favor of a subjective and even slightly mystical view of the world. However, it is just here that the Goethean perspective allows for a correction, demonstrating the existence of another approach to scientific method, in which hypothesis and experiment play a lesser role than data collection and pattern-based analysis. Nabokov's awareness of this methodological contrast shines forth in his story "Ultima Thule." The truth-seeking protagonist, Sineusov, says, "When a hypothesis enters a scientist's mind, he checks it 
by calculation and experiment, that is, by the mimicry and the pantomime of truth. Its plausibility infects others, and the hypothesis is accepted as the true explanation for the given phenomenon, until someone finds its faults. I believe the whole of science consists of such exiled or retired ideas: and yet at one time each of them boasted high rank; now only a name or a pension is left." ${ }^{20}$ This expression of the progress of science reflects quite neatly Goethe's own conception of it-which also included reservations about the power of mathematics. And Goethe is not the only major thinker to raise similar questions: Arthur Eddington, whose expedition had helped confirm general relativity, offered similar doubts. Challenging James Jeans' unequivocal embrace of mathematics, he wrote, "the main reason why the mathematician has beaten his rivals is that we have allowed him to dictate the terms of the competition. The fate of every theory of the universe is decided by a numerical test. Does the sum come out right? I am not sure that the mathematician understands this world of ours better than the poet and the mystic. Perhaps it is only that he is better at sums." ${ }^{21}$ This fundamental stance, according to which all theories are tentative and likely to be overthrown when new facts or new ways of looking are discovered, is really the essence of the modern scientific ethos. The fragility of scientific knowledge is less trumpeted than its spectacular successes, but Nabokov's emphasis on the former over the latter does not make him any less a partisan and enthusiastic practitioner of science. Scientific work was for Nabokov one of the summits of consciousness, alongside artistic creation.

Although he was no conventional scientist, there is every reason to believe that Nabokov would have been a passionate opponent of the idea that all scientific knowledge is essentially compromised by sociological biases. However, he was acutely aware that science was vulnerable to political or personal bias. In fact, he wrote repeatedly and at length about the influence of the observer upon the object observed and of the teller upon the tale. Recognizing the dangers of prejudiced research, or of science blinded by its political commitments, Nabokov also felt that science itself was a practice that could strive for an ideal of impartiality and studied insight, extending the sphere of human knowledge. Recall how he drew attention in his scientific papers to possible weaknesses in his own position or limitations to his empirical data, inviting future researchers to correct him, as we saw in chapter 1 . Scientific work represents the very process of achieving finer and finer detail in the knowledge of phenomenal reality, and current errors or inaccuracies will be swept away by the next generation's refinements. 
Nabokov's science was akin to his art in that it was essentially nonutilitarian from the standpoint of practical survival. He saw "pure science" and "pure art" as partners in the expansion of consciousness and the escape from the struggle for existence. Science as a nonutilitarian endeavor-pursuing knowledge for knowledge's sake-represented one ideal for the passions of the fertile mind. Whatever its weaknesses and tendencies to error, these can be corrected within the normal functioning of the scientific community. As a member of that community, Nabokov worked to create the best possible new knowledge in his own special area, correcting errors of his predecessors while also drawing honest attention to unanswered questions or possible preconceptions in his own work.

Nabokov's interest in diverging from strictly realist, causally based narration in several of his works (Invitation to a Beheading, The Gift, Ada, Transparent Things, "The Vane Sisters") should be considered within the context of his thought on evolution in the 1940s. Although Nabokov used adaptationist language with great consistency in his scientific papers, he also expressed his "dissatisfaction" with all available explanations of its workings. His interest in mimicry as a possible source for anti-Darwinian evidence brings forth his desire to highlight nondeterministic phenomena in nature. On the other hand, he never did publish a scientific work exclusively about mimicry, and had he examined all available examples and discussed the project with his professional colleagues, it is likely he would have realized that this particular anti-selectionist argument would not withstand scrutiny. If he wanted to continue pursuing that line of research, he would have had to broaden his focus to encompass nonadaptive mutations generally, especially the ones that endure over time.

But most likely his interest would have moved in another direction, one also central to his art and to his vision of the natural world. As we saw in chapter 1, Nabokov arrived at his manner of differentiating individual species by developing the concept of "synthetic character." 22 This "synthetic character of the species" is a composite concept, drawn from knowledge of correlated individual variations in several particular organs or suborgans of a given species. It represents a "metaknowledge" of the species, a sense of organism that transcends what is discovered in a single "type" specimen. (Nabokov was perhaps envisioning something analogous to the abstract potential of the genotype with all its variations across individuals, as opposed to the concrete phenotype as expressed in the individual creature.)

This range of phenotypic expression is phenomenally "real" to the knowing consciousness, but is it a part of the mechanism or dynamic of 
evolution's actual development? Do such epiphenomena-not the variations themselves, but the "synthetic character" of all possible variations within each species and genus-have any status in the natural world? Are they useful to the species in question? Or are they simply useful-and perhaps beautiful—to the human beings who wish to categorize them? In short, even within his own established scientific thought process, Nabokov would have had no difficulty finding other routes past the concrete field of mechanism, competition, and survival, and indeed he was already finding them in the 1940s, albeit rather esoteric ones. Consciousness, and art itself, while not part of his scientific research program, also provided him with examples of activities born in nature that extend far beyond the domain of the purely "useful." 23

It has been suggested that Nabokov's scientific intuitions may have had some similarity to insights about emergent phenomena as presented in recent studies of complex systems. ${ }^{24}$ Would the possibility of emergent forms, arising not (exactly) due to natural selection but from saltatory shifts have compensated for the loss of useless mimicry? Only, we may suppose, if the results were equally "useless" in the battlefield of natural selection. In chapter 1, I drew attention to the way that Konstantin Godunov-Cherdyntsev imagines evolution shifting from the realm of physical nature into the domain of consciousness itself. Although in GodunovCherdyntsev's version consciousness is achieved teleologically as part of an idealist outlook, there is no particular reason why consciousness might not be itself an emergent, nonteleological phenomenon while still retaining all the mystery Nabokov ascribes to it. Nabokov sought to determine the "synthetic character" of species, patterns in the unfolding of a day or a life, and other phenomena which, if not "designed," must be emergent properties discoverable by consciousness (or else simply properties of consciousness), or perhaps noncausal indices of “otherworlds” or gaps in reality's fabric: in either case, they all constitute discrete components of phenomenal "reality" as experienced. If they are found, then they could be said to be discoveries (if, say, the "synthetic character" has an ideal reality, as the elder Godunov-Cherdyntsev believes); if invented, then they are creations of the mind, but still real inasmuch as they persist. They emerge from conscious activity and may or may not affect survival, just as they may or may not affect the nature of consciousness itself. I suspect that artworks in general fall into this category of creation for Nabokov, constituting a new realm where what matters is the development or evolution of consciousness, the emergence of new forms of conscious existence. It is precisely this transition that comes forward in the innovative blends of disparate orchids 
in Ada: the possibilities of evolution carry on in the mind, in thought, as much as-if not more than-in other parts of the natural world. ${ }^{25}$

Nabokov's knowledge of and interest in the development of science was central to his effort to conceptualize the world and to make artistic statements about it. I have attempted to show how this concern of his is reflected in all of his works on various levels. But how are we to relate an awareness of this theme to more "comprehensive" interpretations of the novels or stories? Surely it is not enough to suggest that they are primarily "about" the limitations of causality (in psychology, mechanics, or ecosystems), just as Lolita is not "about" the causality of murder-or of pedophilia.

In a study of the scientific contours of Nabokov's literary art, it seems only fitting to consider the manner in which the author himself has become a subject of empirical research as well as aesthetic reflection, and how these two perspectives intersect. There are three major scholarly approaches to Nabokov in recent years that have aspirations to shape or guide all subsequent considerations of his work, and I would like to deal with each of these separately. They are the metaphysicalist/idealist, the ethical, and the semiotic/intertextual. There is some overlap between these areas, but each of them has what I consider a dominant enunciation that is distinct from the others, and for the present purpose I will focus on these dominant forms while attempting to acknowledge the important overlaps where appropriate.

The metaphysical interpretation began its rise to prominence in the 1980s through Brian Boyd's work on Ada and D. Barton Johnson's essays that led to Worlds in Regression: Some Novels of Vladimir Nabokov. In a sense it climaxed with Vladimir Alexandrov's Nabokov's Otherworld, and was further refined by Genady Barabtarlo's Aerial View: Essays on Nabokov's Art and Metaphysics, and Boyd's work on Pale Fire (all with support from a variety of other scholars). This last work showed with masses of evidence and meticulous argumentation how Nabokov's precise choice of intertextual references supported his desire to weave a theme of supernatural agency and answerability into what some consider his most important novel. Throughout his scholarship, Boyd more than any other researcher has maintained keen sensitivity to Nabokov's scientific dimension while laying out the epistemological implications of his artistic practice. ${ }^{26}$ In his emphasis on the experience of multiple readings, on the work of achieving ever more detailed knowledge of a text with its patterns, subtexts, and patterns of subtexts, Boyd has shown close parallels between Nabokov's preferred scientific methodology and the experiential-epistemological process 
of studying (rereading carefully) his works. On the other hand, Boyd has also drawn attention to the tendency of Nabokov's novels to present problems with unique and precise, albeit obscure, correct solutions, like those to chess problems. ${ }^{27}$

Like Alexandrov's and others' emphasis on the highly controlled, determined nature of Nabokov's works, this solution-oriented approach foregrounds and promotes the teleological aspect of his artistry, suggesting that the goal to be reached has been foreseen and predetermined by the author. This approach can be directly at odds with Nabokov's understanding of nature itself, which is "an infinite succession of steps, levels of perception, false bottoms, and hence unquenchable, unattainable." ${ }^{28}$ It is said of Nabokov's novels that when the correct solution is found, it "clicks" characteristically, all the evidence falling neatly into place..$^{29}$ If this is true, and all of his works strive towards an eventual unambiguous solution, it would seem to imply a tension between Nabokov's artistic goals and his scientific philosophy, his epistemology. There is no particular reason why there should not be such tension: a desire for perfect knowledge in the face of its manifest impossibility. However, it is also true that ambiguity has been a consistent feature of Nabokov's art since its earliest expressions. The clicks are real, and there is no doubt about them. But as Boyd's own work has amply shown, the resolutions are always followed by further reconsiderations that destabilize the momentary equilibrium and lead to new sets of problems. And in the case of many of the novels, they lead finally to iconic figures of paradox and the infinite regress inherent in the quest for knowledge (for example, Fyodor's self-distortion paradox in The Gift, and the authorship conundrum in Pale Fire).

One of the biographical details that is frequently cited as a ground for his well-formed narrative structures is Nabokov's affection for chess problems and their unambiguous solutions. However, two of his comments should force us to reevaluate these problems' broader significance for him. In general, he especially loved problems designed to mislead a sophisticated solver to follow a series of complex missteps, before retracing and discovering the simple solution that a naïve solver would find right away, "so that a great part of a problem's value is due to the number of 'tries'delusive opening moves, false scents, specious lines of play, astutely and lovingly prepared to lead the would-be solver astray." ${ }^{30}$ Viewed holistically, the "right" solution involves being taken in, finding one's error, and then seeing the simple answer. A direct path to the final solution is a second approach, simpler but inferior because it ignores ambiguities and hidden signs of complexity. Or take another favorite problem, based on retrograde 
analysis, in which the solution hinges on white's retracting a move before proceeding to the final mating combination. This problem (which Nabokov calls a "fairy") ${ }^{31}$ plays with the fact that, against all appearances, rules of play can be broken. And so chess problems turn out not to provide the kind of unequivocal support for teleological narrative that had seemed to be the case.

It has been supposed, as well, that there is a clash between Nabokov's metaphysical, even supernaturalistic narrative elements and his avowedly empirical scientific work and outlook, and that these two must therefore be kept separate (a separation that would have been supported, for example, by Kant). However, in every case except perhaps Transparent Things, the putative ghostly or other metaphysical intrusions can be interpreted as being nonliteral, as manifestations of complex psychological realities or as models for one way that a system can "break the rules" (in this case, of physics and causality). And even Transparent Things, while seeming to grant the existence and limited influence of departed personal spirits, it does so within a framework that explores the temporal essence of reality ("space being the tumor"), assigning consciousness a privileged and independent status beyond its material substrate. It does not, in any clear way, propose a designed, created teleological system. While such creative fancies or intuitions have almost nothing in common with science, they are closer to the spirit of scientific questioning than to outright metaphysical speculation. In other words, rather than indicating a belief in spirits as actual, unambiguous participants in humanity's progress toward some metaphysical goal, the novel seems to offer a hypothesis in answer to Nabokov's puzzle in Speak, Memory: "If, in the spiral unwinding of things, space warps into something akin to time, and time, in its turn, warps into something akin to thought, then surely, another dimension follows-a special space maybe, not the old one, we trust, unless spirals become vicious circles again." 32 The novel's "special space" is one where all past time becomes manifest in every object, and the near future is also visible, if only hazily. But there is no more here of ultimate truths, of explanations for the ground of existence, than in any of Nabokov's other works. It simply asks a question (alongside other, more mundane ones): what if consciousness can exist outside of time, after death?

Such questions appear at first to be fundamentally unscientific. However, we have seen that Nabokov took a more than passing interest in socalled "psychical research," which attempted, and still attempts in a few quarters, to explore these questions by means of the scientific method. That it has failed to achieve convincing results is not the point: what mat- 
ters is that the reality of psychical phenomena might be amenable to scientific investigation. Or, to put it another way, for someone not committed to a materialistic philosophy, the hope that intuited paranormal phenomena could perhaps be brought under the umbrella of rationality is not unreasonable or anti-scientific or supernaturalist. In part because nothing of this "surplus" is presented as if it were known with certainty, it falls within the domain of hypothesis and thought experiment, and not within any sort of committed spiritualism. It is a proposed extension of scientific thinking, not its direct antithesis.

The ethically grounded interpretation of Nabokov's works is not far distant from the metaphysical, in part because it accepts the existence of $a$ priori moral standards against which we are urged to evaluate the protagonists' actions. Some of the leading proponents of this approach have been Ellen Pifer, in her Nabokov and the Novel, Julian Connolly in Nabokov's Early Fiction, and once again Brian Boyd—especially in his work on Lolita and Ada, and in Gennady Barabtarlo's “Nabokov's Trinity,” which places love at the axiological center of Nabokov's art. ${ }^{33}$ Barabtarlo puts his finger right on the intersection of the scientific and moral-ethical impulses when he states that Nabokov is "driven by an insatiable love for material detail accessible to any of the five senses," which Barabtarlo further defines as "the 'eye-thirsty' love for the created world, in all its micro- and macroforms, for things small and large, unnoticed or unworded before and thus begging to be brought to life by precise and fresh description." 34 Science itself-the work of the naturalist, the taxonomist, the theorist-gives us the purest form of that brand of love in Nabokov's world. In his consistent effort to achieve ever more refined approximations of nature's "truth," both truth of fact (individual, species) and truth of interrelations (genus, family, ecosystem) - he acts out this particular brand of love.

The same principle governs his artistic creations-expressing physical environment and individual personalities-and his metaphysical musings. The valuation we put on our actions towards others constitutes the essence of ethics and morality, and even the attempt to know a person is an ethically charged act, as Mikhail Bakhtin observed. Whether a human being, replete with consciousness, can be the subject of scientific, empirical knowledge in the same way that the nonhuman natural world can is a question of great doubt for Nabokov. Indeed any knowledge of another human being is radically limited, even more so than the knowledge of empirical nature. As a result, Nabokov's works reflect an imperative to imagine the inner lives of other human beings - as we see especially in The Gift, The Real Life of Sebastian Knight, and Pnin-and the harm of its 
neglect, as in Lolita, Pale Fire, and Ada. It is thus an ethical concern that disrupts the science of psychology in Nabokov's art: the idea that scientific study of consciousness runs the risk of obscuring or even dismissing its mystery and, perhaps inadvertently, destroying its autonomy, with consequences like what occurs in the worlds of Invitation to a Beheading and Bend Sinister the probable result (and in some respects it is from this sort of outcome that Timofei Pnin flees at the end of his story).

There is also an ethical component to Nabokov's "advance probes," to borrow Barabtarlo's apt phrase, into the metaphysical beyond. While Nabokov was curious about scientific efforts to provide any glimmers of knowledge of what exists past the horizon of reason and worldly existence, his own artistic engagements with such topics call direct attention to their own hypothetical, if not purely playful, nature. With the exception of Nabokov's explicit assumption of the world's fundamental goodness, all metaphysical suggestions are clearly speculative. The works prove this in part through the repeated use of an inserted icon of the author's presence—an anagram, or a disguised authorial cameo—for us a kind of romantic irony through which the writer refuses to claim or even hint at authoritative status with regard to the ultimate limits and ontological status of the world. (Can one imagine Tolstoy ironizing his metaphysical pronouncements in a similar way?) By withholding such claims of authority, in addition to activating an extreme limit of honesty, Nabokov also leaves his readers maximum scope for their own metaphysical imaginings, embodying the way that claims of science or knowledge can curtail themselves out of ethical concern for others' autonomy. ${ }^{35}$ As a project in knowledge, as a series of artistic representations of the passionate quest for understanding, Nabokov's approach to portraying these three strata-physical, personal, metaphysical-demonstrates one way to figure the organic connection between scientific and metaphysical modes of investigation.

In some ways, the major interpretive movement that I have called "intertextual" relates specifically to this epistemological progression outlined above and embodies the exact spirit of this differentiation. Developed most thoroughly by Alexander Dolinin, Omri and Irena Ronen, Savely Senderovich and Elena Shvarts, Irina Paperno, Yury Leving, and Eric Naiman, this kind of work seeks to discover, as it were, the exact nature of Nabokov's compositional units and rules: it explores the fundamental substances and laws that make up his artistic universe. In its precision, rigor, and certainty, this field of scholarship is the most like "science" in its traditional, Kantian-Newtonian sense: the hypotheses are clear, the evidence is direct, the conclusions are modest, unambiguous, and 
testable. ${ }^{36}$ The density and quantity of cultural and literary allusions in all of Nabokov's work has ensured, and will probably long continue to provide, an extremely fertile field for exploration. This is, one could say, the "pure science" version of literary scholarship, the quest for ultimate constituents that may or may not result in definitive interpretations of a given work's “meaning." As the number of hidden yet verifiable intertextual references grows, it begins to look more and more as though Nabokov intended his creations to interact with their outer cultural context at every step, in almost every single sentence. Whether such a high degree of intertextuality in fact obtains remains to be seen, but already the density is so great that one can assert confidently that Nabokov composed his works by making active and extensive use of a vast wealth of cultural materials as his primary medium, rather than language as such, which was rather forced to accommodate or conform to this dominant compositional law.

By discussing Nabokov's works this way, we liken them to a universe in their own right, which we can come to know through careful study of the materials of which they are made, how they are formed, and how they give rise to meaning. "Meaning" is used here in a modest sense: not a final or ultimate meaning, but a local meaning with special significance to the themes of the work at hand. Practitioners of this approach have tended to avoid the quest for definitive meanings in Nabokov's works, in part, surely, because the job of discovering allusions seems so far from finished. But there is another source for this reluctance, and that is apparently a desire to stay within the confines of a scientific approach-as inheritors, one might say, of the Formalist and Structuralist mantle. There is a tendency to keep assertions and claims on the level of what can be proven empirically, without straying into possible philosophical or metaphysical hypotheses. This approach views the works as empirical phenomena about which some things can be said with high confidence, while others are the realm of speculation. We find this position expressed with particular clarity in the seminal work of Savely Senderovich and Yelena Shvarts:

We set out to reconstruct motifs related by the provenance of reference in order to consider their networks as semantic strata, each spread over the entire body of Nabokov's oeuvre, each endowed with a special function. It is precisely a unique function that turns a network of allusions to a particular writer or to a cultural context into a dimension constitutive to the Nabokov poetic world. [...] Thus, we are advancing a view of Nabokov's oeuvre as a world situated along its own unique dimensions and ruled by its own idiosyncratic laws. From this point we have the 
chance to understand the peculiarities of this world in a precise way, and one intended by the author, and not one that is merely an invitation to imaginative interpretation. ${ }^{37}$

Working in this manner, scholars stick closely to the definition of scientific activity laid out by Kant, and "ultimate meanings" in the works are kept at bay like those metaphysical things about which we can have opinions but no certainty, no empirical knowledge. In the same way Nabokov, in his lepidoptery and in his empirical commentary on Pushkin's Eugene Onegin, kept within the bounds of scientific practice.

Or did he? I have suggested some of the ways that Nabokov tried to break free of science's formal constraints-in the proposal of a magic triangle, or a "synthetic character" of a species, or a nonutilitarian, even artistic principle in nature (of course this last is extremely muted in the published scientific work, in contrast to the fictitious "Father's Butterflies"). And it is worth remembering again Nabokov's apothegm: "science answers to philosophy," not to statistics. Accordingly, his works invite and reward the kinds of speculations about meanings that his characters also engage in, even if these activities do not provide "conclusive evidence" for absolute truth, but may offer support for deeply held "strong opinions." Thus it is no surprise that sometimes, even empirically inclined scholars cross into the more dangerous realm of pure hypothesis, when they feel that they have collected enough evidence to propose a bold theory. Such, after all, was the method advanced by Francis Bacon, and Goethe, and embraced by Konstantin Godunov-Cherdyntsev in his speciation theory.

Nabokov did not see art as governed by the same rules as science: the best art reaches immediately past the rational and the causal in ways that science is forbidden to do. As he wrote in "The Art of Literature and Commonsense": "In this divinely absurd world of the mind, mathematical symbols do not thrive. Their interplay, no matter how smoothly it works, no matter how dutifully it mimics the convolutions of our dreams and the quantums of our mental associations, can never really express what is utterly foreign to their nature, considering that the main delight of the creative mind is the sway accorded to a seemingly incongruous detail over a seemingly dominant generalization." 38 This credo reflects Nabokov's principled belief that rational thought represents a closed system but not an absolute one. Following Kant, science obeys and discovers the rules that reflect the empirical regularities of the world. Art, in contrast, seeks out the irregularities, the singularities and incongruous details. The twist we find in Nabokov's approach is the suggestion that empirical research itself 
leads to glimpses or intuitions of irregularities-that the irregularities are the most exciting and promising area for research, something that proved true for his beloved discovery, the "mysteriously constant" Karner Blue butterfly. ${ }^{39}$ These anomalies may wind up being incorporated by some new theory-at which point they will be replaced by another set of inexplicable data. ${ }^{40}$ Human reason tends toward regularity and consistency, which it will even create from whole cloth-it "will invent a cause or modify an effect rather than have none at all." Thus, by definition, what resists rational systematization is a likely place to seek whatever might be beyond reason's capacity to understand.

Nabokov was very careful about expressing his knowledge in any sphere, his certainty about any theory, and he was always far more likely to criticize than to support reigning theory or ideology. In fact, he was likely to work diligently to undermine the authority of any systematizing theory or claim of knowledge, as he did in the cases of Dostoevsky, Freud, Darwin, and later, even Einstein, an approach recently promoted by physiologist and philosopher of science Robert S. Root-Bernstein. ${ }^{41}$ Nabokov attacked received wisdom in his scientific and in his pedagogical statements, and in his interviews. The similarity between his and Pyotr Ouspensky's statements about science "never knowing" certain things raises a question: if Nabokov admired the thought of Ouspensky enough to echo him in this way, did he value other, more metaphysical aspects of Ouspensky's doctrine? The answer is that we do not know. And the reason we do not know is that Nabokov worked hard to keep all of his writings free of any metaphysical statement with unambiguous meaning; even his earliest journal writings are ambivalent (e.g., in "Poems and Diagrams" ["Stikhi i skhemy"]). There are two apparently contradictory things we do know: that he thought about metaphysical questions; and that he was critical of any and all programmatic expressions of mysticism. In the 1950s, he singled out what he called the "bogus mysticism" of Symbolist plays from the early twentieth century; ${ }^{42}$ in his twenties, he also criticized the same tendency in his brother Sergey's verse. If we combine these facts with Nabokov's oracular claim to "know more than I can express in words," we can begin to extract a common principle: Claims of true knowledge carry enormous responsibility and can be very dangerous due to unpredictable, often dire, consequences. We see this principle enacted in Nabokov's scientific, literary, and expository work. 
Knowledge claims have a central role in the history of humanity, especially in Western history since the eighteenth century. The rise of positivism after Newton and its post-romantic revival under the socialists was the result of the successful transfer of certain kinds of knowledge claims from the domain of science into those of politics and social theory. The kinds of claims that had been, and could be made about phenomena in nature led to their conversion into a political program for reshaping society on rational grounds. This program was based in large part upon confidence in the ability of human science to solve every problem facing society. This confidence became the centerpiece of the socialist and Bolshevik causes, and it eventually turned into the presumed infallibility of the Soviet regime. This transfer was a reenactment of the similar transfer of religious knowledge into state power during the Christianization of Kievan Rus and Muscovy. Such claims to perfect, unquestionable knowledge are religious in character, but that is not the point. More importantly, this path leads to a double bind: the allegedly "true" knowledge is, on the one hand, full of error, which then is ignored; and, on the other, it breeds the likely danger that this sanitized, exploitable "knowledge" can be converted into a compelling program of political action and hence power. It also turns the "knowledge," or "truth," which is largely false, into an idol before which other values must be sacrificed (as we see illustrated dramatically and tragically in Bend Sinister and Invitation to a Beheading).

An infatuation with knowledge-the Faustian bargain—and most especially an unequivocal faith in it leads to the privileging of knowledge over ambivalence and Socratic ignorance. This idolization of positive knowledge may lead to tyranny of thought, if not to outright despotism. How does this happen? Scientists, who operate in a world where they are fully aware of their epistemological limits, nevertheless manage to make positive statements about nature. For various reasons, which Goethe had outlined with regard to Newton, they make selective statements about how their knowledge has been established, and are generally quiet about the messy, uncertain side of their work. ${ }^{43}$ Goethe was opposed to such laconicism, and so, it appears, was Nabokov. They both practiced the full disclosure of scientific process. The danger, they recognized, is that a scientific culture that downplays doubts, mysteries, and missteps ineluctably tempts human beings to place unwarranted confidence in the potential scope of human knowledge. Nabokov appears to have been acutely sensitive to the dangers produced by knowledge claims, largely due to his life's experience, although such an attitude was common among the neo-idealists well before the Bolsheviks took power. Nabokov's utterances conform to a rule: 
any unqualified knowledge claim, whether scientific or religious, is related to an assertion of power. But as no interesting or significant knowledge claim can be truly complete, all-encompassing, and error-free, all assertions of comprehensive knowledge represent an attempt to amass power based on false premises, compounded by the fact that the goal of the claimants is not knowledge, but power. Only claims that continually highlight their own incompleteness, recognizing human cognitive as well as practical experimental limitations, discourage incorporation into a power quest. Thus both Goethe and Nabokov espoused an ethical science that takes into account different possible results of one's discoveries-including consequences not just of their matter, but also of their manner. The truth and knowledge embodied by scientific research reside not only in the end result, but in the entire process of their becoming. And only a selfquestioning science with its characteristic discovery process leads to a culture of knowledge with solid defenses against political appropriation. Those in power-if they like science at all-do not like holistic, messy, self-doubting scientific doctrines, whose model is not easily imparted to the masses and converted into political support. Nabokov's example as someone who refused to tell his readers what to believe, even while urging them to continue searching and asking, makes him one of the most profoundly ethical writers of the modern era.

The arts and sciences represent different kinds of knowledge: art may in fact contain knowledge that is inaccessible to science. ${ }^{44}$ For Nabokov, art and science both point toward what lies hidden at-or even beyond-the limits of reason and consciousness. Art seeks these limits by probing the inner forms of consciousness as the condition of knowledge and experience; science by measuring all the things consciousness can or might know empirically. Approaching from opposite directions, they join, as Nabokov suggests, atop a high, narrow ridge, with a glorious view of the landscapes all around. 

Abbreviations Used in Notes

Works listed are by Nabokov unless otherwise indicated.

ANLo Alfred Appel, Jr., ed., The Annotated Lolita. Rev. ed. New York: Vintage Books, 1991.

AY Brian Boyd, Vladimir Nabokov: The American Years. Princeton: Princeton University Press, 1991.

Berg Coll. Henry A. and Albert W. Berg Collection of American Literature, New York Public Library.

BS Bend Sinister. New York: McGraw-Hill, 1973.

CE Conclusive Evidence. New York: Harper, 1951.

DBDV Dear Bunny, Dear Volodya: The Nabokov-Wilson Letters (1940-1971). Berkeley: University of California Press, 2001 [1979].

FB "Father's Butterflies" (abandoned addendum to The Gift). In Nabokov's Butterflies, 198-234.

Gift The Gift. New York: Vintage International, 1991.

GNBM Dieter E. Zimmer, Guide to Nabokov's Butterflies and Moths 2001.

Hamburg, privately published. 
KQK King, Queen, Knave. New York: McGraw-Hill, 1968.

LCNA Library of Congress Nabokov Archive.

LL Lectures on Literature. Fredson Bowers, ed. New York: Harcourt, Brace, Jovanovich, 1980.

LRL Lectures on Russian Literature. Fredson Bowers, ed. New York: Harcourt, Brace, Jovanovich, 1981.

NB Brian Boyd and Robert M. Pyle, eds., Dmitri Nabokov, trans., Nabokov's Butterflies. Boston: Beacon Press, 1999.

NMGL "Notes on the Morphology of the Genus Lycaedes (Lycaenidae, Lepidoptera)." Psyche 51.3-4 (Sept.-Dec. 1944): 104-38.

NMGLH "The Nearctic Members of the Genus Lycaeides Hübner." Bulletin of the Museum of Comparative Zoology at Harvard College 101, no. 4 (1949): 479-541, plus $18 \mathrm{pp}$. of plates.

NNP "Notes on Neotropical Plebejinae (Lycaenidae, Lepidoptera)." Psyche 52.1-2 (Mar.-June 1945): 1-61.

PF Pale Fire. New York: Vintage International, 1989.

PP Poems and Problems. New York: McGraw-Hill, 1970.

RLSK The Real Life of Sebastian Knight. New York: New Directions, 1959.

RY Brian Boyd, Vladimir Nabokov: The Russian Years. Princeton: Princeton University Press, 1990.

Selected Selected Letters 1940-1977. Dmitri Nabokov and Matthew J. Bruccoli, Letters eds. San Diego: Harvest/HBJ, 1989.

SM Speak, Memory. New York: Vintage International, 1989.

SO Strong Opinions. New York: Vintage International, 1990

SSRP Sobranie sochinenii russkogo perioda v piatii tomakh. Sankt-Peterburg: Symposium, 1999-2000.

Stories The Stories of Vladimir Nabokov. New York: Knopf, 1995.

TT Transparent Things. New York: Vintage International, 1989.

USSR The Man from the USSR and Other Plays. San Diego: Bruccoli Clark/HBJ, 1984.

\section{Introduction}

1. NB, 529 .

2. This translation comes from Robert J. Richards, The Romantic Conception of Life: Science and Philosophy in the Age of Goethe (Chicago: University of Chicago Press, 2002), 403.

3. Such a coincidence is compounded by the fact that Nabokov's next major abode, 
on Nestorstrasse in Charlottenburg, where he wrote his most important Russian works, was equally close-about a kilometer, or four longish blocks— to Max Planck's villa in the neighboring Grunewald district. Planck also shared Nabokov's adopted western birthday, April 23 (his old-style birthday had been April 10).

4. Gift, 28

5. Brian Boyd, RY, 170.

6. For example, letter to Elena Ivanovna Nabokova, 18 October, 1929. Berg Coll.

7. Kurt Johnson relates how "Nabokov told Edmund Wilson that, during this period, he was approaching his scientific research with the obsession of a 'drunkard,' working 1415 hours per day (letter dated May 8, 1944 [5]). Nabokov reported conflicts with Véra over his priorities (letter to Edmund Wilson dated January 3, 1944 [5A]) and a situation that had required serious attention to his health, consultation with doctors, and an extended vacation (letter to Edmund Wilson dated June 21, 1946 [5])." Kurt Johnson, “Lepidoptera, Evolutionary Science, and Nabokov's Harvard Years-More Light and Context," ALA presentation (full version), May 25, 2001: 27. Provided by author. Cf. also a letter to Mstislav Dobuzhinsky, May 8, 1944: "I drew with my own hand 450 drawings in india ink and about 50 in colored pencil for my extensive work on butterflies (which takes up more of my time than my pocket permits-in other words it would be far better if I spent more time on literature)." NB, 312.

8. FB, 211.

9. Strong Opinions (henceforth $\mathrm{SO}$ ), 79.

10. Nabokov's approach to the links of art and science anticipated the work of Robert S. Root-Bernstein, who argued that "the sciences and the arts share a common aesthetic [and] that aesthetic sensibility underlies the most significant creative endeavors in science." "The Sciences and the Arts Share a Common Creative Aesthetic," in Alfred I. Tauber, ed., The Elusive Synthesis: Aesthetics and Science, Boston Studies in the Philosophy of Science v. 182 (Dordrecht/Boston/London: Kluwer Academic Publishers, 1996), 49-82.

11. It also earned him his lowest grade in secondary school, a B (or "4")—his only one. Letter to Andrew Field, 1973, Berg Coll., cited in Boyd, RY, 166.

12. SO, 116.

13. Boyd, RY, 75.

14. On this society, the early collection, and the society's journal Problems of Philosophy and Psychology, see Randall A. Poole, trans. and ed., Problems of Idealism (New Haven: Yale University Press, 2002), esp. "Introduction."

15. RY, 72 .

16. Bukharin, Historical Materialism [1925] 1965; cited in Stephen Turner, "The Intellectual Origins of Science Studies," in Edward J. Hackett et al., eds., The Handbook of Science and Technology Studies, 3rd ed. (Cambridge: The MIT Press, 2007).

17. "Remarks on F. Martin Brown's 'Measurements and Lepidoptera," Lepidopterist's News 4 (1950): 75-76.

18. Dana Dragunoiu has shown important affinities between this claim and the positions of the Moscow Psychological Society philosophers. "Homo ludis, homo faber: The Gift and 'Father's Butterflies," manuscript provided by author. Dragunoiu's forthcoming book, Vladimir Nabokov and the Poetics of Liberalism, provides extensive background information on the politics and philosophy that saturated Nabokov's childhood.

19. Critique of the Power of Judgment, Paul Guyer, ed., Paul Guyer and Eric Matthews, trans. (New York: Cambridge University Press, 2000), 268.

20. See, for example, section III of the "Transcendental Doctrine of Method," in Critique of Pure Reason, ed. and revised by Vasilis Politis, trans. J. M. D. Meiklejohn (Rutland, VT: Everyman, 1993 [1934]), esp. 502-3.

21. SM, 35 . 
22. SO, 45. This statement may provide the closest textual link one can find between Nabokov and Pyotr Ouspensky, who wrote: "There are a great many questions towards the understanding of which science has made no movement at all. ... Such are the problems of life and death, the problems of space and time, the mystery of consciousness." Tertium Organum, E. Kadloubrovsky et al., trans. (New York: Alfred A. Knopf, 1981), 198; quoted in Robin Dunbar, Trouble with Science (Cambridge, MA: Harvard University Press, 1985), 10. The Ouspensky connection has been discussed at length by Vladimir Alexandrov, "Nabokov and Uspensky," in Vladimir Alexandrov, ed., The Garland Companion to Vladimir Nabokov (New York: Garland Publishing, 1995), 548-52, and by Dieter E. Zimmer, "Mimicry in Nature and Art," in Jane Grayson et al., eds., Nabokov's World, 47-57, 50.

23. Nabokov, Stikhi (Ann Arbor, MI: Ardis, 1979), 3. See also Vladimir Alexandrov, "The Otherworld," in Vladimir Alexandrov, ed., The Garland Companion, 566-71.

24. Asked if he believed in God, he famously replied, "I know more than I can express in words, and what I have expressed could not have been expressed, had I not known more." SO, 45.

25. As, for example, in the preface to the reissue of Bend Sinister (xii).

26. For example, psychologist William James, its first president; physicist Sir Oliver Lodge, its fifth; and philosopher Henri Bergson, its sixteenth.

27. See documents and discussion of this episode in Martin Gardner, Science: Good, Bad, and Bogus (Buffalo: Prometheus Books, 1981), 151-58.

28. Nabokov did conduct at least one parapsychological experiment, of a sort: for three months in 1964, he wrote down all of his remembered dreams in order to compare them with real events of the following days. He was looking for signs of time's contingency, about which he had read in J. W. Dunne's An Experiment in Time while working on Ada. See "Notes for a Work in Progress," Berg Coll., New York.

29. See Kurt Johnson's detailed summary of various ways that Nabokov's ideas about predators' visual acuity turned out to be wrong in "Lepidoptera," $48 \mathrm{ff}$. See also Zimmer, "Mimicry in Nature and Art," where on p. 50 he draws parallels between Nabokov's views on mimicry and those of Pyotr Ouspensky in A New Model of the Universe (New York: Alfred A. Knopf, 1969 [1931]), 41-46. As Zimmer observes, Ouspensky's use of mimicry as a disproof of natural selection did not include Nabokov's favorite claim—that mimicry's precision frequently exceeded predators' acuity.

30. Véra Nabokov letter to Rosalind Wilson, July 24, 1952, Selected Letters, 134.

31. As Johnson points out, Nabokov's taxonomic work was neglected by other scientists and did not in his lifetime earn him the authority to assert himself in "higher systematics" or theory. "Lepidoptera," 62.

32. SO, 154.

33. SO, 118.

34. $\mathrm{SO}, 10-11$.

35. Nabokov's attitude is quite distinct from Tolstoy's ideas about false scientific knowledge, which were more focused on the irrelevance of scientific knowledge, and especially Darwinian biological knowledge, to spiritual truth. After a conversation with Nikolai Strakhov in 1884, Tolstoy wrote in his diary that Strakhov's arguments against natural selection were useless, because Darwinism represented "the ravings of madmen." Soon afterwards, Strakhov's article "A Revolution in Science" left Tolstoy with the feeling that "it's useless, you can't possibly demonstrate every single stupidity.” Diary entry for 7 April, 1884, from R. F. Christian, ed. and trans., Tolstoy's Diaries (London: Athlone Press, 1985), 209. See also Lev Tolstoy, PSS, vol. 53, 205; vol. 54, 50; later he called science the "superstition of the present" (PSS vol. 90, 25, 37).

36. LL, 374 . 
37. Kurt Johnson confirms that this was a common view of Darwinian natural selection before 1930 and was not completely overcome by the "new synthesis" until after Nabokov had left professional lepidoptery. "Lepidoptera," 10-33. Cf. Johnson and Coates, Nabokov's Blues: The Scientific Odyssey of a Literary Genius (Cambridge, MA: Zoland, 1999): "It was really not until the 1950s, and even later, that the neo-Darwinian synthesis began to take anything like its final form" (328).

38. "The Tragedy of Tragedy," 326. This tendency, which Nabokov intuited in 1940, was proposed by Hermann von Helmholtz in his Handbook of Physiological Optics (185667 ) and confirmed in the 1990s in studies of human vision and hearing.

39. Nikolai Chernyshevsky (1828-89) was a leading socialist radical and one of the most important figures leading up to the Bolshevik Revolution. His socialist-utopian novel What Is to Be Done (1862) was Lenin's favorite, and it had a transforming effect upon educated progressive Russians (the intelligentsia). See Irina Paperno, Chernyshevsky and the Age of Reaslim: A Study in the Semiotics of Behavior (Stanford: Stanford University Press, 1988). Fyodor's book on him, which makes up chapter 4 of The Gift, was an artistic-epistemological revenge upon the progenitor of "Socialist Realism." The chapter begins and closes with an inverted sonnet about invisible truth.

40. See, for example, Thomas S. Kuhn's discussion of how humans, including scientists, deal with anomalous information: "In science, $[\ldots]$ novelty emerges only with difficulty, manifested by resistance, against a background provided by expectation. Initially, only the anticipated and usual are experienced even under circumstances where anomaly is later to be observed. Further acquaintance, however, does result in awareness of something wrong or does relate the effect to something that has gone wrong before" (The Structure of Scientific Revolutions, 2nd ed. [Chicago: University of Chicago Press, 1970], 64). Kuhn cites a study by J. S. Bruner and Leo Postman as evidence of how the mind often distorts unexpected sensory inputs: "On the Perception of Incongruity," Journal of Personality XVIII (1949): 206-23.

41. See, for example, Dennis L. Sepper, Goethe contra Newton (New York: Cambridge University Press, 1988), 144-45; on the flaws in Newton's own accounts of how he came to his conclusions, see 105-43, esp. 133-34.

42. Vladimir Vernadskii, "Mysli i zamechaniia o Gete kak naturaliste," republished in Izbrannye trudy po istorii nauki (Moscow, 1981), 242-89.

43. Nikolai Gogol (Norfolk, CT: New Directions, 1944), 119.

44. For example, Kant, Critique of the Power of Judgment: “.... .another (higher) understanding than the human one might be able to find the ground of the possibility of such products of nature even in the mechanism of nature, i.e., in a causal connection for which an understanding does not have to be exclusively assumed as a cause" $(275 ; 5: 406)$.

45. FB, 219.

46. On this debate within evolutionary theory from the late nineteenth and early twentieth centuries, see Stephen Jay Gould, The Structure of Evolutionary Theory (Cambridge, MA: Belknap Press of Harvard University Press, 2002), 197-208. Weismann's The Evolution Theory was published in 1904; he contributed an article on "germinal selection" to The Monist in Jan. 1896. This article includes discussion of mimicry in lepidoptera (p. 32, cited in Gould, 217-18).

47. The article is mentioned in an Oct. 20, 1941, letter to Mark Aldanov (NB, 248), and in correspondence with Edmund Wilson. EW to Nabokov, May 6, 1942, and Nabokov to EW, May 30, 1942. DBDV, 66, 70. Reference to the projected large work appears in Véra's letters to Rosalind Wilson, July 24, 1952 (SL, 134-35; and NB, 484-85), and August 10, $1952(N B, 486)$. For reference to the lecture based on the article, presented to the Cambridge Entomological Society on April 29, 1942, see NB, 265, 278. 
48. On this subject, see Kurt Johnson, "Lepidoptera," 61-64. Johnson details how the evidence against Nabokov's hypothesis was growing throughout the 1940s and 1950s, so that by 1955 or 1960 Nabokov would most certainly have abandoned this direction of inquiry if he had kept up with the science-which, Johnson suggests, he likely did.

49. In view of the fact that the article was submitted to the Yale Review, it is likely that it was not a highly technical paper, but rather more of a popularizing piece.

50. Apparently composed in 1939, the "second supplement to The Gift" was originally intended to be included in a republication of the novel, along with a first supplement, a story called "The Circle" ("Krug”).

51. Iulii Aikhenvald, an unrepentantly "subjective" critic and later Nabokov's friend, began battling the "death of the author," first implied by Hyppolite Taine, in his 1911 "Introduction" to Silhouettes of Russian Writers.

52. The published title in English, in Dmitri Nabokov's translation, is "Pushkin, or the Real and the Plausible," The New York Review of Books (March 31, 1988): 38-42.

53. The essay on Pushkin is particularly significant in that its title echoes one of Goethe's, "On the True and the Verisimilar in Art," as well as Chernyshevsky's own master's thesis, "On the Aesthetic Relations of Art to Reality."

54. $L L, 5$.

55. Gift, 110; FB, 219, 221.

56. See above, Nikolai Gogol, 119, and Robert J. Richards, The Romantic Conception of Life: Science and Philosophy in the Age of Goethe (Chicago: University of Chicago Press, 2002), 440.

57. Goethe conceived his first scientific adventure, in optics and the study of color, during his Italian journey precisely because there was yet no science of light and color that was suitable to assist the painter's art and use of pigments. It is science in the service of art and of human perceptive acuity, fully informed by the subtleties of human perceptive faculties. What differentiates Goethe's study of color from Newton's is the former's focus on how colors appear to the mind, which is not at all identical with the "degree of refrangibility," Newton's numerical reduction of color (light waves and wavelengths were not yet known). Color is quintessentially aesthetic, and its varied existence within human aesthetic consciousness is amenable to study - but a different kind of study from the one Newton proposed. Nabokov's interest in color, like Goethe's, was largely psychological, spurred by his own "colored hearing," as he describes at some length in Speak, Memory and in some interviews. Other than a scientifically detailed account of his own color-sound-letter associations, Nabokov did not pursue the science of color theory. But we do know that color itself attains a highly developed artistic importance within his fiction and that this role is closely linked to the prominent place color has in human perception of the visible world.

58. "The Tragedy of Tragedy," 326.

59. Note that Nabokov's subordination of quantitative to qualitative runs against the mainstream of most modern scientific practice. "Remarks on F. Martin Brown's 'Measurements and Lepidoptera,'” in NB, 460.

60. $S M, 50$.

\section{Chapter 1}

1. Gift, 77.

2. In an earlier draft of the chapter, Fyodor mentions simply "An English explorer" (anglichanin puteshestvennik) instead of "my father." LCNA, container 2, "Dar fragments" folder.

3. FB, 203. 
4. Nabokov's Blues: The Scientific Odyssey of a Literary Genius (Cambridge, MA: Zoland, 1999), 48. Kurt Johnson addresses questions of whether Nabokov was a descriptive taxonomist or a theoretician, presenting compelling evidence for the latter, more impressive label, even though the culture of taxonomic science prevented Nabokov from making his mark in systematics and theory during his short professional career. "Lepidoptera, Evolutionary Science, and Nabokov's Harvard Years-More Light and Context," presented at American Literature Association (Cambridge, MA, 2001), 62.

5. This number is based on what he reports in his articles. If he did any dissections beyond this work, the figure would grow, but probably not by much.

6. Cf. Johnson and Coates, from Nabokov's Blues: "In the context of the more than eighty species of South American Blues now known, Nabokov's six genuses for the region are a marvel of economy. It is the extent of their diversity, geographic distributions, and unique taxonomic characters that distinguishes Nabokov's work from the maudlin level of simple, anecdotal retrospective assessment of whether his taxonomy was good or bad. It is the breadth of the groups he originally recognized and named, and their significance to major biological questions, that ends up making his Blues 'big science"” (290). The authors also assert that Nabokov's established groups "are diverse and widespread enough to serve as a database for big questions about evolution and biogeography" (317).

7. Nabokov's Blues, 290.

8. NB, 340: "Two organisms inhabiting non-communicating areas but resembling each other in structure as much as two sympatric individuals do, can be said to belong to one species only by analogy and thus regardless of the fact whether or not they can be made to interbreed in the laboratory. In other words biology helps morphology to establish a structural standard in the case of sympatric species, but from this point on morphology alone evaluates specific affinities and distinctions between allopatric organisms." "Notes for talk 'A Genus of Blue Butterflies," October 10, 1944, NB, 338. Brian Boyd has suggested that Nabokov's view was "closer not to what Zimmer once thought a pre-evolutionary morphological concept but to Hugh Paterson's Recognition Concept of Species of the 1980s." "Review of Dieter E. Zimmer, A Guide to Nabokov's Butterflies and Moths 2001," Nabokov Studies 6 (2000-2001): 215-20, 218.

9. "The impact on the eye of a combination of characters in the whole structure or in an element of it, results in the perception of certain structural types. Structures of the same type imply phylogenetic affinities unless it can be proved, as in some cases it is easy to do, that the resemblance is 'false' i.e., attained by essentially different means. Such false resemblances are extremely rare and the number of characters involved is small, and this is as it should be, since such 'convergence' depends upon the mathematics of chance. False dissimilarities also occur (and are also rare), i.e., the striking difference between one type and another is seen, when analyzed, to be due to a simple and brief process of evolution in an unusual direction.

"Unless we believe that certain structural resemblances and dissimilarities are not due to chance or to gross adaptational modifications, but can be classified according to their phylogenetic sense, all horizontal genera are artificial groupings—of some practical use to collectors (e.g., the convenient lumping of all small blue butterflies with founded hindwings and dotted undersides in one 'genus') but of no scientific value. This brings us to the question as to whether a classification on the basis of genitalia reflects natural relationships better than do other principles. I think the answer is 'yes." NB, 354; NNP, 4.

10. Zimmer, GNBM, 77.

11. Robert M. Pyle, "Between Climb and Cloud," in NB, 44; cf. NMGL, 108;

12. "It is going to remain a wonderful and indispensable thing for some 25 years, after which another fellow will show how wrong I was in this or that. Herein lies the difference between science and art." This comment, in a letter to Edmund Wilson (Oct. 11, 1944, 
DBDV, 159), refers to "Notes on the Morphology of the Genus Lycaeides (Lycaenidae, Lepidoptera)," which, while "intriguingly modern" (Johnson and Coates, Nabokov's Blues, 47), was less ambitious than his "The Nearctic Members of the Genus Lycaeides Hübner" or the thoroughly revisionist and sweeping "Notes on Neotropical Plebejinae." See Johnson and Coates, Nabokov's Blues, 22-23.

13. Victor Fet, personal communication; see also Johnson and Coates, Nabokov's Blues, 53.

14. NMGLH, 482.

15. Ibid., 504.

16. "Nearctic Forms of Lycaeides Hüb.," NB, 280.

17. NB, 302. This metaphor appears to be informed by Nabokov's attraction to Bergson's discussions of time.

18. The narrators of Transparent Things see in four dimensions; that is, they see in an object the complete history of all its constituent parts as well as its current physical situation. Cf. Dennis L. Sepper's description of Goethe's scientific epistemology: “To understand nature and the world we must achieve a perspective from which we can perceive everything as it has been and is: the situation of Lynkeus," in Faust, part II ("Goethe against Newton," 189).

19. In Speak, Memory he takes pains to note the common existence of people who don't even see butterflies or moths and to note how they react toward the strangeness of the enthusiast with a net (129-31). In Nabokov's copy of William J. Holland's The Butterfly Book (Garden City, NY: Doubleday, Doran \& Company, Inc., 1931), he marked the place where Holland presents an anecdote about a lepidopterist who encountered a farmer who "surely thought, when he first saw him, that he had just escaped from a lunatic asylum" (113; Berg Coll.). Nabokov adds his own adventures to this lore: "The older the man, the queerer he looks with a butterfly net in his hand. Stern farmers have drawn my attention to NO FISHING signs; from cars passing me on the highway have come wild howls of derision; sleepy dogs, though unmindful of the worst bum, have perked up and come at me, snarling; tiny tots have pointed me out to their puzzled mamas; broad-minded vacationists have asked me whether I was catching bugs for bait; and one morning on a wasteland, lit by tall yuccas in bloom, near Santa Fe, a big black mare followed me for more than a mile" (SM, 131).

20. "The paucity of true butterflies in the eastern United States is unrivalled in any other general area of the same size in the temperate part of holarctic territory" (NNP, 46n3.)

21. See, for example, Boyd's description in RY, 69.

22. Johnson and Coates, Nabokov's Blues, 38. They also note that this figure is not the highest among arthropods, an honor belonging to beetles.

23. Anna Karenina, part 7, chapters 30-31. On Nabokov's likely engagement with this Darwinian side-trail, see also Stephen H. Blackwell, "Three Notes on The Gift: An Intertext, a Revision, and a Puzzle Solved," The Nabokovian (Spring 1998): 36-39.

24. It is noteworthy, however, that N. G. Chernyshevsky, the leading Russian materialist thinker of the period 1850-80, wrote an article highly critical of Darwin's theory, which offended him in its implication that harm (suffering, war, starvation) can produce good (progress, evolutionary "improvements"). "The Origin of the Theory of the Beneficiality of the Struggle for Life" (published under the pseudonym, "An Old Transformationist") (Russkaia mysl', 1888). Presumably Chernyshevsky would have preferred a more Hegelian version of natural progress; in the article, he extols Lamarck. The Soviet journal Pod znamenem marksizma published several articles in the 1920s relating Darwinism to the dialectic of history. See also Alexander Vucinich, Darwin in Russian Thought (Berkeley: University of California Press, 1988). 
25. Stephen Jay Gould calls this the "standard argument against Natural Selection," in The Structure of Evolutionary Theory (Cambridge, MA: Belknap Press of Harvard University Press, 2002), 359n. It appears variously in works of William James, Charles S. Peirce, Henri Bergson, and, notably, in Nabokov's revered Nikolai Kholodkovskii. Although according to Alexander Vucinich, Kholodkovskii was opposed to teleogy, neo-vitalism, and metaphysics in biology, he nevertheless advised against seeing natural selection as "the only or almost the only factor responsible for such a complex phenomenon as organic development" (emphasis added; quoted in Alexander Vucinich, Darwin in Russian Thought [Berkeley: University of California Press, 1988], 276 and n8; Nikolai Kholodkovskii, Biologicheskie ocherki [Moscow, 1923], 138). For Kholodkovskii, the main weakness of natural selection lay in the "absence of any explanation for the appearance of the first variations that underwent Natural Selection" (Biologicheskie ocherki, 136 [not in Vucinich]). This argument does not really contradict Darwin but merely shifts the rhetorical emphasis. August Weismann countered this view, arguing that although "selection cannot create but only rejects, $[\ldots]$ precisely through this rejection its creative efficacy is asserted." "Germinal Selection," The Monist 6 (1895-96): 250.

26. "While accepting evolution as a modal formula, I am not satisfied with any of the hypotheses advanced in regard to the way it works." NB, 356; cf. NNP, 2.

27. Kurt Johnson, "Lepidoptera," 38-55.

28. FB, 219. This formulation echoes Ralph Waldo Emerson's claim (in a sermon on related themes) that the "Universe ... is adapted to give pleasure to us." This sermon was first published in 1938, in Young Emerson Speaks: Unpublished Discourses on Many Subjects (Boston: Houghton-Mifflin). Laura Dassow Walls suggests that Emerson's sermon was in fact itself echoing William Cudworth's The True Intellectual System of the Universe (four volumes, 1678). Whether Nabokov had access in 1939 to either of these texts is an open question, but they promise fertile ground for comparative study. See Walls, Emerson's Life in Science: The Culture of Truth (Ithaca: Cornell University Press, 2003), 47. As I elaborate later in this chapter, there is good reason to suspect that Nabokov had read and was thinking of Emerson while he wrote The Gift and "Father's Butterflies."

29. FB, 226.

30. For example, Critique of the Power of Judgment, $\$ \$ \$ 75-77$.

31. Some of Nabokov's favorite examples of such mimicry included the Kallima genus, which contains several dead-leaf mimicking butterflies; an invented or misunderstood creature whose caterpillar allegedly mimics the root of a rhubarb or vice-versa (see Zimmer, GNBM, 171); oozing bubble-like spots on Owl Butterflies (Brassolinae; see Zimmer, GNBM, 117, 127; SM, 124; LL, 374); and hummingbird hawkmoths (Sphingidae: these last are not considered true mimics, by Nabokov or other scientists).

32. Competing post-Darwinian evolutionary theories were proposed by many scientists, including Alpheus Hyatt (1880), William Bateson (1894), Theodor Eimer (1888), Hugo De Vries (1910), Simeon L. Berg (1922), and Richard Goldschmidt (1939). See Gould, The Structure of Evolutionary Theory, 351-466; and Kurt Johnson, "Lepidoptera," Part II, $11-33$.

33. Biologicheskie ocherki, 135.

34. FB, 226. Victoria N. Alexander has observed that such spherical imagery has roots in German Transcendentalism, particularly in the work of Carl Gustav Carus. NabokovL, October 27, 2001. Additionally, Friedrich Schelling's First Outline of a System of the Philosophy of Nature (Albany: State University of New York Press, 2004) also invokes the spherical concept in describing species (43-44). Stephen Jay Gould points to Fleeming Jenkin and Julien-Joseph Virey as proponents of spherical models (see Gould, Structure, 147, 219, 297). 
35. Nabokov, "Remarks on F. Martin Brown's 'Measurements and Lepidoptera," Lepidopterist's News 4 (1950): 76.

36. It also became characteristic of V. I. Vernadsky, the polymathic geologist and author of The Biosphere (1926) —and of a study of Goethe's science: "Mysli i zamechaniia o Gete kak naturaliste," in V. I. Verndadskii, Izbrannye trudy po istorii nauki (Moscow: 1981), 242-89; and online at http://www.elibrary.ru/books/vernadsky/2.1.6.htm.

37. A classic example of this phenomenon can be found in the electron-charge experiments of Robert A. Millikan. See Gerald Holton, "Subelectrons, Presuppositions and the Millikan-Ehrenhaft Dispute," in Gerald Holton, ed., The Scientific Imagination (Cambridge University Press, 1978), 25-83. See also Richard Feynman's 1974 Caltech commencement address, "Cargo Cult Science," online at http://calteches.library.caltech.edu/51/02/CargoCult.htm; and Allen Franklin, "Millikan's Published and Unpublished Data on Oil Drops," Historical Studies in the Physical Sciences 11 (1981): 185-201.

38. In addition to various disclaimers throughout On the Origin, Darwin in 1863 wrote in a letter to Hooker ("Life," vol. iii, p. 18): "It is mere rubbish thinking at present of the origin of life; one might as well think of the origin of matter." Quoted in J. T. Merz, History of European Thought in the XIX Century (Edinburgh: 1896-1916; New York: Dover, 1965), vol. 2, 406n.

39. "The strictly biological meaning forcibly attached by some modern zoologists to the specific concept has crippled the latter by removing the morphological moment to a secondary or still more negligible position, while employing terms, e.g., 'potential interbreeding,' that might make sense only if an initial morphological approach were presupposed." NNP, 3.

40. Ibid., 6 .

41. NMGL, 110.

42. Ada, 101. As Kurt Johnson and Steve Coates observe, "The crucial phrase here for modern scientists is 'a phase of evolutional structure.' Nabokov realized, quite remarkably for his time, that what scientists study in the laboratory is merely a momentary glimpse into a constantly changing, ongoing process of structural transformation in living organisms. [ ... S]ince the cladists have essentially returned to the notion of species as delineated by physical structures, precisely the point upon which he insisted and the hallmark of his methodology, Nabokov's point of view has an impressively modern ring." Nabokov's Blues, 338.

43. Nabokov eventually decided to argue against the renowned Nikolai Kuznetsov, who suggested that "the [wing] pattern can be broken down into a series of stripes which undergoes various modifications." Lepidoptera, A. Mercado, trans. (Jerusalem: Israel Program for Scientific Translations, 1967), 166.

44. This system was criticized by F. Martin Brown for its incomplete implementation of statistical analysis, a fairly recent tool which Nabokov had not mastered during his Harvard/AMCZ years. "Measurements and Lepidoptera," Lepidopterist's News 3 (1950). Nabokov replied in the next issue, "After all, natural science is responsible to philosophynot to statistics." Lepidopterist's News 4 (1950): 76.

45. NMGL, 137. Note also the intriguing comment about the hindwing of species within the genus Lyceaides: "Its center in regard to the forewing lies outside the root of the latter at a point corresponding to the root of the forewing on the opposite side of the thorax, i.e., at a distance from the base of the wing equal to the breadth of the body at that point; the hindwing center, however, is situated at the very root of the wing (base of costa), so that in order to make the two curvatures coincide, the right hindwing must be placed upon the right forewing in such a way as to have its hub coincide with the root of the left forewing (see plate $\mathrm{V}$ ). My ignorance of mathematical and mechanical matters is prodi- 
gious, and thus I am quite incapable of following up certain lines of thought which these curious facts suggest" (ibid., 113).

46. Ibid., 138.

47. NNP, 44; all italics original. As we saw above, Nabokov was aware that a group of related living species does not represent perfect historical development, "since a sequence in time is not really deducible from a synchronous series." "Nearctic Forms of Lycaeides Hüb.," NB, 280.

48. For an introduction into Nabokov's possible influences in thinking about mimicry, see Dieter E. Zimmer, "Mimicry in Nature and Art," in Jane Grayson et al., eds., Nabokov's World (Basingstoke, UK: Palgrave, 2002), vol. 1, 47-57.

49. EW to Nabokov, May 6, 1942, and Nabokov to EW, May 30, 1942, DBDV, 66, 70. Nabokov also presented variations on this talk during his lecture tour to the southern United States in October of 1942. Letters to Véra, October 11, 1942, NB, 269; and October $17-18, N B, 270$.

50. Oct. 20, 1941, letter to Mark Aldanov, NB, 248.

51. For a time, Nabokov may have been leaning toward a Bergsonian élan vital, if not an idealist teleology, as the moving force behind mimicry. Victoria N. Alexander has explored the relationship between emergent forms in complex dynamic systems and the appearance of species and mimicry in nature, comparing recent theories to Nabokov's apparent views of evolution. See "Nabokov, Teleology, and Insect Mimicry," Nabokov Studies 7 (2002-2003): 177-214.

52. NB, 310.

53. "From Minutes of the Cambridge Entomological Club," NB, 278.

54. Kurt Johnson, "Lepidoptera," 62.

55. See Zimmer, GNBM, 171, "Hepialus armoricanus Oberthür; and 248, Pseudodemas tschumarae.

56. SM, 125.

57. Johnson, "Lepidoptera," 31.

58. With the very notable exception of Russian/Soviet scientist V. I. Vernadsky-whose work in "holistic science" in such books as The Biosphere was also ignored by the mainstream. See Kendall E. Bailes, Science and Russian Culture in an Age of Revolutions: V. I. Vernadsky and His Scientific School, 1863-1945 (Bloomington: Indiana University Press, 1990).

59. The fact that this chapter was not published or included in the text does not diminish its interest. There were a variety of reasons that Nabokov never followed through on his plan to attach two addenda to The Gift ("The Circle" and "Father's Butterflies"), not least among them the novel's troubled publication history: its crucial fourth chapter was suppressed by the journal Sovremennye zapiski in 1938, and Nabokov had to wait until 1952 to see the complete novel published. The addendum was prepared just before the onset of World War II, at a time when Nabokov was still experiencing the novel's artistic afterglow. By 1952 he had changed countries and languages and was in the final years of his work on Lolita.

60. FB, 216. This metaphor, perhaps unconsciously, inverts an image from Francis Bacon, for whom mind was a "mirror or glass capable of the image of the universal world" (quoted in Walls, Emerson's Life in Science, 47). In Godunov-Cherdyntsev's version, mind comes first and nature is the mirror. This transformation may have taken place with the assistance of Emerson: as Laura Dassow Walls explains, "The important chapter [of Emerson's book Nature] 'Language' develops the idea that since thought was the origin of nature, 'Nature is the vehicle of thought,' connecting us back to the Creator through the three steps of word, fact, and spirit: word is sign of fact; natural fact is symbol of spiritual 
fact. The mirroring of things and thoughts guarantees the analogous relationship by which each is the means to understand the other ..." (110). And: "Emerson alludes to Bacon in Nature when he declares: 'parts of speech are metaphors because the whole of nature is a metaphor of the human mind. The laws of moral nature answer to those of matter as face to face in a glass"” (47).

61. FB, 219.

62. Except perhaps in "Bol'shaia medveditsa" (The Great Bear, Ursa Major): see Boyd, RY, 150-51.

63. Walls describes how for Emerson, "one studies nature to study mind. Intellect 'existed already in the mind in solution: now, it has been precipitated, and the bright sediment is the world'" (Emerson's Life in Science, 123). There is ample circumstantial evidence that Nabokov read Emerson, especially his Nature, sometime before or while composing The Gift. Several key observations, by both Fyodor and his father, seem to echo passages from Emerson. Best known of these is the "complete and free eye" (Gift, 310; cf. Emerson's "transparent eye-ball," Nature, 13); later in the same chapter, Fyodor enjoys an upsidedown view of the Grunewald (332; cf. Nature, 64; William James uses a similar image, which he may also have drawn from Emerson; see chapter 4, n30); Fyodor soon after muses that he might "dissolve completely" (cf. Nature, 13: "I am nothing"); and in "Father's Butterflies," Godunov-Cherdyntsev mentions "rhymes of nature," an extremely rare echo of the same phrase by Emerson (FB, 221; cf. Emerson, Journals of Ralph Waldo Emerson, with Annotations, Edward Waldo Emerson and Waldo Emerson Forbes, eds. [Boston and New York: Houghton Mifflin Company, 1912], 46.)

64. FB, 219.

65. FB, 218-19.

66. Godunov-Cherdyntsev also argues that selection alone could not explain mimicry, for lack of time. August Weismann made a similar argument in 1896, in support of his "germinal selection" thesis (cited in Gould, Structure, 218): "It would have been impossible for such a minute similarity in the design and particularly in the shades of the coloration, ever to have arisen, if the process of adaptation rested entirely on personal selection. ... In such cases there can be no question of accident, but the variations presented to personal selection must themselves have been produced by the principle of the survival of the fit!"

67. FB, 225. This formulation evokes the thought of C. S. Peirce, who argued that the laws of nature themselves evolve and change over time and even that "if we posit a primal habit in nature, viz. the tendency however slight to take on habits, then the result is often a high degree of regularity in the long run. For this reason, Peirce suggested that in the remote past nature was considerably more spontaneous than it later became, and that in general the habits nature has come to exhibit have evolved, just like ideas, geological formations, and biological species have evolved." Robert Burch, "Charles Sanders Peirce," The Stanford Encyclopedia of Philosophy (Spring 2008 Edition), Edward N. Zalta, ed., online at http://plato.stanford.edu/archives/spr2008/entries/peirce/. Although the parallels between this description and what we find in Godunov-Cherdyntsev are striking, the degree of Nabokov's exposure to Peirce is unknown.

68. FB, 228.

69. Ibid.

70. FB, 214, 215, 227. At the time Godunov-Cherdyntsev was supposedly writing, stars were not yet widely known to explode. The first popular accounts of exploding stars (supernovae) appeared from December 1934 through April 1935, concerning "Nova Herculis"-perhaps too late to save Fyodor's or his father's metaphor from anachronism. The earliest report I have found suggesting that Novae were exploding stars appears in E. E. 
Barnard, "Some Peculiarities of the Novæ," Proceedings of the American Philosophical Society 61, no. 2. (1922): 99-106 (accessed via JSTOR).

Walls's discussion in Emerson's Life in Science of astronomical metaphors in Coleridge offers an instructive parallel for Godunov-Cherdyntsev's theories of nature. In detailing how Coleridge framed the subjective and objective aspects of life in nature, Walls notes that "Coleridge felt entirely comfortable borrowing metaphors from astronomy to discuss the formation of intelligence because he believed that ultimately he wasn't borrowing at all: science was the way by which intelligence realized itself" (132). This equation of nature with intelligence is a central part of Godunov-Cherdyntsev's outlook, according to which human intelligence comes from nature's "storehouse."

71. FB, 231.

72. FB, 214.

73. There is also a likely reference to Einstein's early status as a patent clerk (while discovering relativity) in the same passage, where Godunov-Cherdyntsev's intuitive revelation is likened to the "meekest employee who suddenly appears before his employer with a plan that casts a whole new light on a deal the tycoon had negotiated with reckless haste, proposing certain options, a new connection" $(F B, 214)$. This link reappears a few pages later in a comparison of an "evolutionist" to a passenger riding in a train-one of the stock images for the explanation of special relativity $(F B, 218)$.

74. In establishing the boundaries of species, the ability to force two butterflies to mate in the laboratory has little or no significance to Nabokov (nor does it to more recent scientists): see, for example, NNP, 3-4. On the history of "torture" as a metaphor for science, see Carolyn Merchant, "The Scientific Revolution and The Death of Nature," Isis 97 (2006): 513-53, esp. 526-27; accessed online at www.journals.uchicago.edu/ISIS/journal/ issues/v97n3/970308/970308.html. Cf. also Goethe: “The Greeks spoke of neither cause nor effect in their descriptions and stories-instead, they presented the phenomenon as it was. In their science, too, they did not perform experiments, but relied on experiences as they occurred." (From Maxims and Reflections, collected in Scientific Studies, Douglas Miller, ed. and trans. [New York: Suhrkamp Publishers, 1989], 308.)

75. For example, $N B, 309-10$; Fyodor quotes his father as calling Germans "masterful collectors, but wretched classifiers" (FB, 202; see also 199-201, especially the addendum's opening paragraph: "The notorious Schmetterlingsbücher ...").

76. Gift, 63; SSRP, 248.

77. SO, 117.

78. The earliest culture-related instance of the term "morphology" that I have been able to find comes, curiously enough, from Andrey Bely, who employed it in 1909. His essay "Comparative Morphology of the Rhythm of Russian Lyrics in Iambic Dimeter" appeared in his voluminous and influential theoretical work, Symbolism, which Nabokov knew well. This work is widely seen as an important precursor of Formalism. See Victor Ehrlich, Russian Formalism: History-Doctrine (New Haven: Yale University Press, 1981); or Peter Steiner, Russian Formalism: A Metapoetics (Ithaca, NY: Cornell University Press, 1984).

79. See Irina Paperno, "How Nabokov's Gift Is Made," Russell Valentino, trans., Stanford Slavic Studies 4, no. 2 (1992): 295-322; and Marina Kostalevsky, "The Young Godunov-Cherdyntsev or How to Write a Literary Biography," Russian Literature 43.3 (1 April 1998): 283-95. Also Michael Glynn, who explores Nabokov's reliance upon the ideas of Viktor Shklovsky, in "The Word Is Not a Shadow. The Word Is a Thing'-Nabokov as Anti-Symbolist," European Journal of American Culture 25.1 (2006): 3-30.

80. For example, "There comes a moment when I am informed from within that the entire structure is finished. All I have to do now is take it down in pencil or pen" (SO, 
31-32). Or, as Fyodor says in The Gift, "I seem to remember my future works, even though I don't know what they'll be about” (94).

81. In some draft materials written in 1944 that were never incorporated into any article, Nabokov wrote, "It is my firm opinion that in order to discuss a given population, from any point of view, the worker must have had actual field-experience throughout several seasons in the region discussed, must have tramped hundreds of miles and minutely examined hundreds of specimens ..." (Berg Coll., Lepidoptera material, Box 9: NB, 308).

82. The paintings of butterflies and moths apparently served as a partial surrogate for Fyodor, thanks to the living artistry in their depiction. FB, 204.

\section{Chapter 2}

1. Nikolai Gogol, 64.

2. Savelii Senderovich and Elena Shvarts, "Aurelian i Eleonora, ili Gde Nabokov lovil svoikh babochek," Novyi zhurnal 123 (Dec. 1998): 205-12. By the same authors, "Nabokovskii Faust. Predvaritel'nye zametki," in Nora Buhks, ed., Vladimir Nabokov-Sirine; Les Anées Européenes (Paris: Institut d'études slaves, 1999), 155-76; and Omri Ronen, "Nabokov and Goethe," in Gennady Barabtarlo, ed., Cold Fusion: Aspects of the German Cultural Presence in Russia (New York: Berghahn Books, 2000), 241-51. Among other links, Ronen discusses likely sources for the accusation of "poshlust" (247-48).

3. My own German is not strong enough for me to make any claims of special insight into these fascinating texts, which I have read mostly in English with the German text at hand for clarification.

4. Recent scholars have emphasized that Goethe was not against mathematics in science per se, but that he was concerned about its over-application. For example, Dennis L. Sepper: "Is Goethe an opponent of modern physics? He opposed Newton's optics; but few realize that he spoke approvingly of the wave theory of light, which was formulated in a much more sophisticated mathematics than was Newton's" "Goethe against Newton: Towards Saving the Phenomenon," in Frederick Amrine et al., eds., Goethe and the Sciences: A Reappraisal, Boston Studies in the Philosophy of Science, Vol. 97 (Dordrecht: D. Reidel Publishing Co., 1987), 175. Cf.: "Like dialectics, mathematics is an organ for a higher kind of inner sense; in practice it is an art like rhetoric. Both value nothing but form-the content is unimportant. It does not matter whether mathematics counts pennies or guineas, whether rhetoric defends what is true or what is false." Scientific Studies, Douglas Miller, ed. and trans. (New York: Suhrkamp Publishers, 1988), 310.

5. "The object of morphology, as distinct from that of classification, can be defined as the attempt to describe, and if possible to comprehend and explain, the relative similarity as well as the graduated differences of form and structure which natural objects present to our gaze. Although the study can be conducted on a large as well as on a small scale, these similarities and differences sooner made themselves felt in the comparatively smaller objects of living nature." J. T. Merz, History of European Thought in the XIX Century. 4 vols. (New York: Dover, 1965), vol. 2, 231. See also Peter Steiner, Russian Formalism: A Metapoetics (Ithaca: Cornell University Press, 1984), 69-71.

6. In the third edition of On the Origin, Darwin acknowledged Goethe's role as a major precursor to his work. See Robert J. Richards, The Romantic Conception of Life: Science and Philosophy in the Age of Goethe (Chicago: University of Chicago Press, 2002), $4 \mathrm{n} 8$.

7. See Dennis L. Sepper, Goethe contra Newton (New York: Cambridge University Press, 1988), chapter 3, esp. 102-3, and also his "Goethe against Newton." See as well Merz's quite detailed account: vol. 2, 231-52. 
8. See the essays in David Seamon and Arthur Zajonc, eds., Goethe's Way of Science: A Phenomenology of Nature (Albany: State University of New York Press, 1998). The anthology includes scientific and philosophical perspectives on this alternative framework.

9. Scientific Studies, 63.

10. Ibid., 63, 64, 65 .

11. "Neither can we deny the high and seemingly creative independent power found in the inner faculties through which the evidence is grasped, collected, ordered, and developed ("The Experiments as Mediator," Scientific Studies, 12).

12. Ernst Mach, The Science of Mechanics (La Salle, IL: Open Court, 1960), 283.

13. "Experiment as Mediator," Scientific Studies, 11.

14. Ibid., 12. Nabokov appears to have conformed to this requirement, as when he confessed his prejudice on questions of the origin of wing-markings, especially lines, by admitting his own bias: "Although quite possibly my judgment may be affected by the fact that the genus which I have especially studied and to which we must now turn is most honestly 'spotted' - and also by the fact that I am interested more in what happens within a given interspace than in the wing pattern as a whole, still I am quite sure that it would be a waste of time to try and twist this or that illusion created by a transverse continuation of Lycaenid macules into this or that "prototypical line" (NMGL, 120-21). An interesting echo of this rigorous method appears in Carl H. Lindroth's historical sketch of early lepidoptery in "Systematics Specilizes between Fabricius and Darwin: 1800-1859": "[H. T.] Stainton was extremely meticulous and self-critical. 'He goes so far as to recommend that no species should be described upon less than twenty to thirty specimens, and advocated an amount of self-denial in such matters, which I imagine hardly any of us are prepared to put in practice"” (F. D. Godman, Trans. ent. Soc. London, 1892: XLVIII), in Ray F. Smith et al., eds., History of Entomology (Palo Alto: Annual Reviews Inc., 1973), 136.

15. Notably, Dmitri Mendeleyev in his Principles of Chemistry makes a similar observation: "If facts themselves, as evident even from the word's etymology (from factum est), include the person who observes them, then so much more inevitable is the presence of personal views [perspectives, envisionments] in the communication of a developed worldview-derived from and discovered in experiments-that constitutes the essence of science. And therefore, with all the striving for objectivity in the development of science, it will always and inevitably contain more than a little of the subjective-personal and ephemeral." Osnovy khimii, 8th. ed. (St. Petersburg: Tipo-lit. M. P. Frolovoi, 1906), iii.

16. "Experiment as Mediator," Scientific Studies, 13.

17. Ibid., 15.

18. See discussion in Sepper, Goethe contra Newton, 142-57; also, Karl J. Fink, Goethe's History of Science (Cambridge: Cambridge University Press, 1991), chapter 7.

19. Helmholtz was famous in the nineteenth century for his early critique of Goethe's Theory and his late softening or retraction of that critique. See his "The Scientific Researches of Goethe," in Selected Writings of Hermann von Helmholtz (Middletown, CT: Wesleyan University Press, 1971), 56-74, and the later "Goethe's Anticipation of Subsequent Scientific Ideas," ibid., 479-500. Dennis L. Sepper suggests that "in the twentieth century there has been a partial rehabilitation of the Farbenlehre, especially in its treatment of physiological and psychological aspects of color, and a greater readiness to acknowledge its virtues (e.g. concreteness) vis-à-vis modern theoretical physics" ("Goethe against Newton," 175).

20. "Experiment as Mediator," Scientific Studies, 17.

21. Ibid., 14.

22. Robert J. Richards suggests that Goethe's attitude to Newton emerged in part from an affinity with Spinoza: "He was driven by what he thought the defects of the Newtonian approach: insufficient experiment and hasty generalization which violated 'the rights of nature.' And in the essay ['Experiment as Mediator'], the powerful influence of Spinoza can 
still be felt insofar as Goethe understood the trajectory of scientific work to move from a careful, sequential ordering of experimental results to higher principles of connection. Such an ordering would allow the kind of cognition that might constitute an adequate idea and ultimately an intuition into the whole (scientia intuitiva, properly speaking)." Romantic Conception, 439.

23. Gernot Böhme asserts that "in this way, Newton's theory is physics and deals with the objective properties of light; Goethe's theory is 'science of perception' and deals with laws of seeing." "Is Goethe's Theory of Color Science?," in Frederick Amrine et al., eds., Goethe and the Sciences: A Reappraisal, 148-74, 163-64. Sepper suggests, "More than anything else Goethe was combating a defective conception of science and scientific method that had helped bring about the dogmatic entrenchment of diverse refrangibility" ("Goethe against Newton," 182). More recently, Carl Popper refutes Newton's claim to have developed his celestial mechanics by induction. See "On the Status of Science and of Metaphysics," in Conjectures and Refutations (London: Routledge and Kegan Paul, 1963), 184-200, esp. $185-86$.

24. See discussion in Böhme, "Is Goethe's Theory of Color Science?," in Amrine et al., eds., Goethe and the Sciences, 164-68.

25. Goethe relates the anecdote in "Fortunate Encounter," Scientific Studies, 18-21.

26. Romantic Conception, 439-40. Richards quotes the following passage from a brief essay called "The Pure Concept" as a demonstration of Goethe's efforts to bridge the gulf between idealism and realism: "Since the simpler powers of nature are often hidden from our senses, we must seek, through the powers of our mind [die Kräfte unseres Geistes], to reach out to them and represent their nature in ourselves ... [for] our mind stands in harmony with the deeper lying, simpler powers of nature and so can represent them in a pure way, just as we can perceive the objects of the visible world with a clear eye" (439).

27. Quoted in Richards, Romantic Conception, 477-78. Richards further observes, "Schelling's theory of dynamic evolution, which Goethe accepted, postulated an organic foundation for a transformational series (namely in absolute mind), and Goethe's own theory of the archetype augmented the Schellingian conception; moreover, by the time of Z[ur] M[orphologie], researchers had accumulated fossil evidence of such transformations" (490).

28. "Toward a General Comparative Theory," Scientific Writings, 55.

29. Romantic Conception, 9.

30. For example, see "Goethe, Nature, and Phenomenology," in Seamon and Zajonc, eds., 1-14.

31. Quoted in Richards, Romantic Conception, 489. This claim anticipates Nabokov's observation that "average reality begins to rot and stink as soon as the act of individual creation ceased to animate a subjectively perceived texture ...” (SO, 118).

32. As Richards suggests, Goethe learned that "art and science had deep foundations within a nature that encompassed both the subjective and the objective. He would find in imagination not the betrayer of truth but the faculty of creative possibility. And he would be more circumspect concerning scientific theory and the way it might guide one to sound observation" (Romantic Conception, 438).

33. Maxims and Reflections \#1344. Translation by, and quoted in, Richards, Romantic Conception, 403.

34. PP, 155-56.

35. "I would not hesitate a moment to assign to subsolanus and sudderi a subspecific position within the polytypic argyrognomon had they not been centers radiating as it were their own forms ...” (NMGL, 111).

36. See Charles Lee Remington, "Lepidoptera Studies," in Vladimir E. Alexandrov, ed., The Garland Companion to Vladimir Nabokov (New York: Garland Publishing, 1995), 
274-82; Stephen Jay Gould, "No Science without Fancy, No Art without Facts: The Lepidoptery of Vladimir Nabokov," in Sarah Funke, ed., Vera's Butterflies (New York: Glenn Horowitz Bookseller, 1999).

37. NNP, 6, reprinted in NB, 356.

38. NMGLH, 483.

39. Darwin had carefully collected and organized his evidence for two decades before being forced to publish his theory, so he cannot in any way be accused of the same faults that Goethe found in Newton. In addition, Darwin himself, at least in Origin of Species, took pains to point out that natural selection was the main, but not the only, mechanism by which species evolve.

40. This emphasis on the regularity of geographic variation appears to support the early-twentieth-century challenge to natural selection known as orthogenesis. In modern biology, such variation is called "neutral evolution" or "genetic drift."

41. "An Intermaxillary Bone Is Present in the Upper Jaw of Man as Well as in Animals," Scientific Studies, 115-16.

42. NMGLH, 517. Cf. also: "From Alaska southwards and eastwards alaskensis imperceptibly turns into scudderi, the delicate underside maculation becoming clear on a grayish or whitish ground and the female upperside becoming of a brighter blue with more or less developed aurorae." Ibid., 504.

43. NMGL, 111.

44. Knowledge and Error, P. Foulkes and T. McCormack, trans. (Boston: D. Reidel Publishing Co., 1976), 53. Mach, a physicist and philosopher of science, even suggested, "Mechanics does not grasp the foundation, nor even a part of the world, but only an aspect of it" (Die Mechanik in ibrer entwicklung [1908], 554); quoted in Hjalmar Hegge, "Theory of Science in the Light of Goethe's Science of Nature," in Amrine et al., eds., Goethe and the Sciences, 199.

45. Nomogenesis: Or, Evolution Determined by Law, J. N. Rostovtsov, trans. (Cambridge, MA: MIT Press, 1969 [1922]), 314-38, esp. 319-24. For example, "Manders (1911), through observation and experiments conducted in natural surroundings in India and Ceylon, concluded that birds exterminate butterflies to a much greater degree than was previously supposed; according to his computations (p. 741), one hundred bee-eaters (Merops) could exterminate all the butterflies of one species (Catopsilia pyranthe) on a forest road of about seventy miles long within a period of two weeks. But it is noteworthy that birds, in India and Ceylon at least, make no difference between 'edible' and 'inedible' species: with equal satisfaction they consume both the 'unpalatable' Danais and Euploea, which are the imitated forms, and the 'savoury' Hypolimnas and Papilio, which mimic them so unsuccessfully. So that all this masquerade is to no purpose" (319-20). Berg does not argue that no mimicry confers adaptive advantage, but he criticizes the interpretation of accidental acquisition of similarities proposed by natural selection as examples of random convergence. He proposes instead a strong latent tendency of two species to display the same forms: "We assume, on the contrary, that the factors of similarity were present from the very beginning both in the imitator and in the imitated, and an impulse alone was needed for their manifestation" (327). Berg's work was brought to my attention by Victoria N. Alexander, personal communication.

46. See Victoria N. Alexander, "Nabokov, Teleology, and Insect Mimicry," Nabokov Studies 7 (2003): 189; Leona Toker, "Nabokov and Bergson," in Alexandrov, Garland Companion, 367-73, and "Nabokov and Bergson on Duration and Reflexivity," in Jane Grayson et al., eds., Nabokov's World (Basingstoke, UK: Palgrave, 2002), v. 1, 132-40; Stephen H. Blackwell, "The Poetics of Science in, and around, Nabokov's The Gift," The Russian Review 62.2 (April 2003): 256-57.

47. FB, 211. 
48. Ibid., 226.

49. Critique of the Power of Judgment, quoted in Richards, Romantic Conception, 431.

50. SO, 179.

51. "Reine Begriffe," in Johann Wolfgang von Goethe, Sämtliche Werke, Briefe, Tagebücher und Gespräche, vol. 23, pt. 2 (Frankfurt am Main: Deutsher Klassiker Verlag, 1991), 69-70; translated and quoted in Richards, Romantic Conception, 439.

52. $L R L, 11$.

53. PF, 17; SM, 35; Gift, 183, 328.

54. "Stikhi i skhemy," LCNA, container 10; daily diary for 1945, Nov. 17, 1945, Berg Coll. Nabokov described that a given letter, when visualized in combination with its characteristic sound, would always take on a certain hue. See SM, chapter 2, and Donald Barton Johnson, Worlds in Regression: Some Novels of Vladimir Nabokov (Ann Arbor: Ardis, 1985).

55. $S M, 381-82$.

56. This is not to say that audition colorée cannot be studied scientifically: it has interested empirical scientists (including William James) going back into the nineteenth century, and Nabokov made a note of its earliest literary appearance, as reported by Alfred Binet, "Le probleme de l'audition colorée," Revue des Deux Mondes 113 (1892): 586-614 ("Notes on Various Subjects," Berg Coll.).

57. Poslednie novosti, 15 December, 1932.

58. The title's translation is by Dmitri Nabokov; its sense is accurate, although it loses the Goethean overtones and the double emphasis on "truth" in the French, German, and Russian versions of the same phrase, while retaining the poetic rhythm that would be lost in a literal rendition.

59. "Über Wahrheit und Wahrscheinlichkeit der Kunstwerke," Gedenkausgabe der Werke, Briefe und Gespräche (Zürich, Stuttgart: Artemis Verlag, 1965 [1954]), 175-91; see also Karl J. Fink, Goethe's History of Science (Cambridge, UK; New York: Cambridge University Press, 1991), esp. chapters 5 and 7.

60. Nikolai Gogol, 64.

61. Ludmila A. Foster, "Nabokov in Russian Emigré Criticism," Russian Literature TriQuarterly 3 (1972): 330-41, esp. 332-34; Foster cites Mikhail Osorgin, review of Camera obscura, Sovremennye zapiski 54 (1934): 458-60.

62. SM, 218, 139.

\section{Chapter 3}

1. "On a Book Entitled Lolita," AnLo, 314.

2. "I write for my pleasure, but publish for money." "Lolita and Mr. Girodias [from a letter to Girodias of Oct. 5, 1955]," Evergreen Review XI (1967): 37-41. Nabokov adopted the claim from Pushkin, who wrote, “... I write for myself and publish for money and certainly not for the smile of the fair sex." From Pushkin's letter to Prince P. A. Vyazemsky, Mar. 8, 1824, in Aleksandr Pushkin, Pushkin on Literature, Tatiana Wolff, trans., rev. by John Bayley (Evanston, IL: Northwestern University Press, 1998), 85; Pushkin, Polnoe sobranie sochinenii (Leningrad: Akademiia nauk, 1937-59), vol. XIII, 88-89.

3. "The Vane Sisters," Stories, 626.

4. Nikolai Kholodkovskii, Biologicheskie ocherki (Moscow: n.p., 1923), 136. Natural selection can also be seen as an emergent factor that comes about due to the appearance of mutations, a stance Nabokov seems to explore in Godunov-Cherdyntsev's notion that 
evolution itself evolves in nature (FB, 226-28). This question remains of interest today: see Massimo Pigliucci, “Is Evolvability Evolvable?," Nature Reviews Genetics 9.1 (Jan. 2008): 75-82.

5. FB, 219.

6. Ibid., 226.

7. Such a formulation, if accurate, recalls somewhat also Schopenhauer's version of freedom, which is manifest not in the events of the world (which are indeed mechanistically, causally determined) but in the hidden ways of the Will (hidden, that is, from any possibility of human cognition or awareness). See R. B. Haldane and J. Kemp, trans., The World as Will and as Idea (London: Routledge and Kegan Paul, 1883), vol. I (Book IV, \$55), esp. 369, 376-78. Compare also modern theories of complexity and emergence. Although these theories did not exist while Nabokov was composing most of his works, Victoria N. Alexander has argued that he may have intuited something like emergence in his approach to speciation: see her "Nabokov, Teleology, and Insect Mimicry," esp. 177-92.

8. Nabokov suggests in "The Tragedy of Tragedy" that causality is not the basis of life and should not be viewed as fundamental in art (esp. tragedy) or in life. In USSR, 318.

9. Susan Elizabeth Sweeney offers a new perspective on how the nature of human thought itself seems to guide Nabokov's narrative forms, which seem to mimic innate, spontaneous consciousness in their sudden and surprising jumps across chasms of verbal meaning. See "Thinking about Impossible Things in Nabokov," in Duncan White and Will Norman, eds., Transitional Nabokov (London: Peter Lang, forthcoming).

10. "This occurs in scientific classification. Long ago, Linnaeus described a common species of butterfly, adding the laconic note 'In pratis Westmanniae.' Time passes, and in the laudable pursuit of accuracy, new investigators name the various southern and Alpine races of this common species, so that soon there is not a spot left in Europe where one finds the nominal race and not a local subspecies. Where is the type, the model, the original? Then, at last, a grave entomologist discusses in a detailed paper the whole complex of named races and accepts as the representative of the typical one the almost 200-year old, faded Scandinavian specimen collected by Linnaeus; and this identification sets everything right" (The Eye [New York: Phaedra, 1965], 63-64; SSRP, vol. 3, 69). Nabokov included a scientific biography of Linnaeus on his Crimean reading list in October of 1918: Viktor Andreevich Fausek, Linnei, ego zhizn' i nauchnaia deiatel'nost' (Spb: Tipografiia tovarishchestva "Obshchestvennaia pol'za," 1891). "Stikhi i skhemy," inside back cover. LCNA.

11. Donna Tussing Orwin, Tolstoy's Art and Thought, 1847-1880 (Princeton: Princeton University Press, 1993), 102-3. The Henry James story “The Figure in the Carpet" may also have contributed to Nabokov's inspiration in challenging Herzen's analogy. The focus on flaws and gaps, on foldability and linings, develops and expands the metaphysical, or simply mystical, implications of James's metaphor, which had been disarmed in advance by Herzen's critique. James Ramey notes that the theme of flaws becomes part of a larger pattern of "naturalistic literary camouflage" ("Parasitism and Pale Fire's Camouflage: the King-Bot, the Crown Jewels and the Man in the Brown Macintosh," Comparative Literature Studies 41.2 (2004): 185-213, 193), but he does not attend to the fact that it is their status as flaws on one level that breaks through to another plane of significance.

12. PF, 17; Gift, 183.

13. This intimation is echoed also in several stories, for example, "The Vane Sisters" and "Signs and Symbols," as well as in the novel Transparent Things (New York: Vintage International, 1989).

14. Significantly, an artist-turned-waiter from whom Martin orders food near the novel's end is named Danilevski, after N. Ia. Danilevskii, whose 1889 treatise Darwinism was "an elaborately structured synthesis of all anti-Darwinian arguments in circulation at the 
time it was written" (Alexander Vucinich, Darwin in Russian Thought [Berkeley: University of California Press, 1988], 123).

15. Glory (New York: Macmillan, 1970), 198.

16. Aleksandr Dolinin and Grigorii Utgof, "Kommentarii," SSRP vol. 3, 727.

17. Glory, "Foreword," $\mathrm{x}$.

18. Ibid., 111-12.

19. Ibid., 142-43.

20. "Svoeobrazie" could also be rendered as "uniqueness" or "idiosyncrasy." The choice of "originality" in the English may have been intended to preserve an overtone of personal creativity that "uniqueness" lacks, but that would have been overstated by the Russian "original," which means "eccentric." SSRP, vol. 3, 202.

21. Glory, 168, 197; SSRP, vol. 3, 221.

22. Charles Nicol, "Martin, Darwin, Malory and Pushkin: The Anglo-Russian Culture of Glory," in Jane Grayson et al., eds., Nabokov's World (Basingstoke, UK: Palgrave, 2002), vol. 1, 159-72, esp. 170-71. See also his "Why Darwin Slid into the Ditch: An Embedded Text in Glory," The Nabokovian 37 (Fall 1996): 48-53.

23. Glory, "Foreword," xii.

24. Most early reviewers, even the usually supportive Mark Tseitlin, found it too simple, too free of a binding idea or plot. See Dolinin and Utgof, "Komentarii," SSRP, vol. 3, 714-15.

25. Lolita annotator Alfred Appel's fellow soldier called the novel "God-damn litachure" upon reading just two lines, and tossed it aside. ANLo, "Introduction," xxxiv.

26. Nabokov read extensively on adolescent physiology; one source reported that the average onset of puberty among girls was 13 years, 9 months. "Lolita Notes," folder 4, LCNA. Dolly Haze is twelve and five months when Humbert finds her. She does, however, buy some sanitary napkins the morning of their first intercourse, but this does not appear to be due to menstruation. Later, in a gruesome reverie, Humbert does imagine reproducing with Lolita-but only in order to create a string of girl-children, each of whom would replace her mother in his bed at the appropriate age (Lolita, 174; cf. also "litter of Lolitas," $300)$.

27. This assertion brings up the question: does Humbert really love Dolly when he (if he) visits her in Coalmont, now a young woman and six months pregnant? I think that even using the word "love" in Humbert's case is problematic, despite his insistence.

28. "Foreword," Despair (New York: Vintage International, 1989), xiii.

29. In Despair, although Hermann appears either to be infertile or to abjure parenthood, his main sexual energy is self-directed. He represents a parodic incarnation of a wide range of Freudian principles, combined with the Darwinian theme of murdering one's neighbor in the struggle for survival. His narrative, which is intended to justify his murderous act as a work of genius and art, betrays his true motivation: the collection of life-insurance money. Art, Nabokov suggests, is never a tool of struggle, and, of course, murder can never be art.

30. Nabokov's brother Sergey and his Uncle Ruka were both homosexual. The Eye, Glory, Laughter in the Dark, Despair, The Gift all include explicit or tacit homosexual characters or themes.

31. Darwin's second most famous work, The Descent of Man, includes the subtitle "And Selection According to Sex."

32. Nabokov calls Freudianism a "police state of sexual myth" (SM, 325).

33. Love is apparently also absent in Kinbote's sexual world, but not from his dream world: "His dream-love for [Disa] far exceeded in emotional tone, in spiritual passion and depth, anything he had experienced in his surface existence" (note to lines 433-34, PF, 210). 
34. It is worth recalling here his claim that sex organs are relatively isolated from the environmental aspects of natural selection. NNP, 5 .

35. FB, 228.

36. Note to line 629, PF, 238.

37. Brian Boyd, Nabokov's Pale Fire (Princeton: Princeton University Press, 1999), 164; see also Dieter E. Zimmer's more extensive discussion, GNBM, 147-48. Zimmer notes that "Disa" also refers to a butterfly species, Erebia disa (Thunberg, 1791); he has traced the generic name "Disa" to a mythical queen from the Uppsala region, popularized in the first Swedish play, staged by Johannes Messenius in 1611. Zimmer's account is extraordinary and must be seen to be believed. Curiously, the myth itself relates to the problem of survival. Darwin's entire treatise on orchids was designed to demonstrate the law that "higher organic beings require an occasional cross with another individual; or, which is the same thing, that no hermaphrodite fertilizes itself for a perpetuity of generations" (Darwin, The Various Contrivances by Which Orchids Are Fertilized by Insects [Chicago: University of Chicago Press, 1984], 1); and "That cross-fertilization ... is the rule with the Orchidae, cannot be doubted. . . Nevertheless, some species are regularly or often self-fertilized. ... In South Africa Disa macrantha often fertilizes itself; but Mr. Weale believes that it is likewise cross-fertilized by moths" (ibid., 290).

38. Darwin noted, "Considering such cases as those of Ophrys, Disa, and Epidendrum, in which one species alone in the genus is capable of complete self-fertilization, whilst the other species are rarely fertilized in any manner owing to the rarity of the visits of the proper insects; ... we are led to believe that the above-named self-fertile plants formerly depended on the visits of insects for their fertilization, and that from such visits failing they did not yield a sufficiency of seed and were verging towards extinction" (Various Contrivances, 292). This argument suggests that the insects that fertilize these genera were formerly abundant, but are now rare due to unknown ecological shifts. The survival of a useless, even apparently harmful, anatomical feature is indicated, or else this feature is repeatedly regenerated by nature itself. In either case, the tendency toward production of such infertile forms gives Nabokov plausible grounds for his own anti-selectionist biases. Darwin himself expressed uncertainty about the survival value of the self-fertilizing adaptation in these species.

39. The term "Alpha Male" appeared in Science on June 5, 1954: 1179; but it was clearly already common usage by the time Jacob Uhrich wrote "The Social Hierarchy in Albino Mice" in 1937 (Journal of Comparative Psychology 5:2 [April, 1938]: 373-413). The "alpha" theme is present in two of the novel's hereditary trees: Zembla's four monarchs-Alfin, Blenda, Charles, Disa-mirror precisely the four daughters of judge Goldsworth: Alphina, Betty, Candida, Dee.

40. A core concept of Kantian ethics and of Russian neo-idealism; see Randall A. Poole, ed. and trans., "Translator's Introduction," Problems of Idealism (New Haven: Yale University Press, 2002), 28-34, esp. 33.

41. In a letter to his mother, Nabokov called his brother Sergey's homosexuality unnatural and a dead end, while also insisting on his indifference to the religious side of the question (15 June 1926, Berg Coll.). Homosexuality in nature had not yet been demonstrated at that time.

42. "Orchids constitute the largest plant family of them all, perhaps as many as thirty thousand species, making up about 10 percent of the world's plant species." John Alcock, An Enthusiasm for Orchids (Oxford, UK: Oxford University Press, 2006), vi. Darwin, in The Various Contrivances by Which Orchids Are Fertilized by Insects, calls orchids "among the singular and most modified forms in the vegetable kingdom" (1-2). According to the introduction by Michael T. Ghiselin, Darwin's book on orchids "provides the first explicit 
treatment of Darwinian evolutionary anatomy" (xvi) and "evoked a major revolution in botany and in biology as a whole" (xi). "On the other hand the predominant approach to structure was morphology, which, by definition, is the study of pure form, leaving out any consideration of function. This formalistic approach, which has not yet fully died out, was mystical, and rooted in Platonic metaphysics. It was popularized by Oken and Goethe" (xii).

43. See also Bobby Ann Mason's chapters "Insects and Incest" and "Ada or Orchids" in her Nabokov's Garden: A Guide to Ada (Ann Arbor: Ardis, 1974). Mason includes detailed discussion of the botanical and entomological examples used in Nabokov's novel, suggesting that Nabokov includes these as signs of the solipsistic and harmful nature of Van's passion $(49-54,74)$. She also draws attention to Darwin's claim that self-fertilizing orchids were "degenerates" (80) and appears to view the sexual deviations in Ada from an essentially normative perspective (56-57). Mason was also the first to note the possible significance of Erasmus Darwin's The Botanic Garden in Ada and in Pale Fire (170-72).

44. Brian Boyd suggests that they "die into the manuscript record of their past." $A Y$, 537.

45. Ada, 289.

46. Ibid., 99, 100.

47. See Marina Grishakova's related discussion, The Models of Space, Time and Vision in V. Nabokov's Fiction: Narrative Strategies and Cultural Frames (Tartu: Tartu University Press, 2006), 67.

48. The idea can also be found in Kant's Critique of the Power of Judgment, in his discussion of genius in $\$ 46$ : "Beautiful art is art of genius," where he states, "Genius is the inborn predisposition of the mind (ingenium) through which nature gives the rule to art" (Paul Guyer, ed., and Eric Matthews, trans., New York: Cambridge University Press, 2000), 186 [5: 307]). Robert J. Richards suggests that for the Romantics this definition implied that "ineffable rules for the creation of beauty arise from the artist's nature, which is of a piece with nature writ large" (Romantic Conception, 431).

49. For a recent typology and theoretical discussion of Nabokov's use of pattern, see Marina Grishakova, Models of Space, 64-71.

50. See Nabokov's Ada: The Place of Consciousness, Part One (Christchurch, NZ: Cybereditions, 2001), 19-63.

51. Although it is not clear to me that Nabokov makes much use of parasitism as a structural form throughout his art, Pale Fire, at least, largely centers on parasitism. The novel itself is a parasitic parody of the scholarly edition; Kinbote's commentary is parasitic upon John Shade's poem; the title indicates the moon's parasitic relation to the sun's light. James Ramey finds another compelling parasitic mechanism behind Pale Fire's narrative form: the life cycle of the botfly, which uses a mosquito as a courier to transmit its eggs onto a host, into which its newborn larvae then crawl. Nabokov saw a presentation on botfly maggots after his own talk on blue butterflies before the Cambridge Entomological Club in October 1944 (NB, 346). According to Ramey, "Kinbote resembles the botfly in a number of ways [...] Like the botfly, he 'reproduces' himself, in a sense, by attaching what he believes to be his life-story to an unsuspecting carrier, Shade's poem, which is much likelier to reach potential 'hosts' than Kinbote's own publications would be" (Ramey, 189). Ramey proposes that Nabokov's own texts embody the workings of the newly invented, magical insect, the "King-botfly," which uses language to parasitize readers' minds and produce new "little Nabokovs" (208). As attractive and ingenious as this formulation is, I think its final conclusions clash with, or at least understate, the creative possibilities of an artwork elaborated within a new consciousness. From this perspective, Nabokov's original metaphor of wings $(L L, 259)$ is more apt than Ramey's suggestion of authorial selfcloning. 
52. Irina Paperno, "How Nabokov's Gift Is Made” (Stanford Slavic Studies 4.2 [1992]: 295-322) and Marina Kostalevsky, "The Young Godunov-Cherdyntsev or How to Write a Literary Biography" (Russian Literature 43.3 (1 Apr. 1998]: 283-95; also Dieter E. Zimmer and Sabine Hartmann, "The Amazing Music of Truth: Nabokov's Sources for Godunov's Central Asian Travels in The Gift" (Nabokov Studies 7 [2002]: 33-74) and Nabokov reist in Traum in das Innere Asiens (Reinbek: Rowohlt Verlag, 2006).

53. Essays in Poetics 24 (1999): 158-81.

54. The question of "cryptomnesia"-referring to Nabokov's possible subconscious memory of Heinz von Lichberg's story "Lolita," proposed by Michael Maar-would offer a significant counterexample. However, the story is so obscure and such a poor "survivor" that in biological terms, the mimicry definition could not really apply (a creature mimics something in order to resemble it or be mistaken for it). But in reality, the book is not much like the von Lichberg story at all; the phenomenon here, if it is one, would rather be yet another component of Nabokov's cultural butterfly collecting, with the results invisibly pinned into the pattern of a coherent narrative. See Michael Maar, The Two Lolitas (London, New York: Verso, 2005).

55. Discussions on NABOKV-L have also found important kinship with Edsel Ford's poetry: Matthew Roth, "Three Allusions in Pale Fire," The Nabokovian 58 (Fall 2007): 53-60.

56. Stories, 657.

57. "Good Readers and Good Writers," LL, 3. See also Grishakova's discussion, Models of Space, 68.

58. Lectures on Russian Literature (New York: Harcourt, Brace, Jovanovich, 1980), 190-94.

59. AnLo, 283. Humbert's torment is knowing that his crimes matter: "Unless it can be proven to me ... that in the infinite run it does not matter a jot that a North-American girlchild named Dolores Haze had been deprived of her childhood by a maniac-unless this can be proven (and if it can then life is a joke), I see nothing for the treatment of my misery but the melancholy and very local palliative of articulate art."

60. Lolita, 5.

61. Cf. David Burliuk et al., Slap in the Face of Public Taste, in Anna Lawton, ed., Russian Futurism through its Manifestos 1912-1928 (Ithaca: Cornell University Press, 1988), 51.

62. See $\mathrm{n} 48$ above.

63. Finnegans Wake, for example, is a work that Nabokov considered to have departed from the allowable range of variation and therefore, from art itself $(S O, 103)$.

64. The Defense (New York: McGraw-Hill, 1970), 72.

65. SO, 95.

66. Notwithstanding Konstantin Godunov-Cherdyntsev's fantastical assertion, conveyed in "Father's Butterflies," that in nature's earliest days, before the advent of species as such, "a crawling root ... turned into a snake solely because nature, noticing movement, wished to reproduce it" (FB, 225).

67. For example, the structure of Pale Fire is foreshadowed as early as The Gift, in the chapter 5 references to an unreadable text with marginalia mimicking real annotations (Gift, 311), and in "Ultima Thule" in the narrator's illustrations for an epic poem he could not read (Stories, 510). Embryonic Lolita appears in The Gift and in The Enchanter. This phenomenon in nature-the transitory, embryonic appearance of forms that emerge in later stages of evolution-was presented as part of orthogenesis, a theory often opposed to natural selection in the late nineteenth and early twentieth centuries. See L. S. Berg, Nomogenesis: Or, Evolution Determined by Law, J. N. Rostovtsov, trans. (Cambridge, MA: MIT Press, 1969 [1922]), 85. 
68. Compare Goethe's discussion of all plants as being expressions of a "single plant" (the Urpflantze).

69. LCNA, Pale Fire Draft, card 773a. Victoria N. Alexander discusses the suggestive analogy between word golf and "neutral" genetic drift in her "Nabokov, Teleology, and Insect Mimicry," 199-207. The "genetic code" entered the popular sphere in about 1957 (e.g., Time, 14 July 1957: 58).

70. Gift, 349. “Znaesh': potolok, pa-ta-lok, pas ta loque, potolog,-i tak dalee,—poka potolok ne stanovitsia sovershenno chuzhim i odichalym, kak 'lokotop' ili 'pokotol'” (SSRP, 524).

71. It is, of course, highly speculative to suggest that the skull image was on the butterfly's wing before the human skull evolved, but at least it was most likely there before the human idea of the "death's head" image entered cultural currency.

72. Gift, 1 .

\section{Chapter 4}

1. SO, 173,174 .

2. This was actually the world's first psychoanalytic clinic, founded by Ernst Simmel in the former Humboldt Castle, also known as "Schloss Tegel." The Tegel district is home to the Russian church and cemetery where Nabokov's father was buried in 1922.

3. $L L, 3$.

4. BS, 188.

5. George Mandler, A History of Modern Experimental Psychology: From James and Wundt to Cognitive Science (Cambridge, MA: MIT Press, 2007), 144. David Hothersall summarizes the four principles of Gestalt psychology: "1. Holistic Thinking: the whole is always more than the sum of its parts. This tenet of supersummativity was central to the Gestalt psychology. 2. Phenomenological basis: Phenomena are the subject matter of psychology. [...]. 3. Methodology: Gestalt psychology makes use of lifelike (reality) experiments with a small number of subjects. 4. Isomorphism: Psychological processes are directly related to biological, especially brain, processes." History of Psychology, 4th ed. (New York: McGraw-Hill, 2004), 209-10.

6. Mandler mentions the "limited utility of its system" (164).

7. Mandler, 164; Hothersall, 391; Wagner and Owens, "Introduction," D. Alfred Owens and Mark Wagner, eds., Progress in Modern Psychology: The Legacy of American Functionalism (Westport, CT: Praeger, 1992), 10. Mandler elsewhere expresses this disciplinary evolution: "complex emergent functions need their own laws and principles, which cannot without loss of meaning be reduced to the "universal laws" (15). Wilcox hails the holistic (and evolutionary) honesty of ecopsychology or what he calls neofunctionalism (Stephen B. Wilcox, "Functionalism Then and Now," in Owens and Wagner, eds., Progress in Modern Psychology, 31-51, 42ff).

8. In particular, William James expressed such concerns: as Milton Hunt reports, “To a poet friend he writes, in sarcastic allusion to the New Psychology of the German mechanists, 'The only Psyche now recognized by science is a decapitated frog whose writhings express deeper truths than your weakminded poets ever dreamed.' In a letter to his brother, the novelist Henry James, he refers to psychology as a 'nasty little subject' that excludes everything one would want to know. Only two years after completing his huge and magisterial Principles of Psychology he writes: 'A string of raw facts; a little gossip and a wrangle about opinions; a little classification and generalization on the mere descriptive level; a strong prejudice that we have states of mind and that our brain somehow conditions them: 
but not a single law in the same sense in which physics shows us laws, not a single proposition from which any consequence can causally be deduced. This is no science, it is only the hope for a science." "The Psychologist Malgré Lui: William James," from The Story of Psychology (New York: Doubleday, 1993), 144-45.

9. Raymond Tallis, "The Neuroscience Delusion"; "I Think, Therefore I Am, I Think," in "A Survey of the Brain," The Economist (23 Dec. 2006): Insert, 11-12.

10. Taking his turn in what he called "a series of waggish critics," Robert Sessions Woodworth wrote in 1921 that "First psychology lost its soul, then it lost its mind, then it lost consciousness; it still has behavior, of a kind" (Psychology [New York: Holt, 1921], 2; quoted in Paul F. Ballantyne, "History and Theory of Psychology: An Early 21st Century Student's Perspective"; http://www.comnet.ca/ pballan/section5(210).htm). Accessed 6/2/2008.

11. Knight Dunlap, “The Social Need for Scientific Psychology," The Scientific Monthly 11, no. 6. (Dec. 1920): 502-17.

12. What the modern reader of Freud notices is the psychoanalyst's apparently preconceived solutions to his patients' psychoses, based in large part upon Freud's interpretation of his own dreams and inner life. Leland De La Durantaye gives a striking example of this process in Freud's own study of Leonardo. "Vladimir Nabokov and Sigmund Freud, or a Particular Problem," American Imago 62.1 [2005]: 66.

13. Here are a few definitions of psychology available in Nabokov's childhood: in the Brokgauz-Efron encyclopedia, it is the "study of the soul." William James called it "The science of finite individual minds," which "assumes as its data (1) thoughts and feelings, and (2) a physical world in time and space with which they coexist and which (3) they know" (Principles of Psychology [Cambridge, MA: Harvard University Press, 1981], 6). According to Woodworth, "Psychology, then, is a science. It is the science of-what shall we say? 'The science of the soul'- that is what the name means by derivation and ancient usage. 'The science of the mind' has a more modern sound. 'The science of consciousness' is more modern still. 'The science of behavior' is the most recent attempt at a concise formula. None of these formulas is wholly satisfactory" (Psychology, 1).

14. George Sydney Brett's History of Psychology details the place of Alexander Bain in foregrounding the physiological, observationalist approach to psychology, and his resistance to "mystical" concepts such as soul or self. Brett's History of Psychology, R. S. Peters, ed. (New York: Macmillan, 1962), 441-50, 642-46.

15. Cf. James, Principles, chapter 6, "Mind-stuff Theory," esp. 180-82.

16. The same trend is evident in Anglo-American tradition, as a crucial reference from the era attests: James Mark Baldwin, Dictionary of Philosophy and Psychology (New York: Macmillan, 1901-5).

17. Alan C. Elms, "Cloud, Castle, Claustrum: Nabokov as a Freudian in Spite of Himself," in Daniel Rancour-Laferriere, ed., Russian Literature and Psychoanalysis (Amsterdam: John Benjamins, 1989), 353-68. This same line is followed by Geoffrey Green in Freud and Nabokov (Lincoln: University of Nebraska Press, 1988). On Nabokov's opposition to the centrality of sexual issues in Freudian psychoanalysis, see Stephen H. Blackwell, "Nabokov's Wiener-Schnitzel Dreams: Despair and Anti-Freudian Poetics," Nabokov Studies 7 (2002-3): 129-50.

18. Jenefer Shute offers a very nuanced discussion of several of these vexing issues in "Nabokov and Freud," in Vladimir Alexandrov, ed., The Garland Companion to Vladimir Nabokov (New York: Garland, 1995), 412-20, and her "Nabokov and Freud: The Play of Power," PhD diss., University of California at Los Angeles, 1983. Further refinements on this approach, and an assertion of Nabokov's independence from Freudian theory, appear in Leland De La Durantaye, "Vladimir Nabokov and Sigmund Freud, or a Particular 
Problem." American Imago 62.1 (2005): 59-73. The most recent and detailed examination appears in Joanna Trzeciak, "Viennese Waltz: Freud and Nabokov," forthcoming in Comparative Literature.

19. In November 1919, the Cambridge Review included an ironic note on Freudian "quacks" ("Quacks in our Midst," The Cambridge Review, 28 Nov. 1919). The cultural frenzy soon began producing hoaxes and parodies. Freudian hoaxes were international news: see "A Student's Hoax," The Times (London), Dec. 12, 1921, 9, and the follow-up editorial, "A Useful Hoax," The Times (London), Dec. 17, 1921, 11. For further history and background on Nabokov's early exposure to the psychoanalytic cultural phenomenon, see Blackwell, "Nabokov's Wiener-Schnitzel Dreams."

20. For example, Eric Naiman, "A Filthy Look at Shakespeare's Lolita," Comparative Literature 58.1 (Winter 2006): 1-23.

21. Karl Popper, in "Science: Conjectures and Refutations," calls Freudian psychoanalysis non-scientific due to its untestability. Conjectures and Refutations (London: Routledge and Keagan Paul, 1963), 37.

22. Letters to Véra, 5 and 6 June 1926, Berg Coll.

23. "Chto vsiakii dolzhen znat'?” In Vladimir Nabokov, SSRP vol. 3, 697-99. Originally published in Novaia gazeta, May 1, 1931. It is worth noting here that Maurice Couturier's recent book, Nabokov, ou la cruauté du desire: Lecture psychanalytique (Seyssele: Champ Vallon, 2004), offers a subtle and detailed reading of Nabokov's oeuvre from a Lacanian perspective. Regrettably, considerations of space do not allow me to treat this dimension adequately here, and the interested reader is encouraged to consult Couturier's work.

24. Letter to G. Struve: 'I recently published my opinion about 'Freudianism,' which nauseates me, in 'Novaia gazeta,' so I don't have any desire to write about it anew" ["Moe mnenie o 'freidizme' (ot kotorogo mne toshnit) ia nedavno vyskazal v 'Novoi Gazete' tak chto okhoty u menia net pisat' ob etom vnov"”], n.d., 1931. "Pis'ma V. V. Nabokova k G. P. Struve, chast' vtoraia (1931-35)" published by E. B. Belodubrovskii, commentary by A. A. Dolinin, Zvezda 4 (2004): 139-63. Letter 29, 148.

25. Jenefer Shute, "Nabokov and Freud," in Vladimir Alexandrov, ed., Garland Companion, 412-20, offers an incisive reading of Nabokov's tango with Freud. However, one can argue with the claim that "the very methods employed to assert the text's independence are those that undermine it; parody and polemic point insistently to the hors-texte they are designed to deny. Far from articulating an absolute freedom, they inscribe instead the horizons of a particular historical moment and the limits of authorial power" (419). This claim would be true only if the Freudian polemic were the only important layer of significance in the fiction, which manifestly is not the case. One cannot escape the specter of Freudian interpretation, but one can extrude it-like the gargoyles in Speak, Memory-and create space for other, independent modes of signifying and deciphering. Among Shute's many excellent observations, one of the best is that "Nabokov, unlike Freud, considers consciousness, rather than unconsciousness, psychology's proper realm" (418). But to a large extent, both consciousness and unconsciousness remain inscrutable for Nabokov, a position we have seen validated for him by William James. Geoffrey Green, in Freud and Nabokov, in Shute's words, attempts to prove that Nabokov was a Freudian despite himself. Leland De La Durantaye in "Vladimir Nabokov and Sigmund Freud, or a Particular Problem" explores other reasons why Nabokov felt it necessary to battle Freud so tirelessly. Along with the usual suspects (Freud's emphasis on the general over the specific), De La Durantaye identifies an enticing hypothesis: "Nabokov would reproach less the failure of psychoanalysis to be or become a science ... than the very pretensions of psychoanalysis to be a science, its aspiration to function in the realm of the human sciences as would a natural science-as a totalizing, unifying discourse" (63). While agreeing with the second part of 
this statement, I suspect that the imbalance in Freudianism between theory and data-the lack of attention to massive variety free from theorizing (the practice of, say, lepidopterist Godunov-Cherdyntsev in "Father's Butterflies")—contradicted Nabokov's own scientific instincts.

26. See Esther Menaker, Otto Rank: A Rediscovered Legacy (New York: Columbia University Press, 1982), 9, for discussion of Rank's assessment of the place of causality in psychological and psychoanalytical studies. Manaker also presents the issues at the heart of Rank's defection from Freudian orthodoxy, a divergence that led to his excommunication by mainstream Freudians (11-37).

27. Shute makes a similar point but takes it quite a bit further by suggesting that when Nabokov began writing, Freud was "already there" in all the texts he wanted to write, that the "structures of desire that the writer wills into being and weaves into fiction have already been manhandled" by Freud ("Nabokov and Freud," 416). I would argue that while Freudianism was present as a major potential and common interpretive mode, Shute's version goes too far in implying Freudianism's fundamental place as a universal within modern literary discourse. According to Knight Dunlap's critical observation in 1920 (op. cit.), psychoanalysis already "la[id] claim not only to the field of psychology, but also to the fields of literature, art, religion, history, politics, and archaeology" (513). But such claims, Dunlap suggests, were not universally recognized as legitimate.

28. Despair (New York: Vintage International, 1989), 41.

29. On this subject, see especially James's Principles, chapter 7, "Methods and Snares of Psychology."

30. Nabokov told Edmund Wilson that his father gave him James to read when he was twelve or thirteen. Letter of March 24, 1957; DBDV, 344. A partial list of curious echoes from James that appear in various spots, often prominently, includes the crossed-finger and pea illusion (Principles [1981], 732; cf. Glory); hypnogogic hallucinations (Principles [1981], 767-68; cf. SM); inverted head/horizon viewing (Principles [1981], 847; cf. Gift); multiple personalities (Principles [1981], 356ff.; cf. The Eye, PF); train motion (Principles [1981], 736; cf. KQK, SM, TT); kaleidoscope (Principles [1981], 17; cf. LATH, BS); colored hearing (Principles [1981], 676; cf. Gift, SM); Socrates, "Other men are mortal” syllogism (Principles [1981], 1245; cf. PF); convergence of parallel lines (Principles [1981], 1251-52; cf. Gift); aversion to a predecessor's warmth on a seat or other surface (Principles [1890], chapter 24, note 35: http://psychclassics.yorku.ca/James/Principles/prin24.htm; cf. Lolita).

31. For example, James wrote that "our psychology will remain positivistic and nonmetaphysical; and although this is certainly only a provisional halting-place, and things must some day be more thoroughly thought out, we shall abide there in this book, and just as we have rejected mind-dust, we shall take no account of the soul. The spiritualistic reader may nevertheless believe in the soul if he will; whilst the positivistic one who wishes to give a tinge of mystery to the expression of his positivism can continue to say that nature in her unfathomable designs has mixed us of clay and flame, of brain and mind, that the two things hang indubitably together and determine each other's being, but how or why, no mortal may ever know" (Principles, vol. 1, 182).

32. $L R L$, 183. Cf. James, Principles [1890], chapter 10 (vol. 1, 296).

33. Cf. James, Principles [1890], chapter 5, "The Automaton Theory." Of scientific knowledge of the brain's inner states, James writes: "The organ will be for us a sort of vat in which feelings and emotions somehow go on stewing together, and in which innumerable things happen of which we catch but the statistical result" (vol. 1, 138).

34. Letter to Edmund Wilson, March 24, 1957, in DBDV, 344. The philosophical anthology Problems of Idealism was published in 1903 when Nabokov was four years old; given his father's political commitments, Nabokov would have been extremely likely 
to read this collection as well as its successor volume, Vekhi ("Landmarks," 1909), in his teenage years. V. D. Nabokov was close to several members of the Moscow Psychological Society (see Dana Dragunoiu, Vladimir Nabokov and the Poetics of Liberalism [forthcoming], as well as Randall A. Poole, "Introduction" in Problems of Idealism [New Haven: Yale University Press, 2002]), and Nabokov himself became good friends with the society's former secretary Yulii Aikhenvald in the 1920s (Boyd, RY, 287-88; Alexander Dolinin, "Doklady Vladimira Nabokova v berlinskom literaturnom kruzhke," Zvezda 4 (1999): 7-11, reprinted in Istinnaia zhizn' pisatelia Sirina [St. Petersburg: Akademicheskii proekt], 369-75); Stephen H. Blackwell, Zina's Paradox: The Figured Readers in Nabokov's Gift, Middlebury Studies in Russian Literature, vol. 33 (New York: Peter Lang, 2000), 25-36.

35. The first two are mentioned in various letters or interviews; Lombroso, Mechnikov, and Alexandrovskii are named in Nabokov's 1918 notebook, "Stikhi i skhemy," LCNA, container 10. (Lombroso also appears, in a negative light, in "The Art of Literature and Commonsense," $L L$, 377.) Spencer and the rest were very well known figures whose works were available in V. D. Nabokov's private library. Psychological works of particular interest in the collection included: N. Bazhenov, Psikhologiia kaznimykh (Moscow, 1906); V. Bekhterev, Vnushenie i ego rol' (St. Petersburg, 1904) and Psikhika i zhizn' (St. Petersburg, 1904); Charles Darwin, L'expression des emotions chez l'homme et les animaux (Paris, 1877); Rémy de Gourmont, Physique de l'amour Paris n.d.; J. Grasset, Demifous et demiresponsables (Paris, 1907); Otto Weininger, Pol i kharakter [Sex and character]. S pred. A. Volynskogo (St. Petersburg, 1909); Herbert Spencer, Osnovanie nauki o nravstvennosti (St. Petersburg, 1880); and one or more books each by Alexander Bain, Theodule Ribot, Hyppolite Taine, Veniamin Tarnowski, and Wilhelm Wundt. There is no English section for psychological literature in the catalog "supplement" (1911; there may have been no acquisitions on psychology in English between the two editions). Taine appears to have been a figure of interest for Nabokov and admiration for his father; in addition to several of his works individually, the library contains a four-volume set and a biography by FrançoisAlphonse Aulard. For detailed discussion of the significance of Weininger for Nabokov's works, especially Despair, see Joanna Trzeciak, "Viennese Waltz," and her "Visions and Re-visions: Nabokov as Self-translating Author,” PhD diss., University of Chicago, 2005, chapter 3.

36. Sergej Davydov, "Despair," in Vladimir E. Alexandrov, ed., Garland Companion, 100 n 21.

37. In his correspondence, Nabokov was quite reticent about his reading habits. Although he occasionally mentions something or other to his closest correspondents, for the most part he does not reveal his current reading material in his letters. This is as true in the archival materials as it is in the published collections.

38. James was an early president of the Society for Psychical Research, which advocated scientific investigation of paranormal phenomena (see, for example, Hothersall, History, 338). John Ray, Jr., who pens the "Foreword" to Lolita, is a psychologist who is not quite a narrator, although a role for him in Humbert's text has been proposed by George Ferger in "Who's Who in the Sublimelight," Nabokov Studies 8 (2004):137-98.

39. For a thought-provoking angle on this question, see Zoran Kuzmanovich, "Suffer the Little Children," in Gavriel Shapiro, ed., Nabokov at Cornell (Ithaca, NY: Cornell University Press, 2003), 49-57.

40. AnLo, 5-6.

41. This image of Ray is extended by his association with one Dr. Blanche Schwartzmann, whose work on pedophiles has apparently enlightened Ray so little, and by Quilty's reference to Schwartzmann's chromatic inversion, Dr. Melanie Weiss, "psychoanalyst and pornographer." Gennady Barabtarlo points out the proximity of this name to Melanie 
Klein, author of The Psychoanalysis of Children (1932). Phantom of Fact, 161. Compare also "Dr. Albina Dunkelberg," in Pnin (New York: Vintage International, 1991), 50.

42. Pnin, 88 .

43. Ibid., 49.

44. Ada (New York: Vintage International, 1990), 340.

45. Ibid., 338 .

46. Letter to G. Struve: "Krome vsego, freidizma ia, ei Bogu, ne vizhu v literature (u modnykh poshliakov, vrode, skazhem, Stefana Tsveiga, onogo skol'ko ugodno-no ved' eto ne literatura)." [Aside from all that, by God, I don't see any Freudianism in literature (among popular philistines like, say, Stefan Zweig, you'll find as much as you like, but after all that's not literature.] N.d., 1931. "Pis'ma V.V. Nabokova k G.P. Struve, chast' vtoraia (1931-1935)," 142.

47. See, for example, Brett, History of Psychology: "James was decidedly mystical, as perhaps every champion of the will to believe and every defender of an irreducible something called personality, must be mystical. Analysis is not compatible with that mood; it finds satisfaction in the contemplative study of unities, and with James it came to fruition in the study of experiences." Brett's History of Psychology, 657.

48. "The Art of Literature and Commonsense," LL, 376. See also Anthony Anemone, "Nabokov's Despair and the Criminal Imagination." In O Rus! Studia litteraria slavica in honorem Hugh McLean, Simon Karlinsky, James Rice and Barry Scherr, eds. (Berkeley: Berkeley Slavic Specialties, 1995), 421-31.

49. SO, 45.

50. These cases were discussed in Théodule Ribot, Diseases of the Mind, a work which was held in the Nabokov library in St. Petersburg. Ernst Mach, in Knowledge and Error, also cites Ribot, who in turn was citing C.F. Michéa: "Finally, there is Foville's widely known case. 'A soldier believed himself dead since the battle of Austerlitz, at which he had been seriously wounded. When asked about his condition, he would reply: "You want to know how old Lambert is? He is dead; he was carried off by a cannon-ball. What you see here is not he, but a poor machine that they have made, in imitation of him; you ought to ask them to make another." In speaking of himself, he never said "I," but "that thing." His skin was insensible, and often he would fall into a state of complete insensibility and immobility, lasting several days"' (Théodule A. Ribot, The Diseases of Personality [Washington, DC: University Publications of America, 1977]), 32, citing Michéa, Annals medicopsychologiques, 1856: 249ff.) Note also: "This old soldier did not imagine himself another (Napoleon, for example, although he was at Austerlitz)" (34). Ribot's work goes on to consider other sorts of double personalities from various points of view.

51. Nabokov would also have been aware of dissociation from Pierre Janet through William James's account in Principles of Psychology [1890], e.g. chapter 25, n10.

52. Olga Skonechnaia, "Primechaniia," Sobranie sochinenii russkogo perioda v piati tomakh, v. 3, 713. See also her "'People of the Moonlight': Silver Age Parodies in Nabokov's The Eye and The Gift," Nabokov Studies 3 (1996): 33-52; and Anna Brodsky, "Homosexuality and the Aesthetic of Nabokov's Dar," Nabokov Studies 4 (1997): 95-116. A similar but independent reading, focusing on the link with Kuzmin, can be found in Galina Rylkova, "Okrylyonnyy Soglyadatay-The Winged Eavesdropper: Nabokov and Kuzmin," in David H. J. Larmour, ed., Discourse and Ideology in Nabokov's Prose, Studies in Rusian and European Literature vol. 7 (London and New York: Routledge Harwood, 2002), 43-58.

53. The Eye (New York: Phaedra, 1965), 87.

54. Ibid., 93.

55. This interpretation is detailed in Julian Connolly, Nabokov's Early Fiction (Cambridge, UK: Cambridge University Press, 1991), 101-7. 
56. "Stikhi i skhemy," LCNA, container 10. John D. Quin provides a concise and important (though not exhaustive, as he later informed me) overview of neurological disorders whose presence underlay some characters' delusions. "Nabokov's Neurology," Cycnos 10.1 (1993):113-22.

57. The continued dominance of this approach appears to be confirmed by the recent work of Stephen Kern, whose book A Cultural History of Causality (Princeton: Princeton University Press, 2004) traces efforts to explore causal mechanisms behind murder in literature from the Victorian era forward, including a section on Lolita.

58. Defense (New York: McGraw-Hill, 1979), 22, 29, 34, 37.

59. Ibid., 59-60.

60. Ibid., 98-99, 103.

61. Ibid., 163.

62. Ibid., 164.

63. Ibid., 162.

64. Leona Toker's reading of The Defense, one of the most insightful and sensitive, refers frequently to Luzhin's mistakes and errors, among which are to "turn away from human reality in his pursuit of abstract harmonies and meanings" (Nabokov: The Mystery of Literary Structures [Ithaca: Cornell University Press, 1989], 86). The novel asserts a "need for balance between intellectual pursuits and human commitments" (87). This argument suggests that Mrs. Luzhin and others were right to attempt to create balance in Luzhin's life after his collapse, although in fact of course they really attempt to eliminate Luzhin's main intellectual passion, his sphere of mental being. I feel that reducing Luzhin's point of view and behaviors to a "mistake" is unjustifiably normative. We have no reason to believe, for example, that had the match with Turati been allowed to end naturally Luzhin would have had a breakdown; nor, on the other hand, that if he recovered and were allowed to resume his natural life, that such a life would not have had its own form of human warmth (a term Toker also emphasizes in her treatment [87]). See also Julian W. Connolly, Nabokov's Early Fiction, 92-93. Vladimir Alexandrov discusses Gnostic symbolism of evil surrounding Luzhin's "recovery": "The Defense," in Vladimir Alexandrov, ed., The Garland Companion to Vladimir Nabokov, 75-87, esp. 80-82. Nabokov's reading of Kafka's “Metamorphosis" offers an instructive perspective on Luzhin's situation. He writes, "the isolation, and the strangeness, of so-called reality-this is, after all, something which constantly characterizes the artist, the genius, the discoverer. The Samsa family around the fantastic insect is nothing else than mediocrity surrounding genius" $(L L, 260)$.

65. Defense, 16.

66. Ibid., 21-22, 29, 57, 46 (ellipsis in original), 49, 57, 91.

67. Nabokov connects ideas of illness with states of altered consciousness and contact with abstract realms in Speak, Memory. He relates that his short-lived mathematical gift "played a part in tussles with quinsy or scarlet fever, when I felt enormous spheres and huge numbers swell relentlessly in my aching brain. [ . . . ] Such were the monsters that thrived on my delirium, and the only way to prevent them from crowding me out of myself was to kill them by extracting their hearts ..." His mother had been through similar experiences, and her "understanding would bring my expanding universe back to a Newtonian norm" (SM, 36-7).

68. Defense, 95, 97.

69. Ibid., 94. Esther Menaker, writing on Rank's early Der Künstler, suggests that "While at this point, under the influence of Freud, Rank understands the artist's motivation for and production of creative work as stemming form the sublimations of sexual drives, he is already concerned with the social dimension and with the impact of the artist on man's cultural development." Esther Menaker, Otto Rank: A Rediscovered Legacy, 16. Menaker 
details Rank's suspicion of "the inflated, introspective knowledge of self which modern psychology has established as a science of understanding the "causal" motives of thinking, feeling and action'" (from Rank, Psychology and the Soul, quoted in Menaker, 6).

70. Defense, 84, 85, 90, 103, 210, 222.

71. Ibid., 230-31.

72. Ibid., 161.

73. Using an approach based on the "Theory of Mind" branch of evolutionary psychology, Lisa Zunshine also demonstrates that Humbert imputes the views he wants us to adopt onto various other characters in the novel. Why We Read Fiction (Columbus: The Ohio State University Press, 2006), 100-118. See also Nomi Tamir-Ghez, "The Art of Persuasion in Nabokov's Lolita," for a summary of accounts sympathetic to Humbert, in Ellen Pifer, ed., Nabokov's Lolita: A Casebook (New York: Oxford University Press, 2003) 17-37; Tony Moore gives a very detailed reconsideration of Humbert's manipulations in "Seeing through Humbert: focusing on the feminist sympathy in Lolita," in David H. J. Larmour, ed., Discourse and Ideology in Nabokov's Prose (London and New York, Routledge, 2002), 91-110.

74. AnLo, 10. Cf. in his notes: "N. M. Iovetz-Tereshchenko. Friendship-love in adolescence. London, 1936. (Diary of Russian schoolboy with very pedantic-to say the least!first ??mother??)" LCNA, "Lolita Notes," folder 4.

75. AnLo, 13-14, 16.

76. Ibid., 283, 284.

77. Ibid., 282-83.

78. Despair, 4.

79. Ibid., 46. Nabokov vividly expressed his contempt for this kind of causality, arguing that "the Freudian faith leads to dangerous ethical consequences, such as when a filthy murderer with the brain of a tapeworm is given a lighter sentence because his mother spanked him too much or too little-it works both ways." SO, 116.

80. Julian Connolly suggests a causal, psychological explanation: that Hermann is displacing his financial and romantic misfortunes onto Felix, whose death should then purge Hermann's life and enable a new beginning (Nabokov's Early Fiction, 150).

81. Despair, 120. This passage also anticipates Humbert's "seduction" by Lolita, in which she allegedly takes on the active and responsible role.

82. Ibid., 97. Cf. Crime and Punishment, end of chapter 5: "He felt that he had thrown off the terrible burden that had weighed him down for so long, and his heart was light and tranquil. 'Lord,' he prayed, 'show me the way, that I may renounce this accursed ... fantasy of mine!'” Immediately after this prayer, "he went out of his way to cross the Haymarket instead of returning home by the quickest and most direct route [ . . ] It was almost as if fate had laid an ambush for him." Fyodor Dostoevsky, Crime and Punishment, Jesse Coulson trans., George Gibian ed., Norton Critical Edition (New York: W. W. Norton \& Co., 1989 [1964]), 50-51. Humbert Humbert never plays this game: once he sees Lolita, all his actions are directed at ensuring his proximity to her.

83. Despair, 114-15.

84. See Gennady Barabtarlo's discussion of these in Phantom of Fact: A Guide to Nabokov's Pnin (Ann Arbor: Ardis, 1989), 158-64, where he uncovers many of the parodied tests.

85. A minor fact adds to the Freudian/Oedipal motif: Pnin's father was an ophthalmologist, an oblique and deflating reference to Oedipus's self-blinding upon discovering his crimes. During his research for Pnin, Nabokov copied out the following from Ralph S. Banay, Youth in Despair (New York, 1948), 80-one presumes ironically: "Implicit in all these [attempts to kill fathers] acts of homicide or attempted homicide is sexual aggression. 
The choice of the weapons-the gun and the knife, both phallic symbols-is alone a witness to this fact." Nabokov goes on to observe that this passage could also be used in his Eugene Onegin Commentary. "Notes on Various Subjects," Berg Coll.

86. Pnin's behavior could be explored from the Bakhtinian perspective adopted by Julian Connolly in Nabokov's Early Fiction: in this case, the character is unwilling to be "finalized" by an outside description of him, although he is not particularly concerned to become an author himself (unlike the characters Connolly discusses).

87. Pnin, 43.

88. Ibid., 91.

89. Abraham Stone and Lena Levin, American Journal of Psychiatry 107 (1950-51): 195. That Nabokov shifts the article's title in precisely this way confirms its ironic intent. The article in fact derives from Stone's primary work in the study of marital disorders. "Notes on Various Subjects," Berg Coll. Gennady Barabtarlo suggests that Nabokov also looked at Melanie Klein, The Psychoanalysis of Children (London: Hogarth, 1932). Phantom of Fact, 161-62.

90. Ada, 298.

91. Brian Boyd, Nabokov's Ada (Ann Arbor, MI: Ardis, 1985, and Cybereditions 2002).

92. The situation is somewhat clearer in "The Vane Sisters," where at least there had been a relationship that went bad; and in The Defense, we have an intimate view of Luzhin's psychological response to the phenomenal world-although even that does not fully explain his death, as discussed above. Yasha Chernyshevsky's death in The Gift is portrayed as an immature misreading of death-oriented mystical poetry (an exaggeration of romantic pessimism). Kinbote/Botkin in Pale Fire is also obsessed with suicide. We do, in his case, have a wealth of fantastical material in his commentary to help us work out why this might be so.

93. 'O da, est' zemnaia vozmozhnost' bessmertiia. Umershii prodolzhaet podrobno i raznoobrazno zhit' $\mathrm{v}$ dushakh vsekh liudei, znavshikh ego. [ . . . ] I kazhdyi po-svoemu vosprinial cheloveka, tak chto pokoinyi ostalsia na zemle vo mnogikh obrazakh, inogda garmonicheski dopolniaiushchikh drug druga." "Pamiati Iu. I. Aikhenval'da," SSRP, vol. 2, 668.

94. At the "Transitional Nabokov" conference in 2007, Susan Elizabeth Sweeney suggested that Nabokov's works actually mimic, structurally, cognitive strategies used unconsciously by the human mind. Sweeney bases her approach on cognitive literary analysis, and her work promises to demonstrate how Nabokov understood, or intuited, how the mind operates. See Sweeney, “Thinking about Impossible Things in Nabokov," in Will Norman and Duncan White, eds., Transitional Nabokov (London: Peter Lang, forthcoming).

95. Nabokov may have felt that such feelings of guilt, shame, and loneliness were typical of homosexuals - and in his day they certainly cannot have been extremely rare. Nabokov knew that his homosexual brother, Sergey, was struggling with his identity and his yearning to suppress it. In a June 15, 1926, letter to their mother, Nabokov even endorsed Sergey's passionate turn to the Catholic Church in his efforts to change his ways. In a much later note, from the time of Pale Fire's composition, Nabokov speculated about the extreme isolation of a homosexual college professor in a puritanical country, where a handshake would be the only possible erotic contact. "Notes on Various Subjects," Berg Coll.

96. Letter to G. Struve, "Pis'ma V. V. Nabokova k G. P. Struve. 1925-1931.” Letter no. 12 [Late Feb, 1930], Zvezda 11 (2003): 115-50, 130-31.

97. See espcially Art and Artist, 25-26; Rank relates that he first presented the concept in his earlier Der Künstler (1909), while he was still under Freud's influence.

98. Gift, 328.

99. Ibid., 30, 206. 
100. Ibid., 70-76, 338-43, 365.

101. Gift, second paragraph of "Foreword," n.p.

102. RLSK, 35 .

103. He employs this trope in varying ways in Laughter in the Dark, Bend Sinister, and The Real Life of Sebastian Knight as well.

104. Vladimir Alexandrov, "The Defense," in The Garland Companion to Vladimir Nabokov, 75-87.

105. West's book occasioned a full, double-sided card's worth of notes. "Notes on Various Subjects," Berg Coll. The recorded material comes from Donald James West, Psychical Research Today (London: 1954), 58-63, 66, 123. D. Barton Johnson details some of Nabokov's earlier exposure to spiritism by means of his interest in Rupert Brooke and Walter de la Mare, in "Vladimir Nabokov and Walter de la Mare's 'Otherworld," in Jane Grayson et al., eds., Nabokov's World (Houndmills, UK: Palgrave, 2002), vol. 1, 71-87.

106. He jotted from West's bibliography these sources: W. F. Prince, The Case of Patience Worth (Boston, 1927); Proceedings of the Society for Psychical Research, LI (1954).

107. Brian Boyd, Nabokov's Pale Fire (Princeton: Princeton University Press, 1999).

108. This position has been most forcefully advanced by Carolyn Kunin on the NABOKV-L discussion list, beginning in 2002: "Problems with Boyd's Hazel-Solution to Pale Fire," Sept. 4, 2002.

109. Suellen Stringer-Hye, ““'Laura” Is Not Even the Original's Name': An Interview with Dmitri Nabokov," Nabokov Online Journal II, 2008.

110. The passage from West that sparked the multiple personality theme includes a discussion of Ansel Bourne (Psychical Research, 58), whose three-week transformation into a secondary personality had also been described by William James in Principles [1890] (chapter 10: vol. 1, 391-92). Nabokov's preparatory notes begin to transform these concepts into the world of Pale Fire, and he jotted down the following ideas: "subject to hallucinations. A victim of mental dissociation, he developed a secondary personality wearing a radiant crown (the king as a lecturer in Zembla)." The date of this card is not certain, but was most likely after Nabokov had chosen Zembla as his invented land (unless, perhaps, it was while writing this card that he first thought of it). "Notes on Various Subjects," Berg Coll.

111. Principles [1890], chapter 10, vol. 1, 392.

112. Look at the Harlequins! (New York: Vintage International, 1991), 195. Hereafter LATH.

113. Nabokov proposed a variation on the same theme when he composed the following syllogism: "Time without consciousness-lower animal world; time with consciousness-man; consciousness without time-some still higher state" (SO, 29-30). Although Nabokov was reading from rejected notes for Pale Fire, the idea first appears in his "1951 Diary" entry for February 16. This diary was also clearly part of Nabokov's play with the secondary personality theme: during its brief course (he abandoned it by the end of March), he described the life, death, and afterlife of an imaginary alter ego, "Atman" (a term from Hindu and Buddhist philosophy, meaning "self" or "soul"). At times, he mentions thoughts that derive not from himself but from Atman, whom he even suspects of hypnotizing him (Jan. 19)! Needless to say, the self-distancing practice employed while writing this "diary" protects the author from any claims that it reflects his definitive thought. Berg Coll.

114. Like the scene of father being tossed concluding SM, chapter 1 (31-32), and the butterfly hunting scene at the end of chapter $6(138-39)$.

115. LATH, 122-25.

116. BS, 188.

117. The status of Freudian psychoanalysis's potential as a testable theory has been revisited by philosophers with greater sympathy in recent decades. See Edward Erwin's review essay on Adolf Grünbaum, The Foundations of Psychoanalysis: A Philosophical Critique 
(Berkeley: University of California Press, 1984), in Nô̂s 21, no. 1 (Mar. 1987): 77-80. For a more critical perspective, see Hans Jurgen Eysenck, Decline and Fall of the Freudian Empire (New York: Penguin Books, 1991, [1985]).

118. Nabokov's respect for the unexplained is not unlike that described by philosopher of science Émile Meyerson: "Indeed, man, in spite of his invincible tendency to believe in rationality, obviously sensed very early that there is irrationality in nature, that nature is not entirely explicable. [ ...] In sum, we can make only negative or altogether imprecise pronouncements in this area. We know where complete rationalization is impossible, that is, where the agreement between our reason and external reality comes to an end: those are the irrationals already discovered. But we do not know—and shall never know-where the agreement exists, since we can never be sure that there will be no new irrationals to add to the old ones. That is why we shall never be able really to deduce nature, even by taking into consideration all the given and irreducible elements, all the irrationals that we know at a given moment; we shall always need new experiments and these will always pose new problems, causing new contradictions between our theories and our observations to leap out at us, as Duhem puts it." Explanation in the Sciences, Boston Studies in the Philosophy of Science, vol. 128, trans. Mary-Alice and David A Sipfle (Dordrecht/Boston/London: Kluwer, 1991 [1921]), 172. In his classic work, Thomas S. Kuhn makes a similar point: "In science [...], novelty emerges only with difficulty, manifested by resistance, against a background provided by expectation. Initially, only the anticipated and usual are experienced even under circumstances where anomaly is later to be observed. Further acquaintance, however, does result in awareness of something wrong or does relate the effect to something that has gone wrong before." The Structure of Scientific Revolutions, 2nd ed. (Chicago: University of Chicago Press, 1970), 64.

119. Eric Naiman, among others, observes that Nabokov's works deliberately encode parodic enactments of the Freudian literary analyses they seem to invite. "Litland: The Allegorical Poetics of The Defense," Nabokov Studies 5 (1998-99): 1-46.

120. Sept. 26, 1966; Selected Letters, 391. In an editorial footnote, Dmitri Nabokov adds: "Last sentence added in holograph."

121. Principles [1890], chapter 6, vol. 1, 181. James also encouraged scientific investigation of paranormal phenomena, such as trance-possessions, but observed regretfully that it is "a field which the soidisant 'scientist' usually refuses to explore" (chapter 10, vol. 1, 396).

\section{Chapter 5}

1. "Khronika," 3. Cf. "4,500 Battle in Museum to See Einstein Film; Police Quell Stampede after 8 Guards Fail," The New York Times (1857-Current file); Jan 9, 1930; ProQuest Historical Newspapers The New York Times (1851-2003), 1. Arthur Eddington, New Pathways in Science (New York: Macmillan, 1935), 6-7.

2. SO, 116 .

3. Michael H. Whitworth, in Einstein's Wake: Relativity, Metaphor, and Modernist Literature (Oxford, UK: Oxford University Press, 2001), details how the various components of the "new science" penetrated throughout popular culture and modernist literary practice in England during the 1920s, focusing especially on T. S. Eliot, Virginia Woolf, Ezra Pound, and D. H. Lawrence. None of the figures in his study, it should be noted, was ever a scientist.

4. $L R L, 262$. Curiously, in earlier drafts Nabokov first referred to "atoms" and then to "molecules." "Chekhov (TS with Corrections)." Berg Coll. 
5. USSR, 326, 327.

6. Ibid., 327. Dana Dragunoiu's discussion of the philosopher Bishop Berkeley suggests an important precursor to, perhaps inspiration for, Nabokov's explorations of noncausality and immaterialism. See her chapter, "Berkeley, Ada, and the Splendor of Lone Thought," in Vladimir Nabokov and the Poetics of Liberalism (forthcoming).

7. Actually, even Nabokov's first novel offers some likely reflections of Einstein's theory: Mary (1926) begins in an elevator (as it happens, a broken-down one) and ends with the juxtaposition of two train journeys (one arriving in Berlin, one set to depart). Both of these scenes could glance toward relativity: in the first, Ganin wonders about the time and worries about how long he will be stuck; in the second, he abandons one train for another in order to prevent his past (his affair with Mary) from coming back to him in a form he has neither authorized nor authored. Nabokov's revised second novel, King, Queen, Knave (1928/1968) refers to a traveling clock with "its own concept of time" (KQK, 118, not in original: cf. SSRP, vol. 2, 207). However, such allusions are essentially ornamental in these novels whose primary concerns relate more to modernist explorations of time and memory.

8. Nabokov was generous about such terminological appropriation: "Science means to me above all natural science. Not the ability to repair a radio set; quite stubby fingers can do that. Apart from this basic consideration, I certainly welcome the free interchange of terminology between any branch of science and any raceme of art" $(S O, 79)$.

9. Arthur S. Eddington, New Pathways in Science (New York: Macmillan, 1935), 8. In Eddington's extended analogy, consciousness serves as a storyteller, weaving a tale from the sensations brought to it through the nervous system. Lolita includes an analogous scene, also evoking Sir Francis Bacon, in which Humbert Humbert describes the mental spiderthreads that reach out and report to him the contents and goings-on in various rooms of the Haze household (AnLo, 49-50). This passage alludes to a formerly well-known spider analogy from Bacon's The Advancement of Learning (Bk. 1, Pt. IV, Sec. 5); see discussion in my "A New or Little-Known Subtext in Lolita," The Nabokovian 60 (Spring 2008): $51-55$.

10. There were also other, simultaneous expeditions: see A. C. D. Crommelin, "Results of the Total Solar Eclipse of May 29 and the Relativity Theory," Science, New Series, vol. 50, no. 1301 (Dec. 5, 1919): 518-20. "Revolution in Science. New Theory of the Universe. Newtonian Ideas Overthrown," The Times, 7 Nov. 1919, 12. The scientific paper came out later, as F. W. Dyson, A. S. Eddington, and C. R. Davidson, "A Determination of the Deflection of Light by the Sun's Gravitational Field, from Observations Made at the Total Eclipse of May 29, 1919," Mem. R. Astron. Soc. 220 (1920): 291-333.

11. Ronald W. Clark, Einstein: The Life and Times (New York: World Pub. Co., 1971). The Berlin daily Rul' reported on Einstein's travels, illnesses, political views, and a 50th birthday incident involving the Berlin city government, a villa, and a yacht, and a riot surrounding a film on relativity at the New York Natural History Museum (see epigraph).

12. For various examples, see Whitworth, Einstein's Wake (op. cit.); Daniel Albright, Quantum Poetics: Yeats, Pound, Eliot, and the Science of Modernism (Cambridge, UK: Cambridge University Press, 1997); Thomas Jackson Rice, Joyce, Chaos, and Complexity (Urbana: University of Illinois Press, 1997). Marina Grishakova discusses the theme of Einsteinian relativity by means of an elevator scene and a bridge scene in Bend Sinister, which illustrate the relative ideas of location or frame of reference. The Models of Space, Time and Vision in V. Nabokov's Fiction: Narrative Strategies and Cultural Frames (Tartu: Tartu University Press, 2006), 262-63.

13. "Literaturnye zametki," Rul', April 29, 1925, 4-5.

14. For example, "Teoriia otnositel'nosti prof. Einshteina” (film review), Rul', Aug. 25, 1923, 6; book review, "Prof. A. Brandt, 'Teoriia Einshteina,” Rul', April 15, 1924, 4. 
15. In addition to occasional brief news reports, Nabokov's friend V. Tatarinov reviewed I. Krikhborger's Atomnaia teoriia i teoriia kvant ("Atomic theory and the quantum theory") in Rul' on Sept. 16, 1923; also T[atarinov], review of Elektrony i elektricheskie kvanty ("Electrons and electrical quanta") [Berlin: 1924]; "Novye knigi po estestvoznaniiu i sel'skomu khoziaistvu," Rul', Dec. 31, 1924, 4.

16. For example, James Jeans wrote in 1931 that "we are beginning to suspect that we live in a universe of waves, and nothing but waves.[ . . M] ]odern science has traveled very far from the old view which regarded the universe merely as a collection of hard bits of matter in which waves of radiation occasionally appeared as an incident." The Mysterious Universe (New York: Macmillan, 1931), 48. (Criticism of Jeans's account is a commonplace in the history of science; see, for example, Whitworth, Einstein's Wake, 55-57). Eddington reaches a similar conclusion: "Interpreting the term material (or more strictly, physical) in the broadest sense as that with which we can become acquainted through sensory experience of the external world, we recognize now that it corresponds to the waves not to the water of the ocean of reality" (New Pathways, 319). A similar discussion appeared in the Paris daily Poslednie novosti: Iu. Delevskii, "Nauchnye zametki," Dec. 7, 1937, 4.

17. Jan Hilgevoord and Jos Uffink, "The Uncertainty Principle," The Stanford Encyclopedia of Philosophy (Fall 2006 Edition), Edward N. Zalta, ed., http://plato.stanford. edu/archives/fa112006/entries/qt-uncertainty/.

18. Tatarinov, "Atomy i zvezdy." The first supernova to be publicly identified as "exploding" was apparently discovered by J. P. M. Prentice on Dec. 13, 1934. See "New Star Reaches First Magnitude,” New York Times, 23 Dec, 1934, 17 (features explanation of explosion by Professor Harlow Shapley of Harvard Observatory at Oak Ridge); "Nova Herculis, 'Exploding Star,' No Longer Seen by Naked Eye, Fading to First Magnitude,” by The Associated Press, New York Times, Apr. 8, 1935, 21. The theoretical background for describing these explosions was laid out by W. Baade and F. Zwicky, "On Super-novae," Proceedings of the National Academy of Sciences of the United States of America, vol. 20, no. 5. (May 15, 1934): 254-55. The earliest suggestion that novae and supernovae might be exploding stars appears to have been by E. E. Barnard, "Some Peculiarities of the Novæ," Proceedings of the American Philosophical Society, vol. 61, no. 2. (1922): 99-106.

19. In 1919 Nabokov wrote a prose poem about a far-off world, in the album "Stikhi i skhemy" (LCNA, container 10); it is partially quoted in Boyd, RY, 152.

20. Sergei Davydov, "The Gift: Nabokov's Aesthetic Exorcism of Chernyshevskii," Canadian-American Slavic Studies 19.3 (Fall 1985): 357-74.

21. Lenin's work is quoted in the Chernyshevsky chapter of The Gift, where he calls Chernyshevsky "the one truly great writer" who remained true to materialism (Gift, 245); see also A. Dolinin, "Komentarii," in SSRP, vol. 4, 725n.

22. See A. V. Vasiliev's discussion in Prostranstvo, vremia, dvizhenie. Istoricheskoe vvedenie v obshchuiu teoriiu otnositel'nosti (Berlin: Argonavty, 1922); translated as Space, Time, Motion. An Historical Introduction to the General Theory of Relativity, H. M. Lucas and C. P. Sanger, trans. (New York: A. A. Knopf, 1924). (The fictitious editor of The Gift's literary journal is also called Vasiliev.) Mach's intuition had predecessors, but Einstein gave him the most credit. "Ernst Mach," The Collected Papers of Albert Einstein (Princeton, 1997), vol. 6, 141-45. Nabokov would have also read about this genealogy in G. L. Lovtskii's “The Rhythm of the World's Movements" (Ritm mirovykh dvizhenii), Sovremennye zapiski XVII (Apr--May, 1923): 249-80. See Ernst Mach, The Science of Mechanics (LaSalle, IL: Open Court, 1960), 271-305.

23. The following discussion includes and develops further some material from my "The Poetics of Science in, and around, Nabokov's The Gift," The Russian Review 62.2 (April, 2003): 243-61. 
24. "Foreword," Invitation to a Beheading (New York: Vintage International, 1989), 9.

25. Gift, 240. Significantly, Nabokov's chapter demonstrates how Chernyshevsky associated non-Euclidean geometry with the composition of Russian poetry without verbs by Afanasy Fet, whom the critic called "an idiot without peers" (ibid.). A. V. Vasiliev also wrote on the spherical features of the new geometries in Space, Time, Motion (1922).

26. "The Tragedy of Tragedy," USSR, 327.

27. Published in Poslednie novosti, 10-11 March 1934. On Nabokov's misdating of the document, see Boyd, RY, 404-5, 572n57.

28. Nabokov in later years claimed to abandon chronological composition entirely, using note cards to fill in the blanks of a work in any order that suited his inspiration. SO, 68-69.

29. In fact, there are two further associations to the van's inscription: James Clerk Maxwell as the creator of classical electromagnetic theory; and Max Planck's proof that all electromagnetic radiation (that is, visible and invisible light) is noncontinuous and consists of discrete quanta. Physicist and Nabokovian Jerry Friedman suggested to me that these two associations may, in fact, be the strongest, at least for those working in physics.

30. English quotations in the preceding two paragraphs are from Gift, 6, 7; Russian from SSRP, vol. 4, 194, 195.

31. Gift, 334-35.

32. Ibid., 4.

33. Ibid., 6.

34. Ibid., 9.

35. Ibid., 31.

36. Of special significance is the fact that in the passages in chapter 1 of The Gift, Nabokov extends the idea of a speed-time relationship to thought, giving a preview of his later space-time-thought syllogism in Speak, Memory (SM, 301).

37. In another example of misbehaving lines, in chapter 5 while resting and swimming in the Grunewald, Fyodor imagines striving for "infinity, where all, all the lines meet" (Gift, 329).

38. Gift, 282. This phrasing could also evoke Schelling's Nature Philosophy, which considered (with curious foresight) all matter to be a tension of positive and negative charges. See Schelling, Ideas for a Philosophy of Nature as Introduction to the Study of This Science, Errol E. Harris and Peter Heath, trans. (Cambridge, UK: Cambridge University Press, 1988), 174.

39. Gift, 331. This criticism recalls Goethe's remarks about Newton's theory of light and color. The following passage is highly relevant for Nabokov's and Konstantin's point of view: "Empirical data should be presented without any theoretical context. . . Every act of looking turns into observation, every act of observation into reflection, every act of reflection into the making of associations; thus it is evident that we theorize every time we look carefully at the world. The ability to do this with clarity of mind, with self knowledge, in a free way, and (if I may venture to put it so) with irony, is a skill we will need in order to avoid the pitfalls of abstraction ..." (Goethe, Scientific Studies, Douglas Miller, ed. and trans. [New York: Suhrkamp Publishers, 1988], 159). Recall that Konstantin's revolutionary species theory arose from just such a dispassionate consideration of accumulated empirical data. As Dennis L. Sepper describes, Goethe had heard that "Newton's theory expressed the very essence of the facts and could explain them as well as one could desire, but when he compared what he read in Newton with what he saw experimentally he decided that the 'facts' were expressed in a tendentious theory and that the argument was inexact and sometimes specious" (Goethe contra Newton [New York: Cambridge University Press, 1988], 105). 
40. See Niels Bohr, "Light and Life," in Niels Bohr, ed., Atomic Physics and Human Knowledge (New York: John Wiley \& Sons, 1958), 6: "Indeed, any attempt to trace the detailed course of a transition process would involve an uncontrollable exchange of energy between the atom and the measuring instruments which would completely disturb the very energy balance we set out to investigate." Bohr later discusses "this impossibility of distinguishing, in introspection, sharply between subject and object" (22), which he sees as providing some conceptual justification for the concept of free will.

41. Gift, 364. Cf. Henri Bergson: "Evolution would fain go in a straight line; each special evolution is a kind of circle. Like eddies of dust raised by the wind as it passes, the living turn upon themselves, borne up by the great blast of life." Creative Evolution, trans. Arthur Mitchell, trans. (Mineola, NY: Dover Publications, 1998 [1911]), 128. Fyodor's dust returns immediately to light: it "makes the most orange of skies."

42. On this subject, see Alexander Dolinin, "Nabokov's Time Doubling: From The Gift to Lolita," Nabokov Studies 2 (1995): 3-40. It would not be long before Nabokov would make a more definite reference to uncertainty-like arguments: in "Ultima Thule," the clairvoyant Falter expresses his refusal to reveal whether human beings possess an immortal soul by means of the following analogy:

You want to know whether Gospodin Sineusov will forever reside within the snugness of Gospodin Sineusov, otherwise Moustache-Bleue, or whether everything will abruptly vanish. There are two ideas here, aren't there? Round-the-clock lighting and the black inane. Actually, despite the difference in metaphysical color, they greatly resemble each other. And they move in parallel. They even move at considerable speed. Long live the totalizator! Hey, hey, look through your turf glasses, they're racing each other, and you would very much like to know which will arrive first at the post of truth, but in asking me to give you a yes or no for either one or the other, you want me to catch one of them at full speed by the neck-and those devils have awfully slippery necks - but even if I were to grab one of them for you, I would merely interrupt the competition, or the winner would be the other, the one I did not snatch, an utterly meaningless result inasmuch as no rivalry would any longer exist. (Stories, 519)

43. Gift, 67. Louis de Broglie proposed in 1923 that matter had a wave-like nature, akin to light, leading to the discovery of matter's particle-wave duality.

44. On "Ultima Thule," see n42 above. Ambiguities of identity in The Real Life of Sebastian Knight could be viewed as exploring identity problems as raised in quantum theory. Peter Pesic reports how "in 1931, [renowned mathematician] Hermann Weyl wrote with some astonishment of two 'quantum twins,' Mike and Ike: 'It is impossible for either of these individuals to retain his identity so that one of them will always be able to say 'I'm Mike' and the other 'I'm Ike.' Even in principle one cannot demand an alibi of an electron!" (Seeing Double, 98). Cf. Hermann Weyl, The Theory of Groups and Quantum Mechanics (New York: Dover, 1950), 241. The ambiguities of the text generate an instability that, consciously or not, mimics the indeterminacy of the subatomic world. When we narrow the possibilities to one, it is through an act of perspective and choice that effectively sets the rules necessitating that possibility.

45. BS, 171-72. Robert Grossmith offers a powerful reading of these echoes of modern physics in the light of the Greek atomists in "Shaking the Kaleidoscope: Physics and Metaphysics in Nabokov's Bend Sinister," Russian Literature TriQuarterly 24 (1991): 151-62.

46. BS, 188.

47. Ibid., 203-4. 
48. Boyd, AY, 100. Susan Elizabeth Sweeney surveys the early critical response to this chapter and traces its connection to Nabokov's friendship with Edmund Wilson in the 1940s: "Nabokov, Wilson, and Hamlet in Bend Sinister," Nabokov Studies 1 (1994): 179_ 94.

49. One tragifarcical Ekwilist translation of this speech, proposed by Krug's friend Ember, can be rendered "To kill or not to kill ..." (BS, 118).

50. Ibid., 105.

51. Ibid., 108.

52. Eddington, New Pathways, 72-91.

53. BS, 120. This machine could perfectly imitate anyone's handwriting-thus making everyone calligraphically "equal."

54. Eddington and Jeans were criticized by some scientists and philosophers for encouraging and even embracing such metaphysical fancies. See Eddington's response in his New Pathways in Science, chapters XIII ("Criticisms and Controversies") and XIV ("Epilogue"). Eddington replies directly to Herbert Samuel's "Cause, Effect, and Professor Eddington" in The Nineteenth Century and After (April 1933); C. E. M. Joad's Philosophical Aspects of Modern Science (1932); W. T. Stace's "Sir Arthur Eddington and the Physical World," Philosophy 9 (1934): 40; and Bertrand Russell's The Scientific Outlook (New York: W. W. Norton \& Co., 1931).

55. Pnin (New York: Vintage International, 1991), 17. The stone is likely a reference to Einstein: "Stein" is German for "stone." It seems that Nabokov's suspicion of Einstein had already begun to develop while writing Pnin (although Einstein's early Bolshevik sympathies may have contributed to Nabokov's doubts): in a multi-disciplinary pun, the novel also includes a "Dr. Rosetta Stone," "one of the most destructive psychiatrists of the day" (44)-linking the idea of a Freudian translation key ("Rosetta Stone") for the unconscious with the "slick formulae" of relativity (in expositions of relativity, motion is also referred to as "translation"). In a highly ironic twist, during the passage concerning Victor's upbringing by his psychoanalyst parents, the narrator commingles ideas of a Freudian childhood with a search for "frames of religious reference," an unmistakably relativistic turn of phrase. Nabokov's subversive approach to relativity may have derived from his distrust of its reliance upon mathematics as a prospective language for materialist explanation. Compare also the following passage from the lecture "The Art of Literature and Commonsense": "In this divinely absurd world of the mind, mathematical symbols do not thrive. Their interplay, no matter how smoothly it works, no matter how dutifully it mimics the convolutions of our dreams and the quantums of our mental associations, can never really express what is utterly foreign to their nature, considering that the main delight of the creative mind is the sway accorded to a seemingly incongruous detail over a seemingly dominant generalization. When commonsense is ejected together with its calculating machine, numbers cease to trouble the mind. Statistics pluck up their skirts and sweep out in a huff. Two and two no longer make four, because it is no longer necessary for them to make four. If they had done so in the artificial logical world which we have left, it had been merely a matter of habit: two and two used to make four in the same way as guests invited to dinner expect to make an even number. But I invite my numbers to a giddy picnic and then nobody minds whether two and two make five or five minus some quaint fraction" ( $L L, 373)$. These remarks echo the comments on science, statistics, and philosophy in "Remarks on F. Martin Brown's 'Measurements and Lepidoptera'” (1950).

56. Pnin, 129-30.

57. LRL, 194-98.

58. Pnin, 25-26. Later, the narrator's fascination with the materiality of matter emerges again: describing how Pnin's father had removed a granule from his eye, V. V. calls it a 
"black atom" and wonders "where that speck is now? The dull, mad fact is that it does exist somewhere" (176).

59. Pnin, 185. Pnin's comment follows the guidance not only of subject-object psychology here, or only that of quantum theory, but also of Tolstoy, who in War and Peace discourses extensively upon the human tendency to see things subjectively and upon how the very process of turning events into stories causes tellers to change the facts to achieve an effect, to sacrifice truth to style. The need for reporting adds yet another layer on top of the inescapable fact of the subjective observer.

60. The novel's inclusion of a character named "Miss Eisenbohr" sounds very much like a conglomeration of Einstein, Heisenberg, and Bohr. As S. Ilyin and A. Liuksemberg note, it also means "iron drill" in German ("Kommentarii k romanu," http://nabokov. gatchina3000.ru/pnin09.htm, accessed 8 Aug. 2006).

61. Ada (New York: Vintage International, 1990), 51-52.

62. Aleksey Sklyarenko, "Reinforcement of the Rainbow: The Color Allusions in Ada," NABOKV-L, Monday, 5 Nov. 2002. Rainbows and other spectra are frequent and portentous features of several Nabokov works.

63. Nabokov may have seen electricity and light as intrinsically related; John Shade's poem "Electricity" suggests that Shakespeare's soul may illuminate an entire town, upon which Kinbote suggests that "the Earth would not merely fall apart, but vanish like a ghost, if Electricity were suddenly removed from the world" (PF, 193). Emerson made a strikingly anticipatory comment concerning magnetism: "Science is 'a house held up by magnetism,- - draw out the magnet, \& the house falls \& buries the inhabitant" (quoted in Laura Dassow Walls, Emerson's Life in Science: The Culture of Truth [Ithaca: Cornell University Press, 2003], 221). Rachel Trousdale examines metaphysical implications of electricity in Pale Fire: “Faragod Bless Them': Nabokov, Spirits, and Electricity," Nabokov Studies 7 (2002/2003): 119-28. Brian Boyd briefly discusses the place of modern physics in this novel in his Nabokov's Pale Fire: The Magic of Artistic Discovery (Princeton: Princeton University Press, 1999), 258-59.

64. See also in this regard D. Barton Johnson's “Alphabetic Rainbows of Speak, Memory," in Worlds in Regression: Some Novels of Vladimir Nabokov (Ann Arbor: Ardis, 1985), 10-27.

65. A passage from Look at the Harlequins! shows vividly how the famous single- and double-slit experiments, used first to advance the wave theory of light and later to explore the wave-like properties of matter, can be transformed into an artistic moment: “... some damned slit, some atom or dimmet or artificial streetlight or natural moonlight that signaled inexpressible peril when I raised my head with a gasp above the level of a choking dream. Along the dim slit brighter points traveled with dreadful meaningful intervals between them. Those dots corresponded, perhaps, to my rapid heartbeats or were connected optically with the blinking of wet eyelashes but the rationale of it is inessential" (16).

66. Ibid., 171. Any of several problems devised by Leonhard Euler, a prolific mathematician brought to Russia's Academy of Sciences by the Bernoulli brothers under Catherine the Great. In a discussion on NABOKV-L, attention was drawn to Euler problems such as "The Bridges of Koenigsberg" and one that concerns "the movement of a point under attraction by two gravitational centers" (Robert Weldon, NABOKV-L, 30 Oct. 2003). Euler had been in the news in the years shortly before Nabokov began work on Ada: one of his conjectures, concerning the superimposition of "Latin Squares," was disproved in 1959. John A. Osmundsen, "Major Mathematical Conjecture Propounded 177 Years Ago Is Disproved," New York Times (26 Apr. 1959), 1; cf. R. C. Bose and S. S. Shrikhande, "On the Construction of Sets of Mutually Orthogonal Latin Squares and the Falsity of a Conjecture of Euler," Transactions of the American Mathematical Society 95.2 (May 1960): 191-209. 
67. SO, 143.

68. This comment is highlighted and underscored in the card's margin. "Notes for 'The Texture of Time,"” Berg Coll.

69. This series of quotations comes from Ada, 541, 543.

70. The reference is to the essay "Time and Thermodynamics" by Richard Schlegel, in J. T. Fraser, The Voices of Time, 501. Card "Time 5," in "Notes for "The Texture of Time," in "Notes on Various Subjects," Berg Coll. The card continues: "Time isnot [sic] only change and the awareness of change isnot $[$ sic] that of time."

71. Card "Spirals 3," "Notes for 'The Texture of Time," Berg Coll. This card is especially rich in content and worth presenting in detail: "Spiral nebulae. [Are they really orbits that look-owing to a distortion of 'time'-like spirals]." On the card's back: "an atom is an open work structure consisting mostly of empty space, with a small central nucleus and planet-like electron circulating in orbits around it. But electrons have another aspect, too, which is not that of material particles but of waves. A dual and mutually contradictory character. We do not know what an electron really is. P. 160 The modern physicist devises symbols for correlating observation and predicting facts but renounces any desire to know what sort of object is at the root of the explanation." The text Nabokov refers to is Gerald James Whitrow, The Natural Philosophy of Time (Oxford, UK: Oxford University Press, 1960). Whitrow (1912-2000) was a cosmologist, astrophysicist, historian, and mathematician at Imperial College, London. Note above especially the reappearance of interest in particle-wave complementarity.

72. The earliest such edition was Ernest Nagel and James R. Newman, Gödel's Proof (New York: New York University Press, 1958). Gödel's theorems, first published in 1931, were a refutation of David Hilbert's project to define a complete and consistent set of mathematical axioms, especially as embodied in Russell and Whitehead's Principia Mathematica. Nabokov probably had not heard of the theorems in the 1930s, but he did express thoughts of his own that were similar in spirit: Falter, the savant in "Ultima Thule" (1939), tells Sineusov, "'mathematics, I warn you, is but a perpetual game of leapfrog over its own shoulders as it keeps breeding-I kept combining various ideas, and finally found the right combination and exploded, like Berthold Schwartz"' (Stories, 514).

73. From "Wh[itrow]. Card 39," referring to Whitrow, Natural Philosophy, 295.

74. Card "Time 8," concerning Dunne, Serial Universe, 71. "Notes for 'The Texture of Time," Berg Coll. Marina Grishakova provides a lengthy summary of this argument and its connection to Dunne's concept of the "last observer" in relation to the novels Bend Sinister, The Real Life of Sebastian Knight, Transparent Things, and the story "Ultima Thule." Models, 261-72, esp. 262-63.

75. This is V.'s analogy for the elusive similarity between himself and his half-brother: "Their strokes were totally different, and one of the two was far, far better than the other; but the general rhythm of their motions as they swept all over the court was exactly the same, so that had it been possible to draft both systems two identical designs would have appeared" (RLSK, 34).

76. SM, 37; see also Boyd, RY, 70-71.

77. Cards "Relativity 1\&2," "Notes for 'The Texture of Time,"” Berg Coll. It should be emphasized that even in such notes, one never knows whether Nabokov is expressing his own thought or that of one of his characters.

78. Card "Rel[ativity] 8: Whitrow (p 222)," "Notes for 'The Texture of Time,"” Berg Coll. Compare the "traveling clocks" on this card to the same phrase in the 1968 translation of $K Q K$ (see $\mathrm{n} 7$ [this chapter] above).

79. This is so because if three observers are moving at high velocity relative to one another, events happening at two of the moving locations might appear simultaneous to one of the three observers, but would appear sequential to the other two (and for those two 
the sequence might be spaced differently, or even reversed). This is true independent of the distance between the objects, so the distance light must travel is not the issue here.

80. Card "Rel[ativity] 6: Whitrow (p. 179)," "Notes for 'The Texture of Time,"” Berg Coll.

81. Ada, 544. Cf. card "Simult[aneous] ev[ents]. 7," "Notes for 'The Texture of Time,"” Berg Coll.

82. Rel[ativity] 6. = (Wh[itrow] Card 29); "cf. also Sim ev 5 (=Whit card 28) p. 176. ... the individual time of the sentient observer [is the subject of my work]." "Notes for 'The Texture of Time,"” Berg Coll.

83. Nabokov's suspicion of the durability of new discoveries can be seen in the following passage in his notes: "Red-shifts in the spectra of ultimate nebulae are understood to mean that the universe is expanding-just as sun-shifts in the sky provided dramatic evidence to our ancestors that Phoebus was turning around our planet. The nebulae have been successfully receding now, at a spanking speed, for about thirty years; we wonder whose new hunch or gadget will stop them tomorrow-and bring them back, Monday week, shrunk, no doubt, by the next witchdoctor." From "Sim[ultaneous ev[ents] 4," "Notes for 'The Texture of Time,"” Berg Coll. It appears that Nabokov did not understand or rejected the problem of the impossibility of directly perceiving two vastly distant objects in a single field of perception (by a single observer), which makes the concept of simultaneity meaningless; also he did not seem to conceptualize that they may be moving at extreme speeds relative to one another, so that the simultaneity, which might be seen to exist from some arbitrary point of view, is relative to the speed of observer.

84. Antimatter was discovered as early as 1932 , and whole antimatter galaxies had been proposed by scientists before Nabokov began writing this novel (see, for example, Walter Sullivan, "Anti-Matter Test Shows Symmetry," New York Times [Nov. 29, 1959], 78). Moreover, Nabokov was familiar with the mirror-like doubling of various molecules, and the possibility of mirror-worlds, from Martin Gardner's Ambidextrous Universe, whose mock-citation of his Pale Fire he mockingly cites in Ada (Ada, 542). See also N. Katherine Hayles's discussion of Gardner's presence in Ada, in The Cosmic Web: Scientific Field Models and Literary Strategies in the Twentieth Century (Ithaca, NY: Cornell University Press, 1985), 111-37.

85. On the question of freedom vs. determinism, Nabokov made the following note: “'Eddington, A. S. Space Time and Gravitation 1921' 51 'The division into past and future (a feature of time-order which has no analogy in space-order) is closely associated with our ideas of causation \& Free-will. In a perfectly determinate scheme the p. and the F may be regarded as lying mapped out. ... Our knowledge of things where we are not and of things when we are not, is essentially the same ... so, if events are determinate, there is nothing to prevent a person from being aware of an event before it happens.' [this is nonsense] [the idea of such a 'mapping out' and 'awareness' is in itself a refutation of determinism]." Card: "Determinism," "Notes for 'The Texture of Time,"” Berg Coll.

86. On Ada as a part of the "alternate history" tradition in fiction, see Edgar L. Chapman and Carl B. Yoke, eds., Classic and Iconoclastic Alternate History Science Fiction, (Mellen, 2003); William Joseph Collins, Paths Not Taken: The Development, Structure, and Aesthetics of the Alternative History (Davis: University of California at Davis Press, 1990); Nicholas Gevers, Mirrors of the Past: Versions of History in Science Fiction and Fantasy (Cape Town: University of Cape Town Press, 1997); Karen Hellekson, The Alternate History: Refiguring Historical Time (Kent, OH: Kent State University Press, 2001); Edgar Vernon McKnight, Jr., Alternative History: The Development of a Literary Genre (Chapel Hill: University of North Carolina Press, 1994).

87. Ada, 445. This is at least the second time that Nabokov has figured a suicide that 
might have occurred, but is either averted or displaced by an alternate reality (the first is in The Eye [1931]). This passage also recalls the line from Pale Fire (1962): "And here time forked" - $a$ line that coincides with Hazel's Shade's successful suicide. Perhaps significantly, Jorge Luis Borges's similarly inflected story "The Garden of Forking Paths" appeared in English in 1948, and in March 1963 Nabokov told Alvin Toffler that Borges was one of his favorite writers among contemporaries (SO, 44).

88. RLSK, 176.

\section{Chapter 6}

1. SO, 154 (correspondence interview with Allene Talmey of Vogue).

2. Ibid., 45.

3. Compare Eddington's "Epilogue," in New Pathways in Science (New York: Macmillan, 1935).

4. Cf. the recent scandal over falsified data at the University of Vermont involving Eric Poehlman: Jeneen Interlandi, “An Unwelcome Discovery," The New York Times Magazine, Oct. 22, 2006, accessed via http://www.nytimes.com/2006/10/22/magazine/22sciencefraud. html? pagewanted=1\&ei=5088\&en=e03f2ce7d86fd269\&ex=1319169600. Also discussed in Harold C. Sox, MD, ed., and Drummond Rennie, MD, "Research Misconduct, Retraction, and Cleansing the Medical Literature: Lessons from the Poehlman Case," Annals of Internal Medicine 144, no. 8 (18 April 2006): 609-13.

5. Leon-Paul Fargue, 1876-1947, French poet. "Butterflies of Europe," container 4, Berg Coll.

6. DBDV, 137; cf. NMGL, 503.

7. Thomas S. Kuhn famously refers to the overcoming of such fallacious dogmas as "paradigm shifts." See The Copernican Revolution: Planetary Astronomy in the Development of Western Thought (Cambridge: Harvard University Press, 1957) and his The Structure of Scientific Revolutions (Chicago: University of Chicago Press, 1962).

8. This hypothesis came before the scientific acceptance of plate tectonics in the 1960s, although Nabokov may have heard of that theory directly from Vladimir Tatarinov, who translated a book on the subject by Alfred Wegener in 1923 (his The Origins of Continents and of Oceans [1915]). Rul', Sept. 30, 1923.

9. NB, 340-41.

10. Diachronic study of such things as animal skeletons is, of course, common, but the features and organs used for lepidopteral identification cannot usually be preserved in a fossil record.

11. NB, 340-41.

12. Ibid., 383.

13. Oct. 11, 1944, DBDV, 159.

14. “[Notes for a talk 'A Genus of Blue Butterflies,' October 10, 1944],” NB, 342.

15. "Remarks on F. Martin Brown's 'Measurements and Lepidoptera," NB, 460.

16. See his early public lecture, "On Generalities" (original title in English; lecture in Russian). Published and annotated by Aleksandr Dolinin, Zvezda 4 (1999): 12-14. It relates not to statistics or butterflies, but rather to historiography. See the quotation from "The Art of Literature and Common Sense," LL, 374, in the "Introduction."

17. NMGL, 120.

18. Ibid., 137.

19. This contention was, of course, confirmed again in the "Lysenko" affair in Soviet genetics. 
20. Gift, 286.

21. "Philosophically speaking, the padograph subsisted as an Ekwilist symbol, as a proof of the fact that a mechanical device can reproduce personality, and that Quality is merely the distribution aspect of Quantity" (BS, 69-70).

22. "A few vacant lots always remain, alas" $(S O, 31)$.

23. SO, 10-11. Cf. Goethe: "When ways of looking disappear from the world, the objects perceived often go missing too. In fact one can say that, in a higher sense, the way of looking is the object." Maxims and Reflections \#1147; quoted in R. H. Stephenson, Goethe's Conception of Knowledge and Science (Edinburgh: Edinburgh University Press, 1995), 45.

24. Laughter in the Dark (New York: Vintage International, 1989), 261.

25. Ibid.

26. Gift, 164.

27. Ibid.

28. Vladimir Alexandrov calls it an "otherworld," but without the "-ness" suffix it takes on associations that are far too concrete, despite his efforts to ward off such tendencies in his introduction. Nabokov's Otherworld (Princeton: Princeton University Press, 1991). Vadim Vadimich calls it "the hereafter" in his paraphrase of the poem in Look at the Harlequins! (LATH, 26).

29. See Stephen H. Blackwell, "Nabokov's Wiener-Schnitzel Dreams: Despair and AntiFreudian Poetics," Nabokov Studies 7 (2002-3): 129-50; and Alexander Dolinin, "Caning of Modernist Profaners: Parody in Despair," latest version on-line at http://www.libraries. psu.edu/nabokov/doli1.htm.

30. Moscow, 1910; reprint: Munich: Fink Verlag, 1969.

31. Editors usually just list the "missing" stanza numbers in between existing stanzas, and in some cases listing a whole range (for example, [I-VI] for the missing first six stanzas of chapter 4), but without holding space for the absent lines. This idiosyncrasy can be found only in the four-volume Bollingen editions (1963 and 1974); it was eliminated in the posthumous abridged paperback edition of the novel and commentary. The phenomenon of the missing stanzas is of some interest within the context of Pushkin's life and Romantic literature. Pushkin's decision to preserve their numbers rather than relabel the final version was due to a variety of causes. In some instances, Pushkin decided to suppress stanzas he had written for fear of the censor. In others, he simply was never satisfied with the verses he had in mind for a particular spot, but held their place anyway. Some gaps may have been intentionally and ironically produced, with no lines ever composed in that position. Still other missing stanzas were published in the first, serial publication but were suppressed in the first separate edition because they would have offended Pushkin's wife. The absences also reflect the Romantic culture of the fragment, and in that context they would have implied the work's organic, spontaneous nature and its honest presentation to the public, warts (i.e., holes) and all. See, for example, Monica Greenleaf, Pushkin and Romantic Fashion: Fragment, Elegy, Orient (Stanford: Stanford University Press, 1994), chapter 2.

32. Masterstvo Gogolia (Moscow-Leningrad: Gosud. Izdat. Khudozhestvennoi Literatury, 1934).

33. Eugene Onegin, Paperback Edition in Two Vols. (Princeton: Princeton University Press, 1981 [1975]), Commentary pt. one, 164.

34. Clarence Brown was the first to draw attention to the blank pages in Nabokov's translation. See "Nabokov's Pushkin and Nabokov's Nabokov," in L. S. Dembo, ed., Nabokov: The Man and his Work (Madison: University of Wisconsin Press, 1967), 195-208.

35. For further discussion, see my "Reading and Rupture in Nabokov's Invitation to a Beheading," Slavic and East European Journal (Spring 1995): 38-53; and Zina's Paradox (New York: Peter Lang, 2000), chapter 3, "Structure of the Problematic Reading." 
36. RLSK, 35.

37. As Brian Boyd has noted in various places, for example, Nabokov's Pale Fire (Princeton: Princeton University Press), 3.

38. "The man is the book" (RLSK, 175).

39. Gift, 216.

40. James Ramey, "Parasitism and Pale Fire's Camouflage: The King-Bot, the Crown Jewels and the Man in the Brown Macintosh," Comparative Literature Studies 41.2 (2004): $185-213$.

\section{Conclusion}

1. PP, 101.

2. In philosophy, doubts about the "law" of causality as a fundamental part of nature were raised by Hume and refined by Kant, for whom it was simply part of the essential manner in which consciousness perceives events and structures knowledge about them. Thus Nabokov was not breaking any new ground in his resistance to determinism, but in his apparent efforts to find a scientific approach to noncausal phenomena, he was indeed original.

3. There were many other new discoveries, of course, including Roentgen's X-rays. Niels Bohr first presented the idea of complementarity in 1927, at a conference at Lake Como, Italy. Jan Faye, "Copenhagen Interpretation of Quantum Mechanics," in Edward M. Zalta, ed., Stanford Encyclopedia of Philosophy (Spring 2008 Edition). http://plato. stanford.edu/archives/spr2008/entries/qm-copenhagen, 2008.

4. For one detailed discussion of this ambivalence among scientists, see Gerald Holton, Science and Anti-Science (Cambridge, MA: Harvard University Press, 1993), 74-85.

5. Jeans, The Mysterious Universe (New York: Macmillan, 1931), 22. The status of causality in the laws of physics and in "ultimate reality" was a matter of much discussion among scientists and philosophers of science, not only following the popularization of the uncertainty principle, but extending back into the nineteenth century. Émile Meyerson, writing a few years before Heisenberg's principle, suggested that "man, in spite of his invincible tendency to believe in rationality, obviously sensed very early that there is irrationality in nature, that nature is not entirely explicable.... In sum, we can make only negative or altogether imprecise pronouncements in this area. We know where complete rationalization is impossible, that is, where the agreement between our reason and external reality comes to an end: those are the irrationals already discovered" (Explanation in the Sciences, Mary-Alice and David A. Sipfle, trans., Boston Studies in the Philosophy of Science, vol. 128. [Dordrecht/Boston/London: Kluwer, 1991 (1921)], 172). Nevertheless, of vitalism Meyerson wrote that it "will not be able to find a legitimate place in science until research is infinitely more advanced than it is today" (ibid., 192). The question of how science can address these questions that depart from the standard rules of science, especially causality, was also the focus of Philipp Frank's attention in The Law of Causality and Its Limits (Boston: Kluwer Academic Publishers, 1998) (Das Kausalgesetz und seine Grenzen [1932], French translation published 1937): "The claim that only natural laws of the causal kind 'exist' would make sense only if laws would exist 'beside' and 'above' human experience as the knowledge of a higher intelligence in a 'true' world. From the standpoint of a purely scientific conception, each order of experiences is justified that is correct, which means: connects our actual experiences with each other. And the practical significance of the causal order is not the establishment of a general causal law, but of special laws in causal form. ... The question whether nature is causal, or similar questions, cannot be formulated as scientific questions, for they no longer deal with the order of our experiences; this is described 
by complicated factual situations as presented in ch. IX; but with such questions we want to know something about the 'true' world" (274). Thus Nabokov's rejection of physical causality as an ultimate truth about the world corresponded well with the various discussions occasioned by the discovery of quantum phenomena at the subatomic level. Nabokov would have learned of Frank, if not from reading him directly then from chapter 3 of Lenin's Materialism and Empiriocriticism (New York: International Publisheres, 1927), which attacked an earlier version of Frank's work on causality. Gerald Holton relates an amusing anecdote in this connection, Science and Anti-Science, 48-49, n48. Holton cites a letter from Harvard physicist Edwin C. Kemble, who wrote that "of all those with the training of the working physicist Frank is perhaps the most complete philosopher" (ibid., 38).

6. They certainly had that effect for Nabokov's compatriot and fellow exile Wassily Kandinsky, the Bauhaus artist, who began responding to new physical theories as early as 1913, the year Bohr's model succeeded Rutherford's: according to Gerald Holton, "Wassily Kandinsky's autobiographical sketch about the years 1901-1913, in his book Rückblick ... indicates how he overcame a block in his artistic work at that time: 'A scientific event removed the most important obstacle: the further division of the atom. The collapse of the atom model was equivalent, in my soul, to the collapse of the whole world. Suddenly the thickest walls fell. I would not have been amazed if a stone appeared before my eye in the air, melted, and became invisible. Science seemed to me destroyed. ...'” (Baden-Baden: Woldemar Klein Verlag, 1955), 16, cited in Holton, Science and Anti-science, 105, n19.

7. Yuri Leving reports on the archival materials from TsGIA in Garazh, Angar, Vokzal (St. Petersburg: Izd. Ivana Limbakha, 2004), 251, and personal communication.

8. 13 Oct. 1925. Berg Coll. Translated in Boyd, RY, 245.

9. Having received a commitment for some paid translation work for the Times of London, he would not have to "struggle for survival," he wryly observed. 31 Jan. 1924, Berg Coll.

10. "Ultima Thule" offers the most direct expression of such possibilities in the words of Falter and Sineusov (Stories, 514).

11. Victoria N. Alexander argues that these nonutilitarian phenomena may have been a source of fascination for Nabokov as examples of an emergent teleological principle, as "uncanny chance." "Nabokov, Teleology and Insect Mimicry," Nabokov Studies 7 (2003): $182,195$.

12. NNP, 6, 14.

13. This conjecture occurred before the advent of evolutionary psychology, which has recently provided adaptationist accounts of aesthetic activity.

14. "Once biological needs have caused mental life to reach a certain level, this mentality goes on to manifest itself independently beyond those needs. ... A monkey in a zoo caught a 'possum, examined it, found the pouch and took out the young, looked at them and put them back: here the curiousity of the little zoologist goes far beyond biological needs." Knowledge and Error, P. Foulkes and T. McCormack, trans. (Boston: D. Reidel Publishing Co., 1976), 53.

15. Especially in comparison to what he had read in William James's Principles of Psychology (Cambridge, MA: Harvard University Press, 1981). Consider, for example, James's discussion of psychology's field of enquiry: "The boundary-line of the mental is certainly vague. It is better not to be pedantic, but to let the science be as vague as its subject, and include such phenomena as these if by so doing we can throw any light on the main business in hand. It will ere long be seen, I trust, that we can; and that we gain much more by a broad than by a narrow conception of our subject. At a certain stage in the development of every science a degree of vagueness is what best consists with fertility. On the whole, few recent formulas have done more real service of a rough sort in psychology than the Spence- 
rian one that the essence of mental life and of bodily life are one, namely, 'the adjustment of inner to outer relations.' Such a formula is vagueness incarnate; but because it takes into account the fact that minds inhabit environments which act on them and on which they in turn react; because, in short, it takes mind in the midst of all its concrete relations, it is immensely more fertile than the old-fashioned 'rational psychology,' which treated the soul as a detached existent, sufficient unto itself, and assumed to consider only its nature and properties. I shall therefore feel free to make any sallies into zoology or into pure nervephysiology which may seem instructive for our purposes, but otherwise shall leave those sciences to the physiologists" (5). This openness to all avenues of exploration, in contrast to the narrow path selected by Freud, provides a clear picture of Nabokov's scientific biases.

16. For the most detailed examination yet made of Nabokov's debts to Schopenhauer, see Savely Senderovich and Elena Shvarts, “'If We Put Our Heads between Our Legs': An Introduction to the Theme "Vladimir Nabokov and Arthur Schopenhauer'" (forthcoming; manuscript kindly provided by the authors). The image in this title refers to the same upside-down viewing phenomenon mentioned in William James and in Emerson. See also Leona Toker, Nabokov: The Mystery of Literary Structures (Ithaca: Cornell University Press, 1989), and also her "Philosophers as Poets: Reading Nabokov with Schopenhauer and Bergson," Russian Literature Triquarterly 24 (1991): 185-96.

17. Transparent Things (New York: Vintage International, 1989), 92.

18. Philipp Frank presents a fascinating and pertinent discussion of the relation between causality and extra-causal phenomena, or what he calls "miracles": "The other, I should like to say more 'scientific,' conception is that it is not in the character of natural laws that they predetermine everything. Rather they leave certain gaps. Under certain circumstances they do not say what definitely has to happen but allow for several possibilities; which of these possibilities comes about depends on that higher power which therefore can intervene without violating laws of nature" (The Law of Causality, 76).

19. $L L, 374$. Compare the version proposed by the seer Falter in "Ultima Thule": "Mathematics, I warn you, is but a perpetual game of leapfrog over its own shoulders as it keeps breeding-I kept combining various ideas, and finally found the right combination and exploded, like Berthold Schwartz" (Stories, 514).

20. Stories, 514. That this story was written around 1939, combined with all the other evidence, lends weight to the theory that Nabokov was reading Goethe extensively during the preceding decade.

21. New Pathways in Science (New York: Macmillan, 1935), 324. Compare the description of Krug from Bend Sinister: "He had always felt the faint ridicule of a finite mind peering at the iridescence of the invisible through the prison bars of integers. And even if the Thing could be caught, why should he, or anybody else for that matter, wish the phenomenon to lose its curls, its mask, its mirror, and become the bald noumenon?" (BS, 144).

22. For convenience, here is the passage once again: "A priori, I had assumed that in the course of the combination and segregation of generic characters in various racial forms (and this is incidentally the meaning I attach to the term 'form') each of the six structurally different groups (i.e., species) of Lycaeides would be seen to repeat certain stages of the same general (i.e., generic) variation, but would reveal differences in rhythm, scope, and expression, the total of which would produce the synthetic character of one species as differing from the synthetic character of another. This has proved correct insofar as the species are known at present. ..." NMGL, 138.

23. The same is true of the "magic triangles" Nabokov mapped onto the reproductive apparatus of the male butterfly. As we saw in chapter 1, Nabokov was especially interested in these forms because he felt that they were protected from environmental pressures and hence should be more stable than other characteristics. Nabokov's program of synthetic, or 
holistic, approach to species analysis anticipated the work of Stephen Jay Gould and Richard C. Lewontin in their classic article, "The Spandrels of San Marco and the Panglossian Paradigm: A Critique of the Adaptationist Programme," Proceedings of the Royal Society of London, Series B, Biological Sciences, vol. 205, no. 1161, The Evolution of Adaptation by Natural Selection (Sept. 21, 1979): 581-98, esp. 590-97. In that article, the authors lament the atomized focus of the "adaptationist doctrine" with its neglect of the "integrated organism," many of whose features might have no adaptive advantage whatsoever. In ensuing research Gould and Lewontin came to call all nonadaptive (i.e., not due to selective pressures) variations "spandrels." See also Victoria N. Alexander's related discussion in her "Nabokov, Teleology, and Insect Mimicry," 183-86.

24. Victoria N. Alexander has connected this possibility with the concept of "neutral evolution" and genetic drift, whereby radically new traits may appear suddenly when latent genes have mutated over time before some further mutation or environmental change brings those mutations to the surface. Ibid., 199-207.

25. The same could be said of the partially "true," partially "twisted" nature of Fyodor's novel, The Gift.

26. In Nabokov's Pale Fire (Princeton: Princeton University Press, 1999), Boyd ends his first paragraph in this spirit: "In an age that has become particularly skeptical of the possibility of artistic discovery, both in art and about works of art, I want to affirm that writers and readers can discover new ways of writing and reading and that these discoveries have much in common with the process of scientific discovery" (3). In his very first book, Boyd observed that even in apparently metaphysical constructions, the scientific method held sway: "the invention and testing of hypotheses is exactly Nabokov's method of thinking about the afterlife." Nabokov's Ada: The Place of Consciousness, 2nd ed. (Christchurch: Cybereditions, 2001), 238. In RY, Boyd proposes that Nabokov's scientific and chess-problem backgrounds gave him the tools to attempt to mimic nature's rich artistry in his works (317-18).

27. "Experienced Nabokovians should know that Nabokov does not allow dual or multiple solutions: his solutions, like those of his chess problems, are exact (and, of course, not self-contradictory, like an 'invented' foreword)" (“'Even Homais Nods,' or, How to Revise Lolita," Nabokov Studies 2 (1995): 62-86, reprinted in Pifer, Vladimir Nabokov's Lolita: A Casebook [Oxford, UK: Oxford University Press, 2003], 57-82, 76). As Janet Gezari's discussion confirms, Nabokov's and others' chess problems can have multiple solutions and ambiguity: see $\mathrm{n} 30$ below.

28. SO, 10-11. This passage as well may echo Eddington, who wrote: "As for the external objects, remorselessly dissected by science, they are studied and measured, but they are never known. Our pursuit of them has led from solid matter to molecules, from molecules to sparsely scattered electric charges, from electric charges to waves of probability. Whither next?" New Pathways, 322-23.

29. For example, Zoran Kuzmanovich, "From the Editor," Nabokov Studies 10 (2006): viii. Compare also Eric Naiman's assertion that "even the best of Nabokov's fiction rests on the understanding that there are right and wrong ways to read and that for each text there is an underlying 'correct' interpretation: a 'true understanding' of the work." "What If Nabokov Had Written 'Dvoinik'? Reading Literature Preposterously," The Russian Review 64.4 (2005): 575-89.

30. SM, 290. One particularly detailed example follows this passage in $S M$ : "The false scent, the irresistible 'try' is: Pawn to b8, becoming a knight, with three beautiful mates following in answer to disclosed checks by Black; but Black can defeat the whole brilliant affair by not checking white and making instead a modest dilatory move elsewhere on the board. ... However, it is only now, many years later, that the information concealed in 
my chess symbols, which that control permitted to pass, may be, and in fact is, divulged" (293). This is also Problem 1 in Poems and Problems, 182. Similarly Janet Gezari, after a fascinating discussion of "virtual play" as a Nabokovian theme, draws attention to one of Nabokov's last published problems, a prize-winning self-mate problem offering two solutions. "Chess and Chess Problems," in Vladimir E. Alexandrov, The Garland Companion to Vladimir Nabokov (New York: Garland Publishing, 1995), 51-52.

31. Problem 18, PP, 199.

32. SM, 301.

33. Nabokov's ethical themes have also been carefully explored by Leona Toker, Michael Wood, Zoran Kuzmanovich, and Dana Dragunoiu, in their works listed among the Bibliography.

34. "Nabokov's Trinity (On the Movement of Nabokov's Themes)," in Julian W. Connolly, ed., Nabokov and His Fiction: New Perspectives (Cambridge, UK: Cambridge University Press, 1999), 134.

35. This stance conforms to, if it is not inspired by, Kant's treatment of "opinion" in his "Transcendental Doctrine of Method," Critique of Pure Reason (Rutland, VT: Everyman, 1993 [1934]), 501-3.

36. It should be noted that Brian Boyd has also discovered many intertextual allusions, especially in Ada and Pale Fire. However, in Boyd's case these discoveries are shown to have specific functions within a framework of significance (e.g., the thematic relevance of Robert Browning's Pippa Passes as a foil for Hazel Shade's role within Pale Fire). Nabokov's Pale Fire, $142-50$.

37. “Approaching Nabokovian Poetics," Essays in Poetics 24 (1999): 158-81 (179).

38. LL, 374. This passage echoes one in "The Tragedy of Tragedy": "The highest achievements in poetry, prose, painting, showmanship are characterized by the irrational and illogical, by that spirit of free will that snaps its rainbow fingers in the face of smug causality" (USSR, 326).

39. Lycaeides melissa samuelis, NNP, 539, 535 .

40. This is the nature of scientific progress proposed by Thomas S. Kuhn in his Structure of Scientific Revolutions.

41. Root-Bernstein argues that such iconoclastic activity is of great value to science: "we learn most by challenging conventional wisdom with the biggest and best arguments we can muster... [T] he process of trying to undermine dogma often reveals new aspects of knowledge, or forces it to be utilized in new and innovative ways that justify the rethinking." "The Arts and Sciences Share a Common Aesthetic Core," in Alfred I. Tauber, ed., The Elusive Synthesis: Aesthetics and Science, Boston Studies in the Philosophy of Science, vol. 182 (Dordrecht: Kluwer Academic Publishers, 1996), 49-50.

42. Jan. 15, 1951 diary. Berg Coll.

43. As we saw with Goethe's critique of Newton, and the modern Millikan oil-drop experiments. See chapter 1, n37, and Gerald Holton, "Subelectrons, presuppositions, and the Millikan-Ehrenhaft dispute," in The Scientific Imagination (Cambridge, UK: Cambridge University Press, 1978), 25-83.

44. Cf. Root-Bernstein's conclusion that "perhaps artists actually have knowledge about things that scientists do not." "The Arts and Sciences," 75. 


\section{bibliography}

\section{Archival Materials}

Vladimir Nabokov Papers, Berg Collection, New York Public Library

1951 Diary.

"Chekhov (Typescript with Corrections)."

Daily diary for 1945 .

Lepidoptery materials.

Letters to Elena Ivanovna Nabokov.

Letters to Véra

"Notes for "The Texture of Time."”

"Notes for work in progress."

"Notes on various subjects."

"Ritmy shestistopnago iamba. E. A. Baratynskii."

Vladimir Nabokov Papers, Library of Congress Manuscript Division

The Gift, Drafts in Russian. Container 2.

Letter to Raisa Tatarinova. 11 Nov. 1937. Container 1.

Lolita, notes in English. Container 2.

Pnin, notes in English. Container 8.

Pale Fire, draft in English. Containers 3-5.

"Stikhi i skhemy." Container 10.

"Vtoroe dobavlenie k 'Daru." Container 2. 


\section{Books and Articles}

"4,500 Battle in Museum to See Einstein Film; Police Quell Stampede after 8 Guards Fail." The New York Times (1857-Current file); 9 Jan. 1930; ProQuest Historical Newspapers The New York Times (1851-2003), 1.

Abel, Theodora M. and Elaine F. Kinder. The Subnormal Adolescent Girl. New York: Columbia University Press. 1942.

Aikhenval'd, Iulii. "Literaturnye zametki." Rul', 29 Apr. 1925, 4-5.

- Siluety russkikh pisatelei. Moscow: Respublika, 1994.

Alcock, John. An Enthusiasm for Orchids. Oxford, UK: Oxford University Press, 2006.

Albright, Daniel. Quantum Poetics: Yeats, Pound, Eliot, and the Science of Modernism. Cambridge, UK: Cambridge University Press, 1997.

Alexander, Victoria N. "Hopeful Monsters: Literary Teleology and Emergence." Emergence: Complexity \& Organization 7 (2005): 95-104.

"Nabokov, Teleology, and Insect Mimicry." Nabokov Studies 7 (2003): 177-214.

Alexandrov, Vladimir E., ed. The Garland Companion to Vladimir Nabokov. New York: Garland Publishing, 1995.

- Nabokov's Otherworld. Princeton: Princeton University Press, 1991.

. "Nabokov and Uspensky." In Vladimir E. Alexandrov, ed. The Garland Companion to Vladimir Nabokov. New York: Garland Publishing, 1995. 548-52.

Alexandrovskii, Grigorii. Psikhologiia poeticheskogo tvorchestva. St. Petersburg, 1902.

Amrine, Frederick et al., eds. Goethe and the Sciences: A Reappraisal. Dordrecht; Boston: D. Reidel, 1987.

Anemone, Anthony. "Nabokov's Despair and the Criminal Imagination." In Simon Karlinsky, James Rice, and Barry Scherr, eds. O Rus! Studia litteraria slavica in honorem Hugh McLean. Berkeley: Berkeley Slavic Specialties, 1995. 421-31.

Averill, Lawrence Augustus. Adolescence-A Study in the Teen Years. Boston: Houghton Mifflin, 1936.

Baade, W. and F. Zwicky. "On Super-novae." Proceedings of the National Academy of Sciences of the United States of America 20, no. 5 (May 15, 1934): 254-55.

Bailes, Kendall E. Science and Russian Culture in an Age of Revolutions: V. I. Vernadsky and his Scientific School, 1863-1945. Bloomington: Indiana University Press, 1990.

Baldwin, James Mark. Dictionary of Philosophy and Psychology. New York: Macmillan, 1901-5.

Ballantyne, Paul F. "History and Theory of Psychology: An Early 21st Century Student's Perspective." http://www.comnet.ca/ pballan/section5(210).htm. Accessed 2 June 2008.

Barabtarlo, Gennady, ed. Cold Fusion: Aspects of the German Cultural Presence in Russia. New York: Berghahn Books, 2000.

Barabtarlo, Gennady. "Nabokov's Trinity (On the Movement of Nabokov's Themes)." In Connolly, ed. Nabokov and His Fiction: New Perspectives. 109-38.

- Phantom of Fact: A Guide to Nabokov's Pnin. Ann Arbor: Ardis, 1989.

Barnard, E. E. "Some Peculiarities of the Novæ." Proceedings of the American Philosophical Society 61, no. 2 (1922): 99-106. Accessed via JSTOR.

Bazhenov, N. Psikhologiia kaznimykh. Moscow, 1906.

Belyi, Andrei. Masterstvo Gogolia. Moscow-Leningrad: Gosud. izdat. khudozhestvennoi literatury, 1934.

—. Simvolizm. Moscow, 1910; reprint Munich: Fink Verlag, 1969. 331-95.

__ "Sravnitel'naia morfologiia ritma russkoi liriki v dvukhstopnom iambe.” In Andrei Belyi. Simvolism. Moscow, 1910; reprint Munich: Fink Verlag, 1969.

Berg, L. S. Nomogenesis: Or, Evolution Determined by Law. J. N. Rostovtsov, trans. Cambridge, MA: MIT Press, 1969 [1922]. 
Bergson, Henri. Creative Evolution. Arthur Mitchell, trans. Mineola, NY: Dover Publications, 1998 [1911]. 128.

- Duration and Simultaneity, with Reference to Einstein's Theory. Leon Jacobson, trans. Introd. by Herbert Dingle. Indianapolis: Bobbs-Merrill, 1965.

Blackwell, Stephen H. "Fugitive Sense' in Nabokov.” In White and Norman, eds. Transitional Nabokov. London: Peter Lang, forthcoming.

—. "Nabokov's Wiener-Schnitzel Dreams: Despair and Anti-Freudian Poetics." Nabokov Studies 7 (2002/2003): 129-50.

—_. "A New or Little-Known Subtext in Lolita." The Nabokovian 60 (Spring 2008): $51-55$.

. "The Poetics of Science in, and around, Nabokov's The Gift." The Russian Review 62.2 (Apr. 2003): 243-61.

—. "Reading and Rupture in Nabokov's Invitation to a Beheading." Slavic and East European Journal (Spring 1995): 38-53.

- "Three Notes on The Gift: An Intertext, a Revision, and a Puzzle Solved." The Nabokovian 40 (Spring 1998): 36-39.

- Zina's Paradox: The Figured Reader in Nabokov's Gift. Middlebury Studies in Russian Literature, vol. 23. New York: Peter Lang, 2000.

Böhme, Gernot. "Is Goethe's Theory of Color Science?" In Amrine et al., eds. Goethe and the Sciences: A Reappraisal. 148-74.

Bohr, Niels. Atomic Theory and the Description of Nature. New York: AMS Press, 1978 [reprint of Cambridge, UK, 1934].

- "Biology and Atomic Physics." In Niels Bohr. Atomic Physics and Human Knowledge. New York: John Wiley \& Sons, 1958. 13-22.

- "Light and Life." In Niels Bohr. Atomic Physics and Human Knowledge. New York: John Wiley \& Sons, 1958. 3-12.

Boyd, Brian. "Even Homais Nods, or, How to Revise Lolita." Nabokov Studies 2 (1995): 62-86. Reprinted in Pifer, ed. Vladimir Nabokov's Lolita: A Casebook. Oxford, UK: Oxford University Press, 2003. 57-82.

—. "Literature and Discovery." Philosophy and Literature 23.2 (1999): 313-33.

—. "Nabokov, Literature, Lepidoptera." In Nabokov. Nabokov's Butterflies.

- Nabokov's Ada: The Place of Consciousness. 2nd ed. Christchurch: Cybereditions, 2001.

- Nabokov's Pale Fire. Princeton: Princeton University Press, 1999.

—. "Nabokov's Philosophical World.” The Southern Review 14.3 (1981): 260-301.

- . "Nabokov's Transition from Russian to English: Repudiation or Evolution?" Nabokov Studies 11 (forthcoming).

_. "Reflections on Narcissus." Nabokov Studies 5 (1998/1999): 179-83.

- Review of Dieter E. Zimmer, A Guide to Nabokov's Butterflies and Moths 2001. Nabokov Studies 6 (2000-2001): 215-220.

- Vladimir Nabokov: The American Years. Princeton: Princeton University Press, 1991.

- Vladimir Nabokov: The Russian Years. Princeton: Princeton University Press, 1990.

Brandt, A. “Teoriia Einshteina.” Rul', 15 Apr. 1924, 4.

Brett, George Sydney. Brett's History of Psychology. R. S. Peters, ed. New York: Macmillan, 1962.

Brodsky, Anna. "Homosexuality and the Aesthetic of Navokov's Dar." Nabokov Studies 4 (1997): 95-116.

Brown, Clarence. “Nabokov's Pushkin and Nabokov's Nabokov.” In L. S. Dembo, ed. 
Nabokov: The Man and His Work. Madison: University of Wisconsin Press, 1967. 195-208.

Bruner, J. S. and Leo Postman. "On the Perception of Incongruity." Journal of Personality XVIII (1949): 206-23.

Bukharin, Nikolai. Historical Materialism. New York: Russell and Russell, 1965 [1925].

Burch, Robert. "Charles Sanders Peirce.” In Edward N. Zalta, ed. Stanford Encyclopedia of Philosophy (Summer 2007). http://plato.stanford.edu/archives/sum2007/entries/ peirce/.

[Chernyshevsky, N. G.] Staryi Transformist. "Proiskhozhdenie teorii blagotvornosti bor'by za zhizn'.” Russkaia mysl', 1888, no. 9, sec. 2: 79-114.

Clark, Ronald W. Einstein: The Life and Times. New York: World Pub. Co., 1971.

Connolly, Julian W., ed. Nabokov's Early Fiction. Cambridge, UK: Cambridge University Press, 1991.

- Nabokov and His Fiction: New Perspectives. Cambridge, UK: Cambridge University Press, 1999.

Couturier, Maurice. Nabokov, ou la cruanté du desire: Lecture psychanalytique. Seyssele: Champ Vallon, 2004.

Crommelin, A. C. D. "Results of the Total Solar Eclipse of May 29 and the Relativity Theory.” Science, New Series, vol. 50, no. 1301. (Dec. 5, 1919): 518-20.

Darwin, Charles. The Descent of Man and Selection According to Sex." New York: New York University Press, 1989.

- L'expression des emotions chez l'homme et les animaux. Paris, 1877.

. On the Origin of Species by Means of Natural Selection. Joseph Carroll, ed. Peterborough, Ontario: Broadview Press, 2003.

- The Various Contrivances by Which Orchids Are Fertilized by Insects. Chicago: University of Chicago Press, 1984 [reprint of New York: D. Appleton, 1892].

Davydov, Sergei. "Despair." In Vladimir E. Alexandrov, ed. The Garland Companion to Vladimir Nabokov, 88-99.

- "The Gift: Nabokov's Aesthetic Exorcism of Chernyshevskii." Canadian-American Slavic Studies 19.3 (Fall 1985): 357-74.

De La Durantaye, Leland. "Vladimir Nabokov and Sigmund Freud, or a Particular Problem." American Imago 62.1 (2005): 59-73.

Delevskii, Iu. "Nauchnye zametki." Poslednie novosti, 7 Dec. 1937, 4.

Dobzhansky, Theodosius Grigorevich. Genetics and the Origin of Species. New York: Columbia University Press, 1937.

Dolinin, Alexander. "Caning of Modernist Profaners: Parody in Despair." Latest version online at http://www.libraries.psu.edu/nabokov/doli1.htm.

—. "Doklady Vladimira Nabokova v berlinskom literaturnom kruzhke." Zvezda 4 (1999): 7-11. Reprinted in Aleksandr Dolinin. Istinnaia zhizn’ pisatelia Sirina. St. Petersburg: Akademicheskii proekt. 369-75.

—. "Komentarii." In Vladimir Nabokov. Sobranie sochinenii russkogo perioda v 5-i tomakh.

—. "Nabokov's Time Doubling: From The Gift to Lolita." Nabokov Studies 2 (1995): 3-40.

Dostoevsky, Feodor. Crime and Punishment. George Gibian, ed. Jesse Coulson, trans. Norton Critical Edition. New York: W. W. Norton \& Co., 1989 [1964].

Dragunoiu, Dana. "Dialogues with Berkeley: Idealist Metaphysics and Epistemology in Nabokov's Bend Sinister." Nabokov Studies 5 (1998/1999): 47-62.

- "Homo ludis, homo faber: The Gift and 'Father's Butterflies." Manuscript provided by author. 
_. "Vladimir Nabokov's Ada: Art, Deception, Ethics." Contemporary Literature 46.2 (2005): 311-39.

- Vladimir Nabokov and the Poetics of Liberalism. Forthcoming.

Dunbar, Robin. Trouble with Science. Cambridge, MA: Harvard University Press, 1985.

Dunlap, Knight. "The Social Need for Scientific Psychology.” The Scientific Monthly 11, no. 6 (Dec. 1920): 502-17.

Dunne, J. W. An Experiment in Time. London: Faber and Faber, 1939.

- The Serial Universe. New York: Macmillan, 1938.

Eddington, Arthur S. New Pathways in Science. New York: Macmillan, 1935.

- Space Time and Gravitation: An Outline of the General Relativity Theory. Cambridge, UK: Cambridge University Press, 1921.

Ehrlich, Victor. Russian Formalism: History-Doctrine. New Haven: Yale University Press, 1981.

Einstein, Albert. "Ernst Mach.” In John Stachel, ed. The Collected Papers of Albert Einstein, vol. 6. Princeton: Princeton University Press, 1997. 141-45.

Elms, Alan C. "Cloud, Castle, Claustrum: Nabokov as a Freudian in Spite of Himself." In Daniel Rancour-Laferriere, ed. Russian Literature and Psychoanalysis. Amsterdam: John Benjamins, 1989. 353-68.

Emerson, Ralph Waldo. Journals of Ralph Waldo Emerson with Annotations. Edward Waldo Emerson and Waldo Emerson Forbes, eds. Boston and New York: Houghton Mifflin Company, 1912.

- Nature. New York: Scholars' Facsimiles \& Reprints, 1940.

- Young Emerson Speaks: Unpublished Discourses on Many Subjects. Boston: Houghton-Mifflin, 1938.

Erwin, Edward. Review essay on Adolf Grünbaum, The Foundations of Psychoanalysis: A Philosophical Critique (Berkeley: University of California Press, 1984), in Noûs 21, no. 1 (Mar. 1987): 77-80.

Eysenck, Hans Jurgen. Decline and Fall of the Freudian Empire. New York: Penguin Books, 1991 [1985].

Faye, Jan. "Copenhagen Interpretation of Quantum Mechanics.” In Edward N. Zalta, ed. Stanford Encyclopedia of Philosophy (Summer 2002 edition). http://plato.stanford. edu/archives/sum2002/entries/qm-copenhagen/.

Ferger, George. "Who's Who in the Sublimelight." Nabokov Studies 8 (2004): 137-98.

Feynman, Richard "Cargo Cult Science." Commencement Address. CalTech, 1974. http:// calteches.library.caltech.edu/51/02/CargoCult.htm.

Fink, Karl J. Goethe's History of Science. Cambridge, UK; New York: Cambridge University Press, 1991.

Foster, Ludmilla A. "Nabokov in Russian Emigré Criticism." Russian Literature TriQuarterly 3 (1972): 330-41.

Frank, Philipp. The Law of Causality and Its Limits. Robert S. Cohen, ed. Marie Neurath and Robert S. Cohen, trans. Boston: Kluwer Academic Publishers, 1998.

Franklin, Allen. "Millikan's Published and Unpublished Data on Oil Drops." Historical Studies in the Physical Sciences 11 (1981):185-201.

Fraser, J. T., ed. The Voices of Time: A Cooperative Survey of Man's Views of Time as Expressed by the Sciences and by the Humanities. New York: G. Braziller, 1966.

Gardner, Martin. Science: Good, Bad, and Bogus. Buffalo: Prometheus Books, 1981.

Gezari, Janet "Chess and Chess Problems." In Alexandrov, ed. The Garland Companion to Vladimir Nabokov. 44-54.

Gezari, Janet K. and W. K. Wimsatt. "Vladimir Nabokov: More Chess Problems and the Novel.” Yale French Studies, no. 58 (1979): 102-15. 
Ghiselin, Michael T. "Introduction." In Charles Darwin, The Various Contrivances by Which Orchids Are Fertilized by Insects. Chicago: University of Chicago Press, 1984 [reprint of New York: D. Appleton, 1892].

Glynn, Michael. Vladimir Nabokov: Bergsonian and Russian Formalist Influences in His Novels. London: Palgrave Macmillan, 2007.

- " "The Word Is Not a Shadow. The Word Is a Thing'-Nabokov as Anti-Symbolist." European Journal of American Culture 25.1 (2006): 3-30.

Goethe, Johann Wolfgang von. "The Experiment as Mediator between Subject and Object." In Goethe, Scientific Studies. 12.

—. "Fortunate Encounter." In Goethe, Scientific Studies. 18-21.

- Goethe on Art. Berkeley: University of California Press, 1980.

- Goethe's Color Theory. Rupprecht Matthaei, ed. New York: Van Nostrand Reinhold, 1971.

—. "An Intermaxillary Bone Is Present in the Upper Jaw of Man as Well as in Animals.” In Goethe, Scientific Studies. 115-16.

- Metamorphosis of Plants. Wyoming, RI: Bio-dynamic Literature, 1978.

. "Reine Begriffe." Sämtliche Werke, Briefe, Tagebücher und Gespräche, vol. 23, pt.

2. Frankfurt am Main: Deutsher Klassiker Verlag, 1991. 69-70.

- Scientific Studies. Douglas Miller, ed. and trans. New York: Suhrkamp Publishers, 1988.

—. "Toward a General Comparative Theory." In Goethe, Scientific Studies. 55.

. "Über Wahrheit und Wahrscheinlichkeit der Kunstwerke" ["On the True and the Verisimilar in Art”]. Gedenkausgabe der Werke, Briefe und Gespräche. Zürich, Stuttgart: Artemis Verlag, 1965 [1954]. 175-91.

Gould, Stephen Jay. "No Science without Fancy, No Art without Facts: The Lepidoptery of Vladimir Nabokov.” In Sarah Funke, ed. and ann. Vera's Butterflies. New York: Glenn Horowitz Bookseller, 1999.

- The Structure of Evolutionary Theory. Cambridge, MA: Belknap Press of Harvard University Press, 2002.

Gould, Stephen Jay and Richard C. Lewontin. "The Spandrels of San Marco and the Panglossian Paradigm: A Critique of the Adaptationist Programme." Proceedings of the Royal Society of London, Series B, Biological Sciences, vol. 205, no. 1161, The Evolution of Adaptation by Natural Selection (21 Sept. 1979): 581-98.

Grayson, Jane, Arnold McMillan, and Priscilla Meyer, eds. Nabokov's World. 2 vols. Basingstoke, UK: Palgrave, 2002.

Green, Geoffrey. Freud and Nabokov. Lincoln: University of Nebraska Press, 1988.

Greenleaf, Monica. Pushkin and Romantic Fashion: Fragment, Elegy, Orient. Stanford: Stanford University Press, 1994.

Grishakova, Marina. The Models of Space, Time and Vision in V. Nabokov's Fiction: Narrative Strategies and Cultural Frames. Tartu: Tartu University Press, 2006.

Grossmith, Robert. "Shaking the Kaleidoscope: Physics and Metaphysics in Nabokov's Bend Sinister." Russian Literature TriQuarterly 24 (1991): 151-62.

Grot, N. "Psikhologiia.” Entsiklopedicheskii slovar'. Sankt-Peterburg: F. A. Brokgauz, I. A. Efron, 1890-1904.

Hayle, N. Katherine. The Cosmic Web: Scientific Field Models and Literary Strategies in the Twentieth Century. Ithaca: Cornell University Press, 1985.

Hegge, Hjalmar. "Theory of Science in the Light of Goethe's Science of Nature." In Amrine et al., eds. Goethe and the Sciences. 195-218.

Heisenberg, Werner. Across the Frontiers. Woodbridge, CT: Ox Bow Press, 1990.

Helmholtz, Hermann von. "Goethe's Anticipation of Subsequent Scientific Ideas.” In Russell 
Kahl, ed. Selected Writings of Hermann von Helmholtz. Middletown, CT: Wesleyan University Press, 1971. 479-500.

- "The Scientific Researches of Goethe." In Russell Kahl, ed. Selected Writings of Hermann von Helmholtz. Middletown, CT: Wesleyan University Press, 1971. 56-74.

Hilgevoord, Jan and Jos Uffink. "The Uncertainty Principle." In Edward N. Zalta, ed. The Stanford Encyclopedia of Philosophy (Fall 2006 Edition). http://plato. stanford.edu/archives/fa112006/entries/qt-uncertainty.

Holland, William J. The Butterfly Book. Garden City, NY: Doubleday, Doran \& Company, Inc., 1931.

Holton, Gerald. Science and Anti-Science. Cambridge, MA: Harvard University Press, 1993.

- The Scientific Imagination. Cambridge, UK: Cambridge University Press, 1978.

- "Subelectrons, Presuppositions and the Millikan-Ehrenhaft Dispute." In Gerald Holton, ed. The Scientific Imagination, 25-83.

Hothersall, David. History of Psychology. 4th ed. New York: McGraw-Hill, 2004.

Hsu, Steve S. and A. Zee. "Message in the Sky.” Modern Physics Letters A 21.19 (21 June 2006): 1495-1500.

Hunt, Milton. The Story of Psychology. New York: Doubleday, 1993.

Ilyin, S. and A. Liuksemberg. "Kommentarii k romanu." http://nabokov.gatchina3000.ru/ pnin09.htm.

Interlandi, Jeneen. “An Unwelcome Discovery.” The New York Times Magazine, 22 Oct. 2006: 98.

"I Think, Therefore I Am, I Think." In "A Survey of the Brain.” The Economist 23 Dec. 2006: Insert, 11-12.

James, William. Essays in Radical Empiricism. New York: Longmans, Green, and Co., 1922.

- Principles of Psychology. Cambridge, MA: Harvard University Press, 1981.

- Principles of Psychology. [1890]. Classics in the History of Psychology. Dev. by Christopher D. Green. York University. http://psychclassics.yorku.ca/James/Principles/ index.htm.

- Writings, 1902-1910. New York: Literary Classics of the United States, 1987.

Jeans, James. The Mysterious Universe. New York: Macmillan, 1931.

Joad, C. E. M. Philosophical Aspects of Modern Science. London: Allen and Unwin, 1932.

Johnson, D. Barton. "Vladimir Nabokov and Walter de la Mare's 'Otherworld." In Jane Grayson et al., eds., Nabokov's World, vol. 1. Houndmills, UK: Palgrave, 2002. 71-87.

- Worlds in Regression: Some Novels of Vladimir Nabokov. Ann Arbor: Ardis, 1985.

Johnson, Kurt. "Lepidoptera, Evolutionary Science, and Nabokov's Harvard Years-More Light and Context." Extended version of paper delivered on May 25, 2001, American Literature Association Meetings, Cambridge, Massachusetts, provided by author.

Johnson, Kurt and Steve Coates. Nabokov's Blues: The Scientific Odyssey of a Literary Genius. Cambridge, MA: Zoland, 1999.

Kant, Immanuel. Critique of the Power of Judgment. Paul Guyer, ed. Paul Guyer and Eric Matthews, trans. New York: Cambridge University Press, 2000.

- Critique of Pure Reason. Vasilis Politis, ed. and rev. J. M. D. Meiklejohn, trans. Rutland, VT: Everyman, 1993 [1934].

Kern, Stephen. A Cultural History of Causality. Princeton: Princeton University Press, 2004.

Kholodkovskii, Nikolai. Biologicheskie ocherki. Moscow: n.p., 1923.

“Khronika." Rul', 11 Jan. 1930, 3. 
Kostalevsky, Marina. “The Young Godunov-Cherdyntsev or How to Write a Literary Biography." Russian Literature 43.3 (1 Apr. 1998): 283-95.

Kuhn, Thomas S. The Copernican Revolution; Planetary Astronomy in the Development of Western Thought. Cambridge, MA: Harvard University Press, 1957.

- The Structure of Scientific Revolutions. 2nd ed. Chicago: University of Chicago Press, 1970.

Kuzmanovich, Zoran. "From the Editor." Nabokov Studies 10 (2006): vii-x.

- "Suffer the Little Children." In Gavriel Shapiro, ed. Nabokov at Cornell. Ithaca: Cornell University Press, 2003. 49-57.

Kuznetsov, Nikolai. Lepidoptera. A Mercado, trans. Jerusalem: Israel Program for Scientific Translations, 1967.

Larmour, H. J. David, ed. Discourse and Ideology in Nabokov's Prose. Studies in Rusian and European Literature, vol. 7. London and New York: Routledge Harwood, 2002.

Lawton, Anna, ed. Russian Futurism through Its Manifestos 1912-1928. Ithaca: Cornell University Press, 1988.

Lenin, Vladimir. Materialism and Empiriocriticism. New York: International Publishers, 1927.

Leving, Yuri. Garazh, Angar, Vokzal. Sankt-Petersburg: Izd. Ivana Limbakha, 2004.

Levy, David M. "Projective Techniques in Clinical Practice." American Journal of Orthopsychiatry 19 (1949): 140-44.

Lindroth, Carl H. "Systematics Specilizes between Fabricius and Darwin: 1800-1859." In Ray F. Smithet al., eds. History of Entomology. Palo Alto: Annual Reviews Inc., 1973. 119-54.

Lorentz, H. A. et al. The Principle of Relativity. W. Perret and G. B. Jeffrey, trans. New York: Dover, 1952 [1923].

Lovtskii, G. L. "Ritm mirovykh dvizhenii.” Sovremennye zapiski XVII (iv-v), 1923: 249_ 80.

Maar, Michael. The Two Lolitas. London, New York: Verso, 2005.

Mach, Ernst. Knowledge and Error. P. Foulkes and T. McCormack, trans. Boston: D. Reidel Publishing Co., 1976.

- The Science of Mechanics. LaSalle, IL: Open Court, 1960.

Mandler, George. A History of Modern Experimental Psychology: From James and Wundt to Cognitive Science. Cambridge, MA: MIT Press, 2007.

Mason, Bobby Ann. Nabokov's Garden: A Guide to Ada. Ann Arbor: Ardis, 1974.

Mayr, Ernst. Systematics and the Origin of Species. New York: Columbia University Press, 1942.

Menaker, Esther. Otto Rank: A Rediscovered Legacy. New York: Columbia University Press, 1982.

Merchant, Carolyn. "The Scientific Revolution and The Death of Nature." Isis 97 (2006): 513-33. Accessed online at http://www.journals.uchicago.edu/ISIS/journal/issues/ v97n3/970308/970308.html.

Mendeleyev, Dmitri. Osnovy khimii. 8th ed. St. Petersburg: Tipo-lit. M. P. Frolovoi, 1906.

Merz, John Theodore. History of European Thought in the XIX Century. 4 vols. New York: Dover, 1965 [Edinburgh: 1896-1916].

Metchnikoff, Élie. The Nature of Man. Studies in Optimistic Philosophy. Mitchell P. Chalmers, ed. and trans. New York: Putnam's Sons, 1903.

Meyerson, Émile. Explanation in the Sciences. Mary-Alice and David A Sipfle, trans. Boston Studies in the Philosophy of Science, vol. 128. Dordrecht/Boston/London: Kluwer, 1991 [1921].

Moore, Tony. "Seeing through Humbert: Focusing on the Feminist Sympathy in Lolita." In 
David H. J. Larmour, Discourse and Ideology in Nabokov's Prose. London and New York: Routledge, 2002.91-110.

Nabokov, Vladimir. Ada, or Ardor: A Family Chronicle. New York: Vintage International, 1990.

- The Annotated Lolita. Rev. ed. Alfred Appel, Jr., ed. New York: Vintage Books, 1991.

—. "The Art of Literature and Commonsense." In Vladimir Nabokov, Lectures on Literature. 371-80.

- Bend Sinister. New York: McGraw-Hill, 1963.

—. "Chto vsiakii dolzhen znat'?" In Vladimir Nabokov, Sobranie sochinenii russkogo perioda v 5-i tomakh, vol. 3, 697-99. Originally published in Novaia gazeta, Riga, 1 May 1931.

- Conclusive Evidence. New York: Harper, 1951.

- Dear Bunny, Dear Volodya: The Nabokov-Wilson Letters (1940-1971). Rev. ed., Simon Karlinsky, ed. and ann. Berkeley: University of California Press, 2001 [1979].

- The Defense. New York: McGraw-Hill, 1970.

- Despair. New York: Vintage International, 1989.

- Eugene Onegin. Paperback Edition in Two Vols. Princeton: Princeton University Press, 1981 [1975].

- The Eye. New York: Phaedra, 1965.

_. "Father's Butterflies." In Nabokov's Butterflies. 199-234.

—. The Gift. New York: Vintage International, 1991.

- Glory. New York: Macmillan, 1970.

- Invitation to a Beheading. New York: Vintage International, 1989.

- King, Queen, Knave. New York: McGraw-Hill, 1968.

- Laughter in the Dark. New York: Vintage International, 1989.

- Lectures on Literature. Fredson Bowers, ed. New York: Harcourt, Brace, Jovanovich, 1980.

- Lectures on Russian Literature. Fredson Bowers, ed. New York: Harcourt, Brace, Jovanovich, 1981.

- "Lolita and Mr. Girodias [from a letter to Girodias of Oct. 5, 1955]." Evergreen Review XI (1967): 37-41.

- Look at the Harlequins! New York: Vintage International, 1990.

- The Man from the USSR and Other Plays. New York: Bruccoli Clark/HBJ, 1984.

—. Nabokov's Butterflies. Brian Boyd and Robert M. Pyle, eds. Dmitri Nabokov, trans. Boston: Beacon Press, 1999.

—. "Nearctic Forms of Lycaeides Hüb. (Lycaenidae, Lepidoptera)." Psyche 50.3-4 (Sept.-Dec. 1943): 87-99.

- "The Nearctic Members of the Genus Lycaeides Hübner." Bulletin of the Museum of Comparative Zoology at Harvard College 101, no. 4 (1949): 479-541.

- "Notes on the Morphology of the Genus Lycaedes (Lycaenidae, Lepidoptera)." Psyche 51.3-4 (Sept.-Dec. 1944): 104-38.

—. "Notes on Neotropical Plebejinae (Lycaenidae, Lepidoptera)." Psyche 52.1-2 (Mar--June 1945): 1-61.

—. "On Generalities." [original title in English; lecture in Russian]. Aleksandr Dolinin, pub. and ann. Zvezda 4 (1999): 12-14.

- Pale Fire. New York: Vintage International, 1989.

—. "Pamiati Iu. I. Aikhenval'da." Sobranie sochinenii russkogo perioda v 5-i tomakh, vol. 2. 668.

—. "Pis'ma k Glebu Struve." Published by E. B. Belodubrovskii. Zvezda 4 (1999): 23-39. 
_. "Pis'ma V. V. Nabokova k G. P. Struve. 1925-1931.” E. B. Belodubrovskii and A.

A. Dolinin, pubs. Zvezda 11 (2003): 115-50.

—. "Pis'ma V. V. Nabokova k G. P. Struve. Chast' vtoraia (1931-1935).” Zvezda 4

(2004): 139-63.

- Pnin. New York: Vintage International, 1991.

-. Poems and Problems. New York: McGraw-Hill, 1970.

. "Pushkin, or the Real and the Plausible." The New York Review of Books, 31 Mar.

1988, 38-42.

- The Real Life of Sebastian Knight. New York: New Directions, 1959.

. "Remarks on F. Martin Brown's 'Measurements and Lepidoptera." Lepidopterist's

News 4 (1950): 75-76.

—. Selected Letters 1940-1977. Dmitri Nabokov and Matthew J. Bruccoli, eds. San Diego: Harvest/HBJ, 1989.

- Sobranie sochinenii russkogo perioda v 5-i tomakh. St. Petersburg: Symposium, 2000 .

- Speak, Memory; An Autobiography Revisited. New York: Vintage International, 1989.

. Stikhi. Ann Arbor: Ardis, 1979.

. The Stories of Vladimir Nabokov. New York: Knopf, 1995.

- Strong Opinions. New York: Vintage International, 1990.

- "The Tragedy of Tragedy." In The Man from the USSR and Other Plays. New York: Harcourt, Brace, Jovanovich, 1984. 323-42.

- Transparent Things. New York: Vintage International, 1989.

. "Vtoroe dobavlenie k Daru." Zvezda 1 (2001): 85-109.

Nagel, Ernest and James R. Newman. Gödel's Proof. New York: New York University Press, 1958.

Naiman, Eric. "A Filthy Look at Shakespeare's Lolita." Comparative Literature 58.1 (Winter 2006): 1-23.

_ . "Litland: The Allegorical Poetics of The Defense." Nabokov Studies 5 (1998/1999): $1-46$.

—. "What If Nabokov Had Written 'Dvoinik'? Reading Literature Preposterously." The Russian Review 64.4 (2005): 575-89.

"New Star Reaches First Magnitude." New York Times, 23 Dec. 1934, 17.

Nicol, Charles. "Martin, Darwin, Malory and Pushkin: The Anglo-Russian Culture of Glory.” In Jane Grayson et al., eds., Nabokov's World. Basingstoke, UK: Palgrave, 2002. Vol. 1, 159-72.

- "Why Darwin Slid into the Ditch: An Embedded Text in Glory." The Nabokovian 37 (Fall 1996): 48-53.

“Nova Herculis, 'Exploding Star,' No Longer Seen by Naked Eye, Fading to First Magnitude." By The Associated Press. New York Times, 8 Apr. 1935, 21.

Ohi, Kevin. "Narcissism and Queer Reading in Pale Fire." Nabokov Studies 5 (1998/1999): 153-78.

Orwin, Donna Tussing. Tolstoy's Art and Thought, 1847-1880. Princeton: Princeton University Press, 1993.

Osmundsen, John A. "Major Mathematical Conjecture Propounded 177 Years Ago Is Disproved.” New York Times, 26 Apr. 1959, 1.

Ouspensky, Pyotr. A New Model of the Universe. New York: Alfred A. Knopf, 1969 [1931].

- Tertium Organum, E. Kadloubrovsky et al., trans. New York: Alfred A. Knopf, 1981.

Owens, D. Alfred and Mark Wagner, eds. Progress in Modern Psychology: The Legacy of American Functionalism. Westport, CT: Praeger, 1992. 
Paperno, Irina. Chernyshevsky and the Age of Realism: A Study in the Semiotics of Behavior. Stanford: Stanford University Press, 1988.

—. "How Nabokov's Gift Is Made." Russell Valentino, trans. Stanford Slavic Studies 4, no. 2 (1992): 295-322.

Pfister, Oscar. The Psychoanalytic Method. New York, 1917.

Pifer, Ellen. Nabokov and the Novel. Cambridge, MA: Harvard University Press, 1980.

- Vladimir Nabokov's Lolita: A Casebook. Oxford, UK: Oxford University Press, 2003.

Pigliucci, Massimo. "Is Evolvability Evolvable?” Nature Reviews Genetics 9.1 (Jan. 2008): 75-82.

Poole, Randall A. "Introduction." In Randall A. Poole, ed. and trans. Problems of Idealism. New Haven: Yale University Press, 2002.

Popper, Carl. Conjectures and Refutations. London: Routledge and Kegan Paul, 1963.

- "On the Status of Science and of Metaphysics." In Conjectures and Refutations. 184-200.

—. "Science: Conjectures and Refutations." In Conjectures and Refutations. 33-58.

Pushkin, Aleksandr. Polnoe sobranie sochinenii. Leningrad: Akademiia nauk, 1937-59.

- Pushkin on Literature. Tatiana Wolff, trans. Revised by John Bayley. Evanston, IL: Northwestern University Press, 1998.

Pyle, Robert M. "Between Climb and Cloud.” In Nabokov. Nabokov's Butterflies. 32-76.

"Quacks in our Midst." The Cambridge Review XLI (28 Nov. 1919): 111.

Quin, J. D., MRCP. “Nabokov's Neurology.” Cycnos 10.1 (1993): 113-22.

Ramey, James. "Parasitism and Pale Fire's Camouflage: The King-Bot, the Crown Jewels and the Man in the Brown Macintosh." Comparative Literature Studies 41.2 (2004): 185-213.

Rancour-Laferriere, Daniel, ed. Russian Literature and Psychoanalysis. Amsterdam: John Benjamins, 1989.

Rank, Otto. Art and Artist. New York: W. W. Norton, 1989 [reprint of New York: Alfred A. Knopf, 1932].

- The Double. A Psychoanalytic Study. Harry Tucker, Jr., trans. New York: New American Library, 1979.

-. Psychology and the Soul. Baltimore: Johns Hopkins University Press, 1998.

Remington, Charles Lee. "Lepidoptera Studies." In Alexandrov. Garland Companion. 274-82.

"Revolution in Science. New Theory of the Universe. Newtonian Ideas Overthrown." The Times, 7 Nov. 1919, 12.

Ribot, Théodule A. Diseases of Memory; Diseases of Personality; Diseases of the Will. Washington, DC: University Publications of America, 1977 [1882].

Rice, Thomas Jackson. Joyce, Chaos, and Complexity. Urbana: University of Illinois Press, 1997.

Richards, Robert J. The Romantic Conception of Life: Science and Philosophy in the Age of Goethe. Chicago: University of Chicago Press, 2002.

Ronen, Omri. "Nabokov and Goethe." In Gennady Barabtarlo, ed. Cold Fusion: Aspects of the German Cultural Presence in Russia. New York: Berghahn Books, 2000. 241-51.

Root-Bernstein, Robert S. "The Arts and Sciences Share a Common Aesthetic Core." In Alfred I Tauber, ed. The Elusive Synthesis: Aesthetics and Science. Boston Studies in the Philosophy of Science, vol. 182. Dordrecht: Kluwer Academic Publishers, 1996. 49-50.

Roth, Matthew. "Three Allusions in Pale Fire." The Nabokovian 58 (Fall 2007): 53-60.

Rudnytsky, Peter L. "Introductory Essay." In Otto Rank. The Incest Theme in Literature and Legend, Gregory C. Richter, trans. Baltimore: Johns Hopkins University Press, 1992. 
Russell, Bertrand. The Scientific Outlook. New York: W. W. Norton, 1931.

Rylkova, Galina. "Okrylyonnyy Soglyadatay-The Winged Eavesdropper: Nabokov and Kuzmin.” In David H. J. Larmour, ed. Discourse and Ideology in Nabokov's Prose. Studies in Russian and European Literature, vol. 7. London and New York: Routledge Harwood, 2002. 43-58.

Schelling, Friedrich Wilhelm Joseph von. First Outline of a System of the Philosophy of Nature. Keith R. Peterson, trans., intro., and notes. Albany: State University of New York Press, 2004.

- Ideas for a Philosophy of Nature as Introduction to the Study of This Science. Errol E. Harris and Peter Heath, trans. Cambridge, UK: Cambridge University Press, 1988.

Schopenhauer, Arthur. On the Fourfold Root of the Principle of Sufficient Reason, and On the Will in Nature. London: G. Bell, 1915.

- Parerga and Paralipomena: Short Philosophical Essays. Oxford, UK: Clarendon, 1974.

- The World as Will and Idea. R. B. Haldane and J. Kemp, trans. London: Routledge and Kegan Paul, 1883.

Schultz-Venrath, Ulrich. Ernst Simmels psychoanalytische Klinik Sanatorium Schloss Tegel GmbH (1927-1931). Frankfurt am Main, Washington: Deutsche Hochschulschriften 2001, Mikroedition, 1995.

Seamon, David and Arthur Zajonc, eds. Goethe's Way of Science: A Phenomenology of Nature. Albany: State University of New York Press, 1998.

Senderovich, Savely and Yelena Shvarts. "Approaching Nabokovian Poetics." Essays in Poetics 24 (1999): 158-81.

—. "Aurelian i Eleonora, ili Gde Nabokov lovil svoikh babochek." Novyi zhurnal 123 (Dec. 1998): 205-12.

- " "If We Put Our Heads between Our Legs': An Introduction to the Theme 'Vladimir Nabokov and Arthur Schopenhauer." Nabokov Studies 11, forthcoming.

—. "Nabokovskii Faust. Predvaritel'nye zametki." In Nora Buhks, ed. Vladimir Nabokov-Sirine; Les Anées Européenes. Cahiers de l'émigration russe 5. Paris: Institut d'Études Slaves, 1999. 155-76.

Sepper, Dennis L. "Goethe against Newton: Towards Saving the Phenomenon." In Frederick Amrine et al., eds. Goethe and the Sciences: A Reappraisal. 175-94.

- Goethe contra Newton. New York: Cambridge University Press, 1988.

Shute, Jenefer. "Nabokov and Freud." In Alexandrov, ed. The Garland Companion to Vladimir Nabokov. New York: Garland, 1995. 412-20.

- Nabokov and Freud: The Play of Power. PhD diss., University of California at Los Angeles, 1983.

Sistematicheskii catalog biblioteki Vladimira Dmitrievicha Nabokova. St. Petersburg: Tov. Khud. Pech., 1904, 1911.

Sklyarenko, Aleksey. "Reinforcement of the Rainbow: The Color Allusions in Ada." NABOKV-L, 5 Nov. 2002.

Skonechnaia, Olga. "'People of the Moonlight': Silver Age Parodies in Nabokov's The Eye and The Gift." Nabokov Studies 3 (1996): 33-52.

_. "Primechaniia." In Nabokov. Sobranie sochinenii russkogo perioda v 5-i tomakh. Vol. 3, 707-14.

Smith, Ray F. et al., eds. History of Entomology. Palo Alto: Annual Reviews Inc., 1973.

Sox, Harold C., MD, ed., and Drummond Rennie, MD. "Research Misconduct, Retraction, and Cleansing the Medical Literature: Lessons from the Poehlman Case.” Annals of Internal Medicine 144.8 (18 Apr.2006): 609-13.

Stace, W. T. "Sir Arthur Eddington and the Physical World." Philosophy 9 (1934): 40.

Steiner, Peter. Russian Formalism: A Metapoetics. Ithaca: Cornell University Press, 1984. 
Stephenson, R. H. Goethe's Conception of Knowledge and Science. Edinburgh: Edinburgh University Press, 1995.

Stringer-Hye, Suellen. ““' "Laura” Is Not Even the Original's Name': An Interview with Dmitri Nabokov.” Nabokov Online Journal II, 2008. http://www.nabokovonline.com.

"A Student's Hoax." The Times (London), 12 Dec. 1921, 9.

Tallis, Raymond. "The Neuroscience Delusion.” The Times Literary Supplement, 9 Apr. 2008. http://entertainment.timesonline.co.uk/tol/arts_and_entertainment/the_tls-/ article3712980.ece. Accessed 25 Apr. 2008.

Tamir-Ghez, Nomi. "The Art of Persuasion in Nabokov's Lolita." In Ellen Pifer, ed. Nabokov's Lolita: A Casebook. New York: Oxford University Press, 2003. 17-37.

Tarnowski, Veniamin. The Sexual Instinct and Its Morbid Manifestations from the Double Standpoint of Jurisprudence and Psychiatry. Paris: C. Carrington, 1898.

Tatarinov, V. “Atomy i zvezdy.” Rul', 2 Sept. 1925, 4-5.

—. "Novye knigi po estestvoznaniiu i sel'skomu khoziaistvu.” Rul', 31 Dec. 1924, 4.

4.

- Review of The Origins of Continents and of Oceans by Alfred Wegener. Rul', 30 Sept. 1923, 4.

—. "Teoriia otnositel'nosti prof. Einshteina” (film review). Rul', 25 Aug. 1923, 4.

Toker, Leona. "Nabokov and Bergson on Duration and Reflextivity." In Grayson et al., eds. Nabokov's World. Vol. 1, 132-40.

- Nabokov: The Mystery of Literary Structures. Ithaca: Cornell University Press, 1989.

—. "Philosophers as Poets: Reading Nabokov with Schopenhauer and Bergson." Russian Literature Triquarterly 24 (1991): 185-96.

Tolstoy, Lev N. Anna Karenina. Louise and Aylmer Maude, trans. George Gibian, ed. New York: W. W. Norton, 1970.

- Polnoe sobranie sochinenii. Moscow: Gos. izd-vo khudozh. lit-ry, 1928.

- Tolstoy's Diaries. R. F. Christian, ed. and trans. London: Athlone Press, 1985.

Trousdale, Rachel. "'Faragod Bless Them': Nabokov, Spirits, and Electricity.” Nabokov Studies 7 (2002/2003): 119-28.

Trzeciak, Joanna. "Viennese Waltz: Freud and Nabokov." Comparative Literature, forthcoming, winter 2009.

—. "Visions and Re-visions: Nabokov as Self-translating Author." PhD diss., University of Chicago, 2005.

Turner, Stephen. "The Social Study of Science before Kuhn.” In Edward J. Hackett et al., eds. The Handbook of Science and Technology Studies, 3rd ed. Cambridge, MA: The MIT Press, 2007. 33-62.

“A Useful Hoax." The Times (London), 17 Dec. 1921, 11.

Vasiliev, A. V. Prostranstvo, vremia, dvizhenie. Istoricheskoe vvedenie v obshchuiu teoriiu otnositel'nosti. Berlin: Argonavty, 1922.

- Space, Time, Motion. An Historical Introduction to the General Theory of Relativity. H. M. Lucas and C. P. Sanger, trans. New York: A. A. Knopf, 1924.

Vernadskii, Vladimir Ivanovich. The Biosphere. Foreword by Lynn Margulis. New York: Copernicus, 1998.

—. "Kant i estestvoznanie XVIII stoletiia." Voprosy filosofii i psikhologii 74 (1904): 36-70.

—. "Mysli i zamechaniia o Gete kak naturaliste." Reprinted in V. I. Vernadskii. Izbrannye trudy po istorii nauki. Moscow, 1981, 242-89. Online at http://www.elibrary.ru/ books/vernadsky/2.1.6.htm. 
—. "O nauchnom mirovozzrenii." Voprosy filosofii i psikhologii 65 (1902): 1409-65.

Vucinich, Alexander. Darwin in Russian Thought. Berkeley: University of California Press, 1988.

- Einstein and Soviet Ideology. Stanford: Stanford University Press, 2001.

Walls, Laura Dassow. Emerson's Life in Science: The Culture of Truth. Ithaca: Cornell University Press, 2003.

Weininger, Otto. Pol i kharakter [Sex and character]. Foreword by A. Volynskii. SanktPeterburg: n.p., 1909.

Weismann, August. The Evolution Theory. J. Arthur Thompson and Margaret R. Thompson, trans. London: E. Arnold, 1904.

—_."Germinal Selection.” The Monist 6 (1895-96): 250-93.

Weldon, Robert. "Euler problems.” NABOKV-L, 30 Oct., 2003.

West, Donald James. Psychical Research Today. London: Duckworth, 1954.

White, Duncan and Will Norman, eds. Transitional Nabokov. London: Peter Lang, 2009.

Whitrow, Gerald James. The Natural Philosophy of Time. Oxford, UK: Oxford University Press, 1960.

Whitworth, Michael H. Einstein's Wake: Relativity, Metaphor, and Modernist Literature. Oxford, UK: Oxford University Press, 2001.

Wilcox, Stephen B. "Functionalism Then and Now." In Owens and Wagner, eds. Progress in Modern Psychology. 31-51.

Wood, Michael. The Magician's Doubts: Nabokov and the Risks of Fiction. London: Chatto and Windus, 1994.

Zimmer, Dieter E. Guide to Nabokov's Butterflies and Moths 2001. Hamburg: privately published, 2001.

- "Mimicry in Nature and Art." In Grayson et al., eds. Nabokov's World. Vol. 1, $47-57$.

Zimmer, Dieter E. and Sabine Hartmann. "The Amazing Music of Truth: Nabokov's Sources for Godunov's Central Asian Travels in The Gift." Nabokov Studies 7 (2002): 33-74.

- Nabokov reist im Traum in das Innere Asiens. Reinbek: Rowohlt Verlag, 2006.

Zunshine, Lisa. Why We Read Fiction. Columbus: The Ohio State University Press, 2006. 


\section{index}

accuracy, Nabokov's passion for, 169-70 Ada, 8, 13, 34, 74, 84-86, 89, 105, 107, 128-30, 157-58, 160-64, 181, 192, $224 n 43,244 n 86$

Adamovich, Georgy, 89 adaptation, 75

afterlife, 109

Aikhenvald, Iulii, 101, 130, 144, 208n51, 230n 34

Aksakov, Sergei, 169

Aldanov, Mark, 207n47

Aleksandrovskii, Grigorii, 104, 132

Alexander, Victoria N., 211n34, 213n51, 221n7, 226n69, 248n11, 250n23, $250 \mathrm{n} 24$

Alexandrov, Vladimir E., 130, 192-93, $246 \mathrm{n} 28$

alpha male, $223 \mathrm{n} 39$

alternate history, genre, $244 \mathrm{n} 86$

alternate worlds, in Ada, 86

American Museum of Natural History, 2

Anemone, Anthony, 231n 48

Anna Karenina (Tolstoy), 30, 92, 210n23; relativity in, 155
anti-Freudianism, 127

antimatter, $163,244 \mathrm{n} 84$

anti-science, 188-89

archetype in nature, 64

argyrognomon, variation of, 65

Art and Artist (Rank), 133

art: as offspring (progeny), 83; for art's sake, 62; as creation, 191; as evolution in consciousness, 191; as organic, 86-87; as transcription, 67; causality and, 198; evolution of, 93; in nature, 69; psychology of, 234n97; pure, 190; scientific knowledge of, 197; utility of, 220n2

"The Art of Literature and Commonsense," 188, 198

artist, psychology of, 133-34, 232n69 art-nature relationship, 17 art-science relationship, 3, 16, 218n32, $251 \mathrm{n} 41$

artwork, transcendence of, $215 \mathrm{n} 80$ astronomical metaphors, $215 \mathrm{n} 70$ authority, Nabokov's response to, 199 
Bacon, Sir Francis, 8, 142, 154, 198, 213n60, 237n9

Baconian science, 48

Bain, Alexander, 227n14

Bakhtin, Mikhail, 195, 234n86

Baldwin, James Mark, 227n16

Bàlint, Zsolt, 23

Banay, Ralph S., 233n85

Barabtarlo, Gennady, 192, 233n84

Barnard, E. E., 238n18

Bateson, William, 211n32

behaviorism, 97-100, 105, 128, 227n10

"Being in Love," 179

Bely, Andrey, 15, 41, 51, 80, 180, $215 \mathrm{n} 78$

Bend Sinister, 80, 90, 98, 105-7, 130, $139,151-53,155,175,177,182$, 206n25, 240n45, 246n21, 249n21

Benyamini, Dubi, 23

Berdiaev, Nikolai, 5

Berg, L. S., 66, 211n32, 219n45

Bergson, Henri, 66, 73, 149, 184, 206n26, 213n51, 240n41, 210n17

Berkeley, Bishop, 237n6

Binet, Alfred, 220n 56

biography, as a genre, 89,156

Böhme, Gernot, 218n23

Bohr, Niels, 4, 47, 144, 150, 183, 185, 240n40, 242n60, 248n6, 247n3

Bolshevik Revolution, 207n39

Bose, R. C., 242n66

Bourne, Ansel, 135, 235n110

Boyd, Brian, 22, 135, 153, 192-93, 195, 209n8, 242n63, 250n26, $251 \mathrm{n} 36$

Boyle, Robert, 3

Brett, George Sydney, 227n14

Brodsky, Anna, 231n 52

Brooke, Rupert, 235n105

Brown, Clarence, 246n34

Brown, F. Martin, 38, 172, 212n44

Bruner, J. S., 207n40

Bukharin, Nikolai, 5, 205n16

Bulgakov, Sergei, 5

Burliuk, David, 225n61

Butterflies in Art (Nabokov project), 69

Butterflies of Europe (Nabokov project), $68,169,186$

Butterflies of North America, 68, 186

butterfly classification criteria, 25
Cambridge Entomological Club, 38-39, $207 \mathrm{n} 47$

The Cambridge Review, 228n19

Cambridge University, 102

Camera Obscura. See Laughter in the Dark

Carus, Carl Gustav, 211n34

causality, 9, 11, 18, 33, 46, 74, 121, 140-41, 152, 156, 183-84, 186-88, 192, 199, 207n38, 212n38, 221n7, 232n57, 247n2, 247n5, 249n18, 251n38; mechanistic 61-62, 68; in nature 31-32; Nabokov on, 64; otherworldly forces and, 188 ; psychological, 110, 112, 115, 129, 132-33, 139, 233n69, 233n79, $233 n 80,234 n 92$; quantum theory and, 240n40, 247n4

certainty, scientific, 170

change in nature, Nabokov on, 62

Chekhov, Anton, Nabokov lecture, 140, 164, 236n4

Chernyshevsky, Nikolai, 11, 16, 108, 145, 147, 150, 174-75, 207n39, 210n24, 239n25

chess, 111; psychology of, 116

chess problems, 250n30, 250n27; causality and, 194; solutions to, 193-94

child-bride theme, 80

Christianity, 123

"The Circle," 146, 208n50

Coates, Steve, 22, 212n42

cognition as a tool, in Goethe, 56-57

Coleridge, Samuel Taylor, 45, 124, $215 \mathrm{n} 70$

color: consciousness and, 159; Nabokov and, 208n 57 ; science of, 159; theory, 217n19, 218n23, 239n39

colored hearing, 68, 220n54, 220n56

Conclusive Evidence, 39, 90

Connolly, Julian, 195, 233n80, 234n86

consciousness, 13, 75, 92, 143, 191, 227n10, 234n94; as adaptation, 187; allegories of, 142; durability of, 194; evolution in, 191; evolution of, 191; gaps in, 180; knowledge of, 195; in nature, 66, 73, 100; as principle of being, 73 ; in psychology, 101; limits of, $13,138,167,174,179,196$, 201; location of, 194; mystery of, 
97, 107, 117, 119-21, 128-30, 132, 136, 139, 152-53; and paranormal phenomena, 136; and "reality," 137; relativity and, 155; representations of, $221 \mathrm{n} 9$

cosmic synchronization, 70

Couturier, Maurice, 228n23

creativity, 67, 73-74, 84-86, 100; in consciousness, $218 \mathrm{n} 31$; in nature, 19, 87, 92-93, 186; psychology of, $232 \mathrm{n} 69$

Crime and Punishment (Dostoevsky), $125,233 \mathrm{n} 82$

crime: causality of, 121-23; psychology of, 121-23, 125

crypsis (concealment), in nature and art, 88

cryptograms, $142-43,181$

cryptomnesia, 225n 54

Cudworth, William, 211n28

Danilevskii, N. Ia., 221n14

Darwin, Charles, 29-30, 33, 46, 55, 76, $168,199,212 \mathrm{n} 38,216 \mathrm{n} 6,219 \mathrm{n} 39$, 222n31, 223n38, 223n42, 224n43

Darwinism, 2, 11, 30, 39, 63-64, 71, 75, $81,85,87,104,185-86,206$ n 35 , 210n24, 211n32, 250n23

Davydov, Sergei, 144-45, 151, 240n43

De La Durantaye, 227n12, 227n18

de la Mare, Walter, 235n105

De Vries, Hugo, 211n32

deception in nature, 17

The Defense, 94, 105-6, 115-21, 232n64; characters' psychology in, 119-21; Luzhin's psychology in, 111-16, 118

Descartes, René, 101

Despair, 12, 81, 89-90, 103-4, 108-9, 121, 124-26, 175, 179, 222n29, $231 \mathrm{n} 48$

detail in nature, 48

detective novel, 89

determinism, 154, 156, 184, 187, 244n85

dialectical materialism, 30

digressions, Gogolian, 120

disa butterfly (Erebia disa), 223n37

Disa orchids, 223n37

Disa uniflora, 82

disclosure, in science, 200 discontinuities, 191; in art, 180; in nature, $168,180,183-84$

“A Discovery," 63

dissections, Nabokov's, 209n5

Dobzhansky, Theodosius, 25

Dolinin, Alexander, 76, 196, 240n41

Dostoevsky, Fyodor, 13, 80, 123, 125, 174, 199, 233n 82

The Double (Dostoevsky), 13

Dragunoiu, Dana, 205n18, 230n34, $237 \mathrm{n} 6$

Dunlap, Knight, 229n27

Dunne, J. W., 160-61, 182, 206n28

Eckermann, Johann Peter, 69

Eddington, Sir Arthur, 2, 141, 143-44, 153-54, 176, 181, 183-84, 189, 237n9, 238n16, 241n54, 244n85, 245n $3,250 \mathrm{n} 28$

egalitarianism, and science, 175

Eikhenbaum, Boris, 15, 51

Eimer, Theodor, 211n 32

Einstein, Albert, 1-2, 4, 9, 140-41, 143-49, 155, 158-59, 168, 185, 199, 215n73, 236n3, 241n55, 242n60; in émigré press, 237n11, 237n14;

Nabokov's resistance to, 162

electricity, 242n63; as mystery, 158

Eliot, T. S., 144

Ellis, Havelock, 104

embryology, 225n67

emergence, 33, 191, 220n4, 248n11

Emerson, Ralph Waldo, 45, 211n28, $213 \mathrm{n} 60,214 \mathrm{n} 63,242 \mathrm{n} 63$

empathy, ethics and, 195

empiricism, 55; speculation and, 198

The Enchanter, 80

The Entomologist, 2

epistemology, 167, 169, 177-78, 193, 237n9; ideology and, 174; of mind, 98; physics and, 142-43; representation and, 176

equality: differentiation and, 182; nature and, 182

Erwin, Edward, 235n117

ethics: metaphysics and, 196; science and, 195-96; self-reference and, 196 ethics-related approaches to Nabokov, 195-96; science and, 201

Eugene Onegin (Pushkin), 169; gaps in, 
246n31; Nabokov's translation and commentary, 176-77, 198, 234n85, 246n31; missing stanzas in, 180

Euler problems, 242n66

Euler, Leonhard, 242n66

evolution, 30, 34, 60-61, 64-65, 71, 73, $79,92,96,100,185,191,210 \mathrm{n} 24$, 218n27, 219n39, 221n4, 225n67, $240 \mathrm{n} 41$; in art, 93-95; in consciousness, 192 ; creativity of, $46,39,192$; fictitious theory of, 14, 31-32; genitalic morphology and, 34; limits of, 84-86; Nabokov's belief in, 97, 190, 211n26; within Nabokov's oeuvre, 94; psychology and, 101; speciation and, 40, 46; speciation theory (spherical), 41; species diversity and, 32; teleological, 61

evolutionary psychology, 248n13

"Experiment as Mediator between Subject and Object" (Goethe), 57

experimental method, 48 ; vs. observation, 49

experimentum crucis (Newton), 11

The Eye, 12, 75, 89, 109-10, 130, $221 \mathrm{n} 10$

Eysenck, Hans Jurgen, 236n117

falsehood, intractability of, 170

falsification, in science, $245 \mathrm{n} 4$

Fargue, Leon-Paul, 169, 245n5

Faulkner, William, 144

Faust (Goethe), 53, 69-70

"Father's Butterflies," 14-15, 29, 30-31, 39-41, 45-49, 62-63, 66-8, 73-74, $81,100,145,147,208 \mathrm{n} 50,213 \mathrm{n} 59$, 213n60, 214n67, 214n70, 216n82, $225 \mathrm{n} 63$

Ferger, George, 230n38

Fet, Afanasy, 239n25

Fet, Victor, 210n13

"A Few Notes on Crimean Lepidoptera," 2

fictitious science, 21

Field, Andrew, 205n11

Finnegans Wake (Joyce), 225n63

Fitzgerald, George, 152

Ford, Edsel, 225n 55

Formalism, 15, 50-51, 197

Frank, Philipp, 183, 247n5, 249n18
Fraser, J. T., 160

Freidman, Jerry, 239n29

Freudianism, 2, 11, 89, 98-100, 102-5, 107-9, 114, 118, 122, 124, 126-28, 132, 134, 136, 138, 179, 187, 199, 222n32, 227n12, 228n21, 228n24, 228n25, 229n26, 229n27, 234n97, 236 n119; early popularity of, 102 ; in The Defense, 112; in Nabokov's novels, 106; in popular culture, 228n19; as a science, $168,235 \mathrm{n} 117$

functionalism, 97-98, 105, 226n7

gaps: in art, $246 \mathrm{n} 31$; in species variation, 66, 166, 173; epistemological, 11; in reading process, 181 ; in science, denial of, 174; in science, variability of, 171

Gardner, Martin, 165, 206n27, 244n84 genetic drift, 219n40, 226n69 genitalia, evolution of, 223n 34 genius, $110,117,224 \mathrm{n} 48$; in nature, $224 n 48$; as discontinuity, 182

genus (concept), 34

German language, 4

Gestalt psychology, 97-98, 105, 226n5

Gezari, Janet, 250n27, 251n30

ghosts, 130; in Pale Fire, 135

The Gift, 1-3, 11, 13-16, 21, 30, 39, 40, 48-49, 70, 73-74, 78, 80, 86, 89, 90, $94,96,117,133,145-51,178,180$ $81,191,207 \mathrm{n} 39,213 \mathrm{n} 59,214 \mathrm{n} 63$, 215n73, 239n36; early draft, 208n2; socialism in, 174

Glory, 76-79, 94, 222n24

Glynn, Michael, 215n79

Gödel, Kurt, 160-61, 243n72

Goethe, Johann Wolfgang von, 11, 16, $31,32,39,45,50,53,150,175$, 188-89, 198, 200-201, 208n53, 215n74, 216n4, 216n6, 239n39, 246n23, 249n20; on change in nature, 60 ; on collaboration in science, 58; on color theory, 11, 54, $59,159,208 \mathrm{n} 57$; on consciousness, as part of nature, 57 ; on evolution, 60-61; and idealism, 62; "Metamorphosis of Plants," 54, 56; "On Morphology," 54, 56; Nabokov's opinion of, 53; Nabokov's reading of, 69 , 
70; and natural archetype, 60-61, 63; and Nature Philosophy, 59; on Newton's Opticks, 58; on objective science/knowledge, 57-58; and phenomenology, 57; and Romanticism, 59; Russian émigré lectures on, 69; scientific legacy of, 17 ; scientific method of, 17; on subject-object relation, $17-18,57$; on theory, 58 ; and vital force, 60

Gogol, Nikolai, 10, 51, 120, 176, 180, 182

Gold, Herbert, 95

Goldschmidt, Richard, 211n 32

Gould, Stephen Jay, 207n46, 211n34, $211 \mathrm{n} 25,250 \mathrm{n} 23$

Gourmont, Remy de, 104

The Government Inspector (Gogol), 182 grades, Nabokov's, 205n11

Green, Geoffrey, 227n17

Greenleaf, Monica, 246n31

Grishakova, Marina, 224n47, 224n49, $237 \mathrm{n} 12$

Grossmith, Robert, 240n45

group psychotherapy, 128

Grünbaum, Adolf, 235n117

Hamlet (Shakespeare), 142, 153-54, $241 \mathrm{n} 48$

Hartmann, Sabine, 88

Heisenberg, Werner, 4, 17, 144, 150, 160-61, 183, 185, 242n60

Helmholtz, Hermann von, 17, 207n38, $217 \mathrm{n} 19$

A Hero of Our Time (Lermontov), 122, 127

Herzen, Alexander, 75, 221n11

Hilbert, David, 243n72

holism, 49, 98, 213n58, 217n8

holistic phenomena, reality of, 186

Holland, William J., 210n19

Holton, Gerald, 212n37, 247n4, 248nn5-6

homopsis, 38

homosexuality, 81, 109, 131, 222n30, $231 \mathrm{n} 52,234 \mathrm{n} 95$; in nature, 80 ;

Nabokov on, 223n41

Hothersall, David, 226n5

humanism, 175

Hume, David, 247n2

Hyatt, Alpheus, 211n32 iconoclasm in science, $143,251 \mathrm{n} 41$

idealism, 6, 7, 40-41, 45, 63, 67, 152, 173, 200, 218n26, 229n34; and quantum theory, 185 ; and science, 145; German, 59; quantum theory and, 144

identity, quantum, 240n44

ignorance, 200

imagination, reality and, 167

incomplete butterfly projects, 68,169 , 186

incompleteness theorem, 160-62, $243 n 72$

individualism, 175; ethics and, 196 infertility, 83, 85. See also sterility insanity, 110, 112, 117, 136; truth and, 136

intelligence, 84-86; as adaptation, 83 intelligent design, 7 intentionality, possibility of, 138 intermaxillary bone, 65 interpretation (literary science), 154 intertextual approaches to Nabokov, 196-99

Invitation to a Beheading, 80, 90, 117, $146,179-80$

Ioffe, Mlle. (Freud lecture), 102

irregularities: art and, 198; in nature, 75; science and, 199

Jackson Lake, WY, 65

James, William, 99, 101, 104-5, 108, 128, 135-36, 138-39, 173, 184, 206n26, 214n63, 220n56, 221n11, 226n8, 227n13, 229nn30-31, 229n33, 230n38, 231n47, 231n51, 235n110, 236n121, 248n15; Principles of Psychology, echoes of in Nabokov, 229n30

Janet, Pierre, 231n51

Jeans, James, 183, 185, 189, 238n16, $241 \mathrm{n} 54$

Jenkin, Fleeming, 211n34

Johnson, D. Barton, 192, 220n54, 235n105, 242n64

Johnson, Kurt, 22, 23, 25, 39, 205n7, 206n29, 206n31, 207n37, 208n48, $209 \mathrm{n} 4,212 \mathrm{n} 42$

Joyce, James, 132, 142, 144, 225n63

Kafka, Franz, 232n64 
Kandinsky, Wassily, 248n6

Kant, Immanuel, 7, 8, 31, 46, 60-63, 67, 137, 144, 153, 167, 198, 205n20, 207n44, 211n30, 224n48, 247n2, $251 \mathrm{n} 35$

Karner Blue (butterfly), 199

Kemble, Edwin, 248n5

Kepler, Johannes, 47

Kern, Stephen, 232n57

Kholodkovskii, Nikolai, 31, 70, 211n25

King Queen Knave, 94, 108, 145

Klein, Melanie, 231n41

knowledge, 16; elusiveness of, 250n28; ephemerality of, $244 \mathrm{n} 83$; exploitability of, 200; vs. ignorance, 172; incompleteness of, 165,167; limits of, 177, 196; as part of human consciousness, 10; revision of, 172

knowledge claims, 199-200; art and, 201; authority of, 196; falsity in, 10, 170; political power and, 201; science and, 201

Kostalevsky, Marina, 88

Kuhn, Thomas, 207n40, 236n118, $245 \mathrm{n} 7,251 \mathrm{n} 40$

Kunin, Carolyn, 235n108

Kuzmanovich, Zoran, 230n39, 250n29

Kuzmin, Mikhail, 109

Kuznetsov, Nikolai, 28, 212n43

Lacan, Jacques, 228n23

Lamarck, Jean-Baptiste, 75, 210n24

Landmarks, 5

Laughter in the Dark, 12, 80, 108, 177-78

laws of nature: possible contingency of, 157; unknown, 186

laws of physics, 47, 146, 149; apparent lapses in, 179

Leinster, Murry, 163-64

Lenin, Vladimir, 145, 207n39, 238n21

Leninism, 174

lepidoptera, diversity of, 29

Lermontov, Mikhail, 122, 127

Levin, Lena, 234n89

Leving, Yuri, 248n7

Lewontin, Richard C., 250n23

liberal humanism, 173

Lichberg, Heinz von, 225n54

"The Life of Chernyshevsky," 48-49

light: physics of, in Ada, 158; and relativ- ity, in Ada, 159; in relativity, 147,

149; science of, 157; speed of, 149

limits of science. See science, limits of

Linné, Carl, 56, 75, 221n10

literary studies, as science, 15, 196-97

literature, as system, 197

Lobachevsky, Nikolai, 146, 148, 150

Lodge, Oliver, 184, 206n26

logic, causality and, 153

Lolita, 79, 80, 85, 86, 89, 90, 93, 95, 98, 104, 106, 108, 120-24, 126, 222n $25,222 \mathrm{n} 27,225 \mathrm{n} 59,230 \mathrm{n} 38$, 230n41, 233n73, 233n81, 237n9; calendar error in, 91

Lombroso, Cesare, 104, 110, 132, 134

Look at the Harlequins!, 89, 134,136, $137,164,242 \mathrm{n} 65$

Lorentz, Hendrik, 148

love, 222n33; psychology of, 129

Lyceaides, 212n 45

Lysenko affair, 245n19

Maar, Michael, 225n 54

Mach, Ernst, 66, 145-46, 187, 219n44, 238n22, 248n14

Machism, 145

magic triangles, 25-26, 63, 249n23

Mandler, George, 226n7

many worlds, in quantum theory, 157

Mary, 94, 145, 237n7

Mason, Bobby Ann, 224n43

materialist philosophy, 5, 6, 143-45, 153, $155,238 \mathrm{n} 21,241 \mathrm{n} 58$

Materialism and Emperio-criticism

(Lenin), 145

mathematics, 198, 216n4, 241n55, 249n19; in Goethe's thought, 56; limits of, 160-62, 189; Nabokov's early gift for, 162

Maxwell, James Clerk, 239n29

Mayr, Ernst, 25

memory (modernist portrayals of), 149

Menaker, Esther, 232n69

Mendeleyev, Dmitri, 217n15

Merchant, Carolyn, 215n74

Merz, J. T., 216n5, 216n7

meta-causal phenomena, 183

metamorphosis, 96; in nature and art, 90-93

metaphysics: Nabokov and, 185, 194, 206n24, 199; science and, 196 
Metchnikoff, Élie, 104

Meyerson, Émile, 183, 236n118, 247n5

Michéa, C. F., 231 n50

Millikan, Robert, A., 212n37

mimicry, 9, 13, 30-31, 38-40, 45, 66, 69, 185, 191, 207n46, 211n31, 213n51, 234n94; lectures on, 213n49; lost article on, 13, 207n47, 208n49, $213 \mathrm{n} 49$; in nature and art, 87-90; nonutilitarian, 31, 39, 45, 64, 90; as representation, 92; viceroy and monarch, 38

mimicry in nature, proposed book on, 13 , 39, 45, 64, 68, 186

"Mimicry in Theory and Practice," 38

mind, in psychology, 99-100

mind-world interaction, 100-101

Minkowski, Hermann, 147

miracles, causality and, 249n 18

monism, 60

Moore, Tony, 233n73

morphology, 16, 25, 27, 50, 65, 215n78, 216n $5,224 \mathrm{n} 42$

Morphology of the Folktale (Propp), 50

Moscow Psychological Society, 5, 101, 104, 205n14, 205n18, 230n34

Multiple Personality Disorder, in Pale Fire, 235n108

murder, psychology of, 125

Museum of Comparative Zoology, 2, 22 mysticism, 108

Nabokov, Dmitri, 135, 220n58, 236n120

Nabokov, Véra, 8

Nabokov, Vladimir Dmitrievich, 5, 101

Nabokov, Vladimir Vladimirovich: childhood interest in lepidoptera, 29; overwork, 205n7; scientific approach of, 22; scientific character of, 209n4; scientific articles, 209n6, 210n12; scientific readings, 222n $26,230 \mathrm{n} 35$; scientific reputation of, 23,25

Nabokov's art, interpretations of, 192-99

Nabokov's Blues (Johnson and Coates), 23

Nabokova, Elena Ivanovna, 205n6

Nagel, Ernest, 243n72

Naiman, Eric, 236n119

naïve realism, 10 narcissism, 124

narrative levels, 181-82

narrative, psychology of, 131

natural selection, 7, 13, 29, 33, 39, 40, 63, 64, 65, 76, 211n25, 219n39,

220n4; gaps in, 31; materialism and, 30

nature philosophy (Natürphilosophie), $17,59,60,239 n 38$

nature: as nonutilitarian, 186; creativity in, 73, 93; creativity of; 211n25; discontinuities in, 182; freedom in, 74

"Nearctic Members of the Genus Lycaeides Hübner," 27-28

neo-idealism, 5, 223n40 neutral evolution, 219n40

new synthesis (Darwinian), 39, 207n37

Newman, James R., 243n72

Newton, Sir Isaac, 8, 11, 55, 59, 63, 146, 148, 168, 200, 217n22, 218n23, 239n39; Opticks, 56, 58, 159

Newtonian science, 17-18, 48, 151

Nicol, Charles, 78

Nikolai Gogol (Nabokov), 23

non-Euclidean geometry, 146, 239n25, 239n37

nonutilitarian phenomena, 90, 187, $248 n 14$

nonutilitarian principle, 186

nonutilitarian science, 190

note cards, Nabokov's use of, 239n28

"Notes for 'The Texture of Time," 243n70, 243n71, 243n74, 243n77, 243n78, 244n82, 244n83, 244n85

"Notes for a Work in Progress," 160

Notes from Underground (Dostoevsky), 174

"Notes on the Morphology of the Genus Lycaeides," 6, 33, 35, 68, 173

"Notes on Neotropical Plebejinae," 33

"Notes on Various Subjects" (Ada), 160, $163,235 \mathrm{n} 110$

objectivity, 13

Oedipus, 107, 233n85; complex, 126

On the Origin of Species (Darwin), 219 n39

"On the Truth and Verisimilitude of Art" (Goethe), 70

optimism, Nabokov's 131 
orchids, 191, 192, 223n38, 223n42, 224n43; in Ada, 84-85; in Pale Fire, 82

origin of life, $212 \mathrm{n} 38$

orthogenesis, $75,219 \mathrm{n} 40$

Orwin, Donna Tussing, 75

other selves, in consciousness, 130

others, knowledge of, 195

otherworldliness (potustoronnost'), 8, 179, 191; as metaphor, 8

Ouspensky, Pyotr, 206n22, 206n29

“The Overcoat” (Gogol), 176

Pale Fire, 12-13, 74, 81-84, 86, 89-91, $95,104,129,131,135-36,164$, 222n33, 223n39, 245n87, 251n36; paranormal events in, 135-36

Pale Fire notes, 235n110, 235n113

Paperno, Irina, 88, 207n39

parallel universes, in fiction, $157,244 \mathrm{n} 84$

paranormal phenomena, 135, 136, 236n121; Nabokov's interest in, 194-95; science and, 195

parapsychology, 8, 138; Nabokov and, 206n 28

parasitism in art, $224 \mathrm{n} 51$

pattern, 111, 117, 168, 224n49; in nature and art, 87

Pavlov, Ivan, 100

pedophilia, 79

Peirce, C. S., 214n67

perception, artistic, 246n22

Pesic, Peter, 240n44

philosophy, science and, 198

physics, Newtonian, 143

Pifer, Ellen, 195

Pigliucci, Massimo, 221n4

Planck, Max, 4, 144, 155, 205n3

planetary model of atoms, 47

plate tectonics, $170,245 \mathrm{n} 8$

Plebejinae, 25; geographical expansion of, 170

Plebejus idas sublivens Nabokov, 25

Pnin, 68, 84, 89-91, 98, 104-7, 126-28, 155-57, 231n41, 233n85, 241n55, 242n59; Freudianism in, 233n85; narrator of, 127

Pod znamenem marksizma, 210n24

Poe, Edgar Allen, 80

Poehlman, Eric, 245n4 poetry diagrams, 41-43, 214n62

"The Poets," 89

political power, science and, 175, 189, 200-201

Poole, Randall, 205n14, 223n40, 230n34

Popper, Karl, 218n23, 228n21

A Portrait of the Artist as a Young Man (Joyce), 132

poshlust, 70

positivism, 5, 6, 52, 173; religion and, 200

Poslednie novosti, 4

Postman, Leo, 207n40

Principles of Psychology (James), 101, 104

Problems of Idealism, 5

procreation, 85

Proffer, Carl, 139

progress, scientific, 189

Propp, Vladimir, 50

Proust, Marcel, 149

psychoanalysis, 2, 97-99, 103, 124, 126, 127

psychoanalytic clinic, Tegel, 226n2

psychological tests, $233 \mathrm{n} 84$

psychologists, as characters, 105

psychology: definition, 227n13; ethics and, 196; history of, 99; in art, as inductive science, 138; Nabokov's attitude toward, 101; Nabokov's reading in, 104, 230n35, 234n89; noncausal, 111; relation to philosophy, 227n16; as a science, 99, 13738, 192, 226n8, 229n29, 248n15

puns, interlinguistic, 147

Pushkin, Alexander, 70, 79, 176, 177, 180, 246n 31

"Pushkin, or The Real and the Plausible," 15, 70, 208nn52-53

Pyle, Robert M., 22

qualitative phenomena, 186

qualitative science, 20, 32, 100, 172, 208 n 59

quantitative science, subservience of, 172 quantum mechanics, 32, 150-51, 144; many-worlds interpretation, 163 , 164

quantum theory, 144, 157, 185, 238n15, 240n44, 242n59; as metaphor, 156 
Quin, John D., 232n56

Ramey, James, 181, 221n11, 224n51

Rank, Otto, 104, 132, 133, 229n26, $232 \mathrm{n} 69,234 \mathrm{n} 97$

rational thought, limits of, 198-99

reading process: as discovery, 92,181 , 250n26; gaps in, 181; as metamorphosis, 92

The Real Life of Sebastian Knight, 15, 48, 89-90, 134, 160-61, 164, 181, $243 n 75$

“reality," 177, 179; in consciousness, 10, 178

reductivism, 98

relativism, Nabokov and, 188

relativity, $32141,143,151,163,185$, 189, 215n73, 237n12, 237n7, 243n79; in Ada, 159; in The Gift, 146-49; in Pnin, 155; popularization of, 236n3; simultaneity in, 162

Remington, Charles, 22

representation, 176

rhythm (in species variation), 35, 43, 173

Ribot, Théodule, 104, 231n50

Richards, Robert J., 59-61, 204n2, 217n22, 218n27, 218n32, 224n48

romantic fragment, $246 \mathrm{n} 31$

romanticism, 45, 86, 148, 224n48

Ronen, Irena and Omry, 196

Root-Bernstein, Robert S., 199, 205n10, $251 \mathrm{n} 41,251 \mathrm{n} 44$

Rossiia i slavianstvo, 103

Roth, Matthew, 225n55

Rul', 4, 144

"Ruslan and Ludmila" (Pushkin), 79

Russell, Bertrand, 243n72

Rutherford, Ernest, 47, 144, 248n6

Rylkova, Galina, 231n52

scale-line wing analysis, 35,38

Schelling, Friedrich, 59, 61, 67, 211n34, 218n27, 239n38

Schiller, Friedrich, 16, 59, 67

Schopenhauer, Arthur, 50, 187, 221n7, 249n16

Schrödinger, Erwin, 144

science: as approach to world, 52; Bolshevik view of, 145; ephemerality of, 244n83; equality and, 175; errors in,
189; ethics and, 201; fictitious, 21; honesty in, 189; impartiality of, 189; interpretations in, 169; limits of, 7 , $8,126,137,165,168-70,174,189$, 200, 206n22, 207n40, 212n37; and metaphysics, 9, 196; modesty of, 197; Newtonian, 18, 32; overconfidence in, 169; and philosophy, 173; political power and, 175, 189, 200-201; positivist, 153; progress of, 189; "pure," 190; quantitative vs. qualitative, 20 ; as self-conscious, 173 ; socialism and, 6 scientific drawings, Nabokov's, 205n7 scientific method, 137; Nabokov and, $198,216 \mathrm{n} 81$

scientific revolutions, 48 scientization of literary studies, 15 Seamon, David, $217 \mathrm{n} 8$ self, in psychology, 108, 128, 227n10 self-fertilization in nature, 82 self-reference, 196 Senderovich, Savely, 88, 196, 249n16 senses, limits of, 174, 178

Sepper, Dennis L., 207n41, 210n18, 239n39, 216n7 216n4

sexual selection, 79

sexuality, 71

Shakespeare, William, 142-43, 153-54, 177

Shishkov affair, 89

Shklovksy, Viktor, 15

Shrikhande, S. S., 242n66

Shute, Jenefer, 103, 227n18, 228n25, 229 n27

Shvarts, Yelena, 88, 196, 249n16

"Signs and Symbols," 129

Sinclair, May, 144

Sklyarenko, Alexey, 158

Skonechnaia, Olga, 109

social theory, 200

socialism, 173, 175, 200

socialist positivism, 6

Society for Psychical Research, 9, 206n26, 230n38

sociology of science, Nabokov and, 189

solar eclipse (of 1919), 237n10

solipsism, 12, 179

solutions, uniqueness of, 193, 250n27, 250n29

soul, in psychology, 101 
space-time, 147, 163

Speak, Memory, 29, 194, 210n19, 232n67, 235n114

speciation theory, 62, 63, 209n8, 209n9, 212n42, 214n66, 218n35, 225n63; discontinuities in, 171; geographical 245n8; spherical, 63; spiral, 36-37; variety in, $213 \mathrm{n} 47$

species: stability vs. variation in, 171 ; synthetic character of, 35, 66-68, 190-91

species change and variation, 27, 33-35, $65,75,190,219$ n2; gaps in, 66 species definition, 25, 27, 28, 212n39, 215n74; rhythm and, 35

spectroscopy, 148

Spencer, Herbert, 104

Spinoza, Baruch, 60

split personality, 109, 134-35, 137

stasis vs. change, in Goethe's science, 56 statistics, 172

sterility, 84 ; in literature, 82 ; in nature, $82,223 n 38$

"Stikhi i skhemy" (Nabokov notebook), 199, 238n19

Stone, Abraham, 234n 89

storytelling distortion and falsification in, 156; unconscious in, 138

Strakhov, Nikolai, 206n35

stream of consciousness, 104; in Tolstoy, 104

struggle to survive, 187

Struve, Gleb, 103, 107, 228n24

subatomic theory, 47, 140, 185, 248n6; in Bend Sinister, 152; in The Gift, 151

subjectivity, $12,18,169,246 \mathrm{n} 23$; in sci-

ence, 150, 217n11, 217n15, 240n40;

acknowledgment of, 217n14

suicide, psychology of, 129

super-novae, 214n70, 238n18

surprise, in nature, 187

survival of species, 186

Sweeney, Susan Elizabeth, 221n8, 234n94, 241n48

symmetry, 165

syncopatic jerks, 66

synthetic character of a species, adaptive utility of, 190-91

Taine, Hyppolite, 104, 208n51
Tallis, Raymond, 99

Tarnowski, Veniamin, 104

Tatarinova-Aikhenvald circle, 102

Tatarinov, Vladimir, 4, 144-45, 238n15, $245 \mathrm{n} 8$

taxonomy: lumpers vs. splitters in, 22; uncertainties in, 171

Tenishev School, 185

terminology, cross-disciplinary adoption of, $237 \mathrm{n} 8$

theory, 198; Goethe's suspicion of, 55; in science, 150, 175, 188

Theory of Mind, 233n73

Thompson, J. J, 2

thought, in physics, $149,239 \mathrm{n} 36$

time: in Ada, 160; dilation of, 149, 235n114; imagined essence of, 160 ; in physics, 157

Titchener, Edward B., 100

Toker, Leona, 232n64, 249n16

Tolstoy, Leo, 10, 12, 30, 50, 75, 85, 206n 35

"Toward a General Comparative Theory" (Goethe), 61

tragedy (genre), 141

“The Tragedy of Tragedy," 19, 140

transcendentalism, 148

transcription, translation and, 176

translation, 154; incompleteness of, 177; literal vs. paraphrase, 176

Transparent Things, 29, 80, 90, 160-61, 194, 210n18; causality in, 187

Trousdale, Rachel, 242n63

Trzeciak, Joanna, 230n35

Tynianov, Yuri, 15

typographical errors, as discontinuities, 181-82

"Ultima Thule," 240n42, 243n72, 249n19

uncertainty principle, 144, 150, 188, 240n42, 240n44, 247n5, 248n10; as metaphor, 156-57

unknown, the, 52, 236n118

Urpflantze, 16, 59, 226n 68

Urphaenomen, 56

Utgof, Grigorii, 76

utility, 71 ; in nature, 30

"The Vane Sisters," 90 
Vasiliev, A. V., 238n22

Vernadsky, Vladimir, 12, 212n36, 213n58

Virey, Julien-Joseph, 211n34

vision, creative vs. scientific, 167

vital force, 73, 213n51, 247n5

Vucinich, Alexander, 210n24, 211n25

Vyborg manifesto, 5

Walls, Laura Dassow, 211n28, 213n60, 214n63, 215n70, 242n63

Watson, John B., 100

wave-particle duality, 140, 151, 185, 164, 238n16, 242n65, 243n71, 247n3

waves, in physics, 159

Weininger, Otto, 104, 230n35

Weissmann, August, 64, 207n46, 214n66

Weldon, Robert, 242n66

Wells, H. G., 163, 164

West, Donald James, 134, 235nn105-6

Weyl, Hermann, 240n44

What Is to Be Done (Chernyshevsky), $207 \mathrm{n} 39$

"What Should Everyone Know?," 103
Whitehead, Alfred North, 243n72

Whitrow, Gerald James, 160, 243n71

Whitworth, Michael H., 236n3

Wilcox, Stephen B., 99, 226n7

Wilson, Edmund, 171, 205n7, 207n47, 209n12

wing patterns, evolution of, $212 \mathrm{n} 43$; scale analysis, $25,35,38,212 \mathrm{nn} 44-45$

wing spot diagram, 44

Woodworth, Robert Sessions, 227n10, $227 \mathrm{n} 13$

Woolf, Virginia, 144

word golf, 95-96, 226n69

wordplay, as model of natural evolution, 96

Worth, Patience (Pearl Curran), 135

Yale Review, 13, 38

Zajonc, Arthur, 217n8

Zimmer, Dieter E., 22, 82, 88, 206n29, 209n8, 213n48, 223n37

Zunshine, Lisa, 233n73 